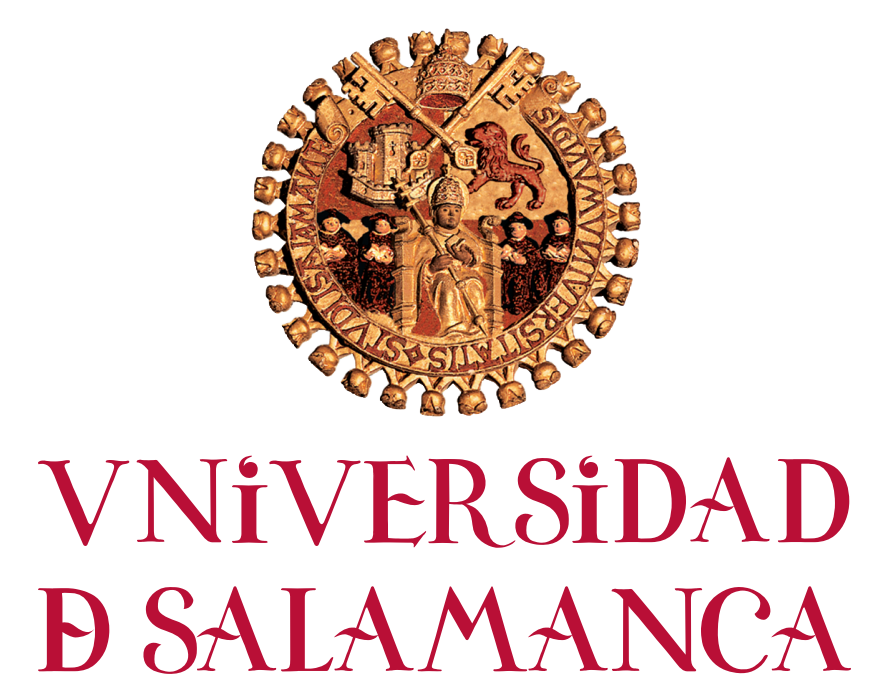

INSTITUTO DE NEUROCIENCIAS DE CASTILLA Y LEÓN

TESÍS DOCTORAL

\title{
INFLUENCIA DE LA PERSONALIDAD EN LA GRAVEDAD DE LOS TRASTORNOS POR CONSUMO DE ALCOHOL
}

Aida Álvarez Pedrero

Salamanca, 2017 


\title{
UNIVERSIDAD DE SALAMANCA
}

\section{DEPARTAMENTO DE NEUROCIENCIAS}

\author{
INFLUENCIA DE LA PERSONALIDAD EN LA GRAVEDAD DE \\ LOS TRASTORNOS POR CONSUMO DE ALCOHOL
}

Dirigida por el Dr. J.J. Ávila Escribano

Co-dirigida por el Pof. Dr. A.L. Montejo González

Realizada por: Aida Álvarez Pedrero

Salamanca, 2017 
EI Dr. ANGEL LUIS MONTEJO GONZÁLEZ, profesor titular del departamento de salud mental de la facultad de enfermería de la Universidad de Salamanca, médico psiquiatra del servicio de psiquiatría del Hospital Universitario de Salamanca, subcoordinador del área de Neurociencias del Instituto de Investigación Biomédica de Salamanca (IBSAL); y el Dr. JOSÉ JUAN ÁVILA ESCRIBANO, médico psiquiatra del Hospital Universitario de Salamanca, coordinador de la Unidad de Salamanca de Trastornos por consumo de alcohol y doctor en medicina

\section{CERTIFICAN:}

Que el presente trabajo de Tesis Doctoral titulado: “INFLUENCIA DE LA PERSONALIDAD EN LA GRAVEDAD DE LOS TRASTORNOS POR CONSUMO DE ALCOHOL", ha sido realizado bajo nuestra dirección por $\mathrm{D}^{\mathrm{a}}$. Aida Álvarez Pedrero, licenciada en Medicina y Cirugía, reuniendo, a nuestro criterio, las condiciones metodológicas, de originalidad y presentación requeridas para ser sometida a la valoración del tribunal constituido para juzgarla y poder optar así al grado de Doctor en Medicina y Cirugía por la Universidad de Salamanca.

$Y$ para que conste a todos los efectos oportunos, firmamos el presente certificado en Salamanca a 29 de Junio de dos mil diecisiete.

Los Directores de la Tesis,

Dr. J.J. Ávila Escribano

Dr..A.L. Montejo González 
Agradecimientos 


\section{AGRADECIMIENTOS}

Al Dr. José Juan Ávila Escribano, por personalizar durante todo este trabajo la organización, la constancia, el ánimo y el apoyo incondicional, tanto profesional como personal. Sin su ayuda esta tesis no habría visto la luz. Muchas Gracias.

Al Dr. Ángel Luis Montejo González, por su orientación y recomendaciones, por allanarme el camino y motivarme, pero sobre todo por confiar siempre en mí. Gracias.

A la Unidad de Trastornos por Consumo de Alcohol de Salamanca por su ayuda, su disposición y su infinita dulzura. Gracias por facilitarme tanto el trabajo.

Gracias a este Servicio de Psiquiatría, adjuntos, residentes y amigos, porque con vuestro cariño y apoyo hacéis éste y cada propósito, más sencillo.

A mi familia, especialmente a mi tía Mercedes, por su ánimo y su confianza, en éste y en cada proyecto vital.

A mis padres, por absolutamente TODO.

$Y$, finalmente, a nuestros pacientes, porque ellos son la causa y razón. 
Índice 
1.- INTRODUCCIÓN...........................................................

2.- TRASTORNO POR CONSUMO DE ALCOHOL.......................5

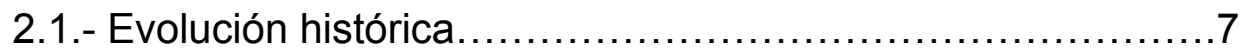

2.2.- Conceptualización...................................... 11

2.3.- Epidemiología......................................... 19

2.3.1.- Características sociodemográficas................19

2.3.2.- Patrones de consumo de alcohol..................26

2.3.3.- Daños relacionados con el consumo de alcohol....33

2.4.- Neurobiología del Trastorno por Consumo de Alcohol.......36

2.4.1.- Neurobiología de la exposición temprana al

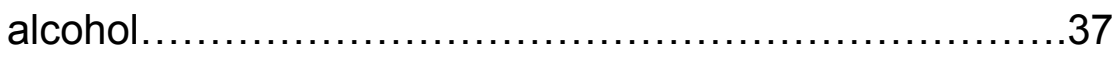

2.4.2.- Sistema de recompensa cerebral...................40

2.4.3- Neurotransmisores implicados....................43

2.4.4.- Modificaciones en el sistema de recompensa

cerebral a largo plazo...............................46

2.4.5.- Neurobiología de la tolerancia y abstinencia al alcohol

2.5.- Tratamiento y Prevención del Trastorno por Consumo de Alcohol.

2.5.1.- Tratamiento del Trastorno por Consumo de alcohol 49

2.5.1.1.- Tratamiento de desintoxicación. 50

2.5.1.2.- Tratamiento de la deshabituación alcohólica .54 
2.5.2.- Prevención del Trastorno por Consumo de alcohol......................................................

2.5.2.1.- Estrategia mundial para reducir el uso nocivo del alcohol. OMS. 2010_.......................59

2.5.2.2.- Estrategia Nacional sobre Drogas 20092016

2.6.- Comorbilidad del Trastorno por Consumo de alcohol.........63

2.6.1.- Trastornos afectivos..........................64

2.6.2.- Trastornos de ansiedad........................85

2.6.3.- Esquizofrenia y otros trastornos

psicóticos...........................................90

2.7- Trastorno por Consumo de Alcohol y Personalidad............96

2.7.1.- Rasgos prevalentes de la Personalidad en los

Trastornos por Consumo de Alcohol...................96

2.7.2.- Tipos de Personalidad en el Trastorno por

Consumo de Alcohol...............................100

2.7.3.- Estudio de la personalidad mediante el test

de Cloninger........................................ 105

3.- Objetivo e hipótesis..............................................119

4.- Material y método..................................................

4.1.- Muestra y procedimiento..................................127

4.2.- Batería de instrumentos.....................................129

4.2.1.- Entrevista semiestructurada......................129

4.2.2.- Escala EuropAsi adaptada..........................129

4.2.3.- Escala EIDA........................................132 
4.2.4.- Cuestionario OCDS..................................133

4.2.5.- Cuestionario TCI-R............................... 133

4.3.- Búsqueda bibliográfica........................................134

4.4.- Análisis de datos...............................................134

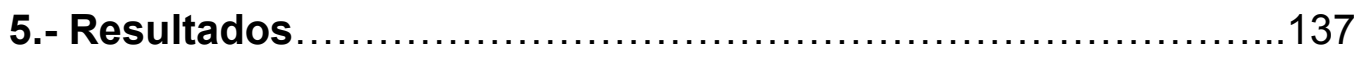

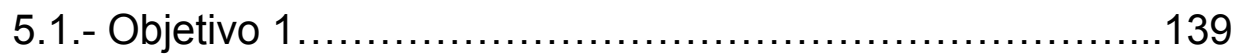

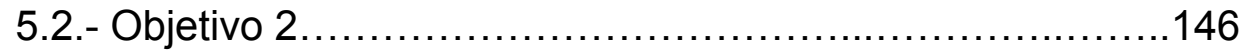

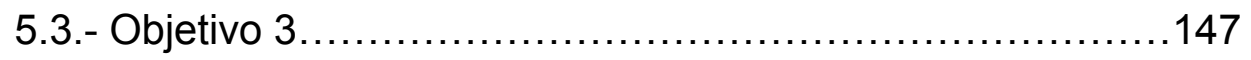

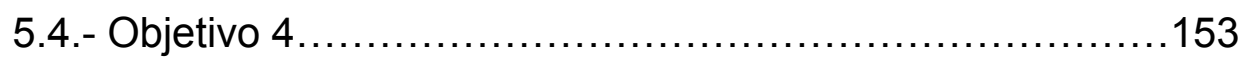

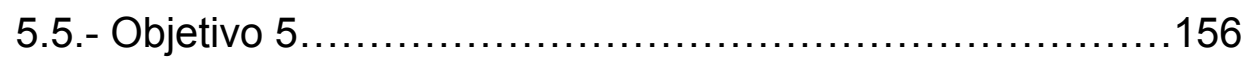

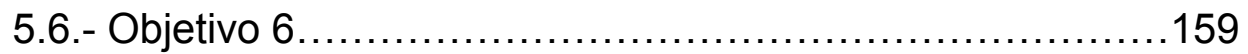

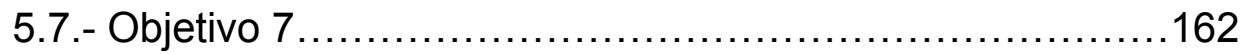

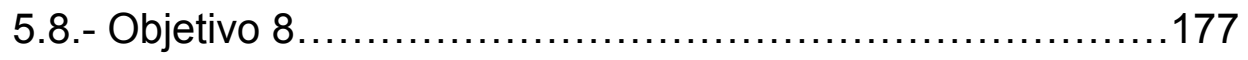

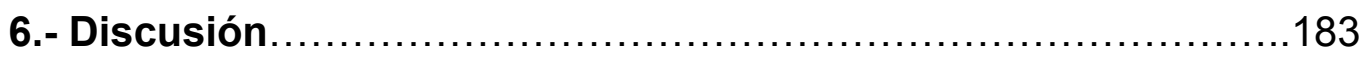

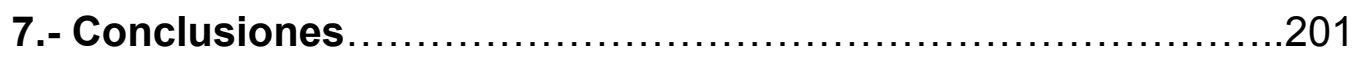

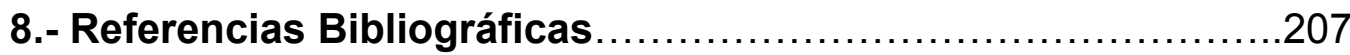

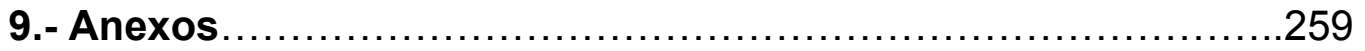

9.1.- Entrevista estructurada....................................261

9.2.- Escala EuropAsi. Índice Europeo de Gravedad de la Adicción

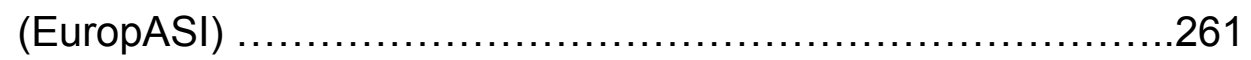

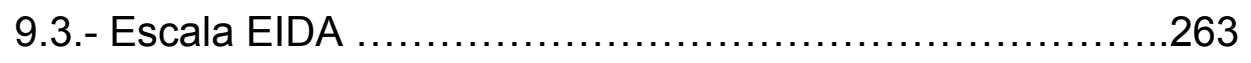

9.4.- Cuestionario sobre los componentes obsesivo-compulsivos

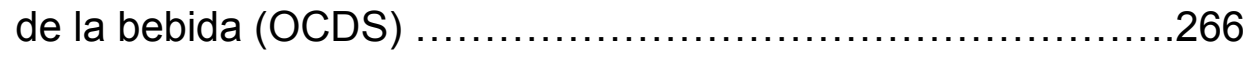

9.5.- Cuestionario TCl-R (Cuestionario de temperamento y carácter de Cloninger, versión revisada)........................272 
9.6.- Consentimiento informado.

.285 
Influencia de la Personalidad en la Gravedad de los Trastornos por Consumo de Alcohol

\section{Introducción}


Influencia de la Personalidad en la Gravedad de los Trastornos por Consumo de Alcohol 


\section{1.- INTRODUCCIÓN}

Se calcula que el uso nocivo del alcohol causa cada año 2,5 millones de muertes a nivel mundial, y una proporción considerable de ellas corresponde a personas jóvenes. El consumo de bebidas alcohólicas ocupa el tercer lugar entre los principales factores de riesgo de mala salud o discapacidad en el mundo -únicamente por detrás del tabaco y de la hipertensión arterial-, lo cual constituye un devastador problema de salud pública (Agrawal, A.; Narayanan, G.; Oltmanns T.F. 2013). Además el uso nocivo del alcohol es uno de los cuatro factores de riesgo de enfermedades no transmisibles importantes que son susceptibles de modificación y prevención (OMS 2014), y el Trastorno por consumo de alcohol (TCA) es el diagnóstico psiquiátrico más prevalente en población general (Lejuez, C.W. 2010).

La detección precoz de los bebedores de riesgo constituye una prioridad desde una perspectiva de salud pública, dada la elevada prevalencia del consumo de riesgo y la efectividad del tratamiento orientado a la disminución del consumo.

Actualmente existen dos fases dentro del tratamiento del Trastorno por consumo de alcohol (TCA): la fase de desintoxicación y la fase de deshabituación.

En la primera, el objetivo consiste en el tratamiento del síndrome de abstinencia y prevención de manifestaciones más graves como crisis convulsivas y "delirium tremens". En dicha fase, el tratamiento es principalmente farmacológico y se utilizan fármacos hipnóticos o sedantes (benzodiacepinas o clormetiazol), anticomiciales, simpaticolíticos, antidopaminérgicos y vitaminoterapia (especialmente tiamina).

En la segunda fase, el tratamiento está orientado al mantenimiento de la abstinencia mediante la disminución del deseo por el alcohol y prevención de recaídas. Se utilizan técnicas de intervención psicosocial y fármacos específicos para reducir el deseo (fármacos interdictores y "anticraving", principalmente).

Debemos señalar la importante dificultad para realizar una estimación precisa de la gravedad del TCA, debido principalmente a la diversidad de las formas de consumo existentes y a la gran variedad de clasificaciones que se 
deben tener en consideración (Valencia Martín J.L., González M.J., Galán I. 2014).

El modelo de personalidad psicobiológico de Cloninger se ha utilizado frecuentemente para el estudio de la dependencia de sustancias. Éste propone 7 dimensiones para explicar la personalidad, agrupadas en temperamento (búsqueda de novedad, dependencia de recompensa, evitación del daño y persistencia), y carácter (autodirección, autotranscendencia y cooperación) (Cloninger, C.R. 1987).

En la actualidad existen múltiples estudios que han analizado las características de personalidad en los pacientes con problemas de adicciones, y en concreto con TCA, encontrando puntuaciones más elevadas que en la población general, en desinhibición, impulsividad, comportamiento antisocial y agresividad; además de rasgos sugestivos de una baja capacidad de control.

Si nos centramos en las variables cuantificadas mediante el Inventario de Personalidad de Cloninger (TCl-R), los resultados no son tan concluyentes. En ocasiones algunos autores encuentran puntuación elevada en evitación del daño, mientras otros observan puntuaciones elevadas en búsqueda de novedad y evitación del daño con puntuaciones bajas en autodirección.

Por otro lado, son escasos los estudios que relacionan los rasgos de personalidad de un paciente con la gravedad de su patología adictiva. Por este motivo, nos planteamos en este trabajo los siguientes objetivos generales:

1) comprobar la relación entre la personalidad, según el cuestionario de personalidad de Cloninger, y la gravedad del TCA.

2) analizar qué dimensiones de la personalidad, en función del inventario de Cloninger se relacionan con una mayor o menor gravedad del TCA.

3) establecer si el sexo, a través de la características de personalidad del inventario de Cloninger, influye en la gravedad del TCA.

Un mayor conocimiento del papel que juega la personalidad en la gravedad y curso evolutivo del TCA, nos permite ofrecer una atención más especializada y, a la vez, más eficiente, con la consiguiente reducción de la morbilidad, mortalidad y gasto sanitario tan importantes, originados por esta enfermedad. 


\section{Trastorno por Consumo de Alcohol}


Influencia de la Personalidad en la Gravedad de los Trastornos por Consumo de Alcohol 


\section{2.-TRASTORNO POR CONSUMO DE ALCOHOL}

\section{1.- Evolución histórica.}

Cuando se habla de bebidas alcohólicas, se olvida frecuentemente su "reciente" aparición en el curso de la evolución de la especie humana. La primera disponibilidad de alcohol, y con el la primera oleada de difusión del mismo, data de los periodos conocidos como mesolítico y neolítico, siendo imposible conjeturar la aparición de dichas bebidas con una antigüedad superior a los 10.000 años (Freixa, F., 1973). En dicho periodo de la prehistoria, la tecnología neolítica, a través de la cerámica permitió almacenar frutos como uvas, cereales y otros vegetales, así como productos animales como la miel, todos ellos con elevado contenido en hidratos de carbono y susceptibles de procesos de fermentación productores de alcohol.

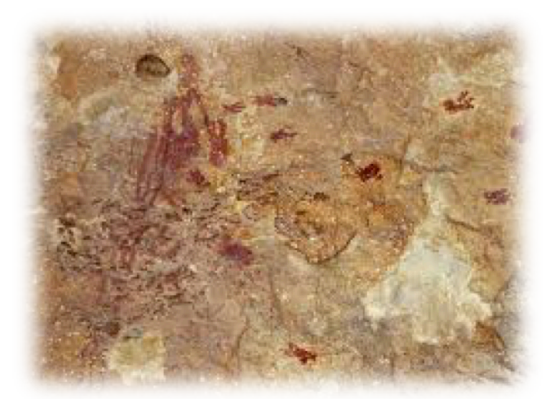

Fig.1.- Pinturas rupestres Cueva de la Araña

Pinturas rupestres como las de la Cueva de la Araña (Valencia) (Fig.1), en las que se ven a las mujeres recogiendo miel, hacen suponer que esta miel fermentada (aguamiel o hidromiel), constituye una de las primeras bebidas alcohólicas, siendo las otras la cerveza y el vino. Así mismo, en dichas obras los eruditos han interpretado la representación de los efectos agradables y, a la vez, tóxicos de las bebidas alcohólicas (F. Freixa et al 1981).

En todas las civilizaciones, en todos los continentes, las tradiciones místico-religiosas han sido atribuidas a las bebidas alcohólicas, relacionándolas con la magia y con lo sobrenatural (Font, 1996). 
Los griegos deificaron dichas bebidas, primero como uno de los aspectos generales de la actividad vegetal, y después como un aspecto específico de dicha manifestación de la vida, mediante la sacralización del vino. Dionisio, dios del vino, fue progresivamente considerado el dios de los efectos del vino, de la embriaguez divina, y lo dionisíaco de la civilización griega pasó a lo báquico, a la bacanal, al dios Baco de los romanos (Fig.2), no tan solo en las regiones propiamente vitivinícolas, sino en todos los confines del Imperio Romano, siendo éstos los protagonistas de la difusión de la vid y el vino por todo el mundo, generando así mismo, leyes sobre su cultivo y comercio (Vallejo Leal, 2011).

Fig.2.- Baco

\section{Michelangelo Merisi, Caravaggio}

(1573-1616)

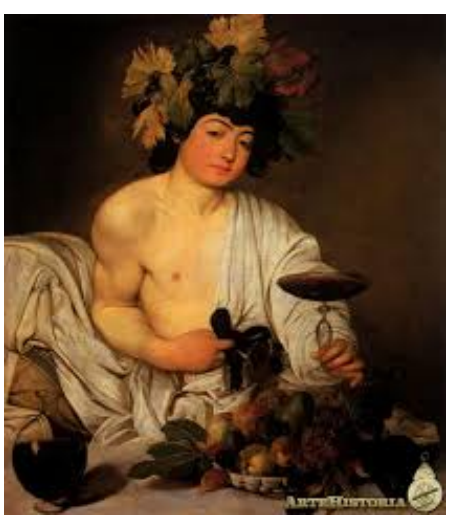

Paralelamente, y hasta cierto punto de forma independiente, la cerveza era conocida en Egipo (siendo la primera cultura encargada de generar normas y advertencias sobre el uso y abuso de la misma) (Vallejo Leal, 2011), en Mesopotamia y también en el continente americano desde las más remotas civilizaciones precolombinas, donde se utilizaban bebidas alcohólicas de baja concentración, procedentes de la fermentación de diversas plantas. De hecho, la "chicha" -cerveza típica actual en Perú y Bolivia especialmente- fue ofrecida a Colón, en su tercer viaje, cuando el 6 de Agosto de 1498 llegó a las costas de la actual Venezuela. Este tipo de cerveza procedente del maíz es también todo un símbolo cultural, que puede, sin duda, documentarse como mínimo desde Guatemala a Bolivia, con su tradición y su magia sagrada peculiares.

Es interesante observar como dos mundos presumiblemente separados, el Viejo Continente y el Nuevo, descubrieron, sin tener conocimiento uno del otro, el proceso fermentativo de los granos (maíz, cebada, etc.), y de los jugos de fruta. 
Simultáneamente a la obtención de alcohol, en mezclas diversas y proporciones distintas, los hombre intentan hallar la "esencia o espíritu" que produce la embriaguez o que, según criterios, posee las cualidades mágicocurativas. De hecho, el hombre sospechó, conociendo como conocía la semejanza de los efectos de las bebidas alcohólicas en sí mismo y sobre los otros, que "algo común" poseían dichas bebidas, originando en diversas lenguas del viejo continente la expresión "espíritu del vino".

Fue el movimiento islámico, a través de la invasión árabe de la Península Ibérica, quien trasmitió a la cultura europea conocimientos y técnicas griegas como el alambique, utilizados por los alquimistas medievales e incorporados a la alquimia, que permitieron la destilación del vino y la obtención de su " 5 a esencia”, en forma de agua ardiente (aquaderns), la cual reanimaba (aquavitae).

En aquellos tiempos, la transmisión de los conocimientos y difusión de la cultura eran muy lentos e imperfectos. No es de extrañar que el mundo cristiano europeo no conociera las técnicas de destilación del vino hasta unos siglos después, y dados los condicionantes geopolíticos, que fuese la Península Ibérica y en una zona vitivinícola, donde se describiera por primera vez el método de la destilación, por Ramón Llull (1233-1315), el cual acuñó a la bebida "agua de la vida", puesto que se creía que prolongaba la misma (Historia de la Psicofarmacología. Francisco López-Muñoz, Cecilio Álamo González), aunque la tradición cultural -no documentada- lo atribuyese a la Escuela de Salerno.

Durante la Edad Media, el vino estuvo en poder de la Iglesia (Fig.3). En las tierras anexas a los monasterios estaban incluidos los viñedos. El vino era imprescindible para las celebraciones religiosas y suponía una fuente de ingresos económicos.

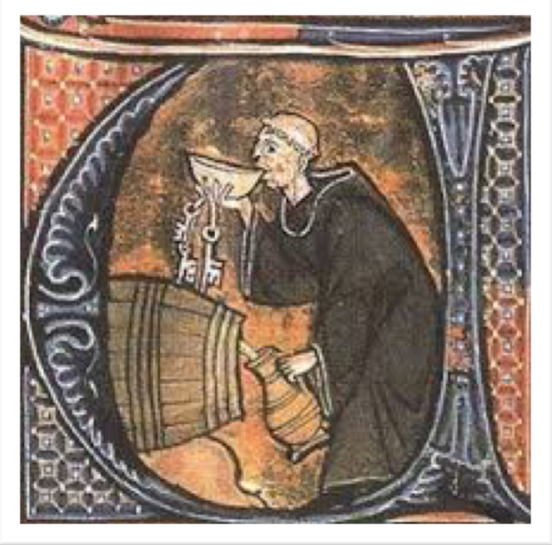

Fig.3.- Monje bodeguero probando el vino 
Esto provocó que, particularmente en Francia, los monasterios constituyesen auténticos centros de comercio relacionado con el alcohol. Los monjes utilizaron los conocimientos árabes sobre la destilación del vino para elaborar bebidas espirituosas, como el güisqui, el Kisck, el chartreuse y otros. Hacia el siglo XIV, el alcohol era una sustancia muy utilizada en los diferentes países para hacer licores, perfumes y medicamentos.

En el tratado de Dioscórides de Anazarba, de Materia Medica, donde se realizó la más extensa de las recopilaciones y sistematización de la farmacopea, se incluyó el vino como agente terapéutico y las diversas afecciones en las que podía utilizarse, no sin advertir sus peligros; dando lugar así, a la segunda oleada de difusión del alcohol.

Esta situación permitía disponer de bebidas de elevada graduación alcohólica, sin depender de las circunstancias ecológicas, produciéndose así la expansión por el norte y este de Europa, y adquiriendo su uso patrones de consumo distinto de los mediterráneos preexistentes.

Esto provocó que a partir del siglo XIV el alcohol se convirtiera en una sustancia importante que se usaba, además de como medicamento revitalizador, analgésico y euforizante, como disolvente en la preparación de perfumes, en relación con otros productos religiosos y en el trueque por otras materias primas.

El uso generalizado de los licores también se ha relacionado con las epidemias del siglo XIV, en particular con la peste negra de 1347-1351.

La tercera oleada de difusión del alcohol tuvo lugar en el siglo XVII, cuando se comenzó con la comercialización moderna del vino y de otras bebidas alcohólicas. Se descubrió que la mezcla de diferentes vinos favorecía su resistencia durante el transporte y frente a cambios de temperatura. Más tarde, cuando se añadieron distintas sustancias también pudo transportarse sin que se alterase. La introducción de los destilados propició el inicio de la comercialización del alcohol que alcanzó un mayor desarrollo en los siglos XVIII y XIX.

La obtención del alcohol procedente de la fermentación de frutos o cereales, es una larga aventura que finaliza en 1857 con Pasteur, quien descubre la intimidad del proceso de la fermentación, y describe el ser 
unicelular, un hongo, cuya capacidad química es asombrosa. Los hábitos alimenticios de los hongos, y en especial del productor del alcohol, son muy curiosos, puesto que el enol, no es otra cosa que un subgrupo de fermentación; subproducto que es capaz de intoxicar al propio hongo matándolo, en una proporción aproximada de un 12-13\%. Pasteur, se dio cuenta que la elaboración de los distintos vinos era el resultados complejo de: rutina de agricultor, tradiciones, empirismo, condiciones climatológicas, ambientales y aún de "micro-climas", en los propios recipientes de la fermentación.

Durante el siglo $\mathrm{XX}$, aumentó mucho su uso en medicina, puesto que el médico inglés R. B. Todd, aseguraba que aceleraba los procesos de cicatrización y las defensas corporales contra la enfermedad. Cuando se hicieron estudios de laboratorio se comprobó que la intoxicación etílica disminuía la temperatura corporal y se utilizó como antipirético. Cada hospital solía tener sus propios tónicos, formados con alcohol, que en algunos casos tenían los nombres de los propios médicos que lo habían elaborado. Estos preparados se utilizaban para el tratamiento de las hemorragias, envenenamientos, fiebre, cólera, malaria, tifus y tuberculosis.

El fenómeno de globalización de los patrones de uso, tuvo lugar durante el siglo XX. Hasta la primera mitad del siglo pasado, cada país tenía unos patrones de consumo propio, que progresivamente se han ido sustituyendo por las formas de beber de países anglosajones.

La cuarta y última oleada de difusión del alcohol, tiene lugar con el aumento de su consumo a nivel mundial tras la $2^{a}$ Guerra Mundial y los cambios subsiguientes, la globalización comercial y la unificación del patrón de uso a nivel mundial conforman el estado actual del consumo de alcohol.

\section{2.- Conceptualización}

El término alcoholismo fue acuñado originalmente en 1849 por Magnus Huss para referirse a los problemas derivados del consumo de alcohol. La categoría inicial de alcoholismo como un vicio, una figura delictiva o una conducta perversa, fue pronto reemplazada en los ambientes más progresistas por el criterio de incluirlo en el capítulo de las enfermedades. 
Desde entonces las definiciones del término han sido múltiples, mientras Fouquet (1959), definía al individuo alcohólico como aquel que había perdido "la libertad de abstenerse del alcohol"; Jellinek (1960), afirmaba que "se puede llamar alcoholismo a todo uso de bebidas alcohólicas que causa un daño de cualquier tipo al individuo, a la sociedad o a los dos", advirtiendo de antemano sobre el escaso valor operativo de esta definición (1). Esta fragilidad provocó que los trabajos de diversos autores posteriores, Pattison y Kaufman, Vaillant y Edwars y Gross, entre otros; estuviesen encaminados a lograr una definición más adecuada y completa del término, bajo diversas modificaciones.

En 1982 los psiquiatras E. Mansell Pattison y D.M. Kaufman, proponen un modelo multivariado que consta de varias proposiciones y de las consecuencias que de ellas se pueden derivar:

a) La dependencia alcohólica consta de una variedad de síndromes definidos por diversos patrones de consumo de alcohol y las consecuencias adversas que se derivan de ese consumo.

b) El uso de alcohol de un individuo puede considerarse como un punto comprendido en un "continuum" que abarca desde el no uso de alcohol hasta varios grados de consecuencias adversas por el consumo del mismo.

c) El desarrollo de problemas derivados del consumo de alcohol sigue un patrón variable, en función del tiempo.

d) La abstinencia no guarda necesariamente relación con la rehabilitación.

e) La dependencia psicológica y la dependencia física del alcohol son fenómenos independientes.

f) El consumo continuado de grandes cantidades de alcohol y durante un tiempo prolongado facilita el inicio de un proceso de dependencia física.

g) El número de personas con problemas de alcohol es muy variado.

h) Los problemas de alcohol están interrelacionados con otros problemas de la vida cotidiana, especialmente cuando la 
dependencia del alcohol está establecida desde hace tiempo.

i) Debido a la fuerte relación entre consumo de alcohol excesivo e influencias ambientales, el énfasis debería realizarse en procedimientos terapéuticos que se centren en el entorno del sujeto donde el consumo se produce.

j) Los servicios de tratamiento y rehabilitación deberían diseñarse para suministrar continuidad terapéutica durante un periodo de tiempo prolongado.

Posteriormente en 1983, el profesor George Vaillant en su libro The Natural History of Alcoholism: Causes, Patterns, and Paths to Recovery, tras una importante experiencia clínica con una cantidad sin precedentes de datos empíricos, aportó como principales conclusiones a la definición de alcoholismo:

a) El alcoholismo es tan social como una condición médica. "El alcoholismo puede reflejar simultáneamente tanto un hábito normalizado como una enfermedad" (Vaillant, 1995).

b) Factores que predicen el alcoholismo se relacionan con la cultura étnica, el alcoholismo en los familiares, y una personalidad antisocial y extrovertida. Una infancia infeliz predijo la enfermedad mental, pero no el alcoholismo, a menos que los problemas de la familia fueran debidos al alcohol.

c) El alcoholismo es generalmente la causa de la depresión, la ansiedad y la conducta sociopática, no el resultado.

d) A pesar de que el alcoholismo no es únicamente una condición médica, es terapéuticamente eficaz para explicar como una enfermedad a los pacientes. El concepto de enfermedad anima a los pacientes a tomar responsabilidad en su consumo de alcohol, sin que exista la culpa debilitante.

e) Para la mayoría de los alcohólicos, los intentos de beber controlado, causan, al final, el retorno al alcoholismo.

f) No existe todavía ninguna cura para el alcoholismo.

Es en el año 1976, cuando Edwars y Gross, introducen dos nuevos 
conceptos diferenciados dentro del conglomerado alcohólico: el síndrome de dependencia del alcohol y los trastornos o discapacidades relacionadas con el consumo de alcohol; abogando por el abandono del término clásico de alcoholismo e intentando así desprenderse del matiz en ocasiones despreciativo de éste.

La imprecisión del término hizo que un Comité de Expertos de la OMS lo desaprobara en 1979, acuñando el término de Síndrome de dependencia Alcohólica que corresponde a "un estado psíquico y habitualmente también físico resultado del consumo de alcohol, caracterizado por una conducta y otras respuestas que siempre incluyen compulsión para ingerir alcohol de manera continuada o periódica, con objeto de experimentar efectos psíquicos o para evitar las molestias producidas por su ausencia".

Tan solo un años después (1980), la Asociación Americana de Psiquiatría (APA), publicaba una nueva actualización de la clasificación de las enfermedades mentales (DSM III), distinguiendo por un lado, los trastornos mentales orgánicos originados por consumo de alcohol, y por otro lado, el abuso y la dependencia alcohólica.

Las modificaciones realizadas por la APA para definir el alcoholismo en su manual diagnóstico han ido evolucionando paulatinamente, principalmente desde la instauración de un modelo de clasificación categorial (DSM III), en el cual se introdujo el concepto "abuso de sustancias psicoactivas", donde se relegaba el término "abuso de alcohol" a una categoría residual. Pasando por la publicación del DSM IV, y posteriormente DSM-IV-tr, en el cual se instaura el capítulo perteneciente a "Trastornos relacionados con sustancias", dentro del cual se encuentra los "Trastornos relacionados con el alcohol", donde se distinguen:

a) Trastorno por consumo de alcohol:

- Dependencia del alcohol.

- Abuso del alcohol.

b) Trastornos inducidos por alcohol: intoxicación, abstinencia, delirium por intoxicación, delirium por abstinencia, demencia, trastorno amnésico persistente, trastorno psicótico, trastorno del estado de 
ánimo, trastorno del estado de ansiedad, trastorno sexual, trastorno del sueño, trastorno relacionado con el alcohol no especificado.

En la actualidad, en el DSM 5, se eliminan los conceptos de abuso y dependencia del DSM- IV; y dentro del capítulo de "Trastornos relacionados con sustancias y trastornos adictivos", éstos se clasifican por grupos. De este modo, se dedica un apartado a los "Trastornos relacionados con el alcohol", dentro del cual existen diversas categorías diagnósticas (Tabla 1).

Tabla 1.- Trastornos relacionados con el consumo de alcohol.

Trastorno por consumo de alcohol

Intoxicación por alcohol

Abstinencia de alcohol

Otros trastornos inducidos por el alcohol.

Trastorno relacionado con el alcohol no especificado.

Del mismo modo, el manual recoge una serie de criterios para realizar el diagnóstico de cada una de sus categorías (Tablas 2,3,4, 5 y 6), introduciendo por primera vez los conceptos de "leve", "moderado" y "grave", en función del número de criterios diagnósticos que se cumplan. 
Tabla 2.- Trastorno por consumo de alcohol. Criterios diagnósticos.

A. Patrón problemático de consumo de alcohol que provoca un deterioro o malestar clínicamente significativo y que se manifiesta al menos por dos de los hechos siguientes en un plazo de 12 meses:

1.- Se consume alcohol con frecuencia en cantidades superiores o durante un tiempo más prolongado del previsto.

2.- Existe un deseo persistente o esfuerzos fracasados de abandonar o controlar el consumo de alcohol.

3.- Se invierte mucho tiempo en las actividades necesarias para conseguir alcohol, consumirlo o recuperarse de sus efectos.

4.- Ansias o un poderoso deseo o necesidad de consumir alcohol.

5.- Consumo recurrente de alcohol que lleva al incumplimiento de los deberes fundamentales en el trabajo, la escuela o el hogar.

6.- Consumo continuado de alcohol a pesar de sufrir problemas sociales 0 interpersonales persistentes o recurrentes, provocados o exacerbados por los efectos del alcohol.

7.- El consumo de alcohol provoca el abandono o reducción de importantes actividades sociales, profesionales o del ocio.

8.- Consumo recurrente de alcohol en situaciones en las que provoca un riesgo físico.

9.- Se continúa con el consumo de alcohol a pesar de saber que se sufre un problema físico o psicológico persistente o recurrente probablemente causado o exacerbado por el alcohol.

10.- Tolerancia, definida por alguno de los siguientes hechos:

a.- Una necesidad de consumir cantidades cada vez mayores de alcohol para conseguir la intoxicación o el efecto deseado.

b.- Un efecto notablemente reducido tras el consumo continuado de la misma cantidad de alcohol.

11.- Abstinencia, manifestada por alguno de los siguientes hechos:

a.- Presencia de síndrome de abstinencia característico del alcohol.

b.- Se consume alcohol para aliviar o evitar los síntomas de abstinencia. 
Tabla 3.- Intoxicación por alcohol. Criterios diagnósticos.

A.- Ingesta reciente de alcohol.

B.- Comportamiento problemático o cambios psicológicos clínicamente significativos, que aparecen durante o poco después de la ingesta de alcohol.

C.- Uno (o más) de los signos o síntomas siguiente que aparecen durante o poco después del consumo de alcohol:

\author{
1.- Habla pastosa \\ 2.- Descoordinación. \\ 3.- Marcha insegura. \\ 4.- Nistagmo \\ 5.- Alteración de la atención o de la memoria \\ 6.- Estupor o coma.
}

D.- Los signos o síntomas no se pueden atribuir a otra afección médica y no se pueden explicar mejor por otro trastorno mental, incluida una intoxicación por otra sustancia.

Tabla 4.- Abstinencia de Alcohol. Criterios diagnósticos.

A.- Cese (o reducción), de un consumo de alcohol que ha sido muy intenso o prolongado.

B.- Aparecen dos (o más), de los signos o síntomas siguientes a las pocas horas o pocos días de cesar (o reducir), el consumo de alcohol descrito en el criterio A:

1.- Hiperactividad del sistema nervioso autónomo

2.- Incremento del temblor de las manos.

3.- Insomnio

4.- Náuseas o vómitos

5.- Alucinaciones o ilusiones transitorias visuales, táctiles o auditivas.

6.- Agitación psicomotora.

7.- Ansiedad.

8.- Convulsiones tónico-clónicas generalizadas. 
C.- Los signos o síntomas del Criterio B provocan un malestar clínicamente significativo o deterioro en lo social, laboral $u$ otras áreas importantes del funcionamiento.

D.- Los signos o síntomas no se pueden atribuir a otra afección médica y no se explica mejor por otro trastorno mental, incluida la intoxicación o abstinencia por otra sustancia.

Tabla 5.- Otros trastornos inducidos por alcohol.

Se agrupan en esta categoría los trastornos cuya causa es el alcohol, pero cuya sintomatología haría más correcto su clasificación en otros capítulos

\section{Tabla 6.- Trastorno relacionado con el alcohol no especificado}

Esta categoría se aplica a las presentaciones en las que predominan los síntomas característicos de un trastorno relacionado con el alcohol, que causan un malestar clínicamente significativo o un deterioro en áreas importantes del funcionamiento, pero que no cumplen todos los criterios de ningún trastorno específico relacionado con el alcohol y/o otras sustancias.

La polémica surgida con la publicación del DSM 5 ha sido extensa, si bien es cierto que los criterios para el diagnóstico de "Trastornos relacionados con el alcohol", son muy similares a los descritos en el DSM-IV para el abuso y la dependencia.

Entre las modificaciones realizadas encontramos las siguientes: 1) establece un modelo dimensional de los trastornos por consumo de alcohol y se eliminan los conceptos de abuso y dependencia; 2) aunque conserva la mayoría (ej., depresión inducida por consumo de sustancias), la amplía a otros nuevos (ej., trastorno bipolar inducido por el consumo de sustancias); 3) elimina el ítem del DSM-IV referido a tener problemas legales, pero añade el ítem del "craving", más en consonancia con los nuevos conocimientos neurobiológicos de la adicción. 


\section{3.- Epidemiología}

\subsection{1.- Características sociodemográficas}

Medir el consumo de alcohol y su impacto en la salud es complejo. Se ha recomendado una aproximación basada en combinar elementos de distintas fuentes para poder construir una imagen más integral a partir de diversos componentes, que por separado, son necesariamente incompletos (datos fiscales, de ventas, producción, etc.) (Brinkman, S.; Stockwell, T.; Chikritzhs, T. 2000).

A nivel internacional, la Organización Mundial de la Salud (OMS) publica anualmente el consumo per cápita de múltiples países a través del Global Information System on Alcohol and Health (GISAH), con datos procedentes del World Drink Trends (1962 a 2001) y desde 2002 con datos propios.

Como muestran los datos más recientes de la OMS, a nivel mundial, las personas mayores de 15 años de edad beben un promedio de 6,2 litros de alcohol puro por año, que se traduce en 13,5 gramos de alcohol puro por día. Sin embargo, existe amplias variaciones en el consumo total de alcohol mundial. En el mundo desarrollado, continúan encontrándose los niveles de consumo más elevados, en particular en Europa y en América. Los niveles intermedios de consumo se encuentran en el Pacífico Occidental y África, mientras que los niveles de consumo más bajos se encuentran en Asia Sudoriental, y particularmente en el Mediterráneo Oriental (Fig. 4). 


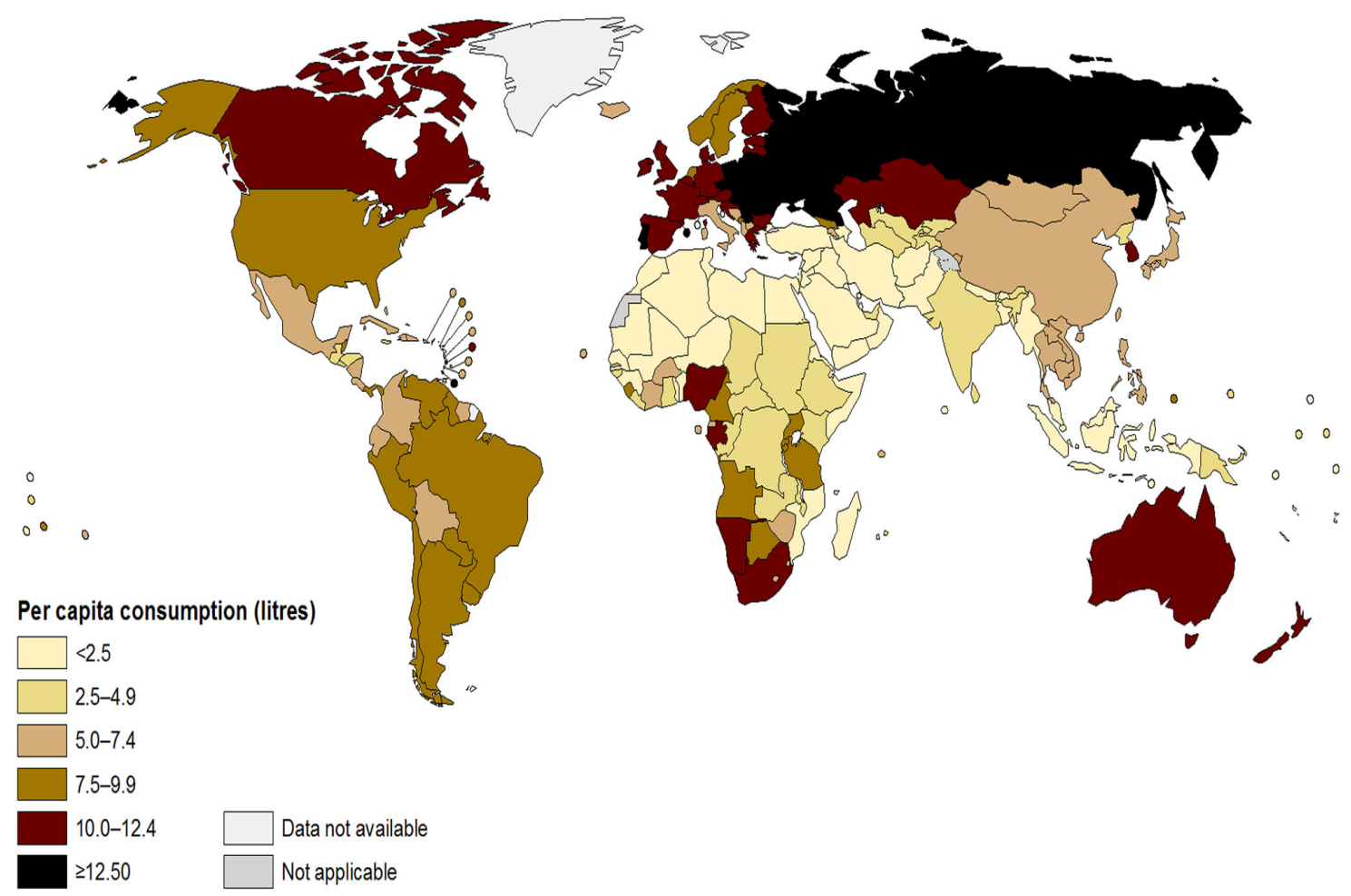

Fig. 4.- Consumo total de alcohol por habitante (más de 15 años; en litros de alcohol puro). Global status report on alcohol and health. OMS 2014.

En nuestro país, según se recoge del informe de la OMS del año 2014, existe un consumo total de alcohol, en mayores de 15 años, de 21,6 litros de alcohol en varones y 10,6 litros de consumo en mujeres al año. Se estima que la mitad de este consumo corresponde a cerveza $(50 \%)$, seguido de bebidas espirituosas (28\%), y en menor grado de vino $(20 \%)$.

Los datos correspondientes al año 2014, disponibles a través de El Instituto Nacional de Estadística (INE), -el cual realiza la Encuesta Industrial de Productos sobre la producción nacional de bebidas alcohólicas; y la Encuesta de Presupuestos Familiares-, son similares: se observa un consumo medio por persona de 21,3 litros de cerveza; 1,3 litros de bebidas espirituosas; 10,7 litros de vino y 0,8 litros de otras bebidas alcohólicas (Fig. 5). 


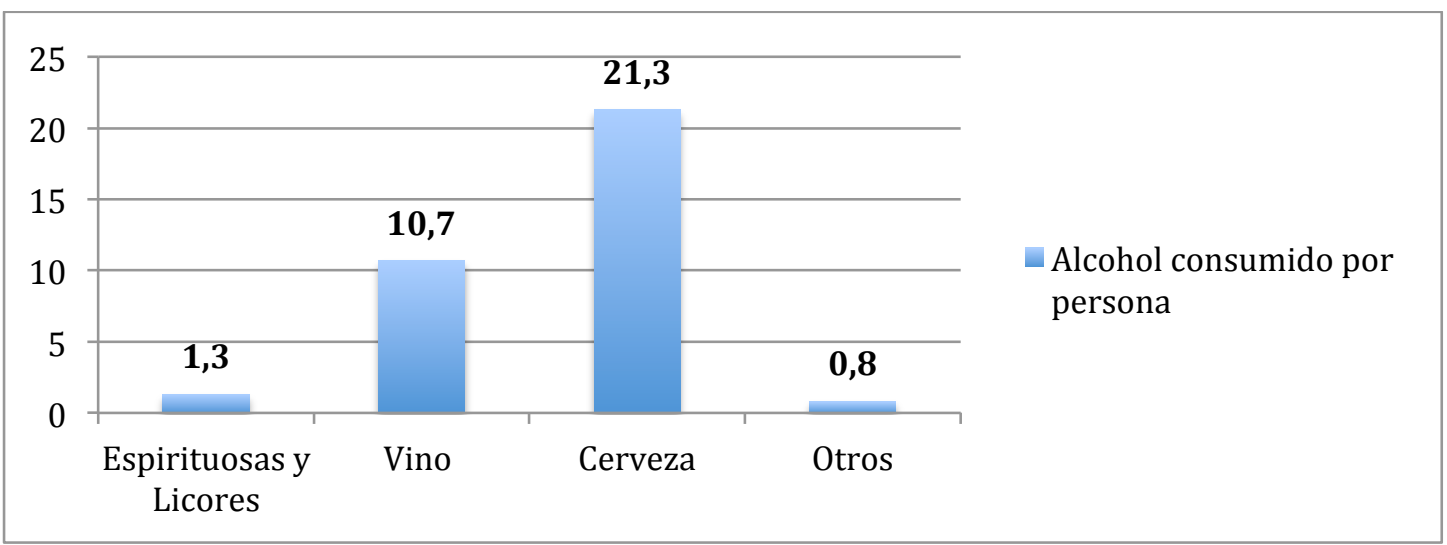

Fig. 5.- Cantidad alcohol consumida / persona / año 2014. INE 2015.

La Encuesta Nacional de Salud de España 2011/12 (ENSE 2011/12), realizada por el Ministerio de Sanidad, Servicios Sociales e Igualdad en colaboración con el Instituto Nacional de Estadística, recoge información sanitaria relativa a la población residente en España. Los resultados obtenidos en su última edición reflejan que el $65,6 \%$ de la población, de 15 o más años residente en España, refiere haber tomado bebidas alcohólicas en el último año. Del 34,4\% que no había bebido (prevalencia de abstinencia), el $22,2 \%$ no lo había hecho nunca, mientras que el $12,2 \%$ había tomado alcohol anteriormente pero ya no lo hacía. (Tabla 7).

La prevalencia de consumo de bebidas alcohólicas en la población es mayor en hombres $(77,5 \%)$ que en mujeres $(54,3 \%)$. El diferencial por sexo se observa en todos los grupos de edad (Tabla 7), pero es menor entre los más jóvenes. En el grupo de 15-24 años la diferencia es de 7 puntos porcentuales, mientras que entre 25 y 54 años está en torno a los 20 puntos, y sigue aumentando con la edad. 
Tabla 7.- Porcentaje de la población adulta (15 o más edad) que ha consumido bebidas alcohólicas en los últimos 12 meses según sexo y grupo de edad. España, ENSE 2011/12, MSSSI/INE.

\begin{tabular}{|l|l|l|l|l|l|l|l|l|l|l|}
\hline & Total & $15-24$ & $25-34$ & $35-44$ & $45-54$ & $55-64$ & $65-74$ & $75-84$ & $85+$ \\
\hline Ambos sexos & 65,6 & 67,3 & 73,7 & 70,6 & 70,2 & 65,9 & 57,1 & 43,13 & 29,3 \\
\hline Hombres & 77,5 & 71,0 & 84,3 & 79,7 & 80,4 & 79,8 & 76,1 & 60,6 & 44,3 \\
\hline Mujeres & 54,3 & 63,5 & 62,9 & 61,1 & 60,2 & 52,7 & 40,6 & 31,1 & 21,3 \\
\hline
\end{tabular}

En cuanto al grupo de edad la prevalencia de consumo de alcohol (en los últimos 12 meses) alcanza pronto niveles elevados. En el grupo de 15 a 24 años ya bebe el 67,3\%. Entre 25 y 54 años se estabiliza en torno a 8 de cada 10 hombres y 6 de cada 10 mujeres, e inicia una bajada escalonada a partir de los 55 años. A los $75-84$ bebe el 43,1\%. En hombres desciende más tarde, sobre todo a partir de los 75 años. En mujeres en cambio el descenso se inicia antes, a partir de los 55, y partiendo ya de niveles muy inferiores. La prevalencia de mujeres que beben decrece de manera importante a partir de esa edad.

Las diferencias de género en la prevalencia de bebedores están relacionadas con los gradientes educativos y ocupacionales. Hay un gradiente social manifiesto (Fig. 6): la prevalencia de consumo es mayor en las clases sociales ocupacionales altas. 


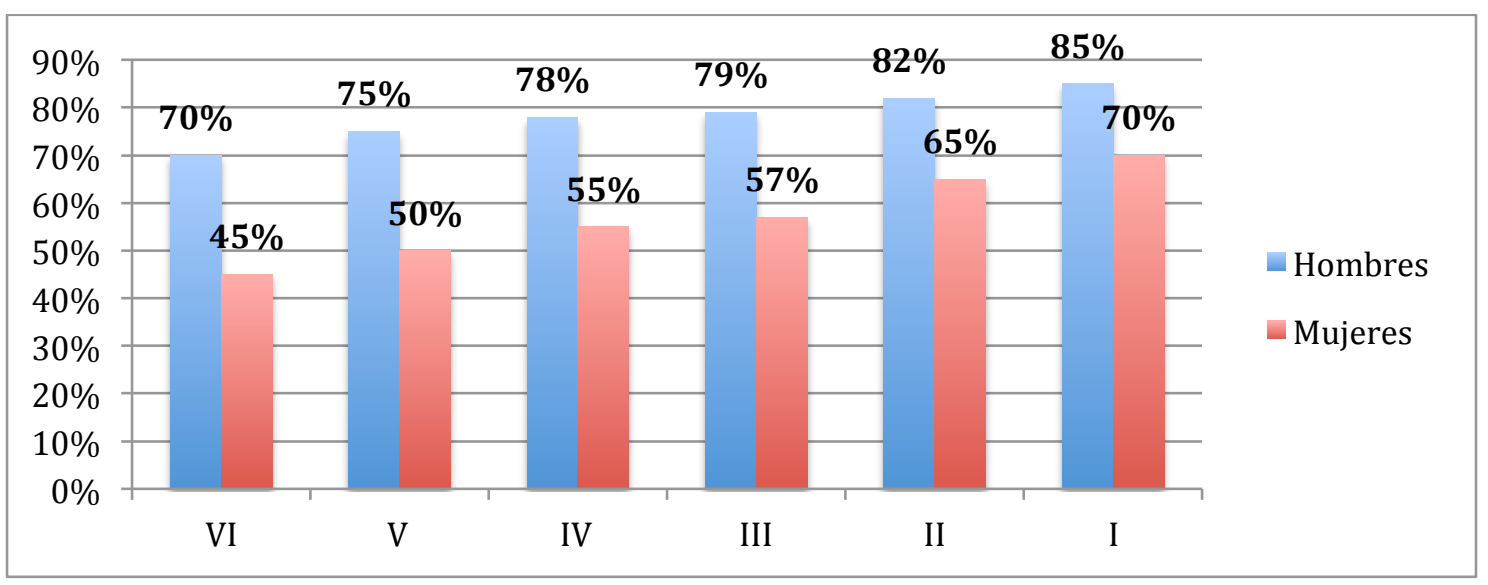

Fig. 6.- Porcentaje de la población adulta (15 y más años) que ha consumido bebidas alcohólicas en los últimos 12 meses según sexo y clase social. ENSE 2011/12 MSSSI/INE

El $78,1 \%$ de la población de clase I consumió bebidas alcohólicas en los últimos 12 meses, proporción que cae escalonadamente hasta la clase $\mathrm{VI}$, en la que solo el 56,9\% consumió alcohol en el último año. Este gradiente se da tanto en hombres (bebe el $85,5 \%$ de la clase I vs $70,4 \%$ de la clase VI) como en mujeres, pero más marcado en estas últimas (bebe el $69,8 \%$ de la clase I, vs el $46,4 \%$ de la clase VI). La razón de prevalencias entre la clase social más alta y la más baja fue de 1,2 en hombres, mientras que en mujeres alcanzó el 1,5 .

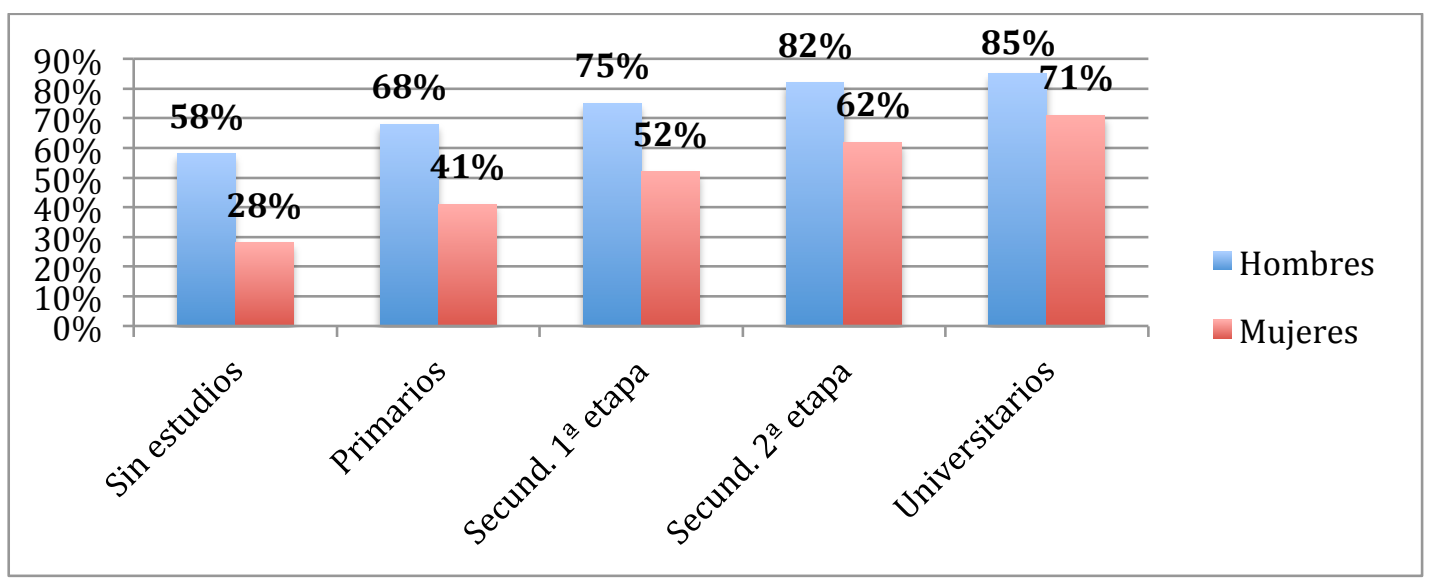

Fig. 7.- Porcentaje de la población adulta ( 15 y más años) que ha consumido bebidas alcohólicas en los últimos 12 meses según sexo y nivel de estudios. ENSE 2011/12 MSSSI/INE . 
Por nivel de estudios los resultados muestran este mismo gradiente, pero más acentuado que por ocupación (Fig. 7).

Es mucho más frecuente haber bebido en el último año en los niveles de formación más altos, el $77,8 \%$ entre los universitarios frente al $40,6 \%$ de los que no habían completado los estudios primarios. Se da en ambos sexos, pero es más marcado en mujeres. El $71,7 \%$ de las universitarias había bebido alcohol en el último año, frente al $27,9 \%$ de las mujeres sin estudios, alcanzando la razón de prevalencias un 2,6. Las prevalencias más bajas se encuentran en la población de menor nivel académico en todos los grupos de edad en ambos sexos (Fig. 7).

Según la relación con la actividad económica actual (Fig. 8), la población que está trabajando es la que declara mayor prevalencia de consumo en el último año $(75,7 \%)$, seguidos de los desempleados $(68,8 \%)$.

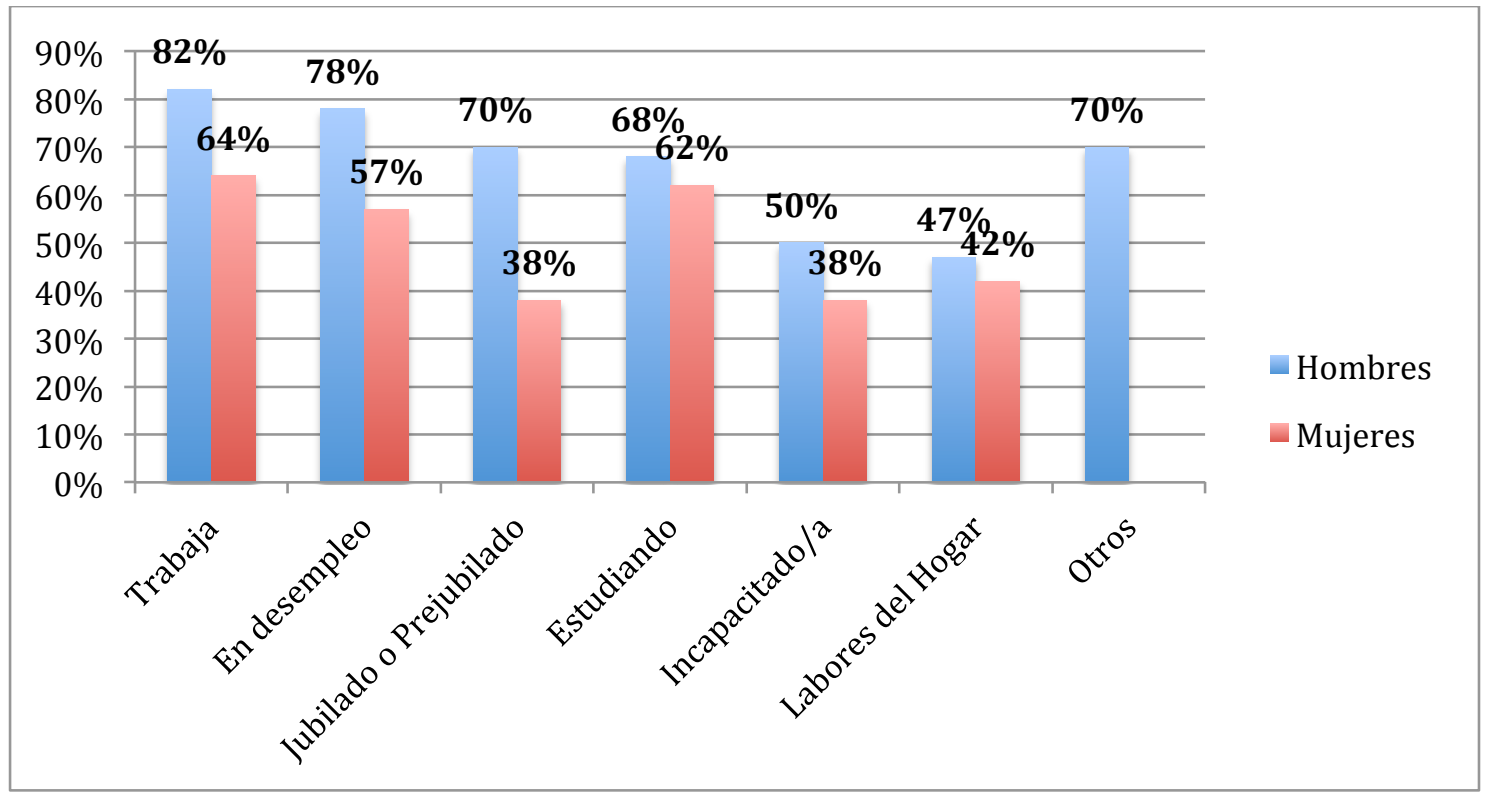

Fig. 8.- Porcentaje de la población adulta que ha consumido bebidas alcohólicas en los últimos 12 meses según sexo y relación con la actividad económica actual. ENSE 2011/12.

Por sexo destaca que en mujeres, el segundo lugar lo ocupan las estudiantes (62,7\%), grupo en el que las diferencia entre hombres y mujeres es menor. Los estudiantes sólo ocupan el cuarto lugar en hombres $(68,7 \%)$, por detrás de los jubilados $(69,7 \%)$. 
Además es interesante, reseñar que en nuestro país existen notables diferencias entre comunidades autónomas en la distribución territorial del consumo de alcohol (Fig. 9).

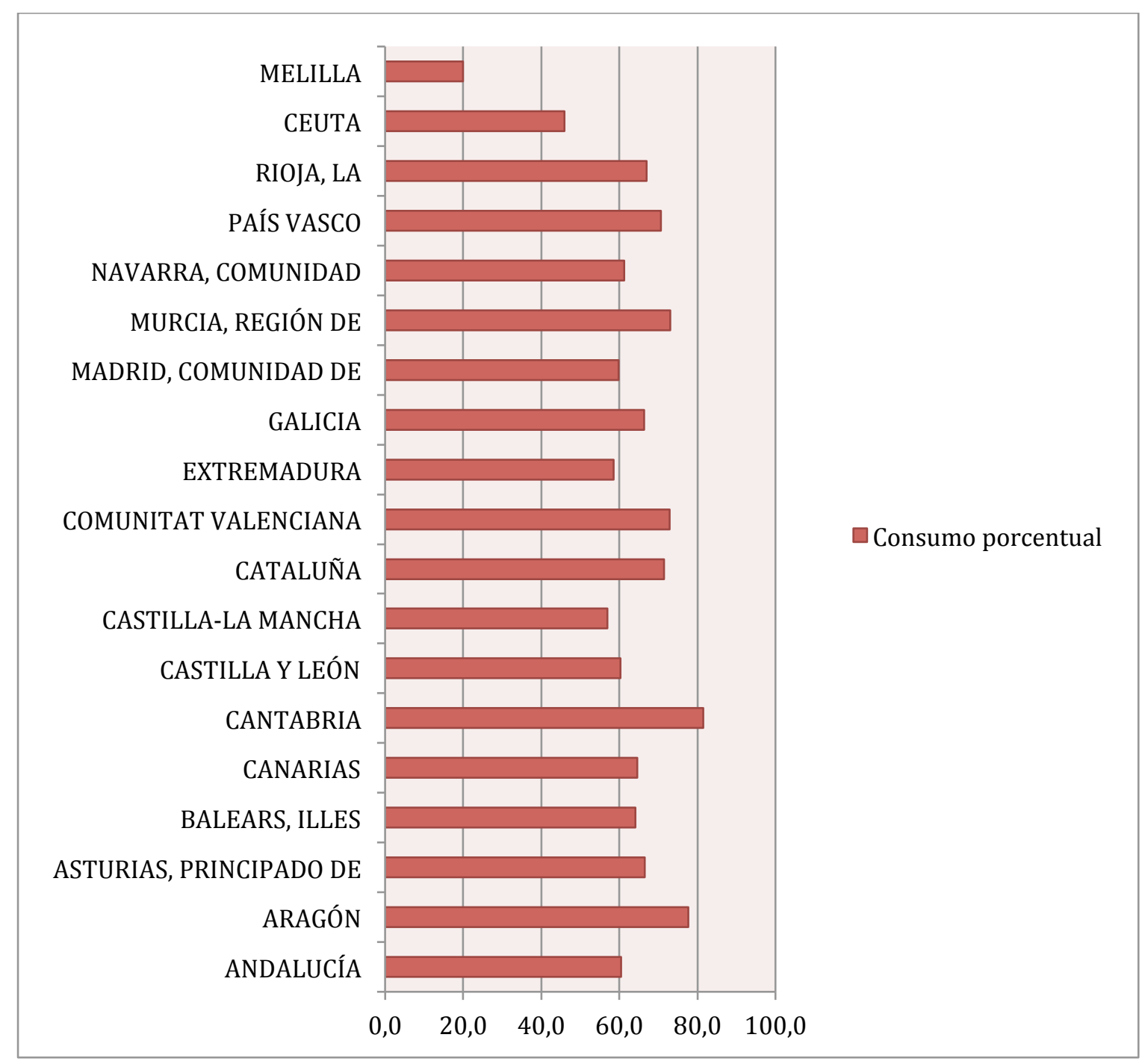

Fig. 9.- Distribución porcentual en población adulta (15+) de consumo bebidas alcohólicas en los últimos 12 meses según comunidad autónoma. ENSE 2011/!2

El porcentaje de la población de 15 y más años que consumió bebidas alcohólicas en el último año está por debajo del 50\% en Ceuta y Melilla, y alcanzó valores máximos en Cantabria y Aragón, en torno al $80 \%$, frente a una media nacional del 65,6\%.

Además, observamos que en las comunidades del norte y del este peninsular es mayor la prevalencia de personas que han bebido alcohol en el 
último año. La diferencia absoluta entre las comunidades autónomas con mayor -Cantabria y Aragón-, y con menor prevalencia -Castilla-La Mancha y Extremadura- fue de $25 \%$. En cuanto al consumo de riesgo para la salud, el promedio diario de alcohol es mayor en la zona centro y norte. El consumo intensivo ocasional o episódico perfila un mapa diferente, con mayor frecuencia en Extremadura, Aragón y Castilla y León, donde más del $8 \%$ de la población bebió de manera intensiva al menos una vez en el último mes, frente al 1,6\% de los residentes en Baleares.

\subsection{2.- Patrones de consumo de alcohol}

Existen diferentes patrones de consumo de alcohol. Tradicionalmente se ha dividido el mundo en regiones con elevado o bajo consumo per cápita, denominando wet cultures o dry cultures respectivamente. En países con wet cultures el consumo de alcohol está integrado en la vida cotidiana y es consumido regularmente acompañando las comidas, las bebidas alcohólicas son fácilmente accesibles y la proporción de personas abstemias es escasa. Esta cultura es característica de los países de la cuenca mediterránea en los que el vino es la bebida predominante.

Por otro lado, en las regiones con dry cultures donde el consumo de alcohol no es habitual con las comidas ni está integrado en las actividades cotidianas, ya que su acceso es más restrictivo, existen tasas de abstinencia muy superiores. Sin embargo, cuando se consume alcohol es más probable que ocurra intoxicación. Este patrón de consumo es típico de los países escandinavos, Estados Unidos y Canadá, donde la cerveza y los destilados son las bebidas preferentes.

Comparaciones más recientes realizadas principalmente en países europeos, describen como la división wet/dry parece ir desapareciendo y la forma de consumo, incluido el tipo de bebidas, se va homogeneizando. Por otro lado, esta dicotomía se ha adaptado a nuevas formas de consumo emergentes, considerando una variedad de comportamientos donde destacan las dimensiones de la regularidad del consumo y del grado de embriaguez. 
España podría situarse en este perfil de países en transición. En los últimos años, en nuestro país se ha producido un cambio en los patrones de consumo y en los estilos de diversión de los jóvenes.

Se ha ido expandiendo un patrón de consumo 'anglosajón' caracterizado por consumo de bebidas alcohólicas sólo en fin de semana, en cantidades altas y abusivas, en muchos casos con el objetivo claro de conseguir en poco tiempo la embriaguez, de esta manera según se recoge del estudio EDADES (2015), existe un importante incremento de las intoxicaciones etílicas, en ambos sexos, pero de forma especial en el grupo de edad más joven (de 15 a 34 años) y más llamativo en las mujeres durante los últimos años, al menos una vez al mes. Además se ha observado una caída en la edad de inicio; aunque el consumo de alcohol en la sociedad española es prácticamente universal.

Desde el punto de vista epidemiológico es importante definir y determinar el consumo de riesgo crónico y el consumo intensivo también conocido como binge drinking.

EI CONSUMO DE RIESGO CRÓNICO, concepto difícil de consensuar al depender del tipo de consecuencia que se esté evaluando. En general, se define como aquella pauta de consumo que puede implicar un alto riesgo de daños futuros. La Organización Mundial de la Salud establece como bebedor de riesgo a aquel que consume 28 UBEs/semana en el caso de los varones y 17 UBEs/semana en las mujeres, aproximadamente $40 \mathrm{~g}$ de promedio diario para hombres y $24 \mathrm{~g}$ para mujeres. No obstante, cualquier consumo de alcohol en menores se considera un consumo de riesgo.

Tal como muestra la Tabla 8, únicamente una minoría de la población de 15 y más años declara beber por encima de los umbrales de riesgo (1,7\%). Si la estimación se hace entre las personas que beben habitualmente (bebedores al menos un día por semana), el porcentaje es de un 4,3\%. En la población general es mayor la proporción de hombres bebedores de riesgo (2\%) que de mujeres $(1,3 \%)$, mientras que en la población de bebedores habituales es más elevada la proporción de mujeres bebedoras de riesgo $(5,2 \%)$ que la de hombres $(3,9 \%)$, siendo menos las mujeres que beben de forma habitual. 
En términos poblacionales, 645.145 personas mayores de 15 años consumen alcohol en cantidad de riesgo para la salud. De ellas el $59 \%$ son hombres.

Tabla 8.- Consumo de alcohol de riesgo para la salud por sexo. Porcentaje de bebedores de riesgo entre los bebedores habituales y en población adulta (15 y más años). ENSE 2011/12, MSSSI/INE

\begin{tabular}{cccc}
\hline Base & Bebedores habituales & Población adulta (+15) & $\begin{array}{c}\text { Valor absoluto } \\
\text { poblacional }\end{array}$ \\
\hline Total & \% bebedores de riesgo & \% bebedores de riesgo & \\
Hombres & 4,3 & 1,7 & 645145 \\
Mujeres & 3,9 & 2,0 & 380705 \\
\hline
\end{tabular}

El consumo de riesgo es mayor en hombres que en mujeres en todas las edades excepto en las más jóvenes. La Figura 10 muestra la prevalencia de bebedores de riesgo en la población de 15 y más años según sexo y edad. El porcentaje de hombres es superior al de mujeres en todos los grupos de edad salvo entre 15 y 24 años, pero sobre todo en los de mayor edad.

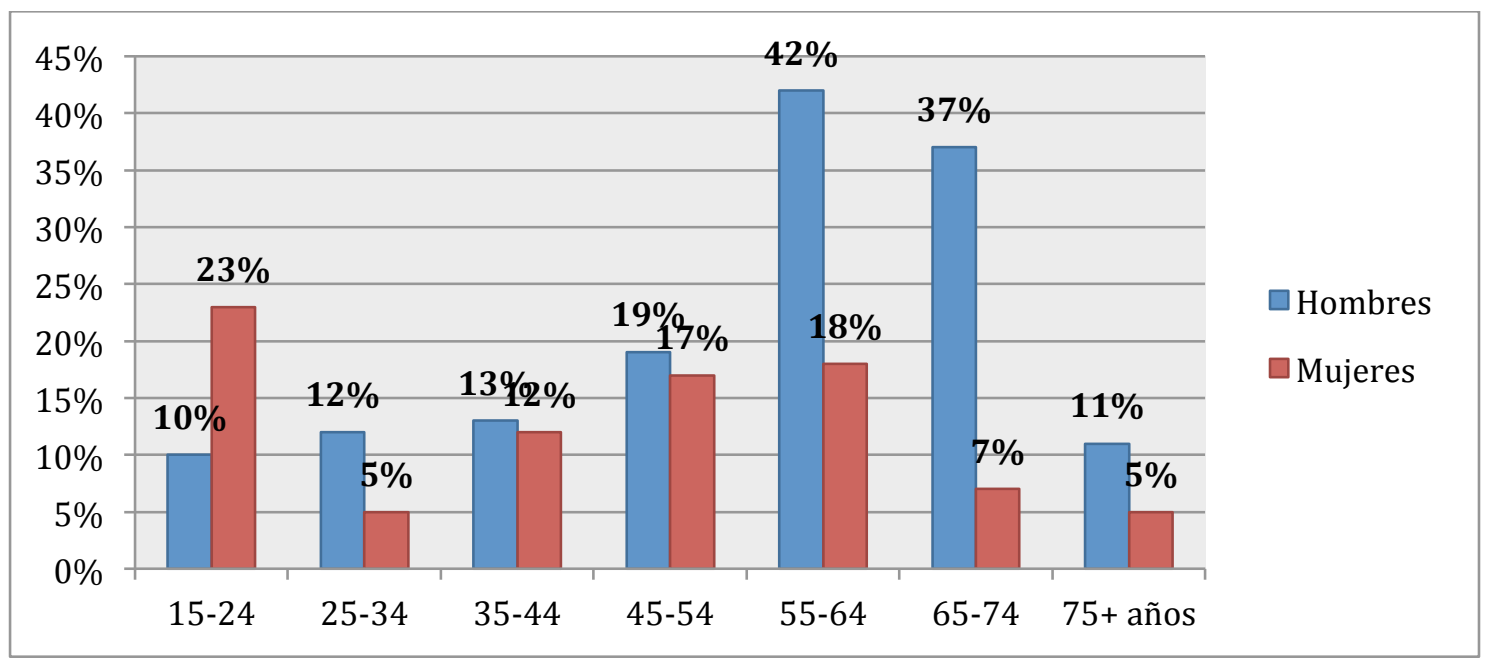

Figura 10. - Porcentaje de bebedores de riesgo según sexo y grupo de edad. Población adulta (15 y más años). ENSE 2011/12, MSSSI/INE. 
En los hombres asciende suavemente desde los más jóvenes $(1,1 \%)$ hasta el grupo de 45 a 54 años, y despunta en el grupo de 55 a 74 años, que alcanza los mayores niveles (4,3\%), para descender a partir de esa edad. Las mujeres son menos y más jóvenes. Destaca el grupo de $15-24$ años: el 2,4\% declara un consumo de bebidas alcohólicas por encima del umbral de riesgo, más del doble que los hombres $(1,1 \%)$. A partir de esa edad en mujeres se mantiene siempre por debajo del $2 \%$.

Si se analiza la frecuencia con que consumen alcohol los bebedores de riesgo se observan notables diferencias según el sexo. En las mujeres el consumo de riesgo se concentra en los fines de semana y en los hombres el consumo es tradicionalmente diario. El 85,3\% de los hombres cuyo consumo medio diario de alcohol supone un riesgo para su salud bebe a diario, mientras que este porcentaje sólo llega al 56,6\% en mujeres. En cambio, de las mujeres bebedoras de riesgo, el $26,8 \%$ concentra la bebida en los fines de semana, frente al 9,2\% de los hombres (Figura 11).

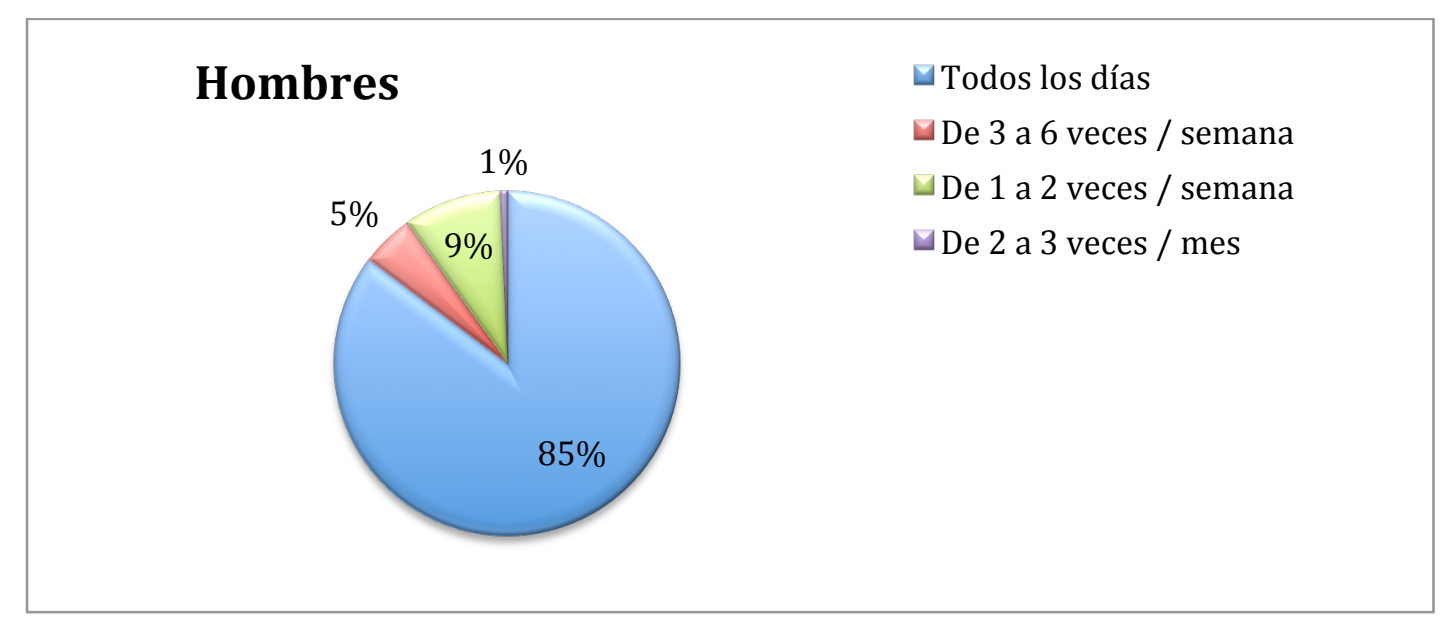


Mujeres

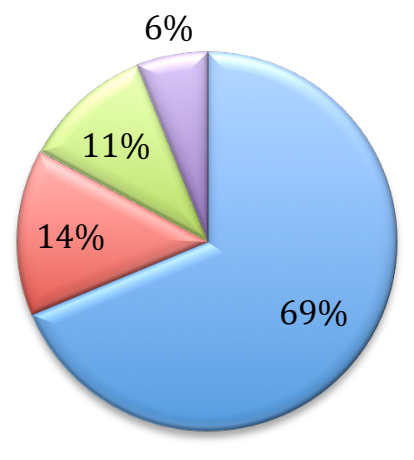

$\square$ Todos los días

$\square$ De 3 a 6 veces / semana

$\checkmark$ De 1 a 2 veces / semana

$\square$ De 2 a 3 veces / mes

Fig. 11 - Frecuencia de consumo de los bebedores de riesgo por sexo. Población de 15 y más años. ENSE 2011/12, MSSSI/INE

EI CONSUMO INTENSIVO DE ALCOHOL se define como el consumo de 6 o más bebidas estándar en un intervalo de cuatro a seis horas en el caso de los hombres y de 5 o más en las mujeres, en los últimos 12 meses.

El $13,4 \%$ de la población de 15 y más años se expuso a los riesgos del consumo intensivo en el último año, $19,8 \%$ de los hombres y $7,3 \%$ de las mujeres (Tabla 9).

Tabla 9. Frecuencia de consumo intensivo de alcohol en el último año (\%). Población de 15 y más años. ENSE 2011/12, MSSSI/INE

\begin{tabular}{ccccccc}
\hline & Total & Nunca & $\begin{array}{c}\text { Menos de } \\
\text { 1 vez / mes }\end{array}$ & Mensualmente & Semanalmente & Diariamente \\
\hline Ambos & 100 & 86,6 & 8,8 & 2,5 & 1,7 & 0,3 \\
sexos & & & & & & \\
Hombres & 100 & 80,3 & 12,6 & 3,9 & 2,7 & 0,5 \\
Mujeres & 100 & 92,7 & 5,2 & 1,1 & 0,8 & 0,2 \\
\hline
\end{tabular}

En la Flgura 12 se muestra la frecuencia con que la población de 15 y más años consume alcohol de forma intensiva, así como la distribución por sexo y grupo de edad de los que han consumido de manera intensiva al menos una vez en el último mes. El 4,5\% de la población de 15 y más años consumió alcohol de manera intensiva al menos una vez al mes. Este tipo de consumo es más frecuente en los más jóvenes, alcanzando el $8 \%$ entre los 15 y los 34 
años, para luego descender a la mitad entre los 35 y los 64 años. Solo a partir de los 65 años está por debajo del $2 \%$.

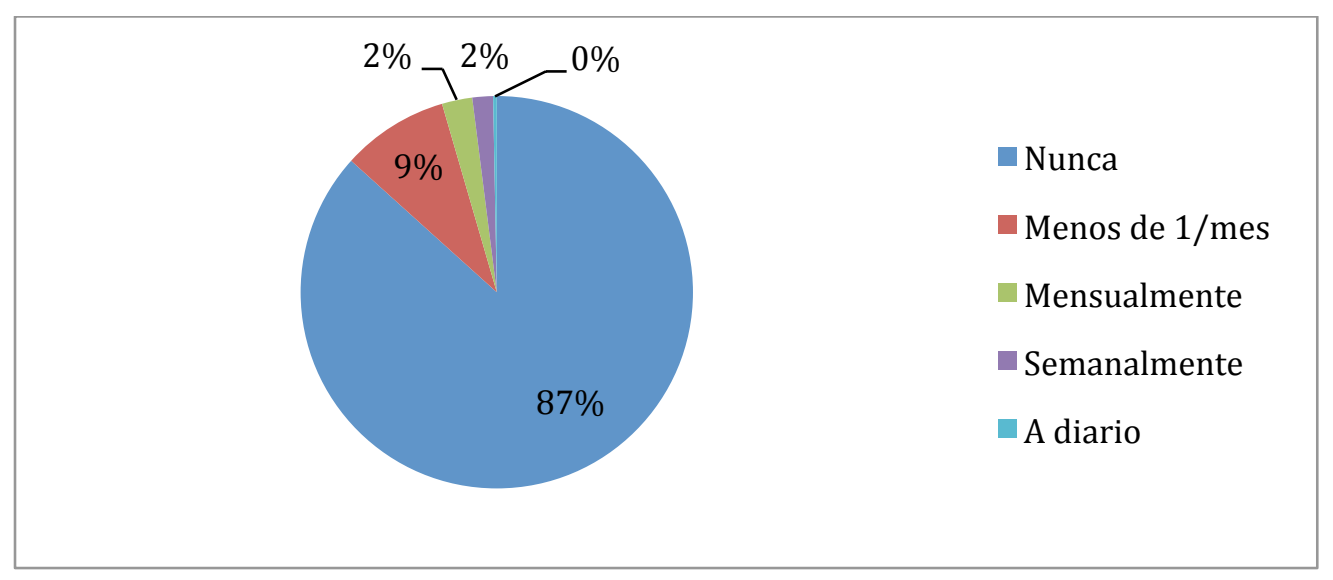

Fig. 12 - Frecuencia de consumo intensivo de alcohol en la población adulta (15 y más años) y consumo intensivo al menos una vez al mes por sexo y edad. ENSE 2011/12, MSSSI/INE

Existen importantes diferencias por sexo en la prevalencia de consumo intensivo de riesgo, aunque hay una aproximación en los grupos más jóvenes. La frecuencia de consumo intensivo en el último mes es mayor en hombres $(7,1 \%)$ que en mujeres $(2,1 \%)$, y lo es en todos los grupos de edad. Uno de cada diez hombres de 15-34 años declaró haber bebido alcohol de forma intensiva al menos mensualmente y casi uno de cada 20 lo hizo todas las semanas. La razón de prevalencias entre hombres y mujeres es 3,4.

En los más jóvenes, de 15 a 24 años, a pesar de ser el grupo de edad con menor diferencial por sexo, los hombres beben de forma intensiva al menos una vez al mes con doble frecuencia que las mujeres (11\% vs 5,6\%). La mayor diferencia se da en el grupo de 25 a 34 años, en el que casi alcanza los 10 puntos porcentuales. En las mujeres, el grupo de edad que consume alcohol de manera intensiva con mayor frecuencia es el de 15 a 24 años, bajando bruscamente la frecuencia de este patrón de consumo a partir de esa edad (Tabla 7). Tres de cada cuatro jóvenes de 15 a 24 años nunca ha consumido alcohol de manera intensiva (71,1\% de los hombres y $82,2 \%$ de las mujeres).

En la actualidad, los datos demuestran una clara modificación de las tendencias. Mientras que en el año 2006 la edad media de inicio de consumo de alcohol en España era de 18,9 años, en el año 2011 se situó en 17,8 años. 
Este ligero adelanto se ha producido principalmente a expensas de las mujeres, que pasan de 20,2 a 18,8. Son sobre todo las mujeres de 65 y más años quienes adelantaron el inicio del consumo en el periodo de estudio, pasando desde los 24,5 años a los 17,6.

La población adulta que ha consumido alcohol alguna vez en la vida se ha incrementado entre 2003 - 2011, pasando del $61,2 \%$ al $77,8 \%$. El incremento se produce en ambos sexos pero es mayor en mujeres, que pasan de $48 \%$ al $69 \%$ en este mismo periodo.

La evolución de la prevalencia de bebedores en los últimos 12 meses muestra tendencia a la estabilización, después de un incremento al inicio del período estudiado (Figura 13). En población total pasa del 56,1\% al 65,6\%. El incremento se observa entre 2003 y 2006, produciéndose a partir de entonces una estabilización e incluso un tenue descenso. La evolución es la misma para ambos sexos.

Disminuye notablemente la prevalencia de consumo de bebidas alcohólicas al menos una vez a la semana, también denominada consumo habitual. En 2006 el 48,6\% de la población adulta era bebedora habitual, y esta proporción se ha reducido al 38,3\% en 2011. La disminución se ha producido en ambos sexos y en todos los grupos de edad.

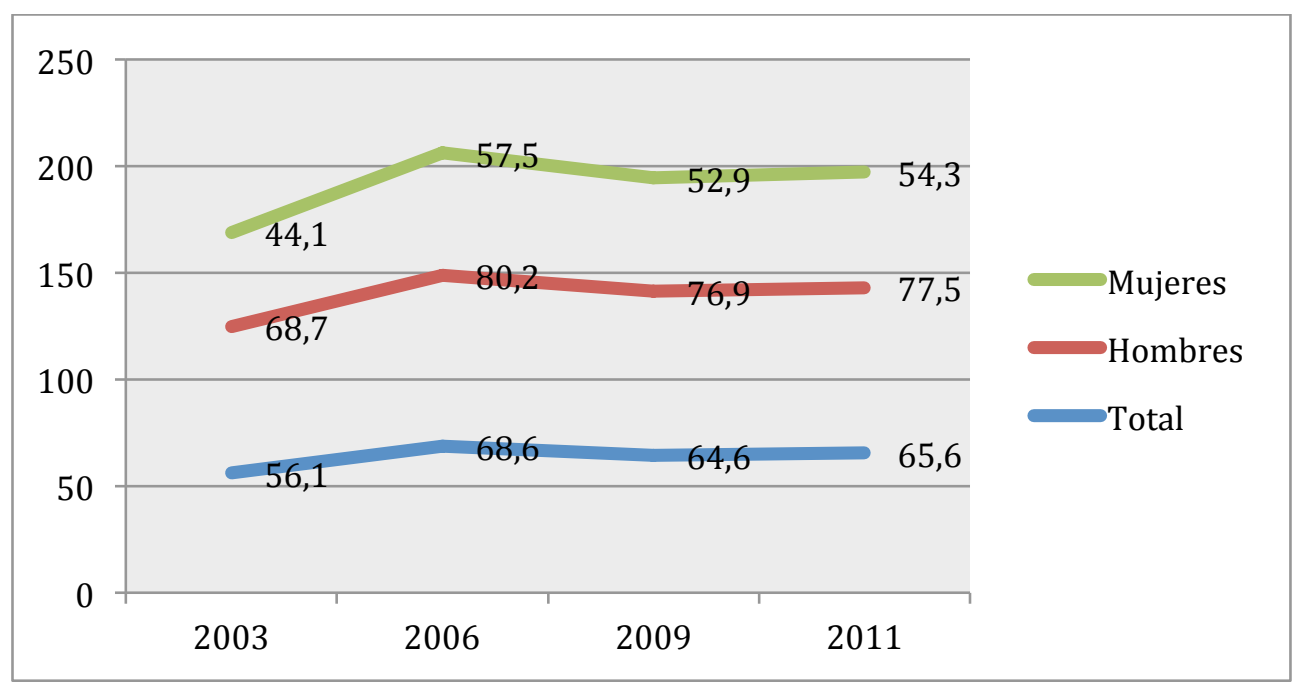

Fig. 13 - Prevalencia de bebedores (último año) en población adulta (15 y más años). España 2003- 2011/12. ENSE y EES, MSSSI/INE.

Como otros países mediterráneos, España se caracterizaba por un consumo de alcohol per capita elevado, siendo el vino la bebida más 
extendida, tomada generalmente a diario y mayoritariamente por los hombres. Los resultados de la ENSE 2011/12 confirman la pervivencia, -aunque decreciente-, de este perfil típicamente masculino, más frecuente en niveles socioeconómicos bajos, que se ha desplazado hacia edades más avanzadas.

Los jóvenes beben de forma diferente. Los datos de la ENSE 2011/12 confirman que consumen cantidades elevadas de alcohol, -generalmente destilados y/o cerveza-, concentrado en los fines de semana. Este patrón era característico de los países del norte de Europa, pero hoy en España el promedio de alcohol que se consume el fin de semana es casi 20 veces mayor que entre la semana en los bebedores más jóvenes.

\subsection{3.- Daños relacionados con el consumo de alcohol.}

El uso nocivo del alcohol es uno de los factores de riesgo más importantes del mundo para la morbilidad, la discapacidad y la mortalidad. Es una causa que aparece en más de 200 condiciones de enfermedad y lesiones que se describen en la Statistical Classification of Diseases and Related Health Problems (ICD) 10th Revision (WHO, 1992)

A nivel mundial, los resultados de consumo de alcohol son de aproximadamente 3,3 millones de muertes cada año, y este número ya se ha ajustado para tener en cuenta el impacto beneficioso de los patrones de bajo riesgo de consumo de alcohol en algunas enfermedades. De todas las muertes en el mundo, el 5,9\% son atribuibles al consumo de alcohol; esto es mayor que, por ejemplo, la proporción de muertes por VIH / SIDA (2,8\%), violencia $(0,9 \%)$ o la tuberculosis $(1,7 \%)$. Además, el $5,1 \%$ de la carga mundial de enfermedades y lesiones es atribuible al alcohol, según se mide en la discapacidad ajustada a los años de vida (DALYs).

Hay una gran variabilidad geográfica en las muertes atribuibles al alcohol. Como se muestra en la Figura 15, la proporción de muertes atribuibles al alcohol en relación con todas las muertes, AAFS (Alcohol-attributable fractions), es más alta en Europa. Esto no es sorprendente, ya que el consumo de alcohol es también el más alto en este continente. Sin embargo, es importante tener en cuenta que las cifras elevadas de muertes atribuibles al 
alcohol AAFS en Europa están casi enteramente impulsadas por los países de Europa del Este.

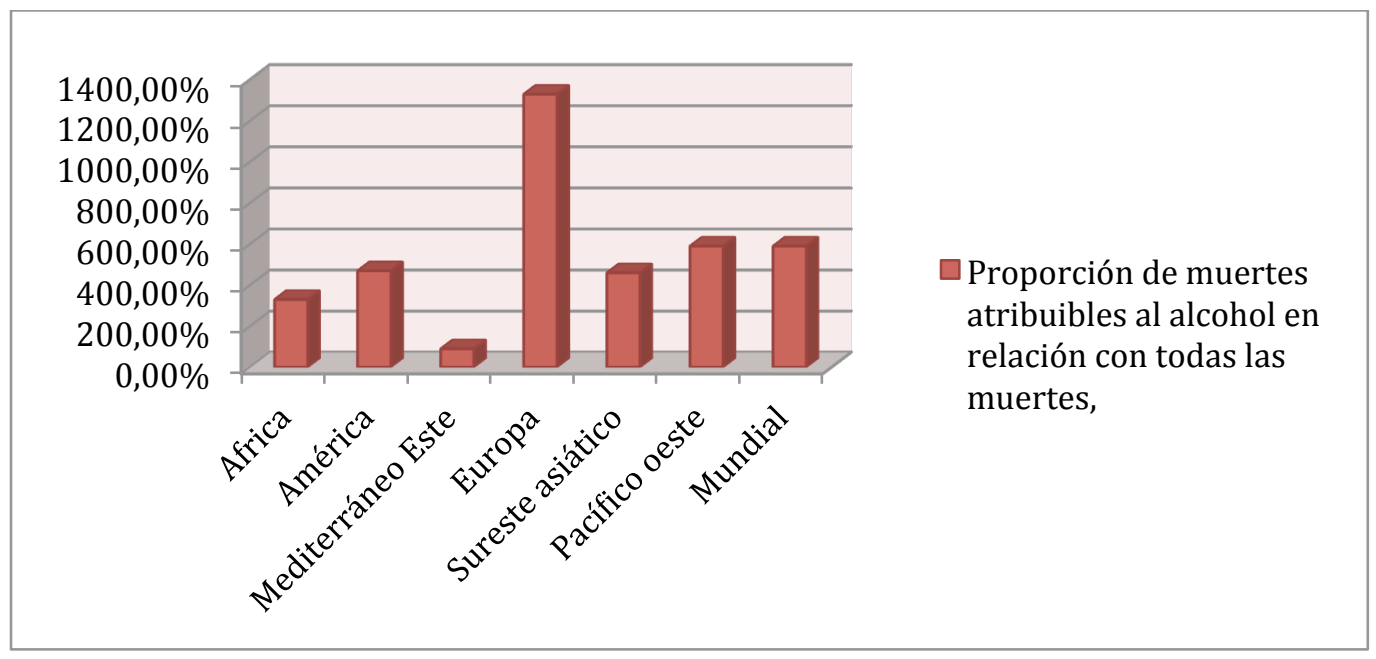

Fig. 14.- Proporción de muertes atribuibles al alcohol en relación con todas las muertes (AAFS). Global status report on alcohol and health. WHO 2014.

De entre el gran número de patologías producidas por el consumo de alcohol, el mayor número de muertes son por enfermedades cardiovasculares, seguidas por las lesiones (especialmente lesiones no intencionadas), enfermedades gastrointestinales (principalmente cirrosis hepática) y cáncer.

En 2012 , el 5,1\% de la carga mundial de enfermedades y lesiones, se atribuye al alcohol. La Figura 15 muestra la distribución de este total en ocho categorías de enfermedades generales.

El efecto relativo del consumo de alcohol sobre la carga de morbilidad de los trastornos neuropsiquiátricos fue mucho más pronunciada que su efecto sobre la mortalidad. Alrededor de una cuarta parte de toda la discapacidad por años de vida atribuibles al alcohol (DALYs), se debieron a trastornos neuropsiquiátricos en comparación con el $4 \%$ de todas las muertes atribuibles al alcohol. Esto se debe principalmente a que éstas patologías causan más discapacidad que mortalidad en comparación con otras enfermedades crónicas (Escudo et al., 2013). 


\section{Población total = 139 millones DALYs}

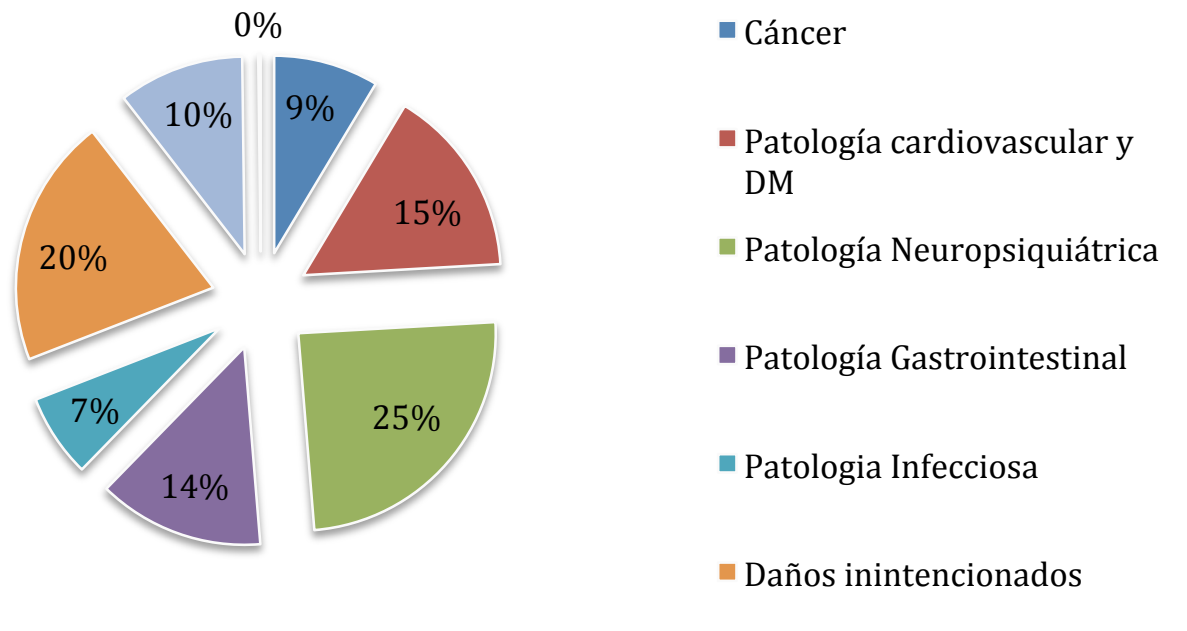

Fig. 15.- Distribución de la discapacidad / años de vida (DALYs), atribuible al alcohol como porcentaje 2012. Global status report on alcohol and health. WHO 2014.

Los mecanismos fisiopatológicos por los cuales se explican los efectos adversos del alcohol sobre el organismo aún no se comprenden con claridad. Se ha postulado una toxicidad directa del alcohol o de los productos resultantes de su metabolismo oxidativo y no oxidativo (acetaldehído y etilésteres de ácidos grasos). Además, pueden producirse cambios de la expresión génica apareciendo patrones anormales de metilación de ADN (hipometilación) y de la cromatina, seguidos de alteración del metabolismo de los carbohidratos, estrés oxidativo, y formación de radicales libres. Por otra parte, algunas patologías en los consumidores crónicos se han relacionado con déficits nutricionales, debido a una dieta desequilibrada o a la interferencia del etanol con la utilización de carbohidratos, lípidos y vitaminas, particularmente la A. De hecho, el etanol inhibe la oxidación del retinol a ácido retinoico (la forma activa de la vitamina) que es esencial para el mantenimiento de los epitelios.

Durante la intoxicación etílica aguda el consumo de alcohol puede afectar negativamente tanto a la persona intoxicada como a otras, a través de su asociación con lesiones o conductas violentas, infecciones de transmisión sexual y problemas laborales y/o familiares.

Los efectos adversos dependen del volumen de alcohol consumido (consumo promedio), de los patrones de consumo (en particular los episodios 
de consumo intensivo o atracones) y de la interacción con otros factores como el contexto del consumo, calidad de las bebidas, predisposición individual y respuesta social al problema.

\section{4.- Neurobiología del Trastorno por Consumo de Alcohol (TCA)}

La neurobiología deL TCA es un campo de conocimiento muy reciente. Los estudios sobre el tema, en los últimos años, han generado y generan una producción teórica bastante copiosa.

Los últimos avances neurobiológicos han permitido profundizar en la fisiopatología de estos trastornos a nivel bioquímico y celular. Actualmente se sabe que los efectos agudos del etanol están fundamentalmente mediados por su interacción con neurotransmisores aminoácidos, así como cambios paralelos en determinadas aminas como la dopamina y la noradrenalina. En las respuestas neuroadaptativas de los receptores de aminoácidos subyacen, probablemente, los componentes más importantes del síndrome de abstinencia y de la muerte neuronal que se encuentra en el consumo crónico de alcohol.

El marcado incremento de la investigación sobre la neurobiología de las adicciones se explica en cierta medida, por el importante desarrollo experimentado en las técnicas de neuroimagen cerebral funcional, la tomografía por emisión de positrones (PET), la tomografía por emisión de fotón simple computerizada (SPECT) y la resonancia magnética funcional (RMF), las cuales proporcionan una medida de la actividad del cerebro, a través de diferentes indicadores.

A partir de estas técnicas y del estudio del flujo sanguíneo cerebral, el metabolismo neural y el funcionamiento cerebral general, se ha profundizado en el conocimiento de los mecanismos de acción del etanol en el cerebro, mejorándose el conocimiento del Sistema de Recompensa Cerebral y pudiéndose determinar, al menos en parte, cuales son los neurotransmisores implicados. 


\subsection{1- Neurobiología de la exposición temprana al alcohol}

Gran parte de los efectos del etanol sobre el sistema nervioso, pueden ser explicados a partir de su interacción con dos complejos proteicos de importancia medular: el receptor $\mathbf{G A B A}_{\mathbf{A}}$, también denominado complejo receptor GABA-ionóforo Cloro (GABA es el acrónimo del ácido gamma-aminobutírico), y el receptor NMDA (N-metil-D-aspartato). El GABA es el neurotransmisor inhibidor por excelencia del Sistema Nervioso Central (SNC), esto significa que las neuronas que lo utilizan disminuyen de forma transitoria las respuestas de otras neuronas a estímulos posteriores. Por el contrario, el glutamato junto con el aspartato es el neurotransmisor excitador por excelencia del SNC, la respuesta de las neuronas inervadas por neuronas glutamatérgicas se ve aumentada.

El etanol, favorece la acción del GABA y antagoniza la acción del glutamato; en consecuencia, a nivel cerebral, el alcohol potencia los efectos inhibidores e inhibe los excitadores, situándose así entre las sustancias depresoras del SNC.

El efecto depresor del alcohol sobre el sistema nervioso se ha relacionado con los efectos de sedación, relajación y somnolencia.

\section{a) Receptor GABA}

El complejo receptor $\mathrm{GABA}_{\mathrm{A}}$-ionóforo $\mathrm{Cl}^{-}$(Cloro) es una proteína constituida por 5 subunidades ensambladas formando un canal en su interior, que atraviesa la membrana neuronal. Los sitios de fijación de la mayor parte de las sustancias que actúan sobre este complejo (sean agonistas, antagonistas o agonistas inversos), suelen estar en la parte extraneuronal, aunque algunos están en el propio canal o en otros lugares. A través del canal pueden pasar moléculas cargadas negativamente y de muy pequeño tamaño, especialmente el anión $\mathrm{Cl}^{-}$. La activación del receptor da lugar a la apertura del canal, lo que permite la entrada de $\mathrm{Cl}^{-}$, y se produce una hiperpolarización de la membrana, que conlleva una disminución de la excitabilidad de la neurona y, consecuentemente, de su actividad funcional (Figura 16). 


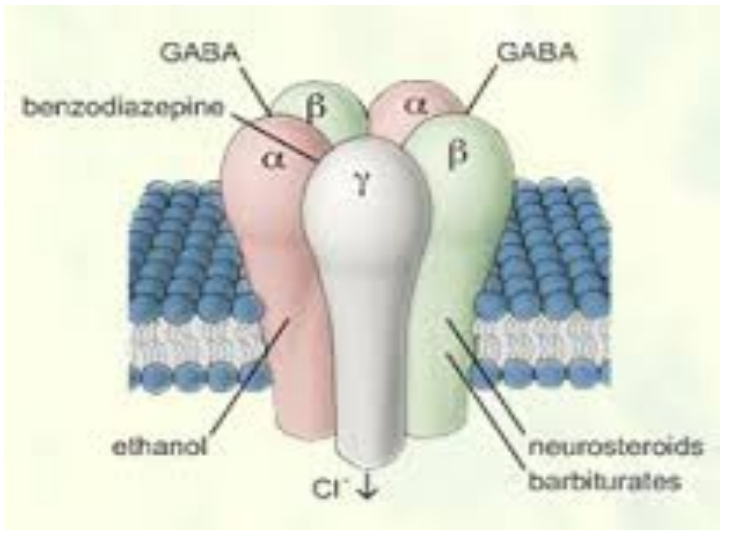

Fig. 16.- Receptor GABA

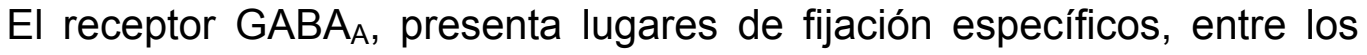
que destacan: el lugar sobre el que actúa el GABA, el sitio de fijación benzodiacepínico y el lugar sobre el que, entre otros, actúan los barbitúricos. El etanol no actúa directamente en estos tres sitios, si bien potencia las acciones de los compuestos que actúan en cualquiera de ellos. Consecuentemente, el etanol favorece el flujo de aniones $\mathrm{Cl}^{\text {}}$, inducido por GABA, benzodiacepinas y barbitúricos; pero no porque produzca, "per se", la apertura del canal, sino porque potencia la acción de las sustancias que lo abren.

Aunque a dosis fisiológicas el alcohol no actúa directamente sobre el canal, a dosis grandes (>250 mg/dl), sí lo hace, al igual que los barbitúricos. Esto justifica porqué, a diferencia de lo que ocurre con las benzodiacepinas (que carecen de acción directa sobre el canal), las intoxicaciones etílicas y barbitúricas son potencialmente mortales.

Aunque las bases moleculares para la selectividad de acción del etanol no se conocen con certeza, suele atribuírsele a la heterogeneidad de las subunidades que componen los receptores $\mathrm{GABA}_{\mathrm{A}}$ (cada receptor está compuesto por 5 subunidades distintas y cada un posee, al menos tres de éstas diferentes); lo cual explicaría el porqué en algunos casos, el etanol potencia la acción inhibitoria y en otros no.

\section{b) Receptor NMDA}


EI NMDA es uno de los principales receptores del glutamato, el principal neurotransmisor excitador cerebral. Su activación da lugar a un aumento de la permeabilidad para varios cationes como el $\mathrm{NA}^{+}$, el $\mathrm{K}^{+}$y el $\mathrm{Ca}^{+2}$, que se traduce en una despolarización de la membrana neuronal o en un aumento de la excitabilidad de la célula (Figura 17).

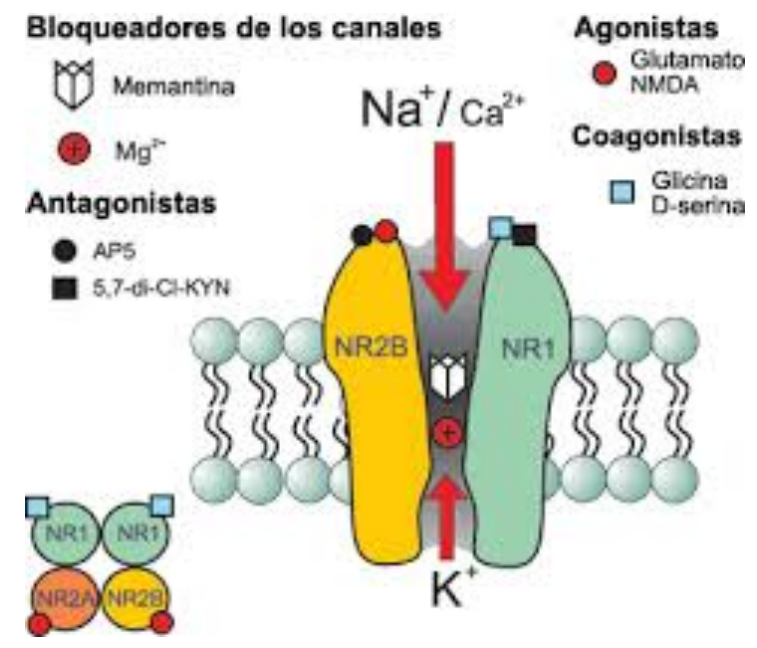

Fig. 17.- Receptor NMDA

La acción aguda del etanol disminuye el flujo de $\mathrm{Ca}^{+2}$, a través del canal, con lo que induce cambios a largo plazo en la función y señalización neuronal. De hecho parte de los efectos de intoxicación por alcohol (amnesia parcial o total acontecida durante los periodos de embriaguez), pueden explicarse a partir de sus efectos inhibidores sobre el receptor NMDA., lo que ocurre a concentraciones mayores de $100 \mathrm{mg} / \mathrm{dl}$. En estos casos se inhibe los circuitos que intervienen en la consolidación de la memoria en el hipocampo, básicamente glutamatérgicos.

Por otro lado, un flujo intracelular de $\mathrm{Ca}^{+2}$ excesivo es neurotóxico, de hecho, la muerte celular inducida por NMDA es un elemento característico en accidentes cerebro-vasculares. Consecuentemente, es posible que en personas no alcohólicas la acción inhibidora del etanol sobre los receptores NMDA tenga un valor protector en las enfermedades cerebrovasculares, en las que los aminoácidos excitotóxicos ocasionan el daño neuronal.

Aún se desconoce la forma en que el etanol ejerce su acción sobre los receptores NMDA. Al igual que en el caso del receptor $\mathrm{GABA}_{\mathrm{A}}$, hay una gran variabilidad local y regional en las acciones del etanol sobre el receptor 
NMDA. Parte de esta diferente sensibilidad depende de la composición de las subunidades de los receptores NMDA (Ayesta, 2002).

\subsection{2.- Sistema de recompensa cerebral (dopaminérgico o mesolímbico-cortical).}

Hace ya medio siglo que se documentó con claridad que las drogas de abuso podían actuar como reforzadores y se constató además que su mecanismo de acción era muy similar al de los reforzadores naturales (Nichols, Headlee y Coppock, 1956).

Así, aunque en los inicios se pensaba que la motivación básica para consumir cualquier droga era evitar el síndrome de abstinencia o alguna patología subyacente, posteriormente se consolidó la hipótesis de que los efectos reforzadores de estas sustancias están más relacionados con su capacidad para estimular los sistemas cerebrales de recompensa (Jiménez, Ponce, Rubio y Palomo, 2003a).

El "Sistema de Recompensa Cerebral” (SRC) fue descrito por primera vez por Olds y Milner en 1954 (Olds y Milner, 1954), con una metodología de estimulación eléctrica intracraneal. Estos autores en sus estudios con animales de experimentación comprobaron cómo éstos se esforzaban por conseguir la estimulación eléctrica de ciertas áreas cerebrales. El modelo de recompensa por estimulación cerebral abrió un importante campo de estudio sobre la interacción entre la acción de una droga y la activación del SRC. Estudios posteriores confirmaron que algunas de las sustancias de abuso aumentaban la sensibilidad de los animales a la estimulación eléctrica en algunas áreas cerebrales (Killam, Olds y Sinclair, 1957). 


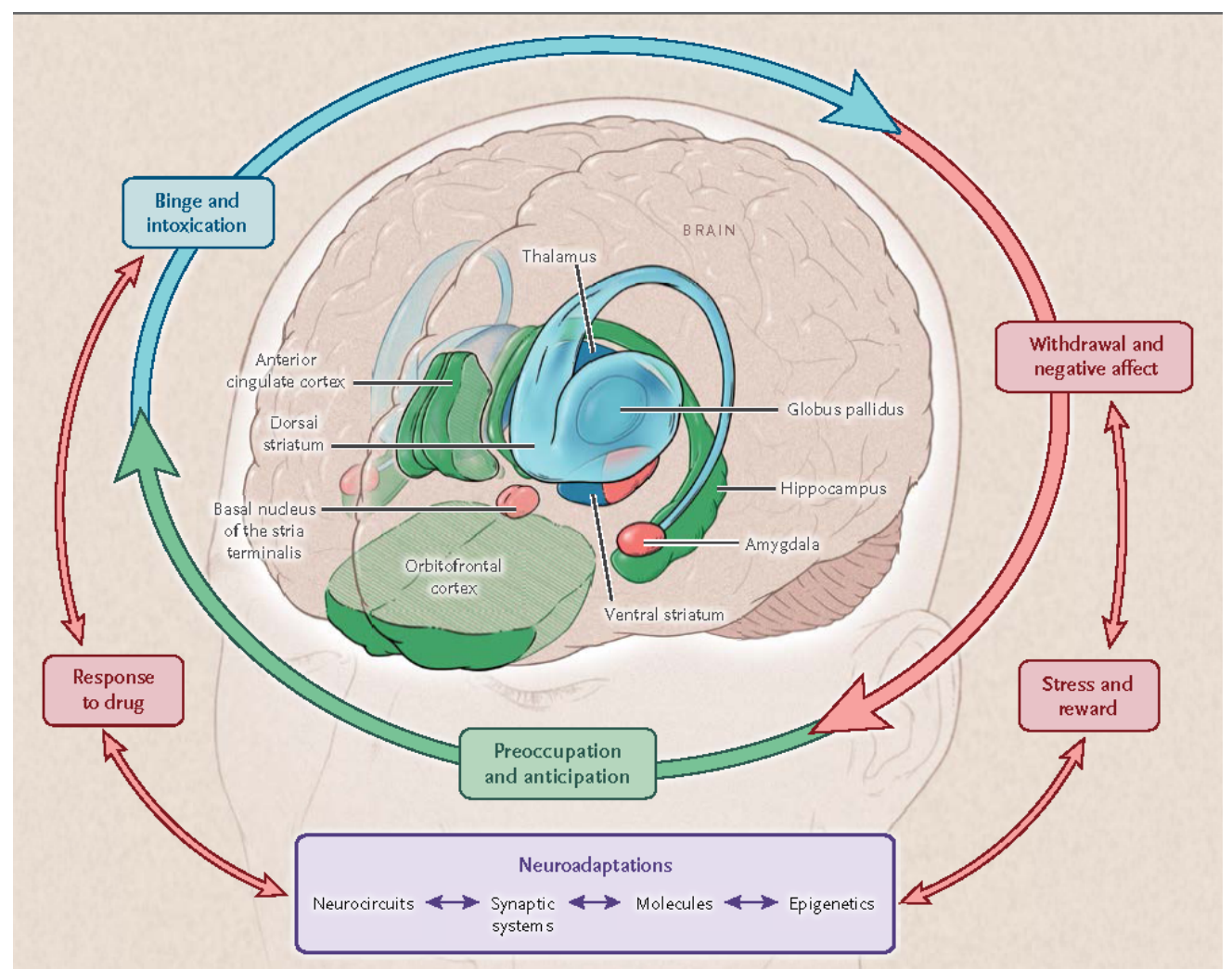

Fig. 18.- Sistema de Recompensa Cerebral. (Volkow ND, 2016)

Estos circuitos cerebrales que están implicados en la génesis y mantenimiento de los procesos adictivos incluyen diferentes regiones y vías cerebrales. Especial importancia tiene el sistema dopaminérgico mesolímbico, dentro del cual destaca el haz prosencefálico medial, formado por un conjunto de neuronas dopaminérgicas que unen el área tegmental ventral con el córtex prefrontal, pasando por el núcleo accumbens que tiene un papel central en el circuito.

Otras estructuras cerebrales se encuentran asimismo implicadas en las conductas adictivas. Entre ellas, amígdala e hipocampo, algunas estructuras motoras, el núcleo basal de Meynert, el núcleo pedúnculo-pontino y el locus coeruleus.

El SRC incluye un conjunto de núcleos cerebrales estrechamente conectados formando un circuito funcional y anatómico que se ha denominado circuito de refuerzo límbico-motor (Watson, Trujillo, Herman y Akil, 1989). Entre las diversas conexiones que incluyen se pueden destacar las siguientes (Jiménez et al., 2003; Volkow, 2016) (Figura 18): 
- El área tegmental ventral envía densas proyecciones hacia el núcleo accumbens, la corteza medial frontal y el hipotálamo lateral.

- La corteza medial prefrontal, el hipotálamo lateral y el hipocampo envían poderosos impulsos hacia el núcleo accumbens.

- El núcleo accumbens y la corteza medial frontal proyectan hacia el área tegmental ventral.

- El núcleo accumbens proyecta hacia el hipotálamo lateral.

La adicción refleja el control del comportamiento por la acción de drogas en circuitos cerebrales. Se ha demostrado que las conductas de dependencia, están críticamente relacionadas con la integridad funcional de la neurotransmisión de los sistemas mesotelencefálicos, especialmente del Sistema de Recompensa o dopaminérico mesolímbico. Éste, constituye uno de los varios sistemas de señalización por dopamina presentes en el cerebro.

Un nivel elevado de dopamina en el núcleo accumbens resulta crucial para el aprendizaje de los efectos de refuerzo positivo. Se produce un incremento en la liberación neuronal de esta sustancia a partir de los axones que descargan en el NAcc, desde los cuerpos neuronales del VTA, cuando éstos cuerpos neuronales se encuentran desinhibidos. Las células existentes en el NAcc se encuentran bajo la influencia del tono inhibidor de las neuronas gabaérgicas. Éstas células gabaérgicas presentan receptores opioides en su membrana (receptores $\mu$ ), que cuando son activados, inhiben la liberación de GABA en el VTA, y por tanto aumentan la liberación de dopamina en el NAcc.

El alcohol estimula la liberación de endorfinas y éstas (al ser ligandos para los receptores $\mu$ ), aumentan los niveles de dopamina, produciéndose así los efectos placenteros que perpetúan el consumo de alcohol (Figura 19). La acción de los opioides sobre el circuito de recompensa constituye también la base del tratamiento de fármacos como la metadona y el opioide inhibidor naltrexona para controlar la conducta adictiva. 


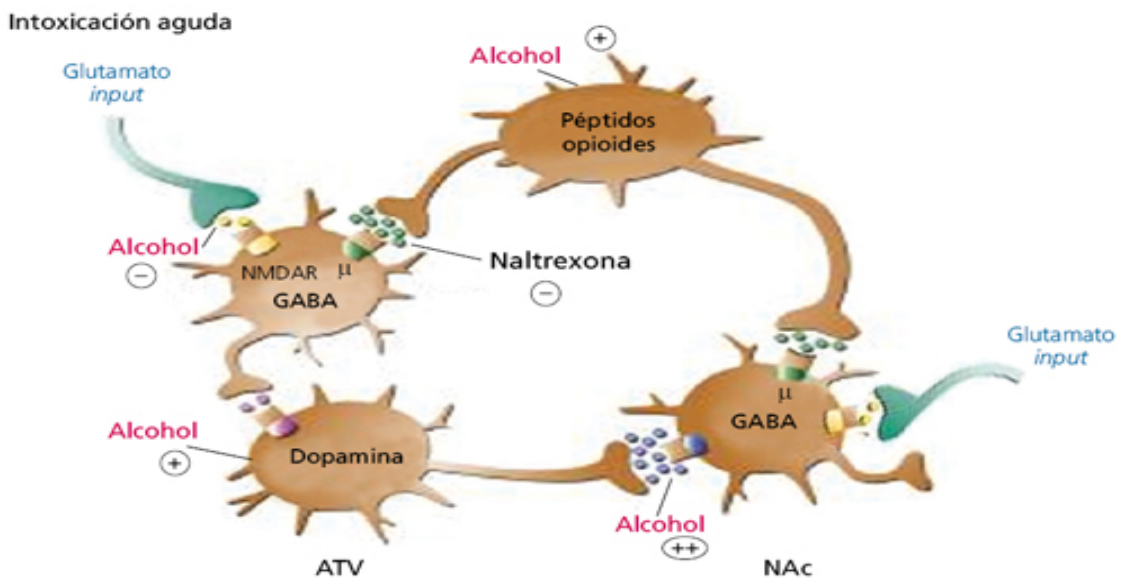

Fig. 19.- Acciones del alcohol sobre el sistema de refuerzo y su modulación en los cambios de glutamato y dopamina durante el consumo de alcohol.

\subsection{3.- Neurotransmisores implicados}

Además del GABA y Glutamato, descritos anteriormente, hay otros sistemas y neurotransmisores que juegan un destacado papel en el desarrollo de la dependencia al alcohol.

\section{a) Dopamina.}

Es el neurotransmisor más estudiado en las adicciones. Esto ha sido así desde el descubrimiento, como se ha explicado anteriormente, de que el haz prosencefálico medial, núcleo central del Sistema de Recompensa Cerebral (SRC), está compuesto fundamentalmente por neuronas dopaminérgicas.

La dopamina también parece estar implicada en el efecto_"craving". Diversos estudios han determinado que las alteraciones sobre el sistema de neurotransmisión dopaminérgico, que se producen como consecuencia del consumo crónico de sustancias psicoactivas, podría constituir, al menos en parte, el sustrato neurobiológico del deseo intenso y prolongado de una droga. Varios estudios sugieren que bajos niveles de dopamina en las sinapsis de los ganglios basales, o una mayor densidad de receptores dopaminérgicos D2, podrían estar relacionados con la recaída precoz en los pacientes alcohólicos, mediado por el efecto "craving" (Guardia et al., 2000). 
Por otro lado, la "teoría de la sensibilización del incentivo" (Robinson y Berridge, 1993), explicaría el proceso de perpetuación del deseo de consumo, y por tanto, de las recaídas tardías. Según esta teoría, la administración intermitente de drogas provoca modificaciones duraderas en los sistemas implicados en los procesos de motivación del incentivo y la recompensa. Estas modificaciones se deben a cambios neuroadaptativos que dejan los sistemas de neurotransmisión hipersensiblizados a las drogas y a los estímulos relacionados. Con ello se incrementa la capacidad del estímulo para resultar atractivo al individuo en función de la experiencia previa. Este proceso induce un patrón compulsivo de consumo por lo que una vez iniciado el mismo el sujeto pierde el control.

Algunos estudios han subrayado el papel de la dopamna en la mediación del síndrome de abstinencia. Los procesos de neuroadaptación subsiguientes a la administración continuada de drogas parecen estar relacionados con el fenómeno de depleción dopaminérgica que ocurre, a partir del cese del consumo de etanol y que está relacionado con el "efecto rebote" de depresión del SRC (Wise, 1996).

En resumen, parece claro que el etanol aumenta las descargadas de las neuronas dopaminérgicas en el área tegmental ventral, así como la liberación de dopamina en el núcleo accumbens. Por otra parte, en la línea de lo mencionado con los receptores GABA y NMDA, también aquí podría existir algún tipo de marcador de vulnerabilidad, lo cual explicaría que en estudios con animales se haya comprobado que las ratas con alta preferencia por etanol liberen más cantidad de dopamina en el núcleo accumbens que las ratas con baja preferencia (Ayesta, F.J. 2002).

\section{b) Sistema opioide}

El sistema opioide también se encuentra implicado en la adicción del alcohol (Davis y Walsh, 1970). Parece tener un papel como mediador de los efectos reforzadores del alcohol y como modulador de su consumo, estando también implicado en el efecto de pérdida de control. Hay que señalar que la implicación del sistema opioide en los fenómenos adictivos ocurre en gran 
parte a través de su incidencia en la activación del sistema dopaminérgico de recompensa (Jiménez et al., 2003), que como se ha visto, es clave en casi todos los procesos adictivos.

Así, parece que el sistema opioide incrementa la actividad dopaminérgica mediante dos mecanismos distintos: un efecto directo inhibitorio sobre estas células, y un aumento de la síntesis y liberación de dopamina en las células del área tegmental ventral que se proyectan sobre el accumbens y a su vez lo inhiben (Schulteis y Koob, 1994).

El etanol si se administra de forma aguda produce una activación de los receptores opioides que, probablemente, se deba a la liberación de opioides endógenos, particularmente $\beta$-endorfina. Por otro lado su administración crónica puede producir modificaciones en la neurotransmisión opioidérgica, alterando la sensibilidad de los receptores opioides (Guardia, J.L.; Segura, L.; Gonzalo, B. 2000).

Así, parece que esta sustancia, a través de un efecto indirecto de activación de determinados receptores opioides, produce liberación de dopamina en el núcleo accumbens, lo que de nuevo está relacionado con el efecto "craving" y la conducta de búsqueda de alcohol. De hecho, la administración de antagonistas opioides (naloxona, naltrexona) reduce la administración oral de etanol, lo que indica que, determinados péptidos opioides endógenos aumentan el reforzamiento etílico (Di Chiara, Acquas y Tanda, 1996).

\section{c) Serotonina}

También la serotonina parece intervenir en los procesos de dependencia del alcohol, aunque su evidencia es más contradictoria.

Por un lado, los antagonistas 5-HT3 han mostrado disminuír la autoadministración de etanol, pero más que a través de una acción directa en los receptores serotoninérgicos, puede deberse a cambios farmacocinétos en la absorción del etanol y a algunas acciones en los receptores 5-HT3 periféricos (León, M. L.; González, L.; León A.; de Armas, J.; Urquiza; A.; Rodriguez, G. 2015). 
Por otro lado, diferentes estudios sugieren que la disfunción serotoninérgica puede aumentar la vulnerabilidad biológica hacia la dependencia del alcohol. Así, un bajo nivel de la recaptación de serotonina en el SNC (medido con niveles de 5HIAA en LCR), se ha asociado a la génesis del abuso de alcohol y a la conducta impulsivo-agresiva. Asimismo, en alcohólicos de inicio precoz este dato se asocia con un curso más grave del alcoholismo y un deterioro del funcionamiento social (Heinz, A.; Highley, J.D.; Gorey, J.G.; Saunders, R.C.; Jones, D.W.; Hommer, D.; Zajiecek, K.; suomi, S.J.; Lesch, K.P.; Weinberger, D.R.; Linnoila, M.1998).

Además parece que la intoxicación crónica de alcohol reduce la densidad del transportador de serotonina, lo que se asocia con ansiedad y depresión, y a su vez, podría aumentar el riesgo de recaída en los alcohólicos (Guardia, J.L.; Segura, L.; Gonzalo, B. 2000).

\section{d) Antagonista nicotínico}

Se postula que los receptores nicotínicos del área tegmental ventral puedan mediar gran parte de las propiedades reforzadoras del etanol, tanto en el núcleo como en el resto del sistema mesolímbico dopaminérgico.

Por otra parte, la exposición crónica a nicotina aumenta en animales de experimentación las propiedades reforzadores del etanol, lo cual podría tener implicaciones clínicas (Wise, R.A. 2000).

\subsection{4.- Modificaciones en el sistema de recompensa cerebral a largo plazo.}

La liberación dopaminérgica y la acción de este neurotransmisor en el NAcc se ven reducidos durante la abstinencia al alcohol, un fenómeno que puede revertirse con nuevas administraciones de la droga, ello tiene importancia en relación con la perpetuación de la conducta de consumo. 
La activación de los complejos de transcripción CREB y $\Delta$ Fos en el núcleo accumbens es una consecuencia de la exposición crónica al alcohol y otras drogas.

Estas adaptaciones moleculares en el circuito de recompensa disminuyen la sensibilidad a los efectos de recompensa de subsecuentes exposiciones a la droga (contribuyendo a la tolerancia), y deterioran las vías de recompensa de tal forma que tras abandonar el consumo, el individuo queda en un estado amotivacional, disfórico o tendiente a la depresión.

Por otro lado se cree que mecanismos celulares en la amígdala que involucran tanto al glutamato como al GABA, constituyen la base de los cambios en el sistema de recompensa como neuroadaptaciones a la exposición crónica del alcohol.

La base de estas remodelaciones puede encontrarse en los cambios moleculares que produce la exposición al alcohol a largo plazo: alterando la expresión de genes, produciendo cambios en la estructura, crecimiento y remodelación celular, etc; todo lo cual se vincula a fenómenos de tolerancia, abstinencia, daño neuronal y crisis nerviosas en pacientes alcohólicos. Estos procesos además de explicar la repuesta adaptativa del cerebro al etanol, contribuirían a la disfunción cognitiva que se observa en alcohólicos con demencia y en niños con el síndrome alcohólico fetal.

\subsection{5.- Neurobiología de la tolerancia y la abstinencia al alcohol.}

Los efectos potenciales de la exposición a corto plazo del alcohol sobre las vías de señalización cerebral y la dinámica intraneural, constituyen el camino hacia transformaciones estructurales y funcionales a largo plazo. Si bien no se ha podido encontrar una justificación biológica precisa a todos los efectos del alcohol a largo plazo, sí ha sido posible correlacionar cambios puntuales en la morfofisiología cerebral, con muchos hallazgos clínicos en el paciente con alcoholismo crónico.

Los fenómenos de tolerancia y abstinencia aparecen en el organismo como repuestas adaptativas a la exposición repetida a determinadas sustancias. Su relación con la dependencia a una sustancia que ha sido tema 
actual de debate. La abstinencia, cobra importancia como agente activo en el establecimiento de la dependencia, ya que sus síntomas implican estados de desequilibrio capaces de inducir a la recaída para ser aliviados.

\section{a) Mecanismos histoquímicos de la tolerancia alcohólica.}

Se constata una pérdida en la intensidad del efecto, que puede alcanzarse nuevamente mediante un aumento de la dosis. Diversos mecanismos contribuyen a este proceso.

Un tipo de tolerancia se instaura paulatinamente a medida que altas dosis de etanol estimulan la actividad del sistema enzimático oxidativo microsomal encargado de la propia metabolización del etanol, por lo que la razón alcoholemia/alcohol ingerido disminuye, lo cual se conoce como tolerancia farmacocinética.

Otros tipos de tolerancia se engloban dentro de una tolerancia farmacodinámica, cuando los efectos del etanol se hacen menores a iguales concentraciones plasmáticas.

La tolerancia tiene su base en adaptaciones celulares a la exposición crónica de etanol, que se traducen en una menor respuesta a sus efectos, todo ello a través de cambios en el número de receptores, en la cantidad y actividad de segundos mensajes, así como en la funcionalidad y cantidad de canales, etcétera. Este conjunto heterogéneo de adaptaciones se establecen en interacción mutua y se agrupan dentro da la llamada tolerancia celular.

\section{b) Mecanismos histoquímicos de la abstinencia alcohólica}

Este fenómeno es debido a un incremento de la excitabilidad neuronal que resulta de una hiperactividad glutamatérgica e hipoactividad gabaérgica (Figura del balance); a este fenómeno se añade una actividad simpática aumentada.

El aumento de la actividad simpática, que se observa en el síndrome de abstinencia, está en gran parte mediado por la hiperactividad del locus coeruleus, debida a la pérdida de la auto-inhibición noradrenérgica. 
Manifestaciones de esta hiperactividad simpática son, entre otros, la taquicardia, la hipertensión, la sudoración y el temblor (Figura 20).

a Equilibrium

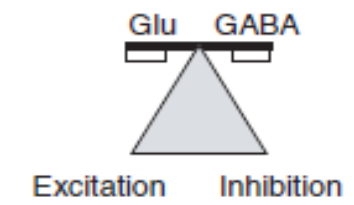

c Chronic ethanol

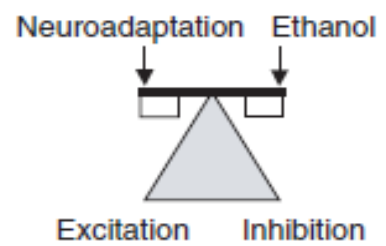

b Acute ethanol

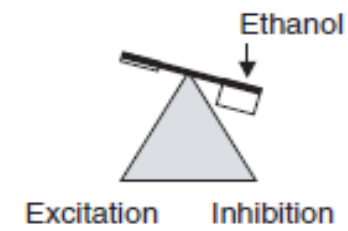

d Withdrawal

Neuroadaptation

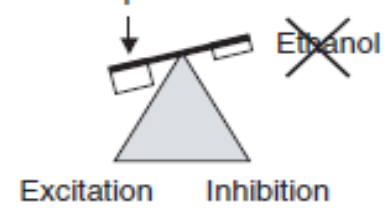

Fig. 20.- Balance /glutamato / GABA en la dependencia del alcohol

\section{5.- Tratamiento y prevención del Trastorno por consumo de alcohol.}

\subsection{1. - Tratamiento del Trastorno por consumo de alcohol.}

El tratamiento del TCA, comprende diversas intervenciones terapéuticas orientadas a modificar la conducta adictiva, y a reparar las consecuencias médicas, sociales, familiares y/o legales que podrían derivarse un consumo prolongado. Dado que el paciente con TCA suele presentar importante comorbilidad con otras patologías, debería ser valorado lo antes posible por un médico especialista en psiquiatría y adicciones, con la finalidad de evaluar el grado de conciencia de enfermedad, la motivación hacia el cambio y la gravedad del trastorno (Sociodrogralcohol, 2012).

El tratamiento de la dependencia de alcohol se subdivide en dos fases: fase de desintoxicación o tratamiento del síndrome de abstinencia y fase de deshabituación. En la primera, el objetivo consiste en cesar el consumo de alcohol, tratar el síndrome de abstinencia y prevenir así las manifestaciones 
más graves como crisis convulsivas y "delirium tremens", siendo el tratamiento principalmente farmacológico.

En la segunda fase, el tratamiento está orientado al mantenimiento de la abstinencia mediante la disminución del deseo por el alcohol y la prevención de recaídas. Se utilizan técnicas de intervención psicosocial y fármacos específicos para reducir el deseo (Sociodrogalcohol 2008).

\subsubsection{1- Tratamiento de desintoxicación}

EI SNC tiene una plasticidad que le permite adaptarse al efecto crónico del alcohol, estos cambios en los sistemas de neurotransmisión, como ya hemos visto, se manifiestan a través de una tolerancia progresiva, menores síntomas de intoxicación y un menor efecto reforzador, ante las mismas cantidades de alcohol. La búsqueda de este efecto reforzador puede llevar a un incremento progresivo de las cantidades de alcohol ingeridas, transformando el SNC del paciente, en un cerebro hiperexitado, que presentará síntomas de abstinencia, cuando el paciente abandone el consumo de alcohol por unas horas, como sucede de madrugada (Guardia, J.; Surkov, S.I.; Cardús, M. 2011), o debido a otra patología, accidente o intervención quirúrgica. La clínica de la abstinencia puede agruparse en tres categorías:

1.- Síndrome de Abstinencia Leve: Tiene lugar en las primeras 24 horas, cursa con: ansiedad, inquietud, náuseas, anorexia, insomnio, sudor facial, temblor ligero, taquicardia fluctuante, hipertensión.

2.- Síndrome de Abstinencia Moderado: Entre las 24 y 72 horas siguientes. Se observa: inquietud y agitación, temblores moderados, diaforesis, nauseas, vómitos, anorexia y diarrea; frecuentemente taquicardia (>120 ppm) e HTA sistólica $(>160 \mathrm{mmHg})$. Pueden presentarse alteraciones sensoperceptivas, un estado confusional y convulsiones generalizadas. 
3.- Síndrome de Abstinencia Grave: Puede aparecer entre las 72 y 96 horas. Se corresponde con la aparición del "delirium tremens", que cursa con: desorientación temporo-espacial, falsos reconocimientos, fluctuación a lo largo del día, amnesia del episodio, fiebre, hipertensión, taquicardia, sudoración profusa, trastornos visoperceptivos -visuales principalmente-, agitación psicomotriz e ideas delirantes de temas cotidianos (delirio ocupacional). Cuando la gravedad es extrema y el paciente no recibe el tratamiento médico apropiado, la presencia de otras patologías concomitantes, como traumatismo cráneo-encefálico, patología cardiovascular, infecciones, neumonías por aspiración o alteraciones hidroelectrolíticas pueden conducir a la muerte (Mayo Smith, M.F.; Beecher, L.H.; Fischer, T.L.; Gorelick, D.A.; Guillaume, J.L.; Hill, A.; Jara, G.; Kasser, C.; Melbourne, J. 2004).

El tratamiento de la desintoxicación alcohólica busca, también, preparar al paciente para el tratamiento de su deshabituación (Ozdemir, V.; Bremner, K.E.; Naranjo, C.A. 1994). Éste se hará de manera ambulatoria preferiblemente, siempre y cuando no exista otra patología psiquiátrica comórbida o requerimiento que así lo impida (Saníger Herrera, J.M.; Alonso Santos, B.; Soler Serra, E.; López Higuera, M.J. 2004) (Fig. 21). 


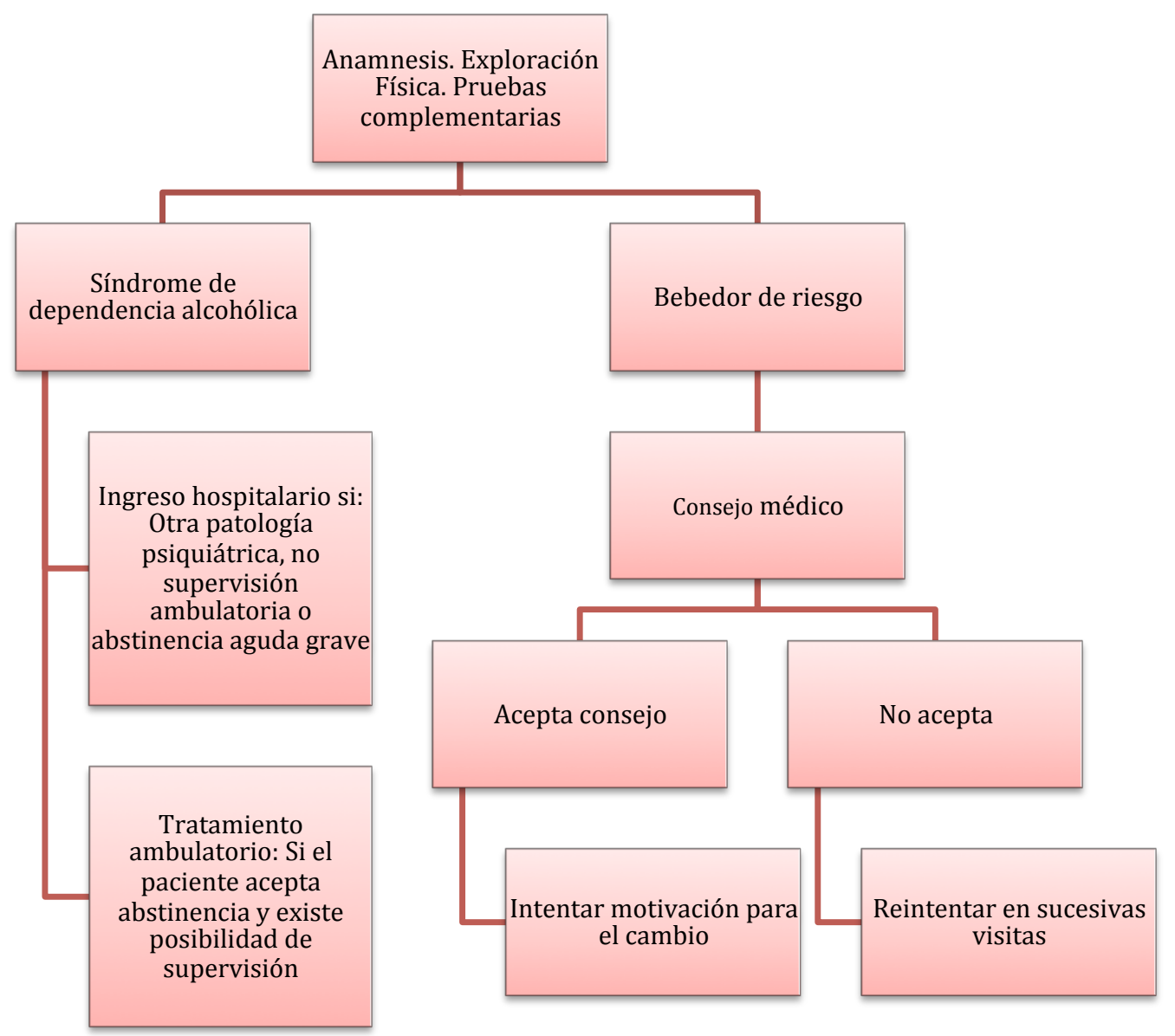

Fig. 21.- Decisiones terapéuticas para la desintoxicación. Saníger Herrera, J.M.; Alonso Santos, B.; Soler Serra, E.; López Higuera, M.J. 2004.

Las benzodiacepinas son los fármacos más estudiados en el tratamiento del síndrome de deprivación alcohólica. Dos metaanálisis y dos revisiones sistemáticas concluyeron que son superiores a placebo en el tratamiento de los síntomas de la abstinencia alcohólica, se asocian a una disminución significativa del riesgo de sufrir crisis epilépticas y previenen el desarrollo de delirium tremens (Mayo Smith, M.F.; Beecher, L.H.; Fischer, T.L.; Gorelick, D.A.; Guillaume, J.L.; Hill, A.; Jara, G.; Kasser, C.; Melbourne, J. 1997; Hollbrook, A,; Crowther, R; Lotter, A.; Gheng, C.; King, D. 1999; Williams, D.; Mc Bride, A.J. 1998. Ntais, C.; Pakos, E.; Kyzas, P.; loannidis, J.P. 2005). Se recomienda el uso de benzodiacepinas de vida media larga (Ritson, B.; Chick, J. 1986; Hoey, L.; Nehum, A.; Vance Bryan, K. 1994).

El clometiazol se ha utilizado en el tratamiento del síndrome de abstinencia alcohólica principalmente en Europa, existen evidencias de que es 
superior a placebo en el control de los síntomas de abstinencia (Burroughs, A.K.; Morgan, M.Y.; Sherlock, S. 1985; Glatt, M.M.; George, H.R.; Frisch, E.P. 1966), y en la prevención de delirium tremens (Pälsson, A. 1986; Schied, H.W.; Kimmerle, K.; Braunschweiger, M. 1986). Su uso no ha sido aprobado por la FDA en Estados Unidos, lo cual limita la información proveniente de ensayos clínicos.

Otros fármacos como los antipsicóticos, pueden ser utilizados para el control de los síntomas de la abstinencia, generalmente como adyuvantes a las benzodiacepinas, si bien no se ha demostrado que tengan un efecto protector de la aparición de crisis epilépticas o delirium tremens (Saitz R 1997, Kraus ML 1985). Por ello, no se recomienda su uso como monoterapia en estos enfermos (Williams, D.; Mc Bride, A.J.; Mc Bride, A.J. 1998, Ntais, C.; Pakos, E.; Kyzas, P.; loannidis, J.P. 2005, Ávila JJ et al. 2012) (Tabla 11).

Más recientemente, se han comunicado resultados favorables respecto a otros medicamentos: la carbamacepina (Malcolm, R.; Myrick, H.; Roberts, J.; Wang, W.; Anton, R.F.; Ballenger, J.C. 2002), el ácido valproico (Reoux, J.P.; Saxon, A.J.; Malte, C.A.; Baer, J.S.; Sloan, K.L. 2001), el ácido gammahidroxibutírico (Nimmerrichter, A.A.; Walter, H.; Gutierrez-Lobos, K.E.; Lesch, O.M. 2002), la gabapentina (Voris, J.; Smith, N.L.; Rao, S.M.; Thorne, D.L.; Flowers, Q.J. 2003), o el baclofen (Addolorato, G.; Leggio, L.; Abenavolli, L.; Agabio, R.; Caputo, F.; Capristo, E.; Colombo, G.; Gessa, G.L.; Gasbarrini, G. 2006), sobre el control de los síntomas de la abstinencia leve-moderada. 
Tabla 11.- Principales fármacos utilizados en el tratamiento de la desintoxicación alcohólica. (Ávila JJ et al. 2012)

\begin{tabular}{|c|c|c|c|c|}
\hline & Benzodiacepinas & Clometiazol & Tiapride & Carbamazepina \\
\hline $\begin{array}{l}\text { Mecanismo } \\
\text { de acción }\end{array}$ & $\begin{array}{l}\text { Activar receptor } \\
\text { GABA }\end{array}$ & $\begin{array}{l}\text { Potencia actividad } \\
\text { gabaérgica }\end{array}$ & $\begin{array}{l}\text { Antagonista } \\
\text { receptor } D_{2}\end{array}$ & $\begin{array}{l}\text { Potencia GABA, } \\
\text { disminuye liberación } \\
\text { de glutamato }\end{array}$ \\
\hline Efecto & $\begin{array}{l}\text { Sedación, ansiolítico, } \\
\text { anticonvulsivante }\end{array}$ & $\begin{array}{l}\text { Sedación, } \\
\text { anticonvulsivante }\end{array}$ & $\begin{array}{l}\text { Antitremorico, } \\
\text { sedación }\end{array}$ & $\begin{array}{l}\text { Reduce abstinencia, } \\
\text { anticonvulsivante }\end{array}$ \\
\hline Dosis & Según tipo de BZD & $\begin{array}{l}1200-1400 \mathrm{mg} / \mathrm{día} 3 \\
\text { tomas }\end{array}$ & $\begin{array}{l}400-800 \mathrm{mg} / \mathrm{dí} a \\
3 \text { o } 4 \text { tomas }\end{array}$ & $600 \mathrm{mg} / \mathrm{día} .3$ tomas \\
\hline Efectos $2^{\circ}$ & $\begin{array}{l}\text { Tolerancia cruzada } \\
\text { con alcohol, riesgo de } \\
\text { dependencia, } \\
\text { alteración cognitiva }\end{array}$ & $\begin{array}{l}\text { Tolerancia cruzada } \\
\text { con alcohol, riesgo } \\
\text { dependencia, } \\
\text { depresión } \\
\text { respiratoria }\end{array}$ & $\begin{array}{l}\text { Desciende el } \\
\text { umbral } \\
\text { convulsivante, } \\
\text { síntomas } \\
\text { extrapiramida- } \\
\text { Les }\end{array}$ & $\begin{array}{l}\text { Sedación, mareo, } \\
\text { ataxia, alteración } \\
\text { hematológica y } \\
\text { hepática }\end{array}$ \\
\hline $\begin{array}{l}\text { Efectos } \\
\text { Adversos }\end{array}$ & $\begin{array}{l}\text { Miastenia gravis, } \\
\text { apnea del sueño }\end{array}$ & $\begin{array}{l}\text { Enfermedad } \\
\text { pulmonar } \\
\text { obstructiva crónica } \\
\text { (EPOC) }\end{array}$ & Ninguna & $\begin{array}{l}\text { Embarazo, alteración } \\
\text { hematológica }\end{array}$ \\
\hline
\end{tabular}

\subsubsection{2.- Tratamiento de la deshabituación alcohólica}

En esta etapa del tratamiento, orientada hacia el mantenimiento de la sobriedad, se debe reducir el deseo por el consumo de alcohol ("craving"), de la misma manera, que fomentar la conciencia de enfermedad y mejorar el funcionamiento global del paciente. El tratamiento se compone de una farmacoterapia específica (fármacos interdictores o los anticraving), asociada a intervenciones psico-sociales, que en este momento adquieren una gran importancia a la hora de alcanzar nuestro objetivo.

\section{1.- Tratamiento farmacológico:}

a) Fármacos aversivos: Pueden ser de gran ayuda para la persona que está motivada a la abstinencia de bebidas alcohólicas. Tanto el 
Disulfiram, como la Cianamida cálcica, producen una acumulación de acetaldehído en el torrente sanguíneo, el cual propicia una reacción clínica, 10-20 minutos después del inicio del consumo de alcohol (Tabla 12).

Tabla 12.- Características diferencias de los tratamientos aversivos. (Bobes García et al J. et al., 2003).

\begin{tabular}{|cll|}
\hline Mecanismo de acción & $\begin{array}{l}\text { Inhibición irreversible de } \\
\text { acetaldehido-deshidrogenasa, } \\
\text { inhibición de la dopamina-beta- } \\
\text { hidroxilasa, oxidasas } \\
\text { microsomiales. }\end{array}$ & $\begin{array}{l}\text { Cianamida cálcica } \\
\text { acetaldehido- } \\
\text { deshidrogenasa. }\end{array}$ \\
\hline Inicio del efecto & 12 horas después & $1-2$ horas después \\
\hline Dosificación & 1 o 2 comprimidos/día & $12-25$ gotas/día \\
\hline Tratamiento continuado & Sí & No \\
\hline Cambio de interdictor & Esperar 10 días & Esperar 24 horas \\
\hline Polineuropatía & Sí & No \\
\hline Hepatotoxicidad & + & +++ \\
\hline
\end{tabular}

b) Fármacos anticraving: La utilización de fármacos para disminuir el deseo y la compulsión a la bebida reduce el número de recaídas y, si éstas aparecen, ayudan a recuperar la abstinencia más fácilmente. Es por ello que estos fármacos deben mantenerse aunque surjan recaídas (Ponce G, 2003). La Naltrexona, un antagonista competitivo de los receptores opioides $\mu, \kappa$ y $\partial$, ampliamente estudiado en adicciones, reduce la euforia tras la ingesta de alcohol, la capacidad reforzante del mismo y las expectativas del uso; por otro lado aumenta la autoeficacia para detener la recaída y el malestar tras el consumo de alcohol.

El Acamprosato bloquea los receptores NMDA del glutamato y restaura la actividad gabaérgica, alterada por el consumo crónico de alcohol. De esta forma contribuiría a estabilizar la abstinencia (Mann, K. 2004).

\section{c) Otros fármacos:}


- Topiramato: se trata de un anticomicial utilizado para disminuír el "craving", si bien las muestras de estudio son pequeñas y los resultados poco específicos, se cree que podría ser útil en pacientes que presentan comorbilidad con trastornos de personalidad o sujetos impulsivos (Rubio, G.; Ponce, G.; Jiménez-Arriero, M.A.; Palomo, T.; Ferre, F. 2002).

- Nalmefeno: es un antagonista opiáceo específico para el receptor delta y mu; y agonista parcial de los receptores kappa. Debido a este efecto, y a la normalización del estado hipodomaninérgico, el nalmefeno ha conseguido disminuír el consumo de alcohol y el "craving" por el mismo en los pacientes con dependencia de esta sustancia (Walker, B. W.; Zorrilla, E. P.; Koob, G. F. 2011. Spanagel, R.; Vengeliene, V. 2012).

A partir de los resultados de los estudios ESENSE 1 y 2 (Gual, A., He, Y., Torup, L., Van den Brink, W.; Mann, K. 2013), se confirma la indicación de nalmefeno para la reducción del consumo de alcohol en personas que presentan dependencia del esta sustancia, habiendo la Agencia Europea de Medicamentos aprobado esta nueva indicación en 2013 (Guardia Serecigni J. 2011)

- ISRS: Son muchos los estudios que se han llevado a cabo con estos fármacos, pero en general los resultados obtenidos han sido poco satisfactorios. Su eficacia es mayor en pacientes con dependencia alcohólica de inicio tardío, o en aquellos que presentan psicopatología depresiva asociada. Recientemente se ha demostrado que aquellos pacientes que asocian ISRS a su tratamiento, presentan mayor probabilidad de abstinencia y duración de la misma (Pettinati HM et al. 2010)

- Tiapride: Bloquea el efecto dopaminérgico de las sustancias de abuso. Los estudios sobre su empleo en deshabituación no han podido encontrar un efecto específico, pero en algunos pacientes ayuda a controlar con más éxito los síntomas de la abstinencia y a alcanzar una 
mejor puntuación en las escalas que miden estado anímico y satisfacción (Monte Secades, R.; Rabuñal Rey, R. 2011).

\section{2.- Tratamiento psico-social:}

Es un componente esencial del tratamiento del TCA. Mediante estudios controlados se ha comprobado la eficacia de diversas intervenciones: la terapia cognitivo-conductual, la terapia motivacional, la de refuerzo comunitario, la terapia breve, la terapia de pareja y familiar y, por último, la terapia de grupo.

La terapia cognitivo-conductual (TCC): Radica en la prevención de recaídas, por medio de la identificación de situaciones de riesgo, el aprendizaje y ensayo de estrategias de afrontamiento (cognitivas y conductuales) y el reconocimiento y afrontamiento de los estados de "craving" (Kadden, R.M.; Carroll, K.; Donovan, D.; Cooney, N.; Monti Abrams, D.; Litt, M.; Hester, R. 1992).

La terapia motivacional: Consiste en diversas técnicas, como escucha reflexiva, explorar pros y contras del cambio, apoyar la auto-eficacia, retroinformación personalizada (resaltando la discrepancia) y promover afirmaciones auto-motivadoras (Miller, W.R.; Rollnick, S. 1999).

La terapia de refuerzo comunitario: Está basada en los principios de la teoría del cambio y en la teoría del aprendizaje social. Las estrategias empleadas para conseguirlos son múltiples: aprendizaje de habilidades sociales, asesoramiento en actividades laborales, sociales y recreativas, administración de disulfiram e implicación de la familia (Miller WR et cols, 1992).

La terapia familiar y de pareja: Los objetivos de este tipo de terapia son mantener la abstinencia y modificar y mejorar el sistema de relaciones y comunicación familiares, frecuentemente deteriorado en estas situaciones (Miller, W.R.; Zweben, A.; Di Clemente, C.C.; Rychtarick, R.G. 1992).

La terapia de grupo: Es la técnica más utilizada en la actualidad. Hay diferentes clases de grupos según los principios teóricos en los que se fundan: grupos de orientación dinámica, terapia emocional correctiva de Ellis, grupos cognitivo-conductuales, grupos de autoayuda (alcohólicos anónimos, alcohólicos rehabilitados) y grupos de terapia de facilitación basados en los 12 
pasos. Los factores que intervienen en este tipo de terapias son: identificación, comprensión de la influencia del alcohol en sus problemas, modelado y aprendizaje de estrategias para mantener la abstinencia y control externo del consumo (Miller, W.R.; Zweben, A.; Di Clemente, C.C.; Rychtarick, R.G. 1992).

Los pacientes alcohólicos y sus familiares suelen presentar una problemática socio-laboral y económica que puede llegar al desempleo prolongado, la disgregación familiar, la pobreza y la pérdida del domicilio. Por tanto, el trabajo social resulta imprescindible para la recuperación de estos pacientes y para la ayuda a sus familiares, ya que su desadaptación persistente en las diversas áreas de su funcionamiento va a contribuir de manera decisiva en las recaídas, a pesar de su tratamiento continuado (Sociodrogralcohol, 2012).

\subsection{2- Prevención del Trastorno por consumo de alcohol.}

La ciencia tiene un peso cada vez más importante en el desarrollo de las políticas internacionales de salud, lo cual es especialmente patente en el caso de la respuesta mundial a los problemas relacionados con el consumo de alcohol. En mayo de 2010, la Asamblea Mundial de la Salud adoptó la resolución WHA63.13, sobre la "Estrategia Mundial para reducir el uso nocivo del alcohol" (OMS, 2010), basada en parte en los muchos datos que demuestran tanto la importante contribución del alcohol a la carga mundial de morbilidad como la eficacia de las políticas adoptadas para mitigar los daños que ocasiona (OMS, 2007).

Por otro lado, a nivel nacional, el Ministerio de Sanidad y Política Social lleva más de 25 años trabajando en la prevención activa del uso nocivo del alcohol, incluyendo esta acción en la Estrategia Nacional Sobre Drogas 2009-2016 (PNSD, 2009). 


\subsubsection{1.- Estrategia mundial para reducir el uso nocivo del alcohol.} OMS. 2010.

La estrategia tiene cinco objetivos (Fig. 22. OMS 2010):

a) Aumentar la concienciación mundial respecto de la magnitud y naturaleza de los problemas sanitarios, sociales y económicos causados por el uso nocivo del alcohol, y reforzar el compromiso de los gobiernos para adoptar medidas que contrarresten su uso.

b) Consolidar el acervo de conocimientos sobre la magnitud y los determinantes de los daños relacionados con el alcohol y sobre las intervenciones que reducen y previenen eficazmente esos daños.

c) Incrementar el apoyo técnico prestado a los Estados Miembros y reforzar su capacidad para prevenir el uso nocivo del alcohol y gestionar los TCA y los problemas de salud asociados.

d) Fortalecer las alianzas e intensificar la coordinación entre los interesados, y aumentar la movilización de los recursos necesarios para adoptar medidas adecuadas y concertadas de prevención del uso nocivo del alcohol.

e) Mejorar los sistemas de seguimiento y vigilancia a distintos niveles, y la difusión y aplicación más eficaz de la información para fines de promoción, desarrollo de políticas y evaluación. 


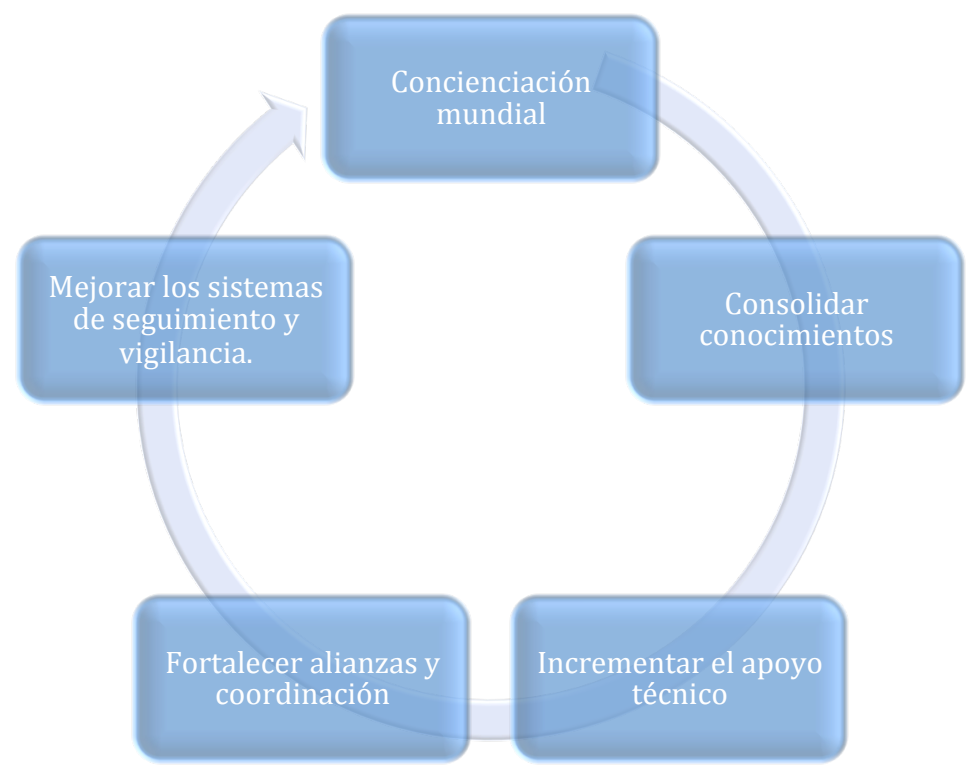

Fig. 22.- Objetivos de las Estrategias propuestas por la OMS (OMS 2010)

Las siguientes 10 propuestas de intervención que se realizan a los Estados Miembros desde la WHO, se basan en los conocimientos científicos actuales, en la evidencia disponible sobre su eficacia y costo-eficacia, en la experiencia y en las prácticas adecuadas.

Propuesta 1.- Liderazgo, concienciación y compromiso: Para que la acción sea sostenible, hace falta un firme liderazgo y una sólida base de concienciación, voluntad política y compromiso. La expresión ideal de esos compromisos sería adoptar políticas nacionales integrales e intersectoriales, suficientemente financiadas, en las que se definieran claramente la contribución y las responsabilidades de los distintos miembros asociados.

Propuesta 2.- Respuesta de los servicios de salud: Los servicios de salud deben ofrecer intervenciones de prevención y tratamiento a los individuos y las familias que corren el riesgo de sufrir trastornos por el consumo de alcohol y afecciones asociadas, o que ya los padecen.

Propuesta 3.- Acción comunitaria: Los gobiernos y otros interesados pueden ayudar a las comunidades y potenciar su capacidad para que utilicen conocimientos teóricos y prácticos locales para adoptar enfoques eficaces que permitan prevenir y reducir el uso nocivo del alcohol modificando el comportamiento colectivo 


\section{Propuesta 4.- Políticas y medidas contra la conducción bajo los} efectos del alcohol: Las estrategias de reducción de los daños asociados al alcohol al volante deben incluir medidas disuasorias destinadas a disminuir las probabilidades de que una persona conduzca bajo los efectos del alcohol, así como medidas que creen un entorno de conducción más seguro .

Propuesta 5.- Disponibilidad de alcohol: Esas estrategias prevén medidas esenciales para evitar el acceso fácil al alcohol por parte de grupos vulnerables o de alto riesgo. Dicha disponibilidad puede contribuir a modificar las normas sociales y culturales que favorecen el uso nocivo del alcohol.

Propuesta 6.- Marketing de las bebidas alcohólicas : La reducción del impacto del marketing, sobre todo entre los jóvenes y adolescentes, es un objetivo importante si se quiere reducir el uso nocivo del alcohol, ya que cada vez, se promociona de un modo más sofisticado, como por ejemplo vinculándolo a las actividades deportivas y culturales.

Propuesta 7.- Políticas de precios: Se pueden emplear políticas de fijación de precios para reducir el consumo de bebidas alcohólicas para menores de edad, detener la tendencia a experimentar la ingestión de grandes cantidades de alcohol en escasos periodos de tiempo y/o episodios de borrachera, y ejercer influencia en las preferencias de los consumidores.

Propuesta 8.- Mitigación de las consecuencias negativas del consumo de alcohol y la intoxicación etílica: La evidencia y las prácticas adecuadas actuales respaldan las intervenciones complementarias en el marco de una estrategia más amplia de prevención o reducción de los efectos negativos del consumo de alcohol y la intoxicación etílica, siempre y cuando no parezca que se está promoviendo el consumo de alcohol.

Propuesta 9.- Reducción del impacto en la salud pública del alcohol ilícito y el alcohol de producción informal: El consumo de alcohol producido de manera ilícita o informal podría tener otras consecuencias negativas para la salud, debido al mayor contenido de etanol y a la posible contaminación con sustancias tóxicas, como el metanol.

Propuesta 10.- Seguimiento y vigilancia: Se requieren medidas de seguimiento y vigilancia a nivel local, nacional e internacional para monitorizar la magnitud y las tendencias de los daños relacionados con el alcohol, 
fortalecer las actividades de promoción, formular políticas, y evaluar el impacto de las intervenciones.

\subsubsection{2.- Estrategia Nacional Sobre Drogas. 2009-2016}

La Estrategia Nacional sobre Drogas 2009-2016 (2009) se configura como un marco de referencia para todas las Administraciones Publicas y las organizaciones sociales. Aspira a ser una herramienta que pueda ser usada para promover, facilitar y apoyar a cada instancia a desarrollar su trabajo desde el ámbito competencial en el que se encuentra. Todo ello para lograr la disminución, de forma significativa, del consumo de diferentes sustancias adictivas, entre ellas el alcohol, y prevenir al máximo el impacto sanitario y social de los diversos problemas y daños relacionados con las mismas. Para ello se plantean 5 ámbitos de actuación principalmente (Plan Nacional Sobre Drogas, 2009):

2.1.- Reducción de la demanda: Comprende desde la promoción de la salud hasta las estrategias de prevención del consumo y problemas asociados, pasando por la disminución de riesgos y reducción de daños y la asistencia e inserción social. Así pues, este ámbito incluye tres componentes, cada uno de los cuales requiere un abordaje específico, la prevención, la disminución del riesgo y reducción del daño, y la asistencia e integración social.

2.2.- Reducción de la oferta: Se debe poner el énfasis en la normativa sobre publicidad, venta y consumo, haciendo especial referencia a la edad y a los lugares donde se puedan vender dichos productos y donde sea legal su consumo, junto con las circunstancias aplicadas en cada caso.

\section{3.- Mejora del conocimiento científico básico y aplicado:} Incrementar la cantidad y la calidad de la investigación, con el fin de conocer mejor las diversas variables relacionadas con las drogas y su 
capacidad de producir adicción, su consumo, su prevención y tratamiento. Además de potenciar la evaluación sistemática de los programas y actuaciones orientadas a dicho fin.

2.4.- Formación: Se trata, de contribuir a la mejora de las competencias profesionales de quienes desarrollan su trabajo en los servicios sociales, educativos y sanitarios. Especialmente, en los contextos concretos donde se realicen actuaciones destinadas a la promoción de estilos de vida saludables y a la difusión de contenidos relacionados con un mejor desarrollo de la salud en la comunidad.

Como conclusión, debemos señalar que la principal necesidad a día de hoy es adquirir una mayor conciencia de la magnitud del problema del alcohol en el mundo, y conseguir un mayor compromiso político para aplicar estrategias de control del alcohol basadas en la evidencia.

Evidentemente, cualquier cambio de política debe hacerse con cautela y con espíritu de experimentación para determinar si efectivamente tiene los resultados previstos. Sin embargo, no debemos desistir en reforzar los vínculos entre el ámbito científico y el normativo para poder reconocer y sintetizar los resultados más prometedores de las investigaciones y transmitírselos eficazmente a los formuladores de políticas y, principalmente, a nuestro público (Babor, T.F. 2010)

\section{6.- Comorbilidad del Trastorno por consumo de alcohol}

Los pacientes con TCA, presentan altas tasas de comorbilidad con otros trastornos psiquiátricos. Se ha constatado que el sexo femenino tiene más posibilidades de presentar una comorbilidad psiquiátrica que el masculino. La existencia de comorbilidad en el TCA implica un peor pronóstico en la evolución de la enfermedad. El tratamiento se hace más complejo debido a que estos pacientes padecen más frecuentemente otras complicaciones médicas, problemas psíquicos, familiares, sociales y mayor índice de suicidios que 
aquellos pacientes que no presentan comorbilidad (Sánchez Peña, J.F.; Álvarez-Cotoli, P.; Rodríguez-Solano, J.J. 2012)

\subsection{1.- Trastornos Afectivos}

\section{a) Epidemiologĺa}

Los trastornos del estado de ánimo son, junto con los de ansiedad, los más frecuentes en pacientes afectos de TCA. Aún considerando que estos trastornos presentan también una elevada prevalencia en población general, la probabilidad de presentar un trastorno depresivo o un trastorno bipolar es más elevada en un sujeto con TCA que en un sujeto no alcohólico, como se expondrá a continuación

La patología depresiva y el TCA, conviven en una estrecha relación, que ha sido objeto de estudios en multitud de ocasiones. Sobre la prevalencia de dicha asociación, existe una importante controversia, con diferencias significativas de estimación entre unas publicaciones y otras.

En este sentido, vale la pena destacar los resultados de los principales estudios epidemiológicos llevados a cabo en diferentes áreas geográficas, los cuales se reflejan en la Tabla 13. En ella se observa una amplia coincidencia en los cinco estudios que indican una probabilidad entre uno y medio, y cuatro veces mayor de padecer problemas del estado de ánimo si está presente un diagnóstico de TCA. 
Tabla 13.- Odds Ratios de comorbilidad entre Trastornos Afectivos y TCA, según diversos estudios.

\begin{tabular}{|c|c|c|c|}
\hline Estudio, autor y año & $\begin{array}{l}\text { Cualquier } \\
\text { trastorno anímico }\end{array}$ & Depresión Mayor & Distimia \\
\hline \multicolumn{4}{|l|}{ National Epidemiologic } \\
\hline Survey on Alcohol and & & & \\
\hline $\begin{array}{l}\text { Related Conditions III. } \\
\text { Epidemiology of DSM-5 }\end{array}$ & 1,5 & 1,3 & 1,3 \\
\hline $\begin{array}{c}\text { Alcohol Use Disorder. } \\
\text { (Bridget F. Grant, Risë B. } \\
\text { Goldstein et al. 2015) }\end{array}$ & & & \\
\hline \multicolumn{4}{|l|}{ National Epidemiologic Survey } \\
\hline $\begin{array}{c}\text { on Alcoholism and Related } \\
\text { Conditions. (Hasin, Stinson, } \\
\text { Ogbun y Cols. 2007) }\end{array}$ & 3,4 & 2,2 & 2,6 \\
\hline $\begin{array}{l}\text { National Comorbidity Survey } \\
\text { (Kessler, Crum, Warner et al, } \\
\text { 1997) }\end{array}$ & 2,34 & 2,07 & 4,37 \\
\hline \multicolumn{4}{|l|}{ Epidemiologic Catchment Area } \\
\hline Study (Robins, Regier, 1991) & 2,90 & 2,92 & 2,47 \\
\hline \multicolumn{4}{|l|}{ Epidemiologic Study of Puerto } \\
\hline $\begin{array}{c}\text { Rico (Canino, Bird, Shrout et } \\
\text { al., 1987) }\end{array}$ & 2,67 & 2,80 & 4,33 \\
\hline
\end{tabular}

En relación con el Trastorno Bipolar, son múltiples los estudios epidemiológicos y clínicos que describen la elevada comorbilidad encontrada con el TCA (Merikangas, K. R., Akiskal, H. S., Angst, J., Greenberg, P. E., Hirschfeld, R. M., Petukhova, M., Kessler, R.C. 2007; Mitchell, J. D., Brown, E. S., and Rush, A. J. 2007; Oquendo, M. A., Currier, D., Liu, S. M., Hasin, D. S., Grant, B. F., and Blanco, C. 2010). Además de ello, el Trastorno Bipolar, es la patología psiquiátrica del eje I más frecuentemente asociada con el TCA (Regier, D.A.; Farmer, M.E.; Rae, D.S.; Locke, B.Z.; Keith, S.J.; Judd, L.L.; Goodwin, F.K. 1990; Kessler, R. C., Rubinow, D. R., Holmes, C., Abelson, J. M., and Zhao, S. 1997) (Tabla 14). En un reciente meta-análisis, se observó que la prevalencia del TCA, afectaba aproximadamente a un tercio de los 
pacientes con Trastorno Bipolar durante su vida, principalmente a los varones (44\%) en comparación con las mujeres (22\%) (Di Florio, A., Craddock, N., and Van Den Bree, M. 2014).

Tabla 14.- Probabilidad de comorbilidad entre Trastorno Bipolar y TCA, según diversos estudios.

$\begin{array}{cccc}\text { Estudio, autor y } & \text { Trastorno } & \text { Trastorno } & \text { Cualquier } \\ \text { año } & \text { Bipolar I } & \text { Bipolar II } & \text { Trastorno Bipolar }\end{array}$

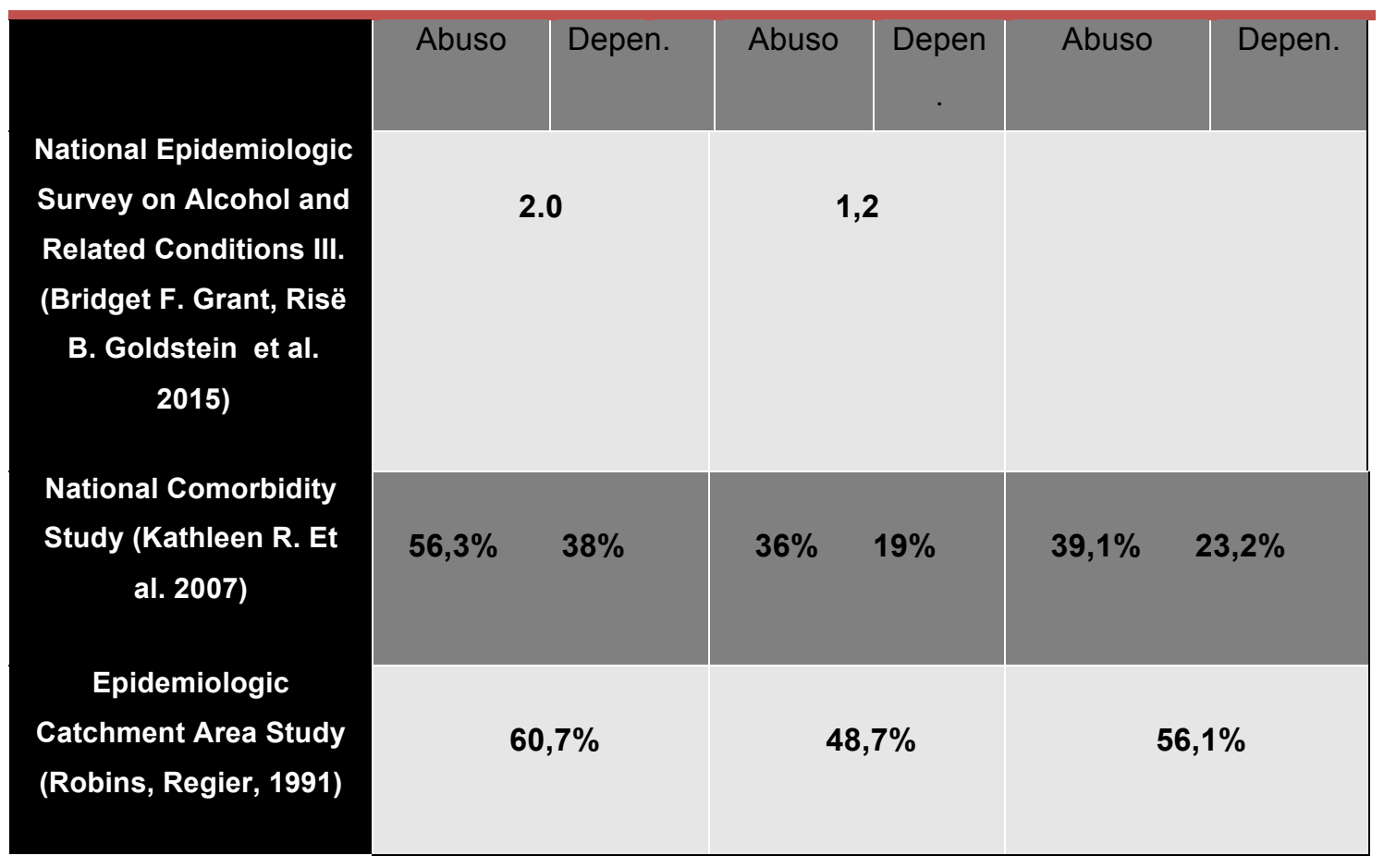

Los pacientes con TCA tienen una probabilidad entre 5 y 6 veces superior a la de la población general de presentar un Trastorno Bipolar (Kessler, R. C., Rubinow, D. R., Holmes, C., Abelson, J. M., and Zhao, S. 1997), sin embargo, y a pesar de lo expuesto anteriormente, esta comorbilidad no se ha estudiado tan extensamente como la existente con el Trastorno Depresivo Mayor (Balanzá-Martínez, V.; Crespo-Facorro, B.; González-Pinto, A. and Vieta, E. 2015) 


\section{b) Etiología y Neurobiología}

Existen diferentes hipótesis que tratan de explicar la asociación tan importante que existe entre los trastornos afectivos y el TCA. Entre las principales hipótesis están quienes defienden que no existe relación alguna entre ambas patologías, sino tan sólo la coexistencia de dos trastornos altamente prevalentes en la población general, en una misma persona en un determinado periodo de su vida, tal y como defiende Shuckit (Schuckit, 2006). Por lo que cada uno de los trastornos seguiría su propio curso evolutivo independiente.

Algunos autores han manifestado que la alta prevalencia de comorbilidad entre ambos trastornos es debida principalmente a un factor de confusión, debido a que tanto la intoxicación como la abstinencia del alcohol pueden presentar un cuadro fenomenológicamente similar a diversos trastornos afectivos, de manera que estos estados desaparecerían una vez remitida la intoxicación o con el tratamiento adecuado de la abstinencia (Chinchilla A. 2008).

Otros autores defienden la teoría de la depresión inducida por el consumo de alcohol. Esta hipótesis se encuentra abalada por diversos estudios en los que se muestra la aparición de síntomas depresivos causados por el consumo de alcohol, en pacientes previamente eutímicos, que desaparecen tras lograrse la abstinencia, sin necesidad de tratamiento antidepresivo (Raimo, E. y Schuckit, M. 1998). Se trataría pues, de un trastorno afectivo inducido por alcohol, diferente a un episodio depresivo "per se" (Gibson, S. y Becker, J. 1973; Isbell, H.; Fraser, H.F.; Wikler, A.; Belleville, R.E. y Eiseman, A.J. 1995; Tamerin, J.; Weiner, S. y Mendelson J. 1970).

Por el contrario, también existe la posibilidad de que sí exista una relación no casual entre ambos trastornos, de manera que la evolución de uno estaría fuertemente relacionada con la del otro. En este caso encontramos cuatro plausibles hipótesis:

- En primer lugar, el trastorno afectivo como la causa del TCA. Esta hipótesis es también conocida como la hipótesis de la "automedicación", en la que los pacientes que están teniendo 
problemas afectivos serios, de índole depresiva, o en relación con el Trastorno Bipolar utilizan el consumo de alcohol para atenuar su patología afectiva (Bizzarri, J. V.; Rucci, P.; Sbrana, A.; Miniati, M.; Raimondi, F.; Ravani, L.; Massei, G.J.; Milani, F.; Milianti, M.; Massei G.; Gonnelli, C.; Cassano, G.B. 2009;. Do, E.K. y Mezuk, B., 2013). Dentro de esta teoría encontramos el trabajo llevado a cabo sobre una muestra de 1818 estudiantes universitarios (O’Hara, R.; Armeli, S.; Tennen, H. 2014), en el cual se encontraron evidencias significativas, que relacionaban a los estudiantes con alteraciones anímicas, principalmente de tipo depresivo con un mayor y más frecuente consumo de alcohol.

- En segundo lugar, el consumo de alcohol como la causa de sufrir una patología afectiva, hablaría pues de las dificultades sociales, físicas y de salud, que origina, las cuales contribuirían a la aparición de un trastorno depresivo (Sarasa Renedo, A.; Sordo, L.; Molist, G.; Hoyos, J.; Guitart, A.M. y Barrio G. 2014).

En este apartado, merece especial mención las manías inducidas por el consumo de tóxicos. Se ha demostrado que las mujeres con un primer episodio de manía, que requirieron ingreso hospitalario mantenían un consumo de alcohol superior a los hombres, previo al ingreso. Hecho que se ha analizando como un posible desencadenante del episodio maníaco (Parial, S.; 2015; MacKinnon, D.F.; Zandi, P.P.; Cooper, J.; Potash, J.B.; Simpson, S.G.; Gershon E.; Nurnberger, J.; Reich T.; DePaulo, J.R. 2002).

- En tercer lugar, encontramos la hipótesis de la neuroadaptación. Según la cual los cambios neurobiológicos y metabólicos que el alcohol provoca en el cerebro supondrían una mayor vulnerabilidad o un detonante para la aparición de trastornos afectivos (McEachin, R.C.; Keller, B.J.; Saunders, E.F.; Mcinnis M.G. 2008). Bajo esta hipótesis subyace que el $40-50 \%$ del riesgo de sufrir un trastorno depresivo, es un riesgo genético (Fava, M. and Kendler, K.S. 2000), lo que convierte la depresión en una enfermedad altamente heredable como muchas otras patologías médicas complejas (DM tipo II, asma, hipertensión, etc). Por 
otro lado, para complicar más la fisiopatología de esta enfermedad, la importancia de los factores no genéticos también es relevante como el papel que juegan el estrés, traumas emocionales o incluso infecciones virales (Akiskal, H.S. 2000; Fava, M. and Kendler, K.S. 2000). El rol que juega el estrés está particularmente estudiado, y hay evidencia de que muchos episodios de depresión mayor ocurren en el contexto de alguna forma de estrés. Sin embargo, éste por sí solo no es suficiente para producir un episodio depresivo (Nestler, E.J. 2002).

\section{Circuito neurobiológico de la depresión}

Mientras que muchas regiones del cerebro han sido implicadas en la regulación de las emociones, aún tenemos un entendimiento muy rudimentario del circuito neural subyacente al estado de ánimo normal y por tanto, de las alteraciones responsables en la causa de la depresión.

Es probable que muchas regiones del cerebro medien en los diversos síntomas de la depresión. Estudios de neuro-imagen cerebral en etapas relativamente tempranas de la enfermedad han demostrado cambios en el flujo sanguíneo o alteraciones anatómicas en varias áreas del cerebro, entre las cuales se encuentran la región prefrontal, la corteza cingular, el hipocampo, el núcleo estriado, la amígdala y el tálamo (Drevets, W.C. 2001. Liotti, M.; Mayberg, H.S. 2001, Zhu, M.Y., Klimek, V., Dilley, G.E., Haycock, J.W., Stockmeier, C., Overholser, J.C., Meltzer, H.Y., and Ordway, G.A. 1999;. Manji et al, 2001; Rajkowska, 2000) (Figura 23).

Conocer el funcionamiento normal de estas regiones, nos permite conocer cuales de ellas deben estar implicadas en la compleja y múltiple sintomatología depresiva. 
Fig. 23.- Circuito neural de la depresión. Nestler E.J.(2002)
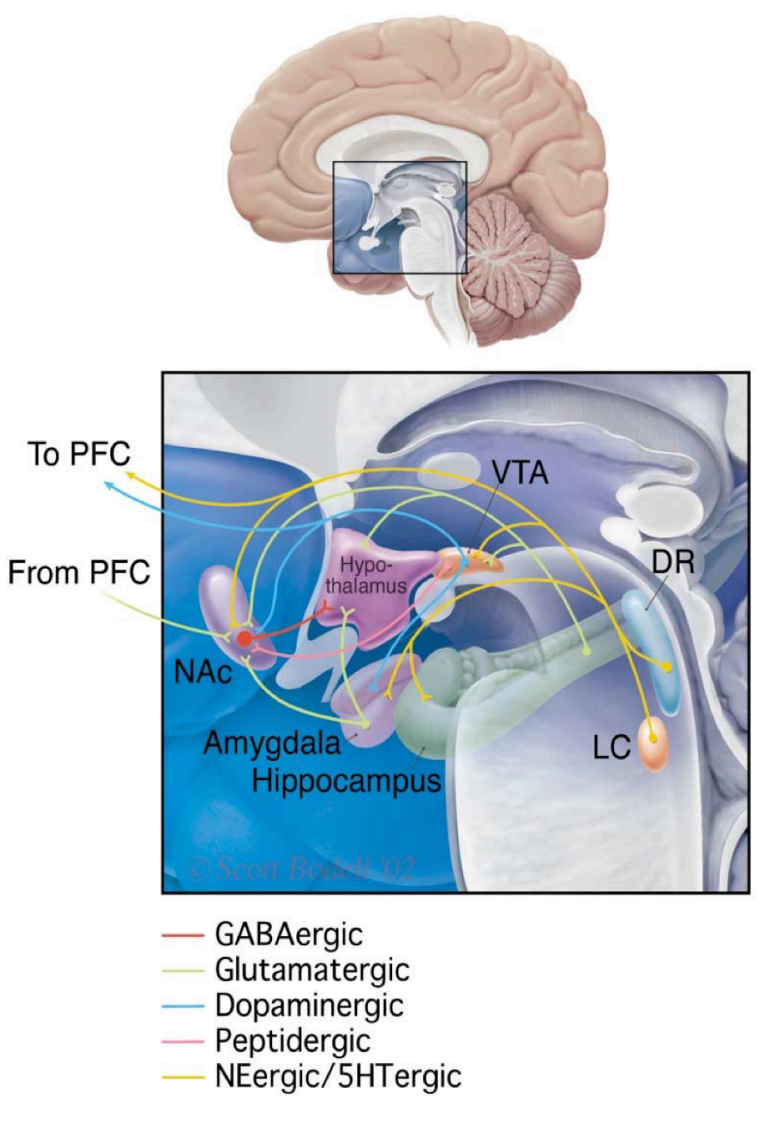

hipocampo pueden mediar en los aspectos cognitivos de la depresión, tales como deficiencias y sentimientos de inutilidad, desesperanza, culpa, y las tendencias suicidas. El cuerpo estriado (en particular el estriado ventral o núcleo accumbens [NAc]) y la amígdala, son importantes en la memoria emocional, y podrían, por consiguiente, mediar en la anhedonia, ansiedad y reducción de la motivación que predominan en muchos pacientes. Dada la importancia de los llamados síntomas neurovegetativos de la depresión, incluyendo hipersomnia o el insomnio, la astenia, así como la apatía, se ha especulado en la implicación del hipotálamo.

Por supuesto, estas diversas regiones del cerebro funcionan en una serie de circuitos paralelos altamente interactuantes, de los cuales, tal vez, surja un circuito neural implicado en la depresión (Fig. 23) 


\section{Disregulación del Hipocampo y del Eje Hipotálamo-Hipofisario-Adrenal.}

Un mecanismo importante por el cual el cerebro reacciona al estrés, tanto agudo como crónico, es la activación del eje hipotálamo-hipofisarioadrenal (HHA) (Fig. 24).

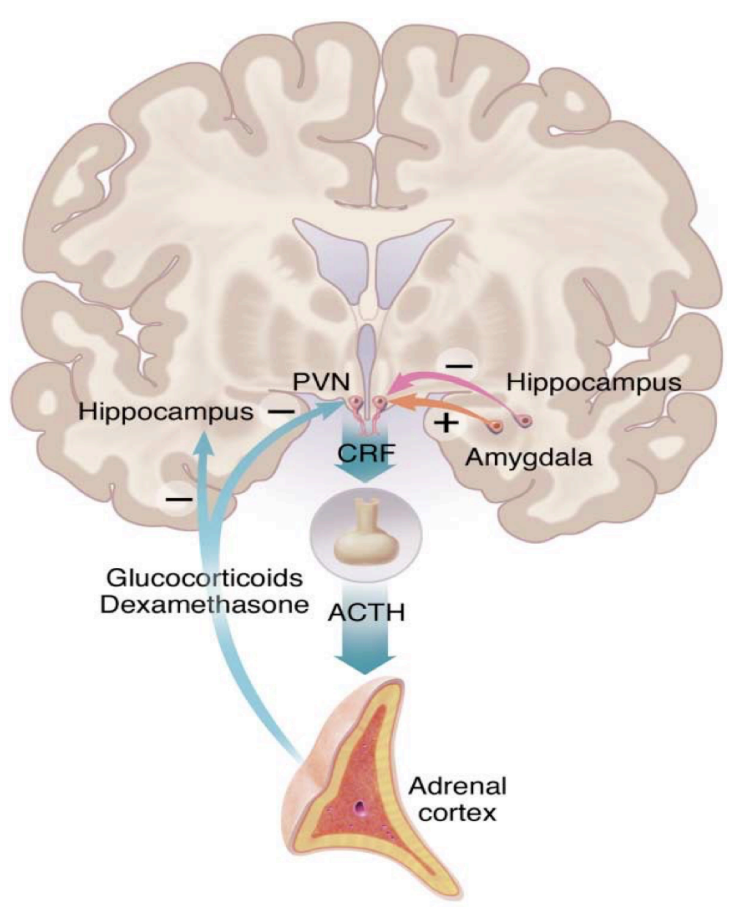

Fig.- 24. Eje Hipotálamohipofisario-adrenal. Nestler E.J.(2002)

Las neuronas del hipotálamo, a través de la secreción del factor de liberación de corticotropina (CRF), aumentan la síntesis y liberación de glucocorticoides en la corteza suprarrenal.

La actividad del eje HHA se encuentra controlada por varias áreas del cerebro, entre las que encontramos el hipocampo (que inhibe la liberación de CRF) y la amígdala (que aumenta su secreción) (Fig. 26) .

Los corticoides afectan al metabolismo general y a nuestro comportamiento a través de acciones directas en numerosas regiones del cerebro.

Sostenidas elevaciones de glucocorticoides, como consecuencia del estrés grave y prolongado, pueden dañar las neuronas del hipocampo, lesionando sus espinas dendríticas (McEwen, B.S. 2000; Sapolsky, R.M. 2000), o reduciendo el nacimiento de células nuevas (Fuchs, E.; Gould, E. 2000). 
Tal proceso de retroalimentación positiva con consecuencias patológicas se cree que pudiera estar implicado en un subgrupo de los trastornos depresivos. Una excesiva activación del eje HHA se observa en aproximadamente la mitad de los pacientes con depresión, donde dicha alteración se corrige con el tratamiento con fármacos antidepresivos (Arborelius, L., Owens, M.J., Plotsky, P.M., and Nemeroff, C.B. 1999; Holsboer, F. 2001).

\section{Deterioro de los mecanismos neurotróficos}

Los efectos patológicos del estrés en el hipocampo, han contribuido a otra hipótesis reciente, que propone un papel de los factores neurotróficos en la etiología y tratamiento de la depresión (Duman, R.S., Heninger, G.R., and Nestler, E.J. 1997; Altar, C.A. 1999). Los factores neurotróficos son potentes reguladores de la plasticidad y la supervivencia de las neuronas y células gliales. El estrés agudo y crónico disminuye los niveles de expresión de BDNF (factor neurotrófico derivado del cerebro), en la circunvolución y capa de células piramidales del hipocampo en roedores (Smith, M.A.; Makino, S.; Kvetnansky, R. and Post, R.M. 1995).

Según esta hipótesis una deficiencia en BDNF puede contribuir a la patología del hipocampo durante el desarrollo de la depresión, por lo que la inversión de esta deficiencia mediante antidepresivos contribuiría a la resolución de sus síntomas (Fig. 25).

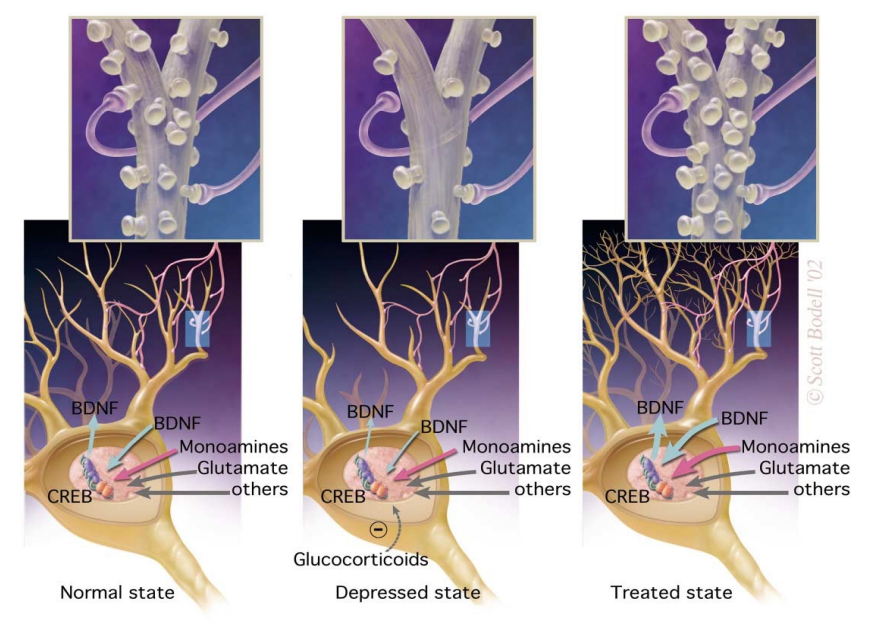

Fig.- 25.

Mecanismos

neurotróficos en depresión.Nestler

E.J.(2002) 


\section{Deterioro del valor de los circuitos de recompensa del cerebro}

Los estudios relacionados con la etiología y tratamiento de la depresión, se han centrado en el hipocampo como el principal lugar implicado, así como en los mecanismos serotoninérgicos y noradrenérgicos. Por otro lado, en el campo de las adicciones, el aumento de la transmisión dopaminérgica que las drogas de abuso producen en el área tegmental ventral (VTA), y concretamente en el núcleo acumbens (NAc), con la finalidad de producir efectos gratificantes, ha sido diana de la mayor parte de las investigaciones.

Debido a esta distinción artificial, la posible participación de la vía VTANAc en la regulación del ánimo y en la depresión no está bien estudiada.

Estudios recientes sobre el factor CREB, ilustran la relación entre las modificaciones moleculares y celulares que se producen en la vía VTA-NAc tras la exposición a drogas de abuso en el contexto de modelos de depresión (Berke, J.D., and Hyman, S.E. 2000; Nestler, E.J. 2001; Shaw-Lutchman, T.Z., Barret, M., Wallace, T., Gilden, L., Zachariou, V., Impey, S., Duman, R.S., Storm, D., and Nestler, E.J. 2002).

Las drogas de abuso activan el factor CREB en el NAc, dicho aumento produce la disminución de la respuesta a la recompensa a dichas sustancias, mientras que la disminución de CREB en el NAc tiene el efecto contrario (Carlezon, W.A., Jr., Thome, J., Olson, V.G., Lane-Ladd, S.B., Brod- kin, E.S., Hiroi, N., Duman, R.S., Neve, R.L., and Nestler, E.J. 1998; Pliakas, A.M., Carlson, R.R., Neve, R.L., Konradi, C., Nestler, E.J., and Carlezon, W.A., Jr. 2001).

En relación a este hecho, se ha observado recientemente que CREB también se ve elevado en el NAc en respuesta al estrés tanto agudo como crónico. Curiosamente, el aumento de la función de CREB en esta región, disminuye la sensibilidad de un animal a diferentes estímulos aversivos (ansiogénicos y/o nociceptivos, por ejemplo), mientras que la disminución de CREB aumenta dicha sensibilidad.

Por lo tanto, CREB en el NAc controla las respuestas de comportamiento de un animal a los estímulos emocionales en general, de tal manera que el aumento de CREB (a través del estrés o la exposición a un 
fármaco), puede contribuir a los síntomas de apatía y anhedonia que se observan en algunas formas de depresión, trastorno de estrés postraumático (TEPT), y síndromes de abstinencia a drogas (Nestler E.J.; Barrot M.; DiLeone R.J.; Eisch A.J.; Gold S.J. and Monteggia L.M., 2002).

Otro ejemplo del paralelismo entre ambos circuitos es el papel que juegan los factores neurotróficos (BDNF, principalmente). Éstos en el hipocampo están implicados en la acción antidepresiva, sin embargo, en la vía VTA-NAc, BDNF potencia drásticamente los mecanismos de recompensa de las drogas (Horger, B.A.; lyasere, C.A.; Berhow, M.T.; Messer, C.J.; Nestler, E.J., and Taylor, J.R. 1999). Estos datos implican a BDNF en el sistema mesolímbico dopaminérgico, para la regulación del estado anímico, la motivación y posiblemente, la depresión; y ponen de relieve la necesidad de examinar los circuitos neuronales para una completa comprensión de estos fenómenos.

En conclusión, es evidente la compleja interacción existente entre ambos circuitos, y la necesidad de estudios específicos que ayuden a comprender la participación de la vía VTA-NAc en los mecanismos de regulación del ánimo, depresión y adicción a drogas, en general y alcohol, en particular, a través de modelos moleculares y celulares.

- En último lugar la hipótesis genética, postula la relación entre los TCA y los trastornos afectivos como la consecuencia de una determinada predisposición genética. The Collaborative Study on the Genetics of Alcoholism (COGA), publicó un reciente estudio en el que el cromosoma 1 estaba implicado en ambas patologías, pudiendo predisponer en algunas personas a la patología adictiva y a otras a la depresión (la cual podría ser inducida por el consumo alcohol) (Nurnberger, J. I. Jr.; Foroud, T.; Flury, L.; Meter, E.T.; Wiegand, R. 2002).

En lo referente a Trastorno Bipolar también se ha hablado de la posibilidad de una base genética común, que aumentaría el riesgo para sufrir cualquiera de las dos patologías, (Johnson, C.; Drgon, T.; McMahon, F. J. and Uhl, G. R. 2009), sin que en este caso, esta vulnerabilidad genética pudiera 
atribuirse a factores de confusión, como en el caso de los trastornos de ansiedad (Carmiol, N.; Peralta, J. M.; Almasy, L.; Contreras, J.; Pacheco, A.; Escamilla, M. A.; Knowles, E.E.; Raventós, H.; Glahn, D.C. 2014).

\section{c) Diagnóstico}

Los pacientes con patología dual plantean un reto diagnóstico en sí mismos que requiere la elaboración de una historia clínica detallada en la que se recojan datos referentes a la cronología, las características clínicas, los tratamientos previos y la respuesta a los mismos. La tarea es ardua, pero de ello depende una orientación adecuada, que prevenga las graves consecuencias médicas y psicosociales a las que éstos pacientes se encuentran expuestos.

Inicialmente, existe la posibilidad de que nos encontremos ante un trastorno depresivo secundario a un TCA, es decir, que tal y como se ha explicado anteriormente, el consumo mantenido de alcohol, haya originado daños neurales que han predispuesto al paciente al desarrollo de una depresión. En este caso, la cronología de aparición de ambas patologías y la duración de la sintomatología depresiva una vez alcanzada la abstinencia, será de vital importancia. No debemos olvidar, que muchos pacientes presentan un síndrome de abstinencia prolongado o diferido que puede persistir durante meses y que se caracteriza por insomnio, irritabilidad, dificultad de concentración y estado de ánimo bajo que fluctúa a lo largo del día y de intensidad moderada. Del mismo modo, han de tenerse en cuenta las consecuencias médicas, familiares, sociales y laborales a las que el paciente se ha encontrado expuesto y donde, como ya hemos visto anteriormente, el estrés es un promotor biológico de los episodios depresivos.

Por otro lado, la última actualización de la American Psychiatric Association (DSM-5), recoge entre sus criterios diagnósticos el trastorno depresivo inducido por sustancias y/o medicamentos. Además refleja la posibilidad de que la patología afectiva se inicie en el periodo de intoxicación o en el periodo de abstinencia. Si bien, la complejidad de dicho diagnóstico no es pequeña, y no deben obviarse las numerosas consultas que la sintomatología 
depresiva genera, buscando paliar las consecuencias de un TCA en muchas ocasiones, silente y subyacente.

En el caso del diagnóstico diferencial, con un trastorno depresivo independiente o primario, es importante explorar la presencia de antecedentes de un posible trastorno afectivo previo al inicio del TCA, ansiedad de separación en la infancia, fobias o trastornos de ansiedad, reacción hipomaníaca a los antidepresivos, o antecedentes familiares de trastorno bipolar o de trastornos depresivos (Casas, M. y Guardia, J. 2002). Además si comparamos estos pacientes con aquellos que presentan depresión secundaria a un TCA, encontramos que es más frecuente en mujeres, casadas, caucásicas, con un TCA infra-tratado, y mayor número de intentos de suicidio previos (Schuckit, M.A., Smith, T.L., Danko, G.P., Pierson, J., Trim, R., Nurnberger Jr., J.I., Kramer, J., Kuperman, S., Bierut, L.J., Hesselbrock, V. 2007).

Por otro lado, el diagnóstico de un trastorno bipolar en el contexto de un TCA, es una labor compleja. Como es sabido, la intoxicación por alcohol puede producir síntomas que no se diferencian de la manía o la hipomanía durante el tiempo que permanece el efecto farmacológico de la droga (Brady, K.T.; Sonne, S.C. 1995). Finalmente, la propia retirada del alcohol puede producir sintomatología depresiva, como se aprecia en los periodos de abstinencia, en los que los síntomas depresivos pueden persistir entre 2 y 4 semanas (Brown, S.E.; Suples, T.; Adinoff, B.; Thomas, N.R. 2001).

Por este motivo, se recomienda en pacientes con TCA sin antecedentes de trastorno bipolar y que presentan episodios de depresión bipolares presuntamente, reevaluar mediante los mismos instrumentos y escalas específicas de depresión que se utilizan en pacientes con trastorno bipolar, una vez transcurridas 4 semanas de abstinencia.

Ante un episodio de manía, se considera que es necesario que pase un periodo de 2 semanas para descartar un cuadro inducido o provocado por el efecto del alcohol. La evaluación del episodio de manía en pacientes con trastorno bipolar y TAC se realizará mediante los instrumentos habituales destinados a pacientes con TB para manía (Casas, M.; Franco, M.D.; 
Goikolea, J.M.; Jiménez-Arriero, M.A.; Martínez-Raga, J.; Roncero, C.; Szerman, N. 2008).

\section{d) Evolución}

La existencia de comorbilidad psiquiátrica entre el TCA y los trastornos afectivos implica un peor pronóstico en la evolución de la enfermedad a causa de un escaso cumplimiento terapéutico (Harver, B. 2003; Burns, L.; Teesson, M.; O`Neill, K. 2005), y una mayor probabilidad de recaídas en el TCA. Además estos pacientes padecen más complicaciones médicas, psíquicas, familiares y sociales (Pérez, B.; de Vicente, M.P.; García, L.; Romero, C.; Oliveras, M.A. 2008; Baigent, M.F. 2005; Bischof G, Rumpf HJ, Meyer C, Hapke, U.; John, U. 2005; Compton, W.M.; Thomas, Y.F.; Stinson, F.S.; Grant, B.F. 2007), que los pacientes sin comorbilidad. De hecho, los pacientes con patología dual tienen, menor tasa de abstinencia y de adherencia al tratamiento, y mayor tasa de abandono, que aquellos con TCA (Fig. 26).

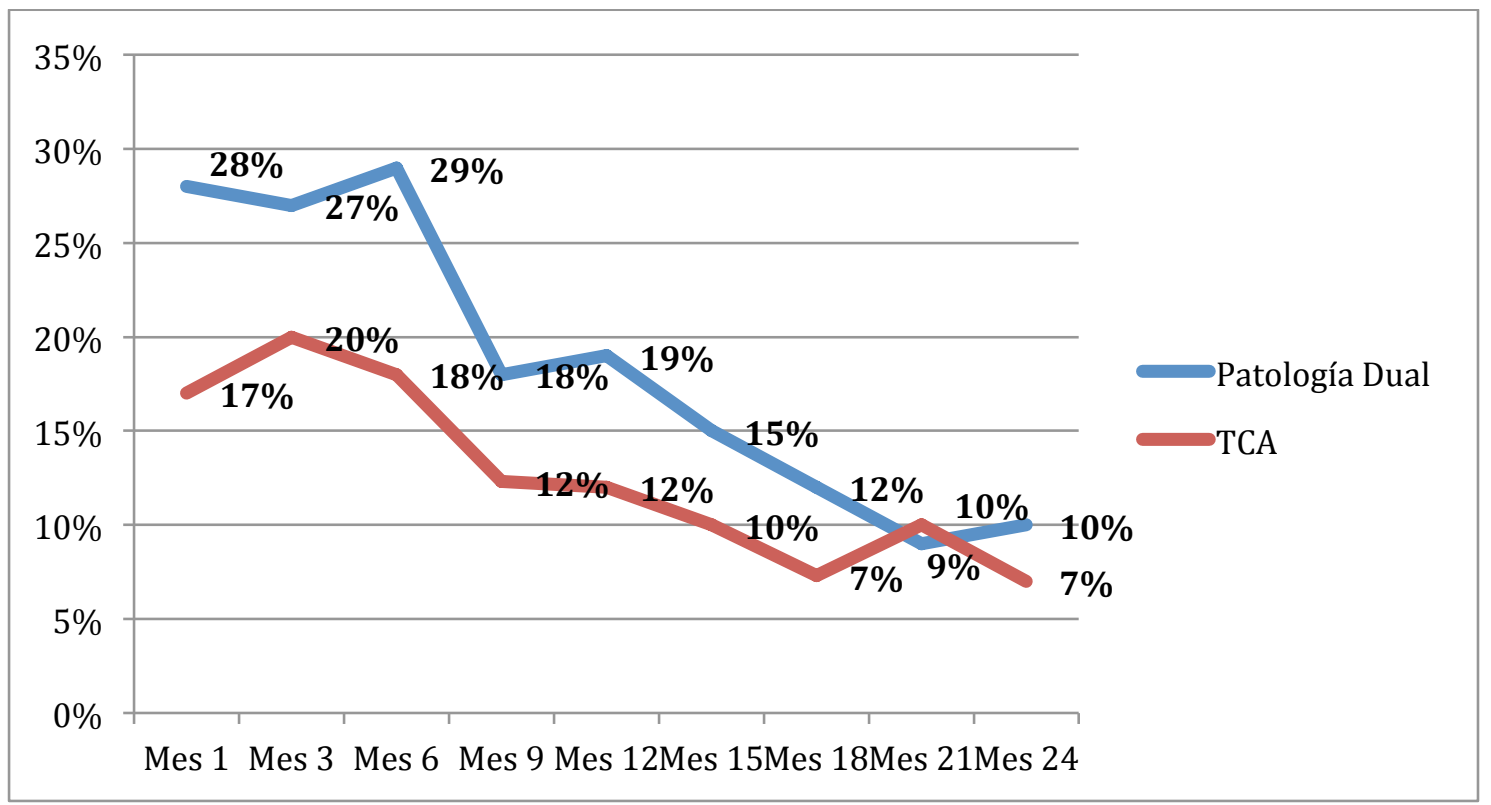

Fig.- 26. Evolución de la recaída en pacientes con patología dual vs TCA. (Sánchez-Peña, J.F.; Álvarez-Cotoli, P.; Rodríguez-Solano, J.J. 2012) 


\section{Evolución de la comorbilidad entre depresión y TCA}

La existencia de patología depresiva en un paciente afecto de un TCA predice peores índices de recuperación en la conducta adictiva de estos pacientes, por lo menos en varones; y un aumento del riesgo de conductas suicidas. Los estados emocionales negativos son el factor de recaída más habitual. Los episodios depresivos pueden aumentar el riesgo de recaída, mientras que la remisión de la depresión, predice un menor riesgo de recaída en el consumo de alcohol (Casas, M.; Guardia, J. 2002).

Dada la elevada prevalencia de patología depresiva inducida por el consumo prolongado de alcohol, es especialmente importante una abstinencia mantenida de esta sustancia para alcanzar una mejor evolución del trastorno depresivo, además de que un consumo mantenido de alcohol interfiere con la recuperación de la patología depresiva asociada y puede generar lo que se conoce como un trastorno psiquiátrico refractario al tratamiento, incluso cuando dicho trastorno recibe el tratamiento farmacológico adecuado, como antidepresivos y terapia cognitivo-conductual (Casas, M.; Guardia, J. 2002).

\section{Evolución de la comorbilidad entre trastorno bipolar y TCA}

Si comparamos los pacientes con Trastorno Bipolar sin comorbilidad, con aquellos que además sufren un TCA, encontramos que éstos últimos debutan a una edad más temprana, poseen peor adherencia al tratamiento y consecuentemente respuesta al mismo, hospitalizaciones más frecuentes y más largas (a causa de desestabilizaciones de su patología anímica), más episodios mixtos y ciclaciones rápidas, mayor comorbilidad con trastornos de ansiedad y mayor impulsividad, agresividad y tentativas de suicidio (Swann, A. C. 2010; Tolliver, B. K., and Hartwell, K. J. 2012; Nery, F. G.; Hatch, J. P.; Monkul, E. S.; Matsuo, K.; Zunta-Soares, G. B.; Bow- den, C. L.; Jair, C.S. 2013).

La comorbilidad con el TCA empeora de manera sustancial el funcionamiento y la evolución de los pacientes con Trastorno Bipolar y viceversa. De hecho, en ocasiones el impacto de dicha comorbilidad produce un detrimento en el funcionamiento y una pérdida de habilidades mayor que la 
existente en los pacientes con esquizofrenia (Nery, F. G.; Matsuo, K.; Nicoletti, M. A.; Monkul, E. S.; Zunta-Soares, G. B.; Hatch, J. P.; Lafer, B.; Soares, J.C. 2011).

Además de ello, la mayoría de los estudios han reflejado que dicha comorbilidad produce mayores déficits neurocognitivos, principalmente en las áreas de memoria verbal y cognición ejecutiva. Dado que ambas patologías producen disfunciones cognitivas independientemente, en conjunto producen una mayor gravedad y un mayor deterioro neuronal (Balanzá-Martínez, V.; Crespo-Facorro, B.; González-Pinto, A. and Vieta, E. 2015).

\section{Suicidio}

Entre los factores de riesgo más importantes para realizar un intento de suicidio y/o llevar a cabo un suicidio consumado, encontramos la depresión, como el trastorno del ánimo más frecuentemente asociado. Sin embargo, los pacientes afectos de comorbilidad con el TCA, presentan mayores índices de tentativas y de suicidios, en una probable relación con un comportamiento más agresivo, o con una mayor impulsividad (Nery, F. G.; Hatch, J. P.; Monkul, E.

S.; Matsuo, K.; Zunta-Soares, G. B.; Bow- den, C. L.; Jair, C.S. 2013. BalanzáMartínez, V.; Crespo-Facorro, B.; González-Pinto, A. and Vieta, E. 2015).

En un reciente estudio prospectivo realizado en Canadá sobre 816 jóvenes, desde los 16 hasta los 30 años, se observó que el riesgo de suicidio era de un $13,3 \%$ en aquellos que presentaron un Trastorno Depresivo Mayor sin comorbilidad y del $3,7 \%$ en aquellos que presentaron un TCA sin comorbilidad. Sin embargo, éste aumentaba hasta un $34,5 \%$ si los pacientes deprimidos desarrollaban un TCA, y hasta un 19,2\% si los pacientes con TCA, desarrollaban posteriormente un episodio depresivo (Brière, F.N.; Rohde, P.; Seeley, J.R.; Klein, D.; Lewinsohn, P.M. 2014). No obstante, otros estudios han concluido que cuando el cuadro afectivo es tan grave que la ideación suicida requiere hospitalización psiquiátrica, no existe un mayor riesgo de tentativa o suicidio consumado en comparación con los pacientes que presentan además comorbilidad con TCA (Britton, P.C.; Stephens, B.; Wu, J.; Kane, C.; Gallegos, A.; Asharafioun, L.; Tu, X. Conner, K.R. 2015). 
El siguiente punto, radicaría pues, en la necesidad de estrategias preventivas que disminuyan y/o eviten las altas tasas de muertes violentas auto-infringidas que esta comorbilidad genera (Shoval, G.; Shmulewitz, D.; Wall, M.M.; Aharonovich, E.; Spivak, B.; Weizman A, Hasin, D. 2014.; Moustgaard, H.; Joutsenniemi, K.; Sihvo, S.; Martikainen, P. 2013).

Por otro lado, tanto los pacientes con trastorno bipolar como aquellos que presentan TCA, tienen mayor prevalencia de suicidio que la población general, de manera que la esperanza de vida es 8-9 años menor, en ambos sexos, que en el resto de la población (Crump, C.; Sundquist, K.; Winkleby, M.A.; Sundquist, J. 2013; Harris, E.C.; Barraclough, B. 1997; Goodwin, F.K., Jamison, K.R., 2007; Baldessarini, R.J.; Pompili, M.; Tondo, L. 2006).

Según un reciente meta-análisis, en el cual se evaluaron 222 estudios y un total de 31294 pacientes, se concluyó que en comparación con los pacientes sin patología dual, aquellos con comorbilidad entre Trastorno Bipolar y TCA eran más propensos a realizar intentos de suicidio (Figura 27).

De esta conclusión, se deduce pues, la necesidad de que esta población sea objeto de intensos esfuerzos terapéuticos para la prevención de dichos actos (Carrà, G.; Bartoli, F.; Crocamo, C.; Brady, K.T.; Clerici, M. 2014).

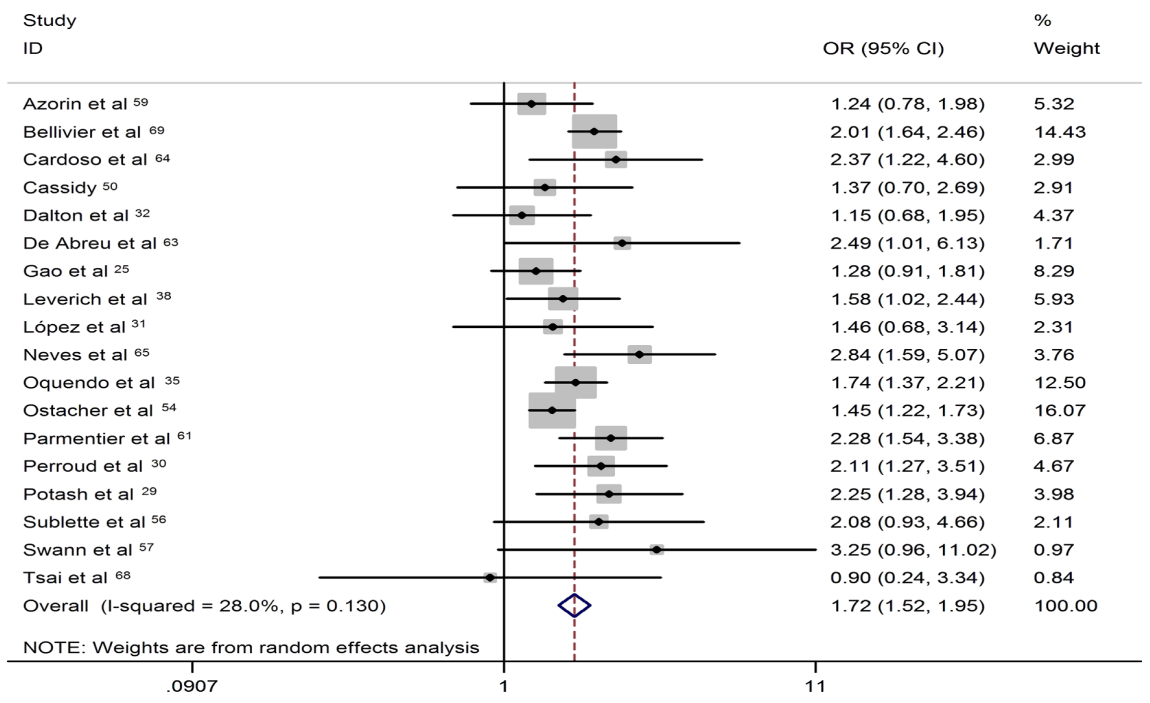

Fig.- 27. Asociación entre esperanza de vida e historia de intentos de suicidio en los pacientes con TAC. Abreviación: OR1/4odds ratio. Carrà, G.; Bartoli, F.; Crocamo, C.; Brady, K.T.; Clerici, M. (2014) 


\section{e) Tratamiento}

El tratamiento de la patología dual debe tener en cuenta ambos trastornos, y basarse en el proceso diagnóstico llevado a cabo. De manera generalizada, la patología depresiva en el contexto de un TCA, debe tratarse a pesar de que el paciente esté en situación de consumo activo, sin que ese tratamiento sirva de sustituto para el tratamiento del TCA, debiendo plantearse un tratamiento concomitante específico para éste. Existen diversos algoritmos de tratamiento (Figura 28).

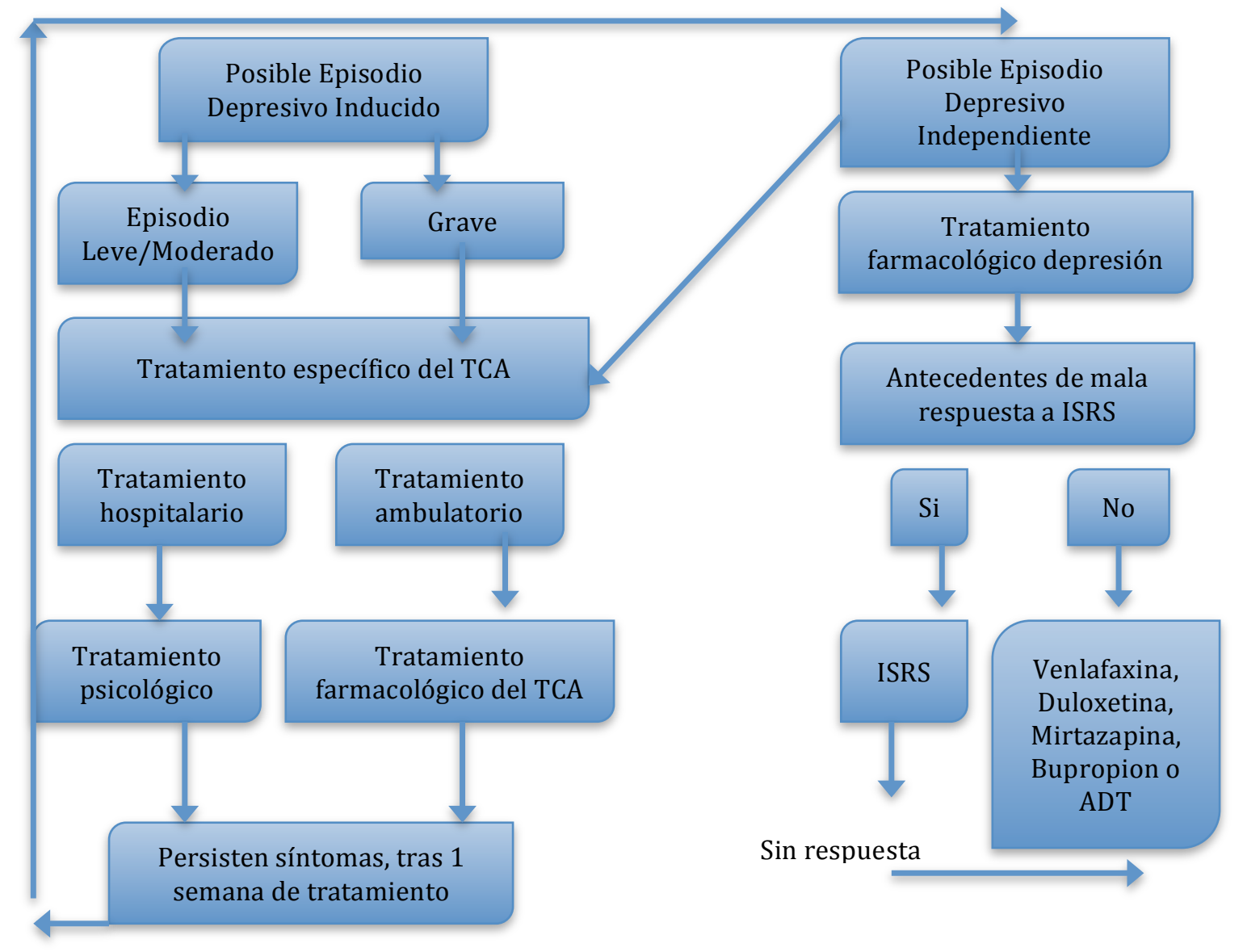

Fig. 28.- Algoritmo de tratamiento de la patología depresiva y el TCA. Adaptación de Nunes, E.V. y Levin, F.R. (2008). 
- Inicialmente debemos tratar correctamente los síntomas de la intoxicación y/o abstinencia que el alcohol produce, de esta manera los síntomas afectivos producidos por ella, evolucionarán hasta su desaparición.

- Si nos encontramos ante un trastorno depresivo inducido por alcohol, no sería necesario iniciar tratamiento antidepresivo, pues estos síntomas remiten espontáneamente tras varias semanas de abstinencia (Raimo, E. y Schuckit, M. 1998). Si por el contrario, la clínica se mantuviese habría que valorar la necesidad de comenzar con tratamiento farmacológico.

- Si el consumo de alcohol mantenido ha contribuido a la aparición de un trastorno depresivo independiente, más allá de los efectos de intoxicación o abstinencia de esta sustancia, el tratamiento farmacológico y psicoterapéutico para el mismo, está indicado (Sarasa Renedo A, Sordo L., Molist G, Juan Hoyos, Guitart AM y Barrio G. 2014).

En el tratamiento de abstinencia al alcohol los sedantes más usados en nuestro medio son el clometiazol, el tiapride y las benzodiacepinas. En algunas ocasiones se inicia de forma simultánea la toma de fármacos más específicos para la deshabituación (Mosquera Nogueira, J. 2005).

La instauración de fármacos interdictores (disulfiram, cianamida), naltrexona y acamprosato, y psicoterapia busca lograr una abstinencia mantenida. La mayoría de los estudios publicados coinciden en que la mayor eficacia de estos fármacos se logra cuando el paciente toma la medicación bajo supervisión y al mismo tiempo recibe algún tipo de apoyo psicoterapéutico. Los interdictores, a día de hoy, continúan jugando un papel activo en el tratamiento de la dependencia al alcohol (Girón García, S. 2014)

Aunque los fármacos ISRS continúan siendo una buena opción, sobre todo por su perfil de tolerabilidad, seguridad y escasas interacciones con el alcohol, no debemos olvidar que han obtenido resultados poco satisfactorios en 
la mayoría de los estudios, por lo que debemos tener en consideración el uso con antidepresivos no ISRS en estos pacientes,. Añadir un perfil más noradrenérgico o mecanismos mixtos de acción parece ser más eficaz (Nunes, E.V.; Levin, F.R. 2004; Torrens, M.; Fonseca, F.; Mateu, G.; Farré, M. 2005; Nunes, E.V.; Levin, F.R. 2008).

Un reciente estudio realizado con 5003 individuos con TCA y trastorno afectivo y 6734 pacientes con TCA sin patología afectiva, objetivó que los pacientes que presentan dicha comorbilidad son más propensos a buscar tratamiento de su patología adictiva que aquellos que no la presentan. Del mismo modo, se observó que el grupo comórbido también era más probable que se sintiese insatisfecho con el tratamiento (Kaufmann, C.N.; Chen, L.Y.; Crum, R.M.; Mojtabai, R. 2014). Este hecho demuestra cierta coherencia, si partimos de la base de que la comorbilidad refleja una menor respuesta al tratamiento con antidepresivos, reflejando un probable efecto inhibido del alcohol sobre la acción de estos fármacos a nivel cerebral (Hashimoto, E.; Tayama, M.; Ishikawa, H.; Yamamoto, M.; Saito, T. 2015).

Por otro lado, el uso de la terapia cognitivo conductual y la entrevista motivacional han demostrado un pequeño pero significativo efecto en la clínica de estos pacientes, en comparación con el tratamiento habitual, según se recoge en un reciente meta-análisis (Riper, H.; Andersson, G.; Hunter, S.B.; Wit, J.; Berking, M. and Cuijpers P. 2013).

En el caso del trastorno bipolar y el TCA, el tratamiento requiere una mayor complejidad, dados los diferentes episodios afectivos que puede presentar el paciente, como consecuencia de su trastorno bipolar. Si bien según la reciente revisión sistemática de la evidencia científica y el consenso entre profesionales expertos, se realizan las siguientes recomendaciones: (Casas M., Franco MD, Goikolea JM , Jiménez-Arriero MA, Martínez-Raga J, Roncero C., Szerman, N. 2008):

- Episodio maníaco: Se recomienda con un grado "b" de evidencia, la instauración del tratamiento para el episodio maníaco y para el TCA simultáneamente, sin priorizar uno sobre el otro. Está indicado el uso de antipsicóticos atípicos y los anticonvulsivantes clásicos (carbamazepina 
y ácido valproico), siendo los antidepresivos un tratamiento inadecuado en este contexto.

\section{- Episodio maníaco asociado a una intoxicación aguda o síndrome} de abstinencia: los antipsicóticos atípicos y los nuevos anticonvulsivantes son las opciones idóneas para el tratamiento, seguidos de los anticonvulsivantes clásicos y las benzodiacepinas. Los inhibidores selectivos de la recaptación de serotonina (ISRS) y los antidepresivos tricíclicos, son inadecuados. Además, en este contexto, es preciso adaptar el tratamiento del episodio maníaco.

- Episodio depresivo: tanto si se encuentra en el contexto de una intoxicación aguda y/o un síndrome de abstinencia, se recomienda el tratamiento con ISRS (asociados siempre con un eutimizante), lamotrigina y quetiapina.

- Cicladores rápidos: el tratamiento idóneo de la ciclación rápida asociada o no a una intoxicación aguda o a un síndrome de abstinencia, son los antipsicóticos atípicos y/o los anticonvulsivantes. Hay que tener en cuenta que si el TCA se presenta como intoxicación aguda o síndrome de abstinencia obliga a adaptar el tratamiento de la ciclación rápida.

Para concluir, debemos subrayar que el uso de psicoterapia, principalmente terapias psicoeducativas, cognitivas y conductuales en pacientes con trastorno bipolar y TCA constituyen intervenciones psicológicas que han demostrado ser eficaces en la profilaxis de nuevas recurrencias. Una combinación de psicoterapia y farmacoterapia puede permitir a los pacientes conseguir una mejoría más rápida de su sintomatología (Colom, F.; Vieta, E. 2004). 


\subsection{2.- Trastornos de Ansiedad}

\section{a) Epidemiología}

La elevada comorbilidad entre los trastornos de Ansiedad y el TCA, también ha sido objeto de múltiples ocasiones. La prevalencia de este tipo de comorbilidad, se sitúa de manera general, entre el $11 \%$ y el $37 \%$ según los distintos estudios epidemiológicos, existiendo una amplia variabilidad entre ellos (Tabla 15) (Kessler RC, Chiu WT, Demler O, Merikangas KR, Walters EE. 2005; Grant, B.F.; Hasin, D.S.; Stinson, F.S.; Dawson, D.A.; June Ruan, W.; Goldstein, R.B.; Smith, S.M.; Saha, T.D.; Huang, B. 2005; Fatseas, M., Denis, C., Lavie, E., y Auriacombe, M. 2010; Marmorstein, N. R. 2012).

Este hecho puede explicarse desde diversas vertientes. Por un lado, hay que considerar la posible confusión entre la sintomatología de abstinencia y los trastornos de ansiedad. La mayoría de los pacientes que inician tratamiento de desintoxicación, presentan de manera espontánea síntomas de ansiedad, los cuales desaparecen con el mantenimiento de la abstinencia (Brown, S.A.; Irwin, M.; and Schuckit, M.A., 1991). Por otro lado, podría explicarse por los distintos trastornos de ansiedad incluidos (Kushner M.G., Sher K.J.; Erickson D.J. 1999), o por las herramientas metodológicas utilizadas para su evaluación.

Los resultados que se muestran, recogen los datos de los principales estudios epidemiológicos americanos y australianos. Se observa que, tanto en Estados Unidos como en otros países, la relación entre ansiedad y TCA, es superior a lo que cabría esperarse, oscilando la odds ratio (OR), que caracteriza la comorbilidad entre ambos trastornos entre 2,1 y 3,3. Es decir, dos a tres veces mayor de lo que el azar podría ocasionar (Smith JP y Randall C.L., 2012). 
Tabla 15.- Odds Ratios de presentar un diagnóstico añadido de ansiedad en pacientes con TCA, según estudios.

\begin{tabular}{|c|c|c|c|c|c|c|}
\hline ESTUDIO & $\begin{array}{l}\text { Cualquier } \\
\text { ansiedad }\end{array}$ & $\begin{array}{l}\text { Tr. de } \\
\text { Pánico }\end{array}$ & Agorafobia & $\begin{array}{l}\text { Fobia } \\
\text { simple }\end{array}$ & $\begin{array}{l}\text { Fobia } \\
\text { social }\end{array}$ & $\begin{array}{l}\text { Ansiedad } \\
\text { generali- } \\
\text { zada }\end{array}$ \\
\hline $\begin{array}{l}\text { National Epidemiologic } \\
\text { Survey on Alcohol and } \\
\text { Related Conditions III. } \\
2015\end{array}$ & 1,3 & 1,3 & 1,0 & 1,2 & 1,0 & 1,2 \\
\hline $\begin{array}{l}\text { The Epidemiology of } \\
\text { comorbidity between } \\
\text { alcohol use disorders and } \\
\text { mental disorders in } \\
\text { Australia. } 2011\end{array}$ & 3,3 & 3,9 & 2,3 & - & 3,2 & 3.3 \\
\hline $\begin{array}{l}\text { National Epidemiologic } \\
\text { Survey on Alcohol and } \\
\text { Related Conditions } \\
\text { (NESARC). } 2004\end{array}$ & 2,7 & 3,5 & - & 3,5 & 2,3 & 3 \\
\hline $\begin{array}{l}\text { National Comorbidity } \\
\text { Survey (NCS) } 1994\end{array}$ & 2,6 & 1,7 & 2,6 & 2,2 & 2,8 & 4,6 \\
\hline $\begin{array}{c}\text { National Epidemiologic } \\
\text { Survey on Alcohol and } \\
\text { Related Conditions (ECA) } \\
1990\end{array}$ & 1,1 & 0,8 & 1,4 & 2,3 & 0,9 & 0,9 \\
\hline
\end{tabular}

\section{c) Etiología y Neurobiología}

Existen diversas hipótesis que tratan de explicar la elevada comorbilidad entre el TCA y la ansiedad. Algunos autores abogan por la hipótesis de la automedicación (Álamo, C., López-Muñoz, F. y Cuenca, E.2002; Marquenie, L. A., Schadé, A., van Balkom, A. J., Comijs, H. C., de Graaf, R., Vollebergh, W. van den Brink,, W. 2007), situando la ansiedad cronológicamente como la causa del TCA. Desde un punto de vista neurobiológico, se ha observado en ratas que situaciones de estrés producen un incremento de la dopamina mesolímbica y a su vez facilitan el consumo de psicoestimulantes y opiáceos. Esta situación haría más vulnerable a la persona para desarrollar una dependencia a través de una potenciación de la actividad del sistema dopaminérgico mesolímbico en los estadíos tempranos del consumo 
(Manzanares, J., García, M. S., Celorrio, M. L., Sánchez, M. M., y Rubio, G., 2010).

Otros autores, defienden el papel del alcohol como desencadenante de la ansiedad, en donde el TCA es primario y los síntomas de ansiedad son consecuencia del uso o de la abstinencia de la sustancia. En estos casos, la pérdida de control sobre los consumos y/o la alteración de determinados sistemas de neurotransmisión facilitarían la aparición de determinados trastornos de ansiedad, así como el detrimento de las condiciones psicosociales, jugaría un papel fundamental, para facilitar la aparición de procesos ansiosos secundarios (Kushner M.G.; Sher K.J. y Erickson D.J. 1999). Por último, y no por ello menos relevante, se encuentra la hipótesis de que el TCA y la ansiedad forman parte de una base biológica o psicosocial común, en la que a corto plazo, existe una disminución de la ansiedad (inducida por el alcohol), que favorece su consumo, mientras que el consumo crónico y la abstinencia del mismo inducen síntomas de ansiedad, lo cual refuerza los consumos (Kushner, M.G., Abrams, K., y Borchardt, C. 2000; Cosci, F., Schruers, K. R., Abrams, K., y Griez, E. J. 2007).

De igual modo, para complicar más aún el tema, hay que señalar la existencia de estudios que ponen de manifiesto la existencia de una agregación y transmisión familiar entre el trastorno por uso de alcohol y el trastorno de pánico (Goodwin, R. D., Lipsitz, J. D., Chapman, T. F., Mannuzza, S., Klein, D. F., y Fyer, A. J. 2006; Cosci, F., Schruers, K. R., Abrams, K., y Griez, E. J. 2007), lo cual indicaría que ambos trastornos comparten una causa genética común.

\section{c) Diagnóstico}

Una preocupación fundamental es el establecimiento del diagnóstico correcto y la exclusión de otros diagnósticos, sobre todo debido a la dificultad inherente para discernir si la ansiedad presente en la evaluación inicial es inducida por alcohol o el signo de un trastorno de ansiedad independiente. La plena confianza en los datos proporcionados por el paciente puede deteriorar el diagnóstico, especialmente con la presencia de sesgos de memoria más presentes cuando una persona se encuentra en un estado vulnerable (Brown, 
S. Irwin, M. y Schuckit, M. 1991). Por lo tanto, la evaluación cuidadosa implica la recopilación de una línea de tiempo retrospectiva completa y detallada, entrevistando a informantes colaterales, revisando la historia clínica del paciente, los datos de laboratorio disponibles, y observando los síntomas durante un período mantenido de abstinencia (Anthenelli, R.M. 1997; Watkins, K.E.; Hunter, S.B.; Burnam, M.A.; Pincus H.A.; Nicholson G. 2005).

La duración del periodo de abstinencia preciso para establecer un diagnóstico de trastorno de ansiedad independiente varía en función del tipo de trastorno. Es decir, los trastornos de ansiedad cuyos síntomas son similares a los producidos por la abstinencia de alcohol (por ejemplo, trastorno de pánico y trastorno de ansiedad generalizada) requieren períodos más largos de abstinencia que aquellos con una sintomatología más diferenciada (por ejemplo, agorafobia).

Por lo tanto, una manera prudente de llevar a cabo el diagnóstico, consiste en esperar varias semanas para determinar la naturaleza y origen de los síntomas. Sin embargo, algunos individuos no consiguen mantener la abstinencia durante un período de tiempo suficiente para determinar el diagnóstico. En estos casos, tratar de identificar los antecedentes y consecuencias de la ansiedad y del TCA, puede ser útil (Wyman, K., and Castle, D.J. 2006).

Tal vez lo más importante, sea tratar de recopilar la mayor información posible, a través de todas las estrategias disponibles, para dar un diagnóstico más preciso (Smith J.P. y Randall C.L. 2012).

\section{d) Evolución}

Independientemente de la etiología de la comorbilidad entre ansiedad y TCA, una vez que ésta se instaura, contribuye a la perpetuación de ambas patologías de manera recíproca. Este hecho influye considerablemente en el diagnóstico, el plan terapéutico y la evolución.

Por eso la evolución de dicha comorbilidad será mejor en aquellos casos en que ambas patologías sean tratadas, especialmente si se hace desde un enfoque integrado, a pesar de que los datos sobre la eficacia de los tratamientos combinados son limitados (Baillie, A.J.; Stapinski, L.; Crome, E.; 
Morley, K.; Sannibale, C.; Haber, P.; Teesson, M. 2010; Schade, A.; Marquenie, L.A.; Van Balkom, A.J.; De Beurs, E.; Van Dyck, R.; Van Den Brink, W. 2003;. Watkins, K.E.; Hunter, S.B.; Burnam, M.A.; Pincus H.A.; Nicholson G. 2005).

\section{e) Tratamiento}

En cualquier caso, y sea cual fuere la etiopatogenia de la dualidad, el abordaje terapéutico suele ser semejante al utilizado cuando se presenta cada una de las patologías independientemente. Los fármacos antidepresivos constituyen el tratamiento de primera línea en los trastornos de ansiedad y existen datos que ponen de manifiesto que el uso de determinados ISRS, como la paroxetina y la sertralina son eficaces en la reducción de la ansiedad en pacientes con TCA y ansiedad comórbidas, si bien los resultados sobre la dependencia de alcohol son dispares (Brady, K. T., y Verduin, M. L. 2005; Schadé, A., Marquenie, L. A., van Balkom, A. J., Koeter, M. W., de Beurs, E., van den Brink, W. van Dyck, R. 2005).

Por otro lado, los antiepilépticos de nueva generación han demostrado eficacia, principalmente la gabapentina, la pregabalina y el topiramato en el TCA (Saíz Martínez, P.A.; Jimenez Treviño, L.; Díaz Mesa, E.M.; García-Portilla González, M.P.; Marina González, P.; Al-Halabí S.; Szerman, N.; Bobes García, J.; Ruiz P. 2014).

Las benzodiacepinas deben evitarse en este tipo de pacientes por el potencial desarrollo de tolerancia y dependencia al fármaco, como se ha destacado en diferentes estudios realizados en nuestro país (OECD, 2012).

Merece la pena hacer una breve referencia a la psicoterapia cognitivoconductual, dada su eficacia demostrada en el tratamiento de los trastornos de ansiedad, sin olvidar el enfoque psicosocial (Baker, A. L., Thornton, L. K., Hiles, S., Hiles, y L., Lubman, D. I. 2012; Hesse, M. 2009). 


\subsection{3.- Esquizofrenia y otros trastornos psicóticos.}

\section{a) Epidemiología}

La mayoría de los estudios norteamericanos estiman que alrededor del $50 \%$ de las personas diagnosticadas con esquizofrenia también cumplen criterios para el diagnóstico de trastorno por uso de sustancias.

Según se recoge del estudio ECA (Epidemiologic Catchment Area) el $33,7 \%$ de las personas con un diagnóstico de esquizofrenia o trastorno esquizofreniforme cumplen criterios para el TCA; y en comparación con aquellas personas que no sufren patología psicótica, la probabilidad de tener un TCA es tres veces superior en las personas con esquizofrenia (Rane, A.; Nadkarni, A.; Kanekar, J.; Fernandes, W.; Borker, H.A.; Pereira, Y. 2012).

Estudios europeos similares, como el realizado en el Reino Unido, muestra que la prevalencia de TAC en personas con esquizofrenia era del $32 \%$ al año de seguimiento y del $11,7 \%$ en el primer episodio psicótico (AbouSaleh, M.T.; Janca, A. 2004; Schifano, F. 2002).

En Australia, se ha observado que la prevalencia del consumo de alcohol en la psicosis es del $38 \%$ en hombres y $17 \%$ en mujeres. El uso actual de alcohol en pacientes esquizofrénicos alcanza tasas del 77,3\% (Rane, A.; Nadkarni, A.; Kanekar, J.; Fernandes, W.; Borker, H.A.; Pereira, Y. 2012).

En conclusión, se objetivan diferencias en la prevalencia de TCA en pacientes afectos de patología psicótica, en función de diversas características culturales y sociodemográficas. Si bien, el riesgo de presentar este diagnóstico dual, se incrementa de manera global entre 3 y 4 veces en la población psicótica en comparación con la población general (Hartz, S.M.; Pato, C.N.; Medeiros, H.; Cavazos-Rehg, P.; Sobell, J.L.; Knowles, J.A.; Bierut, L.J.; Pato, M.T.; 2014).

\section{b) Etiología y Neurobiología}

Las causas de tan frecuente asociación con la esquizofrenia no son del todo conocidas. Existen principalmente tres plausibles hipótesis que tratan de explicar la etiopatogenia de dicha comorbilidad. 
Algunos autores abogan por la hipótesis de la automedicación, en la cual postulan que estos pacientes utilizan el tóxico para aliviar los síntomas psicóticos y/o los efectos secundarios de los medicamentos utilizados para tratar la esquizofrenia (Tsai J. and Robert A. Rosenheck R.A., 2013). Aunque una parte de los individuos con esquizofrenia reportan mejorías subjetivas en el sueño y otros síntomas con el alcohol, el uso de sustancias no siempre se correlaciona con la gravedad de los síntomas y los estudios han sido incapaces de confirmar la hipótesis de la automedicación como la causa de las altas tasas de sustancias utilizadas en esta población (Blanchard, J.J.; Brown, S.A.; Horan, W.P.; Sherwood, A.R. 2000).

Otros autores abogan por el modelo de diátesis estrés neuronal, en el que la vulnerabilidad neurobiológica interactúa con factores de estrés ambiental, incluyendo el uso de sustancias, para dar lugar a un TCA en individuos vulnerables (Akerman S.C., Brunette M.F., Noordsy D.L., and Green A.I 2014). Por otra parte, las personas con esquizofrenia parecen ser más vulnerables a los efectos perjudiciales del consumo de sustancias (D'Souza, D.C.; Abi-Saab, W.M.; Madonick, S.; Forselius-Bielen, K.; Doersch, A.; Braley, G.; Gueorguieva, R.; Cooper, T.B.; Krystal, J.H. 2005).

En último lugar encontramos la hipótesis de la desregulación en el sistema de recompensa cerebral, este modelo defiende una alteración en la vía mesocorticolímbico mediada por la dopamina como causa subyacente de la presencia simultánea de esquizofrenia y el TCA, pudiendo el uso del alcohol aliviar temporalmente este déficit, a pesar de que su consumo empeora los síntomas y el curso de la esquizofrenia (Roth, R.M.; Brunette, M.F.; Green, A.L. 2005).

\section{d) Diagnóstico}

El diagnóstico se efectúa a través de la historia clínica, la información de familiares o amigos, exploración física, neurológica y psiquiátrica, síntomas de intoxicación o abstinencia, analítica general, determinación de sustancias en la orina y neuroimagen (TAC, RM, SPECT).

En la elaboración del diagnóstico dual, es muy importante tener en cuenta la edad de inicio de la dependencia del alcohol, la edad de aparición de 
los síntomas psicóticos y las características clínicas de éstos. Además debemos valorar la edad y duración de la primera abstinencia prolongada (más de 3 meses) y la evolución en ese momento del trastorno psicótico (Casas M., Guardia J., 2002),

De esta manera, se trata de realizar un diagnóstico adecuado de trastornos psicóticos comorbidos con el TCA, y también de aquellos trastornos psicóticos cuya aparición es inducida por el consumo del alcohol (Craighead, W.E.; Miklowitz, D.J.; Craighead, L.W. 2013):

- El delirium tremens constituye un trastorno mental orgánico que cursa con un síndrome confusional, trastornos perceptivos (ilusiones o alucinaciones), interpretaciones delirantes, alteraciones emocionales secundarias, agitación psicomotriz, insomnio, síntomas vegetativos y alteraciones hidro-electrolíticas; todo ello secundario a un proceso de abstinencia del TCA inadecuadamente tratado.

- La alucinosis alcohólica se define como un trastorno psicótico inducido por alcohol con predominio de las alucinaciones, se caracteriza por alteraciones sensoperceptivas e ideas delirantes que aparecen durante el consumo de alcohol o después de un periodo corto de abstinencia, con nivel normal de conciencia. Es un diagnóstico poco frecuente $y$, generalmente, ocurre en pacientes con un consumo de alcohol elevado y prolongado (Álvarez Pedrero, A. y Ávila Escribano, J.J. 2015)

- El trastorno delirante cursa con ideas delirantes de tipo persecutorio o celotípico, y un riesgo de auto o hetero-agresión, principalmente contra la pareja en el caso de que la temática sea principalmente celotípica.

- La intoxicación alcohólica idiosincrática es un grave trastorno de conducta, de tipo agresivo o violento, que se produce tras una pequeña 
ingesta de alcohol, la cual no produciría intoxicación en la mayoría de personas.

- Otras alteraciones orgánicas como la hemorragia cerebral, la hipoglicemia y la encefalopatía hepática, pueden cursar con un estado confusional que conviene diferenciar del delirium tremens, la encefalopatía de Wernicke u otras encefalopatías alcohólicas y que cuando se acompañan de agitación psicomotriz pueden confundirse con otros trastornos psicóticos.

\section{e) Evolución}

Los pacientes con esquizofrenia y uso de sustancias, sufren de manera general un impacto negativo en el curso de su patología. En comparación con aquellos pacientes psicóticos que no presentan patología dual, éstos primeros sufren mayor número de hospitalizaciones, escasos resultados en la prevención de suicidio, mayor impulsividad, violencia y se encuentran más frecuentemente sin hogar. Además suelen tener mayor número de problemas legales y de salud (Addy, P.H.; Radhakrishnan, R.; Cortes J. A. and D'Souza D. C.; 2012). De manera similar, existe evidencia de que los pacientes esquizofrénicos con TCA tienen una sintomatología neurológica y psiquiátrica más acusada, que la población psicótica sin TCA (Zhornitsky, S.; Stip, E. and Potvin, S. 2011). Todo ello, parece contribuir a que los pacientes esquizofrénicos obtengan peores resultados a la hora de tratar su patología adictiva, que aquellos que no sufren ningún tipo de psicosis.

Los pacientes con esquizofrenia presentan una mortalidad significativamente mayor a la población general, principalmente debido a la interacción entre las más de 23 complicaciones médicas que sufren, entre las que se hallan principalmente complicaciones diabetogénicas, depresivas, asmáticas, de la EPOC, y del TCA (Schoepf, D. 2014). Es decir, a pesar del claro empeoramiento evolutivo de los pacientes con esquizofrenia y TCA en comparación con aquellos sin consumo de alcohol, no sería esta comorbilidad la única responsable de incrementar la mortalidad de este grupo de pacientes 
(Fig. 23) (Koola, M.M.; McMahon, R.P.; Wehring, H.J.; Liu, F.; Mackowick, K.M.; Warren, K.R.; Feldman, S.; Shim, J-C.; Love, R.C.; Kelly D.L. 2012).

All Cause Mortality Controlling for Age and Alcohol Use

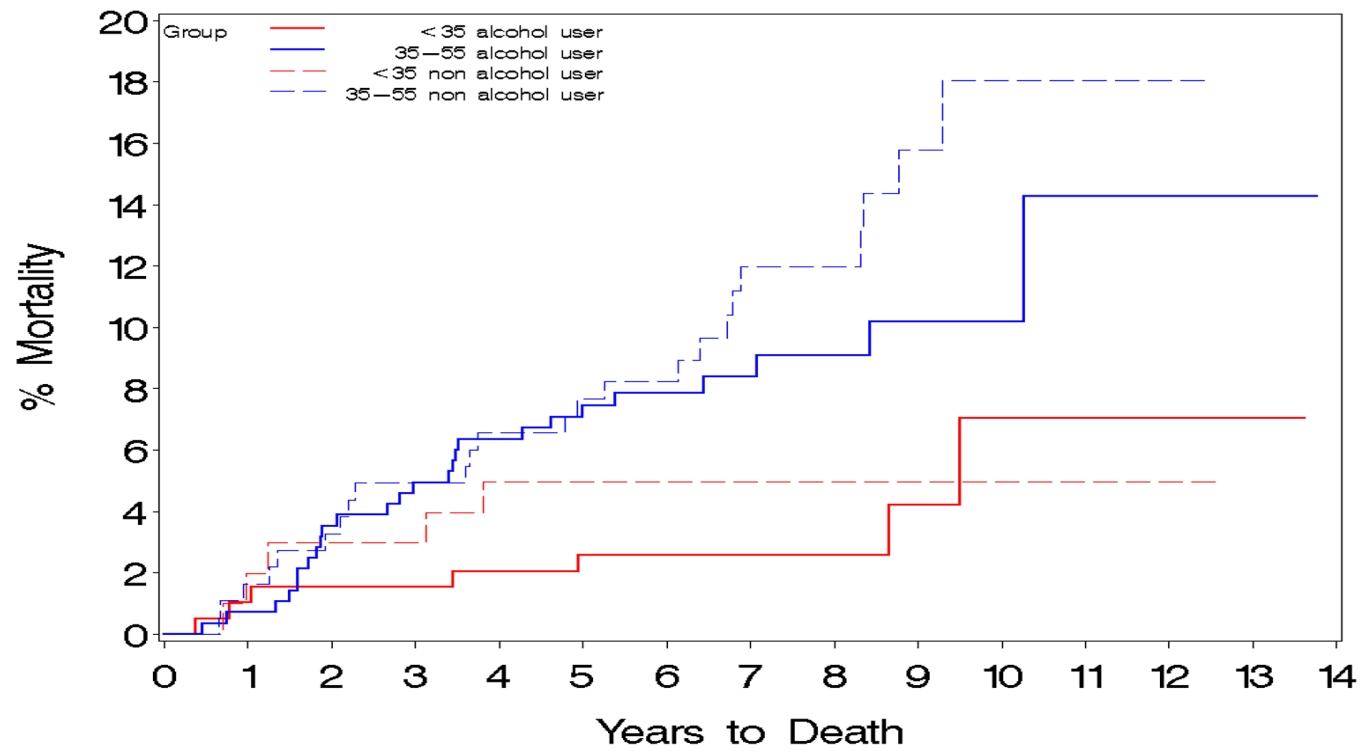

Fig. 23. Causas de mortalidad en pacientes psicóticos con y sin comorbilidad por consumo de alcohol. (Koola, M.M.; McMahon, R.P.; Wehring, H.J.; Liu, F.; Mackowick, K.M.; Warren, K.R.; Feldman, S.; Shim, J-C.; Love, R.C.; Kelly D.L. 2012)

Cuando los pacientes mentales graves dejan de beber, presentan una importante mejoría en su bienestar, mejorando su adaptación y su pronóstico. En el estudio ECA, entre los pacientes esquizofrénicos que dejaron de beber, se objetivó una disminución las tasas de depresión y hospitalización, al año de seguimiento (Casas M., Guardia J., 2002), por lo que los esfuerzos puestos en el tratamiento dual de estos pacientes retribuyen en importantes beneficios tanto de salud como económicos.

\section{e) Tratamiento}

El tratamiento óptimo para la comorbilidad entre esquizofrenia y el TCA consiste en farmacoterapia, psicoterapia coordinada, e intervenciones psicosociales (Drake RE, Mueser KT, Brunette MF, et al. 2004). Entre los 
principales tratamientos farmacológicos para dicha comorbilidad, encontramos:

- Tratamiento con antipsicóticos: mientras que los antipsicóticos típicos y atípicos reducen eficazmente los síntomas psicóticos en pacientes con esquizofrenia, la investigación no ha demostrado un tratamiento antipsicótico óptimo para los pacientes con esquizofrenia y TCA. Los antipsicóticos típicos no parecen disminuir el consumo de sustancias, aunque los estudios preliminares sugieren que el tratamiento con clozapina puede ser eficaz en el tratamiento de estos pacientes con diagnóstico dual. El uso de risperidona, olanzapina, quetiapina, y aripiprazol hasta ahora ha sido menos prometedor y, la literatura no aporta sobre el posible papel de estos antipsicóticos atípicos más nuevos, en este tipo de pacientes.

- Tratamiento del TCA: Hay un número de agentes farmacológicos disponibles para su uso en el tratamiento del TCA como agentes adyuvantes a los antipsicóticos en estos pacientes. La FDA (The Food and Drug Administration), ha aprobado tres medicamentos para el tratamiento del TCA en estos casos: el disulfiram, la naltrexona, y el acamprosato.

- Antiepilépticos: Algunos de ellos se han mostrado prometedores en el tratamiento de la dependencia del alcohol, pero ninguno está actualmente aprobado por la FDA para este uso. El topiramato, parece reducir el consumo excesivo de alcohol en pacientes dependientes del alcohol. El valproato, puede aumentar el tiempo hasta la recaída de bebida. $\mathrm{Y}$, por último, en un estudio reciente, el levetiracetam no ha demostrado resultados de eficacia para el tratamiento de la dependencia del alcohol. A pesar de lo expuesto, los estudios sobre estos fármacos y los pacientes con esquizofrenia y TCA son muy escasos.

- Antidepresivos tricíclicos: En dos pequeños estudios publicados hace más de 20 años se objetivó que los antidepresivos tricíclicos 
podían tener un papel como tratamiento adyuvante (agregado a los antipsicóticos típicos) en individuos con esquizofrenia y TCA. Según algunos estudios preliminares la combinación del antidepresivo tricíclico desipramina con la risperidona puede reducir el consumo de alcohol más que cualquiera de los fármacos solos.

Por otro lado, entre los principales tratamientos psicosociales encontramos: terapias de motivación, terapia cognitivo conductual, terapia de grupo, manejo de contingencias, apoyo al empleo, el tratamiento asertivo comunitario, y tratamiento residencial a largo plazo, los cuales pueden mejorar los resultados en los pacientes con diagnóstico dual tratados con antipsicóticos, aunque las tasas de recaída son altas (Hunt, G.E.; Siegfried, N.; Morley, K.; Sitharthan, T. and Cleary, M. 2013).

El tratamiento óptimo para los pacientes con esquizofrenia debe atender a ambos trastornos concurrentes. Aunque existen datos preliminares prometedores en cuanto al uso de clozapina, naltrexona y disulfiram para el tratamiento de esta población clínica, son necesarias investigaciones adicionales con la finalidad de poder realizar recomendaciones basadas en la evidencia médica (Akerman, S.C., Brunette, M.F., Noordsy, D.L., and Green A.I. 2014).

\section{7- Trastorno por consumo de alcohol y personalidad.}

\subsection{1.- Rasgos de personalidad prevalentes en los trastornos por consumo de alcohol}

Entre los pioneros en el estudio de la personalidad pre-alcohólica destacan Alonso Fernández y Valentín Matilla (Bases psicosociales del alcoholismo, 1979). Describen la personalidad premórbida de estos pacientes como dependiente, con tendencia al aislamiento, la soledad (McCord, 1959,1960,1962), la desesperanza (E. Minkowski, 1973) y caracterizada por una importante intolerancia a la frustración. Según Keller, M. (1966), para Jellinek (1942), el impacto del alcohol en una personalidad pre-alcohólica es 
diferente al producido en otras personas, generando en los primeros, una sensación de liberación y bienestar.

Según este autor la clave de la génesis del TCA radica en la personalidad. Los sujetos que se vuelven "alcoholómanos", presentan determinados rasgos comunes, mientras que en los demás aspectos su personalidad se muestra radicalmente diversa. Así pues, estos autores no hablan únicamente de un tipo de personalidad prealcoholómana, sino de agrupación de rasgos que constituyen la base de la personalidad prealcoholómana.

Posteriormente, son muchos los autores que han estudiado las características de la "personalidad adictiva". Para algunos de ellos se trataba de personas evitativas y para otros personas esquizoides; un tercer grupo de autores señalaba que los pacientes con TCA serían básicamente dependientes y posesivos y, finalmente algunos autores los describían como perfeccionistas y compulsivos (Rivera Reyes, 1984).

La búsqueda de un tipo de personalidad pre-adictiva fue abandonada, ante el evidente fracaso obtenido hasta entonces (Lang, 1983). La investigación, especialmente en la última década, se ha centrado en encontrar los elementos de la personalidad que favorecen el consumo de sustancias, la implantación del hábito, la aparición y mantenimiento de la dependencia y el abandono del consumo (Eysenck, 1997).

La exploración de los rasgos de personalidad, y de sus patrones disfuncionales de comportamiento que predisponen a la adicción al alcohol y otras sustancias, ha sido estudiado desde diferentes enfoques teóricos que han abordado la descomposición de la personalidad en sus diferentes elementos, donde 2 modelos han demostrado su superioridad: el de las 7 dimensiones de Cloninger y el de los 5 grandes factores de personalidad de McCrae y Costa (Grucza y cols. 2007)

Los diversos modelos dimensionales de la personalidad convergen en la existencia de determinados factores comunes que pueden influir en la predisposición a la adicción al alcohol, hablamos de los denominados factores internalizantes (la baja autoestima, el malestar anímico, el pesimismo, etc), y los factores externalizantes (la búsqueda de sensaciones y la impulsividad). 
Dentro de los Factores Internalizantes destacan:

- La abulia y apatía. El primero definido como un estado emocional transitorio que actúa a modo de disregulación de la voluntad. El segundo definido como disminución o anulación de la voluntad e impotencia para actuar. Estos síntomas definen un estado emocional negativo, del cual se ha constatado su implicación en el consumo de alcohol (Vallejo-Nágera, 1997).

- Las fluctuaciones anímicas, especialmente la intolerancia psíquica y física al estrés 0 el distrés emocional (el desbordamiento de los mecanismos de afrontamiento del individuo ante una demanda del entorno), también constituyen factores predisponentes (Braverman, 2001).

- Por último, se ha aludido a la ansiedad rasgo y ansiedad estado o tendencias depresivas como factores precipitantes, de modo que el paciente recurre al consumo de alcohol para evitar dicha sintomatología (Barnea, Teichman y Rahav, 1992; Rivera y Prados, 2001).

Los Factores Externalizantes son los que más frecuentemente se han relacionado $\mathrm{y}$, por consiguiente, estudiado en los pacientes con TCA, principalmente la impulsividad y la búsqueda de sensaciones.

- Entendemos por impulsividad una predisposición a realizar determinadas acciones de un modo rápido y escasamente reflexivo, como consecuencia de un deseo interno o de un determinado estímulo, sin valorar las consecuencias perjudiciales que esta acción podría conllevar. La impulsividad es uno de los rasgos de la personalidad que se relaciona con más frecuencia con las conductas adictivas, y en particular con la adicción al alcohol (Barratt, E.S.; Stanford, M.S.; Kent, T.A.; Felthous, A. 1997). Diversos estudios señalan que puede ser un factor de riesgo para iniciarse en el consumo de alcohol, y para una mayor gravedad del trastorno (APA, 2013; Dom, G.; D'haene, P.; 
Hulstijn, V.; Sabbe, B. 2006). Por otra parte, el consumo continuado de esta sustancia contribuiría a una falta de control sobre la conducta, y a la perpetuación de conductas de carácter impulsivo (Dougherty D.M., Bjork, J.M., Moeller, F.G., Harper, R.A., Marsh, D.M., Mathias, C.W. \& Swann, A.C. (2003). Además, la impulsividad se asocia al comportamiento agresivo descrito en consumidores de alcohol y otras drogas (Bjork, J. M.; Hommer, D. W.; Grant, S. J.; Danube, C. 2004; Moeller, F.G. et al., 2002; Nielsen, D.A. et al., 2012; Roozen, H. G.; Wetering, B.J. Franken, H.A. 2013).

- La búsqueda de sensaciones, es otro rasgo de la personalidad que frecuentemente se ha asociado con el TCA. Consiste en una necesidad de vivir nuevas experiencias y nuevas sensaciones, a pesar de que este hecho, conlleve exponerse a riesgos físicos y sociales. Existen evidencias de que personalidades con elevados niveles en búsqueda de sensaciones tiene más riesgo de abusar de diversas sustancias (Hittner, J.B.; Swickert, R. 2006; Zuckerman, M. 1994), al igual que niveles bajos estarían asociados al mantenimiento de la abstinencia prolongada (Fein, G.; Di Sclafani, V.; Finn, P. 2010).

Entre los instrumentos que más frecuentemente se han utilizado para evaluar los Rasgos de Personalidad, encontramos el Inventario Multifásico de la Personalidad de Minnesota (MMPI). Diversos estudios señalan la adaptación psicológica precaria que presentan los pacientes con TCA, con una tendencia a presentar puntuaciones elevadas en relación con sentimientos de inferioridad, falta de seguridad y una personalidad introvertida, las cuales se representan principalmente a través de las escalas Hs (histeria), D (depresión), Sc(esquizofrenia) y Ma (manía) (Ávila Escribano, JJ. 1989; Vinet, W.V.; Faúndez, X. 2012), analizaron una muestra de 74 adolescentes y observaron que los varones con consumo problemático de alcohol obtenían diferencias marginalmente significativas en la subescala Ma (manía), en relación con las mujeres, las cuales presentaban puntuaciones significativamente elevadas en la escala Dp (desviación psicópata), frente a la población normal. Por otro lado, 
Monras Arnau (2010), señala como única diferencia entre sexos una puntuación mayor en la subescala Hs (histeria), presentando los varones mayores quejas hipocondríacas.

Podríamos por tanto concluir, que en la actualidad no disponemos de unos rasgos de personalidad adictivos, que predispongan a desarrollar un TCA desde su adolescencia, sin embargo sí encontramos determinados rasgos de personalidad implicados en el inicio del consumo, la perpetuación del mismo y la evolución del tratamiento. Si bien, los resultados de los que disponemos son dispares en relación a su prevalencia, lo cual se debe en parte a la existencia de un bajo grado de concordancia entre los distintos instrumentos de medida, lo que indica una baja fiabilidad en el diagnóstico de estos trastornos, siendo aún mayor con instrumentos de autoinforme, ya que éstos se encuentran condicionados por la subjetividad del evaluado (Fernández-Montalvo, J.; Echeburúa, E. 2006)

\subsection{2.- Tipos de Personalidad en el Trastorno por Consumo de} Alcohol.

Durante años, múltiples estudios han abordado el análisis de los tipos de personalidad en pacientes con TCA (Bravo de Medina, R. et al., 2007; Echeburúa, E.; De Medina, R. B.; Aizpiri, J. 2008).

La comorbilidad del TCA con los TP en población española varían entre el 30 y 80\% (Bravo de Medina, R.; Echeburúa, E.; Aizpiri, J. 2007; MartínezGonzález, J.M.; Graña, J. L.; Trujillo, H. M. 2009; Sánchez-Peña, J. F.; ÁlvarezCotoli, P.; Rodriguez-Solano, J. J. 2012). Estas diferencias de prevalencia, tal y como se ha expuesto anteriormente, se explican en parte por los instrumentos de evaluación, pero otros factores como el tamaño de la muestra, el contexto del estudio (pacientes internos vs. ambulatorios), la distribución por sexos, los criterios de inclusión o exclusión aplicados, el sistema de clasificación empleado, el momento de la evaluación y el marco temporal considerado, también ejercen un papel fundamental (Verheul, Van den Brink y Hartgers, 1995).

Según el último estudio NESARC (2010), los TP más frecuentemente asociados al TCA son el Trastorno Límite de la Personalidad y el Trastorno 
Antisocial (Tabla 17). La prevalencia del TCA en el Trastorno Límite de la Personalidad es dos veces mayor en comparación con otros TP (Walter et al., 2009). Se ha descrito la hipótesis de la existencia de un déficit de opioides en personas con Trastorno Límite de la Personalidad, que explicaría las altas tasas de consumo de alcohol y opiáceos con la mejoría emocional que estas personas experimentarían ante el consumo de estas sustancias (New, A.S.; Stanley, B. 2010).

Tabla 17.- Prevalencia a 3 años de TP en pacientes afectos de TCA. National Epidemiologic Surveys on Alcohol and Related Conditions. (2010).

\begin{tabular}{cccc}
\hline & $\begin{array}{c}\text { Trastorno por consumo de } \\
\text { alcohol }\end{array}$ & $\begin{array}{c}\text { Abuso de alcohol } \\
\text { Personalidad }\end{array}$ & $\begin{array}{c}\text { Dendencia de } \\
\text { alcohol }\end{array}$ \\
$\begin{array}{c}\text { Paranoide } \\
\text { Personalidad } \\
\text { Esquizoide }\end{array}$ & 6,54 & 6,45 & 6,58 \\
Personalidad \\
$\begin{array}{c}\text { Esquizotipica } \\
\text { Personalidad } \\
\text { Antisocial }\end{array}$ & 7,17 & 5,97 & $\mathbf{5 , 8 0}$ \\
Personalidad \\
Límite
\end{tabular}


Langas, A.M. et al. (2012) estudiaron la prevalencia de TP en una muestra de 61 pacientes con trastorno por consumo de sustancias encontrando un $46 \%$ de TP, preferentemente del clúster B, siendo el Trastorno Antisocial y Trastorno Límite los más prevalentes con un porcentaje del $16 \%$ y el $13 \%$ respectivamente.

Otros muchos autores (Preuss et al., 2009; Sclafani, V.; Finn, P.; Fein, G. 2007; Wagner, T.; Krampe, H.; Stawicki, S.; Reinhold, J.; Jahn, H.; Mahlke, K., Barth, U.; Sieg, S.; Maul, O.; Galwas, C.; Aust, C.; Kröner-Herwig, B.; Brunner, E.; Poser, W.; Henn, F.; Rüther, E.; Ehrenreich, H. 2004). sitúan al Trastorno Antisocial entre los TP que más frecuentemente se asocian con TCA. Estos pacientes se caracterizan por presentar una mayor impulsividad, violencia, falta de honestidad y de respeto hacia los demás, incluyendo problemas para controlar el consumo de sustancias.

Además del Trastorno Antisocial de la Personalidad y del Trastorno Límite, otros TP también se ligan frecuentemente al consumo de alcohol, entre los que encontramos, el Trastorno Paranoide (Echeburúa, E. et al. 2007; Preuss, U. W.; Johann, M.; Fehr, C.; Koller, G.; Wodarz, N.; Hesselbrock, V.; Wong, W. M.; Soyka, M. 2009); y el Trastorno Narcisista de la Personalidad (Preuss, U. W., Johann, M., Fehr, C., Koller, G., Wodarz, N., Hesselbrock, V., Wong, W. M., Soyka, M. 2009; Zikos, E.; Gill, K. J.; Charney, D. A. 2010).

Bravo de Medina, R. et al. (2008), en una muestra de pacientes con dependencia al alcohol, subrayan una prevalencia significativamente más alta del Trastorno Paranoide y Narcisista en hombres que en mujeres, donde las mujeres principalmente mostraban TP del clúster C (ansioso-temeroso) y en hombres los más prevalentes pertenecían al clúster B (dramáticos, emocionales y erráticos).

Entre los instrumentos que más frecuentemente se han utilizado para evaluar los Trastornos de Personalidad, encontramos el cuestionario de evaluación IPDE, cuestionario de personalidad SCID, y el Inventario Clínico Multiaxial de Millon (MCMI-II), ampliamente empleados, especialmente en el ámbito de las drogodependencias, y permiten una clasificación categorial de las distintas personalidades de los sujetos. 
Mediante el MCMI-II de Millon, diversos autores llegan a conclusiones similares. Por un lado, Fernández-Montalvo, J. et al. (2002) encontraron que $62.8 \%$ de los pacientes con TCA en tratamiento ambulatorio presentaban al menos un TP. El observado con mayor frecuencia fue el Trastorno PasivoAgresivo en un $34.1 \%$, en segundo lugar se encontraba el Trastorno Antisocial y en tercer lugar el Trastorno Dependiente en un $20.45 \%$ de los casos.

Por otro lado, Fernández-Montalvo, J.; Landa, N.; López-Goñi, J. J.; Lorea, I. (2006), utilizando la misma herramienta, describieron una prevalencia de TP en la muestra con diagnóstico de TCA del $52 \%$ frente a un $18.1 \%$ en la población general, siendo el Trastorno Dependiente el más prevalente en el grupo de TCA con un 16\%. Estos mismos resultados son apoyados por el estudio realizado por Bravo De Medina, R. B.; Echeburúa, E.; Aizpiri, J. (2007). Por otro lado Pedrero-Pérez, E. J.; Puerta-García, C.; Langares-Roibas, A.; Sáez, A.; Maldonado A. (2003) encontraron la presencia del Trastorno Histriónico, Antisocial y Agresivo-Sádico como los trastornos más frecuentes en el grupo de alcohólicos estudiados.

La realidad es que la literatura publicada hasta la fecha es extensa, y los resultados encontrados, ofrecen un amplio abanico en cuanto a lo que a Trastornos de Personalidad se refiere. Esta importante variabilidad atiende a diferentes cuestiones, entre las que destaca el instrumento de medida utilizado. Prueba de ello son las diferentes prevalencias observadas en función del instrumento de evaluación utilizado (Tabla 18).

En conclusión, hoy en día no se ha relacionado de manera inherente un determinado TP que predisponga al desarrollo de un TCA. Este hecho, se debe, en parte a que no existe una validación consistente de las categorías diagnósticas de los Trastornos de Personalidad (TP), lo que pone en duda la fiabilidad diagnóstica de los trastornos e, incluso, su validez como constructo teórico. De hecho, los Trastornos de Personalidad constituyen uno de los puntos más conflictivos de la psicopatología y los intentos de evaluación sistemática de estos trastornos son muy recientes (Echeburúa y FernándezMontalvo, 2006) 
Tabla 18.- Prevalencia de los trastornos de personalidad según los estudios e instrumentos empleados. Landa, N.; Fernández-Montalvo, J.; López-Goñi, J.J.; Lorea, I. (2005)

\begin{tabular}{|c|c|c|}
\hline Autores & Tasa & Instrumento \\
\hline De Jong et al. (1993) & $78 \%$ & SDIP \\
\hline Zimmerman y Coryell (1989) & $43,4 \%$ & SDIP \\
\hline Nurnberg et al. (1993) & $64 \%$ & SCID \\
\hline Pettinati et al. (1999) & $35,6 \%$ & SCID \\
\hline Powell y Peveler (1996) & $24 \%$ & SCID-II \\
\hline Morgenstern et al. (1997) & $57,9 \%$ & SCID-II \\
\hline Verheul et al. (1998a) & $54 \%$ & PDQR \\
\hline Pedrero-Pérez et al. (2003) & $76 \%$ & MCMI-II \\
\hline Fernández-Montalvo et al. (2002) & $64 \%$ & MCMI-II \\
\hline Driessen et al. (1998) & $34 \%$ & IPDE \\
\hline Verheul et al. (1998b) & $31 \%$ & IPDE,CIDI \\
\hline Grant et al. (2004) & $28,6 \%$ & Criterios DSM-IV \\
\hline
\end{tabular}

A pesar de estas dificultades, desde una perspectiva clínica es fundamental llegar a determinar el alcance de la personalidad en los pacientes con TCA, principalmente porque existe cierta evidencia empírica de la influencia de ésta en el pronóstico terapéutico (Cangas y Olivencia, 2001; Nace, Davis y Gaspari, 1991), ya que la comorbilidad de una adicción con una personalidad patológica aumenta considerablemente las dificultades en el manejo clínico de estos pacientes (Cangas y Olivencia). Algunos estudios han encontrado una relación significativa entre la presencia de un determinado Trastorno de Personalidad y el mayor riesgo de recaída en el alcohol o en el abandono del tratamiento (Fernández- Montalvo et al., 2004; Verheul, Van den Brink y Hartgers, 1995). Otros autores, sin embargo, apuntan a la existencia de 
una eficacia terapéutica diferencial en función del tipo concreto de personalidad presente (Poldrugo y Forti, 1988).

\subsection{3.- Estudio de la personalidad mediante el test de Cloninger.}

La gran mayoría de los estudios realizados en pacientes con problemas de adicciones, con la finalidad de conocer sus rasgos de la personalidad, se han realizado a través del inventario de Temperamento y Carácter de Cloninger (TCI), (Cloninger, C.R.; Svrakic, D.M.; Przybeck, T.R. 1993), basado en su modelo psicobiológico de personalidad (Cloninger, 1987). Para Cloninger, la personalidad refleja diferencias en las respuestas de los sistemas neuroadaptativos relacionados con el aprendizaje (Cloninger, C.R. 1994; Cloninger, C.R.; Przybeck, T.R.; Svrakic, D.M.; Wetzel, R.D. 1994; Cloninger, C.R. 1987; Cloninger, C.R.; Svrakic, D.M.; Przybeck, T.R. 1993), medianta dos conceptos principalmente: el concepto de temperamento y el concepto de carácter. (Fig. 24).

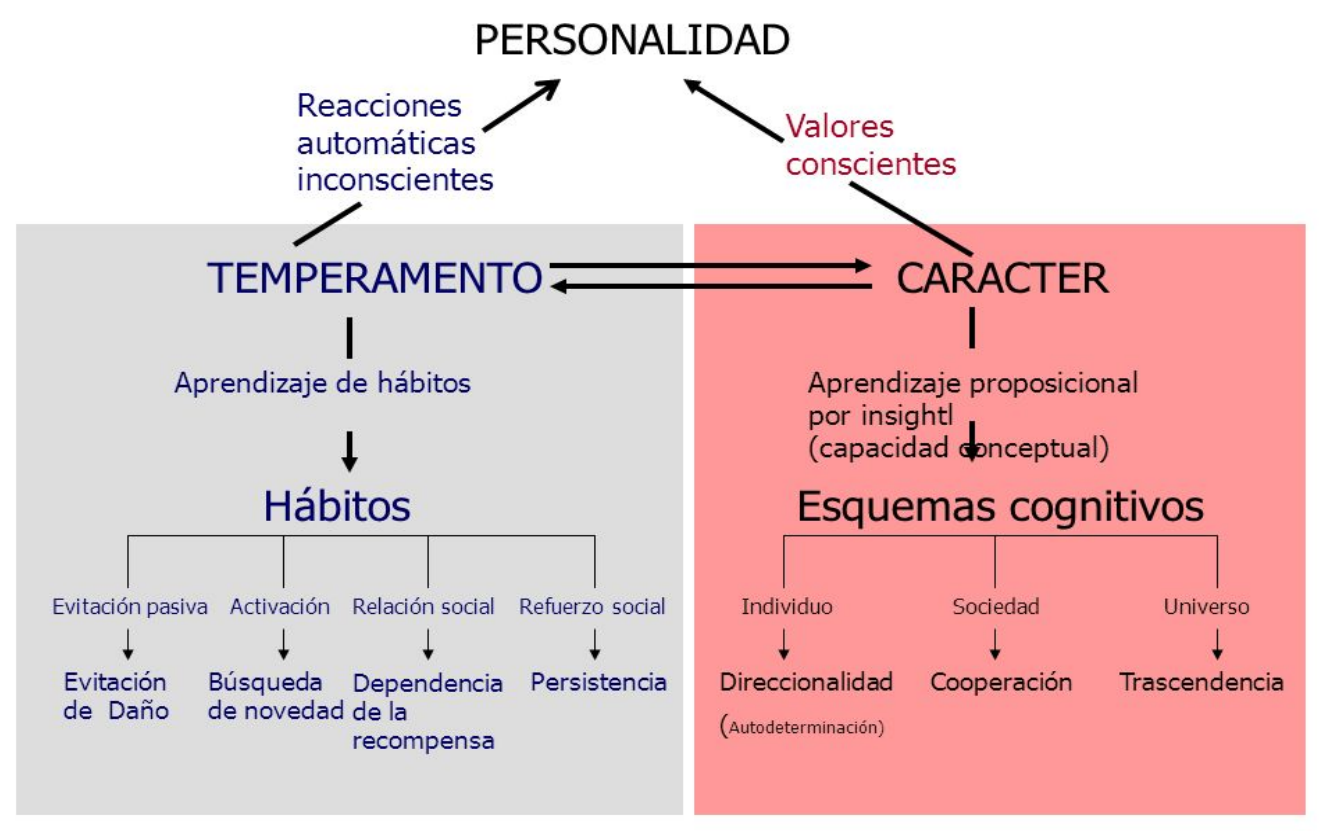

Esquema de la personalidad. Tomado de C. Bayon y R Cloninger

Fig. 24.- Esquema de la Personalidad. Cloninger, R. C.; Bayon, C.; Svrakic, D.M. (1998)

El temperamento o núcleo emocional de la personalidad se define como las diferencias individuales en los hábitos y habilidades relacionados con las emociones, se hereda alrededor de un $50 \%$, es moderadamente estable 
desde la infancia hasta la etapa adulta, y es consistente en su estructura en distintas culturas y grupos étnicos. Se describen cuatro rasgos o dimensiones temperamentales que constituyen diferentes expresiones conductuales, emocionales y/o cognitivas de una misma tendencia o patrón conductual, las cuales son búsqueda de novedad (BN), evitación del daño (ED), dependencia de la recompensa (DR) y persistencia (P) (Flg. 25).

Se ha demostrado en estudios de gemelos que cada una de estas dimensiones es genéticamente homogénea e independiente y se asocia a distintos sistemas de neurotransmisores (Cloninger, C.R. 1998).

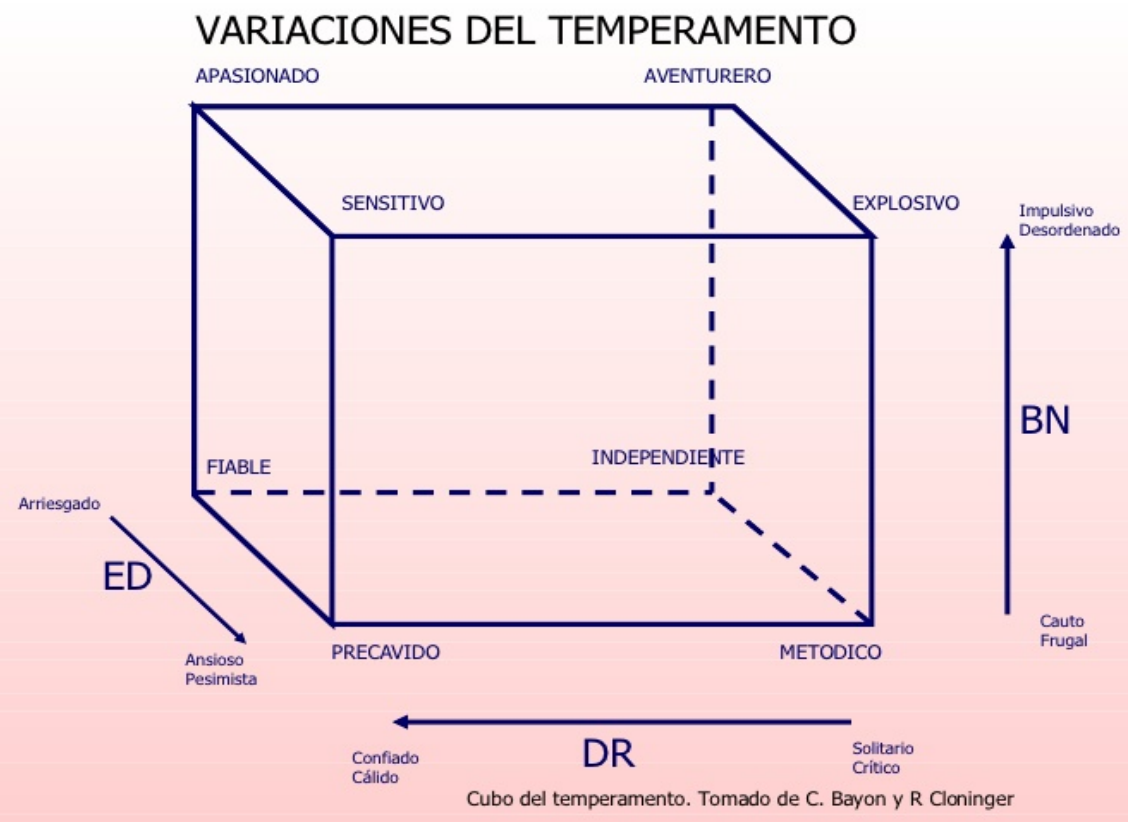

Fig. 25.- Cubo del Temperamento. Cloninger, R. C.; Bayon, C.; Svrakic, D.M. (1998)

Tanto el mecanismo neuroquímico como las aportaciones que estas dimensiones ejercen en el constructo de la personalidad son diversas, entre las características más reseñables en cada una de ellas, encontramos:

- Búsqueda de novedad: tendencia hereditaria hacia la búsqueda de excitación e interés por los estímulos novedosos. Este rasgo está mediado por la dopamina que actúa en el sistema de 
activación conductual o sistema de recompensa, que a su vez se asocia con un patrón de respuesta fisiológica del despertar, aumentando la frecuencia cardíaca y disminuyendo el umbral de sensación. Estas personas serían impulsivas, excitables, curiosas y entusiastas

- Evitación del daño: se trata de la tendencia hereditaria a responder intensamente a señales de estímulos adversos estimulando el sistema de inhibición conductual, probablemente a través de la serotonina. Ejerce una influencia moduladora sobre la respuesta de búsqueda de la novedad $(B N)$. Los sujetos con valores altos en esta dimensión desarrollan respuestas condicionadas de evitación ante estímulos aversivos, lo que hace que sean personas cautelosas, aprensivas y temerosas.

- Dependencia de la recompensa: corresponde a la tendencia a responder intensamente a estímulos o señales de recompensa y a mantener la conducta previamente asociada con dicha recompensa. Esta respuesta está mediada por la noradrenalina en el sistema de mantenimiento o persistencia conductual. Tiene que ver con el refuerzo social y la sensibilidad a los estímulos sociales y al malestar por la separación del grupo.

- Persistencia: la cual implica una tendencia neurobiológica a mantener conductas en condiciones de extinción. Es decir, la capacidad del organismo de seguir emitiendo conductas asociadas al refuerzo a pesar de la desaparición de éste. Estaría asociada a la transmisión serotoninérgica y a los circuitos orbitofrontales.

El carácter o núcleo conceptual de la personalidad se hereda en menor grado y está influido de forma moderada por el aprendizaje social y las expectativas culturales sobre el rol social en relación con la edad, ocupación y otras circunstancias sociales (Cloninger, C.R.; Svrakic, D.M.; Przybeck, T.R. 1993). Está en relación con los procesos cognitivos superiores de la lógica, la construcción, la evaluación y la invención de símbolos abstractos que regulan las diferencias individuales en el procesamiento de metas y valores, y sólo se 
encuentra plenamente desarrollado en individuos maduros. Existen tres dimensiones caracteriales: autodirección (AD), cooperación (CO) y autotrascendencia (AT). Las cuales se caracterizan por:

- Autodirección: se trata de la habilidad de regular la conducta y de comprometerse con las metas elegidas. Se relaciona con la madurez, la autoestima y los recursos generales de adaptación.

- Cooperación: es la capacidad de identificarse y aceptar a los demás. Hace referencia a los comportamientos prosociales del sujeto. Tiene que ver con el altruismo, la empatía y la solidaridad. Es una medida de buena adaptación social.

- Autotrascendencia: representa la capacidad de identificarse como parte integral del universo. Se relaciona con la creatividad, la fantasía y la imaginación (Bordalejo, D.; Boullosa, O.; Hadid, E.; Puricell, M.; Romero, E.; Tannenhaus, L.; Vieitez, A.; Vázquez, G. 2014).

De esta manera, Cloninger ha propuesto un modelo que permite el contraste empírico y el estudio de la contribución diferencial entre elementos genéticos y ambientales a la estructura de la personalidad (Vallejo J.; Leal C. 2012). Es importante resaltar que son las combinaciones de estas variables las que dan lugar a diferentes correlatos de personalidad (Pedrero Pérez, E.J.; Ruiz Sánchez de León, J.M.; Olivar Arroyo, A.; Rojo Mota, G.; Marcos Llanero, L.; Puerta García, C.; 2011).

Los trastornos de personalidad en el modelo psicobiológico de Cloninger se definen como variaciones extremas de los rasgos del temperamento asociados al fracaso para conseguir los logros de identidad, vinculación e intimidad. Son principalmente las dimensiones del carácter, Autodirección y Cooperación, las que determinan la presencia o ausencia del diagnóstico (Bayon, C. 2006).

Svrakic y cols (1993) muestran que puntuaciones bajas en estas dos dimensiones del carácter se correlacionan de forma consistente con un número elevado de síntomas de cualquier trastorno de personalidad y con cada uno de los clusters definidos según el DSM-5. El temperamento resulta esencial en el 
diagnóstico diferencial de los clusters del DSM. El cluster A (Excéntrico) se correlaciona con puntuaciones bajas en Dependencia de la recompensa, el cluster B (dramático) se asocia con puntuaciones elevadas en Búsqueda de novedad y el cluster $C$ (ansioso) se correlaciona con puntuaciones elevadas en Evitación del daño.

En conclusión, la descomposición multidimensional que se obtiene con el TCl-R, permite al clínico describir de forma única a los individuos, facilita el realizar un plan terapéutico más preciso y sobre todo evita el solapamiento diagnóstico que se produce al utilizar clasificaciones categoriales como el DSM. Los trastornos de la personalidad se definen en términos de interacciones dinámicas entre los componentes de un sistema adaptativo complejo. Además, este modelo de 7 factores integra la aproximación categorial y dimensional en el diagnóstico de los trastornos de la personalidad y de este modo sirve, tanto a clínicos (más dados a tener un pensamiento categorial), como a los investigadores (quienes precisan más de una perspectiva dimensional), como una línea prometedora de desarrollo en el avance en la genética y neurobiología de la personalidad (Bayon, C. 2006).

\section{El modelo de Cloninger para el estudio de las adicciones}

El Inventario de Temperamento y Carácter de Cloninger (TCl-R), ha sido ampliamente utilizado en el campo de los trastornos adictivos, tanto en el estudio de diferentes aspectos de éstos como su influencia en la preferencia por determinadas sustancias (Gerdner, A.; Nordlander T.; Pedersen, T. 2002; Le Bon, O.; Basiaux, P.; Streel, E.; Tecco, J.; Hanak, C.; Hansenne, M. et al., 2004), en el consumo de sustancias particulares (Hosak, L.; Preiss, M.; Halir, M.; Cermakova, E.; Csemy, E. 2004), en estudios comparativos entre consumidores de diversas sustancias (Gutiérrez, F.; Sangorrín, J.; MartínSantos, R.; Torres, X.; Torrens, M. 2002), en estudios relacionados con el "craving" (Zilberman, M.L.; Tavares, H.; El-Guebaly, N. 2003), los trastornos de la personalidad (Ball, S.A.; Tennen, H.; Poling, J.C.; Kranzler, H.R.; Rounsaville, B.J. 1997) o la calidad de vida de los adictos (Fassino, S.; Daga, G.A.; Delsedime, N.; Rogna, L.; Boggio, S. 2004). 
De esta manera, la mayoría de los estudios epidemiológicos resalta ciertas características comunes en los pacientes afectos de patología adictiva, en comparación con la población general:

- Búsqueda de novedad (considerada un factor de inicio y de recaída en el consumo), la cual caracterizaría a una población que tiende a usar sustancias para obtener sensaciones nuevas y excitantes.

- Evitación del daño (considerada un factor de mantenimiento del consumo), la cual se relaciona con el mantenimiento de la adicción y la dependencia (Howard, Kivlahan y Walker, 1997). No obstante, la puntuación alta en ED se relaciona con la inhibición de la búsqueda de sustancia y parece más vinculada a determinados subtipos de adictos. Por el contrario, la baja ED se relaciona con un aumento de la apetencia por la sustancia, apareciendo con valores bajos en consumidores de estimulantes y con patrones de abuso más que de dependencia (Dughiero Schifano y Forza, 2001). La ED no parece vincularse a variables de consumo proximales, tales como las expectativas o la cantidad consumida (Galen, Henderson y Whitman, 1996), sino a variables distales, como la evitación del dolor (Pud, Eisenberg, Sprecher, Rogowsk y Yarnitsky, 2004).

- Dependencia de la recompensa: Una elevada puntuación de DR junto a una elevada puntuación de ED y baja de BN se asocia al alcoholismo tipo I de Cloninger, mientras que los valores bajos de DR y ED junto a altos de BN se asocia a alcoholismo tipo II de Cloninger o forma antisocial del alcoholismo (Orengo, T.; M. González, M.; Benito A.; Ballester, F.; Cervera, G.; Haro G. 2007).

- Persistencia: Se ha relacionado principalmente con el grado de abstinencia, de tal manera que a mayores puntuaciones en $\mathrm{P}$, mayor sobriedad (Sellman et al. (1997).

- Autodirección: Puntuaciones bajas en AD se han relacionado frecuentemente, asociadas a una elevada BN y ED, como características de la población con adicción frente a la población sana (Pedrero y Rojo, 2008). 
En términos neuropsicológicos la interpretación de estos datos apunta a relacionar las conductas adictivas con una pérdida de control prefrontal (baja AD) que posibilita las conductas de carácter impulsivo, no orientadas a metas, posiblemente basadas en la actividad del circuito corticoestriatal no regulado (alta BN) y de conductas guiadas por impulsos emocionales, procedentes de la amígdala, que tampoco pueden ser reguladas por el cortex prefrontal (alta ED) (Pedrero, E.; Ruiz, J.M. 2012).

Otras dimensiones de la personalidad también se han relacionado con las conductas adictivas:

- Cooperación: Bajas puntuaciones en CO, asociadas con bajas puntuaciones en $A D$, describen un mayor nivel de gravedad del trastorno en cuanto a un mayor deterioro en el funcionamiento (Cloninger, C. 2000).

- Autotrascendencia: Bajas puntuaciones en AT, acompañadas con elevadas en BN y ED, se han observado más prevalentes en las poblaciones de adictos (Gómez-Perreta, C.; Pérez, M.I.; Portolés, M.; y Salom, R. 2001). A pesar de que Cloninger, relacionase estas puntuaciones con mayor prevalencia de TP, Benito, A.; Haro, G.; Orengo, T.; González, M.; Fornés, T.; Mateu, C. (2012), llegan a conclusiones contrarias.

Diferentes estudios parecen indicar que las sustancias de elección de los sujetos están más relacionadas con sus dimensiones temperamentales que con el carácter (Le Bon, O.; Basiaux, P.; Streel, E.; Tecco, J.; Hanak, C.; Hansenne, M.; 2004). Respecto al temperamento, se observa que cuanto más sustancias adictivas consumen los sujetos, más rígidos e independientes se muestran. Respecto al carácter, los que dependen de más sustancias se sienten más culpables, presentan falta de dirección a metas, no tienen una naturaleza secundaria congruente, poseen menos autodirección, son más intolerantes socialmente, menos serviciales, más vengativos, se auto-sirven y son menos cooperativos. Asimismo, tienden hacia el auto-abandono y presentan más identificación transpersonal y autotrascendencia (Conway, K.P.; 
Swendsen, J.D.; Rounsaville, B.J.; Merikangas, K.R. 2002; Conway, K.P.; Kane, R.J.; Ball, S.A.; Poling, J.C.; Rounsaville, B.J. 2003).

Como conclusión, Orengo, T.; M. González, M.; Benito A.; Ballester, F.; Cervera, G.; Haro G. (2007), encuentran una relación entre la elección de la sustancias de abuso y las variables temperamentales, mientras que la gravedad de la adicción, y, en concreto, la dependencia de varias sustancias estaría más relacionada con variables caracteriales. Esto indicaría que el temperamento influye en la susceptibilidad a desarrollar una dependencia, mientras que el carácter lo haría en el patrón de consumo que se establece.

\section{El modelo de Cloninger en el estudio del TCA}

Cloninger (1987) propone una clasificación del alcoholismo desde su modelo psicobiológico en donde la dependencia del alcohol se explicaría desde un aprendizaje neurobiológico. Supone un intento específico de diferenciar el tipo de dependencia al alcohol más precoz, con mayor carga genética, mayor presencia de psicopatología y, en general, peor pronóstico (Gual, A. 2006). Estudios recientes llevados a cabo en pacientes afectos de un TCA en relación con las diferencias clínicas y temperamentales según haya sido el comienzo temprano o tardío del trastorno dan apoyo a la tipología de Cloninger, mostrando una alta capacidad discriminativa (Se-Won, L.; Kang-Seob, O.; Young-Chul, S. et al., 2008).

Según esta clasificación habría dos tipos fundamentales de pacientes con TCA:

- Pacientes Tipo I: de comiendo tardío a partir de los 25 años, con episodios esporádicos de pérdida de control sobre el consumo, con respuestas a influencias ambientales, sin predisposición previa ni conductas problemáticas asociadas y con predominio de dependencia psicológica más que física.

- Pacientes Tipo II: de comienzo precoz, de rápida evolución, con mayor psicopatología comórbida, asociada con ciertas dimensiones de la personalidad como son la búsqueda de sensaciones, 
impulsividad y escasa evitación del riesgo, predisposición familiar, asociado a conductas conflictivas y problemas judiciales. Según esta clasificación el trastorno antisocial de la personalidad, se asociaría con mayor frecuencia al Tipo II (Echeburúa E. et al., 2008).

Por otra parte, la alta comorbilidad entre TP y TCA ha sido extensamente estudiada. Los pacientes dependientes del alcohol muestran un elevado nivel de impulsividad y de búsqueda de sensaciones, manifiestan una sintomatología ansioso-depresiva elevada y presentan en un $40 \%$ trastornos de personalidad (especialmente, el dependiente, el paranoide y el obsesivocompulsivo) (Bravo de Medina, Echeburúa y Aizpiri, 2007).

En general los resultados obtenidos mediante el inventario TCl-R, muestran una puntuación elevada en evitación del daño (ED) (Monras, M.; Mondon, S.; Jou, J. 2008). Siendo la combinación más frecuentemente encontrada las puntuaciones elevadas en las dimensiones búsqueda de novedad (BN) y evitación del daño (ED) con puntuaciones bajas en autodirección (AD) (Basiaux, P. et al., 2001; Ducci, F. et al., 2007; Nöel, X. et al., 2011; Pedrero, E.J. et al., 2011). Mateos Agut, J. y Mateos Agut, M (2005), además se observan diferencias significativas en cuanto al sexo, en donde los varones con TCA, son más cooperativos y autodirectivos, mientras que las mujeres puntúan más alto en Evitación del Daño y en Dependencia de la Recompensa.

Teniendo en cuenta estos hallazgos, algunos investigadores han identificado dos subtipos de pacientes alcohólicos (Ávila, J.J.; Sánchez, M.; Álvarez, A.; López, A.; Recio, J.; Rodríguez, M.; Fraile E. 2016):

- El subtipo I: se caracteriza por puntuación elevada en ED y DR, y baja en BN, asociado a una importante pérdida de control

- El subtipo II: presenta puntuación elevada en BN y baja en ED y DR (Basiaux et al., 2001; Ducci et al., 2007).

En conclusión, los estudios epidemiológicos publicados hasta la fecha muestran una estrecha relación entre trastornos de personalidad y TCA. Los 
modelos dimensionales de la personalidad, como el de Cloninger, permiten formular diagnósticos capaces de discriminar entre estilos de conducta disfuncionales transitorios y rasgos relativamente más estables. Este hecho permite estudiar la relación entre la personalidad y las características de su consumo: la edad de inicio, la comorbilidad psicopatológica, las características de su consumo, y por tanto de la gravedad de su patología y su probable evolución (Staiger, P.K.; Kambouropoulos, N.; Dawe, S. 2007).

\section{Capacidad de Predicción del modelo de Cloninger en el desarrollo de un TCA}

El valor predictivo de los Trastornos de Personalidad para el desarrollo de un TCA, ha sido objeto de diversos estudios. Se ha observado que determinados rasgos influyen en el inicio y posterior desarrollo de la dependencia del alcohol. Entre estos rasgos dimensionales destacan la impulsividad, búsqueda de sensaciones, la desinhibición y el neuroticismo (Dick et al., 2010; Lejuez et al., 2010; Littlefield, Sher y Wood, 2010; Shin, Hong y Jeon, 2012; Simons, Carey y Wills, 2009).

Algunos autores (Dick et al. 2010; Shin et al., 2012) han estudiado el influjo de la impulsividad en el inicio de los trastornos por uso de alcohol y han comprobado que ésta, y la búsqueda de sensaciones predice un inicio precoz del consumo, así como mayor gravedad del mismo.

El Inventario de Temperamento y Carácter de Cloninger (TCl-R), se ha utilizado como una herramienta predictora ante la posibilidad de padecer un TCA. Se ha observado, en población adolescente que puntuaciones elevadas en impulsividad y búsqueda de sensaciones se asocian al consumo de drogas, tanto en estudios transversales como longitudinales y en diferentes tipos de muestras (clínicas, comunitarias, otras). Un gran número de estudios han encontrado una relación significativa entre las puntuaciones elevadas en búsqueda de sensaciones, y el posterior inicio en el consumo de alcohol (Hicks, Durbin, Bloningen, lacono y McGue, 2011).

Por otro lado, puntuaciones elevadas en Evitación del Daño (Wills et al., 1994; Kuo et al., 2002) y el Sistema de Inhibición Conductual (SIC; Knyazev et al., 2004), han sido inversamente relacionados con el desarrollo de un TCA 
en adolescentes sanos, mientras que las puntuaciones obtenidas en la muestra de adolescentes en tratamiento por abuso de sustancias eran bajas (Gabel et al., 1999). Es decir, las bajas puntuaciones en ED predicen el comienzo más temprano en el consumo de alcohol (Cloninger et al., 1988; Masse and Tremblay, 1997), así como la existencia de un patrón de abuso de alcohol en la edad adulta (Cloninger et al., 1988).

Por el contrario, también existen estudios en los que no se encuentra ninguna relación entre las dimensiones relacionadas con este rasgo y las conductas de consumo de alcohol (Wills et al., 1998; Hill et al., 2000; Kuo et al., 2002; Knyazev et al., 2004).

A pesar de recibir algunas críticas por la inconsistencia de su formulación neurobiológica (Paris, 2005), el modelo de Cloninger ha resultado ser de los más útiles en la clínica (Cloninger, 2006), y su instrumento, el TCI-R, el mejor predictor de trastornos de personalidad en adicciones (Grucza, R.A.; Goldberg, L.R. 2007).

\section{Evolución del TCA según el modelo de Cloninger}

En cuanto a la evolución y pronóstico Pedrero et al. (2011) han señalado, que una baja puntuación en AD se correlaciona con déficits prefrontales que inciden en la errónea toma de decisiones e incapacidad para controlar los efectos reforzantes del alcohol, factores que mantienen la dependencia y son un riesgo para la recaída, relacionando por tanto, dichas puntuaciones con una peor evolución. Estos trabajos establecen una posible relación entre los distintos tipos de pacientes, en función de las combinaciones de sus rasgos de personalidad, la sintomatología frontal presentada y la neurobiológica que la justifique, permitiendo así conocer de antemano su evolución (Figura 26). 


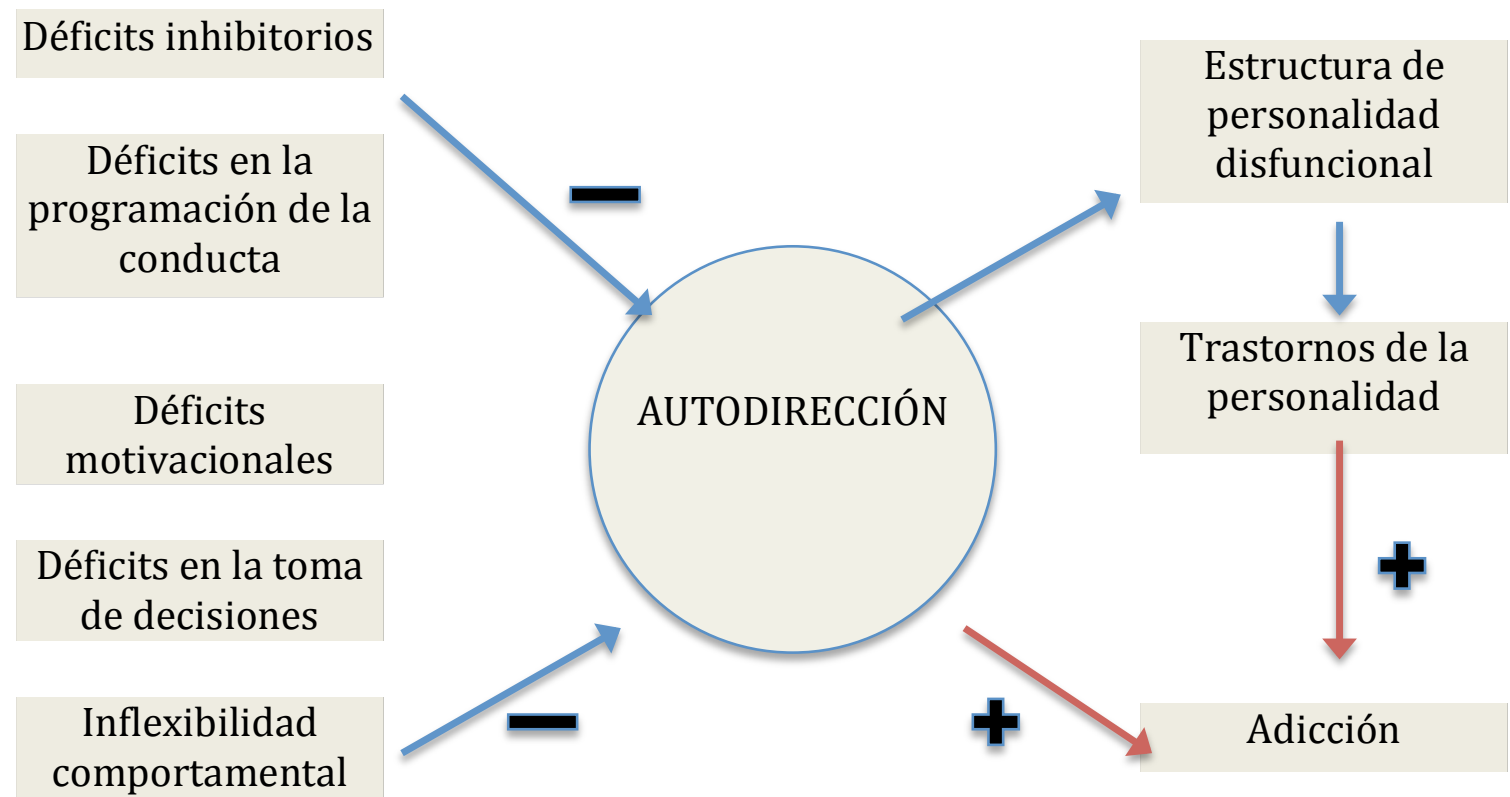

Figura 26.- Relación entre variables de diversos ámbitos conceptuales. Pedrero et al. (2011)

En los últimos años se está haciendo hincapié en este último aspecto (deterioro cognitivo y déficit del control de impulsos por lesiones en la corteza prefrontal), describiéndose en algunos artículos alteraciones específicas entre la función ejecutiva-cognitiva, una puntuación elevada en BN y la toma de decisiones bajo presión en pacientes con TCA, lo cual favorecería el mantenimiento de la conducta adictiva (Nöel, X., et at 2011).

Por otro lado, respecto a la evolución de pacientes con TCA, en función de su personalidad, encontramos escasa literatura. Monras, M.; Mondon, S.; Jou, J. (2008), hallaron, en su investigación, que los pacientes con puntuaciones elevadas en persistencia (P), autodirección (AD) y cooperación (CO) evolucionaban mejor. Sin embargo, Ávila J.J.; Pérez, A.; Rodríguez, M.; Recio, J.; Fraile, E. (2012), encontraron que la abstinencia estaba fuertemente relacionada con menor puntuación en búsqueda de novedad (BN) y puntuación elevada en trascendencia (T). Finalmente, Nöel,X. et al. (2011) concluyeron, con los resultados de su investigación, que los sujetos dependientes del alcohol con puntuaciones elevadas en búsqueda 
de novedad (BN) tomaban decisiones erróneamente y eran más propensos a recaer.

Recientemente Ávila, J.J.; et al (2016), en una muestra de 237 pacientes, observaron que el grupo que presentaba mayores tasas de abandono, obtenía una puntuación en BN, significativamente más elevada ( $p=.004)$ que el grupo que seguía en tratamiento, mientras que puntuaciones bajas en la dimensión BN incrementa la retención en el tratamiento, y por tanto una mejor evolución.

Otros autores también observan que puntuaciones elevadas en BN estaban relacionadas con una menor adherencia al tratamiento (Evren, C.; Durkaya, M.; Evren, B.; Dalbudak, E.; Cetin, R. 2012; Kravitz, H. M.; Fawcett, J.; McGuire, M.; Kravitz, G. S.; Whitney, M. 1999). Sin embargo, Monras, M. et al. (2008), en un estudio realizado en nuestro país, encontraron que la puntuación alta en $\mathrm{P}, \mathrm{CO}$ y AT favorecía la continuidad del tratamiento.

En definitiva, parece que puntuaciones elevadas en $\mathrm{BN}$, están fuertemente relacionadas con una tendencia a mantener la conducta adictiva, a presentar mayores tasas de abandono de tratamiento y mayor frecuencia de recaídas en el consumo de alcohol, es decir, estos resultados elevados permiten prever una peor evolución del TCA. Por el contrario, aunque menos desarrollado, también existe una relación entre puntuaciones elevadas en las dimensiones de $\mathrm{P}$ y $\mathrm{CO}$, y una mejor evolución de la patología adictiva en este subtipo de pacientes, a través de una mayor adherencia al tratamiento y el mantenimiento de la abstinencia.

\section{Gravedad de los TCA según el modelo de Cloninger}

De importante interés clínico y menos analizado, es la relación entre la personalidad y la gravedad del TCA. Echeburúa, E.; De Medina, R. B.; Aizpiri, J. (2008), analizaron una muestra de 158 pacientes con dependencia de alcohol, y comprobaron que aquellos pertenecientes al subtipo II de Cloninger, con puntuaciones más elevadas en $\mathrm{BN}$, correspondían a pacientes con mayor gravedad de su TCA.

Pedrero, E. J.,; Ruiz, J. M.; Olivar, A.; Rojo, G.; Llanero, M.; Puerta, C., en un estudio publicado en 2011, señalaron que los pacientes con elevadas 
puntuaciones en ED, mediante sus conductas favorecerían el mantenimiento de la adicción y bloquearían los intentos de alcanzar la abstinencia por temor a sus consecuencias. Estos pacientes obtienen las puntuaciones de gravedad más importantes (criterios ASI), e inician el consumo a edades tempranas.

Por otro lado, los pacientes con elevada BN, muy baja DR, también mostrarían valores de gravedad intensa e inicio temprano, describiendo además patrones de personalidad y consumo estrictamente patológicos.

Por último, aquellos pacientes caracterizados por una baja $A D y$, solo una leve elevación de sus puntuaciones en $\mathrm{BN}$ y puntuaciones críticamente bajas en $\mathrm{CO}$; presenta un TCA de moderada gravedad e inicio temprano del consumo.

Para Evren, C.; Durkaya, M.; Evren, B.; Dalbudak, E.; Cetin, R. (2012), según su estudio sobre una muestra de 102 pacientes ingresados, las puntuaciones elevadas en $\mathrm{BN}$, implican además de un inicio temprano en el consumo, la ingesta de una mayor cantidad de alcohol. Concluyen, además, que existe una importante relación entre estas puntuaciones y una mayor impulsividad, y deseo de consumo ("craving"). Lo cual conlleva una mayor gravedad de su dependencia.

Tal y como se concluye de lo expuesto anteriormente, la literatura que se nos proporciona en torno al TCA y los trastornos de personalidad más prevalentes, según la tipología de Cloninger, es extensa y plural.

La totalidad de los estudios publicados hasta la fecha, muestra una relación entre puntuaciones elevadas en $\mathrm{BN}$ y una mayor gravedad del TCA, pero dicha literatura, es escasa y no permite obtener nuevas conclusiones referentes a la gravedad de estas patologías y su relación con el modelo psicobiológico de Cloninger. El objetivo del presente trabajo, es por tanto, poder esclarecer un patrón de personalidad y tal vez sociodemográfico asociado a una mayor gravedad del TCA, lo cual nos permitiría focalizar un mayor esfuerzo terapéutico en aquellos pacientes susceptibles de un mayor consumo, un mayor deseo por el alcohol y unas tasas mayores de abandono y recaída en su trastorno. Este hecho supone, además la posibilidad de ser más eficientes en el tratamiento del TCA y por tanto, en la utilización de los recursos clínicos disponibles. 
Objetivo e hipótesis 
Influencia de la Personalidad en la Gravedad de los Trastornos por Consumo de Alcohol 


\section{3.- OBJETIVO E HIPÓTESIS}

Durante la redacción de este trabajo, hemos encontrado múltiples variables orientadas a determinar la gravedad que puede existir en el Trastorno por Consumo de Alcohol (TCA). Por este motivo, según la bibliografía, se establecen parámetros de naturaleza diversa con la finalidad de obtener una estimación global de la gravedad existente en el TCA (Valencia Martín J.L., González M.J., Galán I. 2014), los cuales han sido tenidos en cuenta durante la elaboración del presente trabajo: entrevista semiestructurada, variables biológicas, escala EuropAsi, escala EIDA y escala OCDS. Además hemos utilizado el Test de Personalidad de Cloninger, TCI-R, para llegar a cabo el objetivo de nuestro estudio.

La personalidad del paciente con TCA, ha sido sujeto de estudio en incalculables ocasiones, tal vez debido a la elevada comorbilidad entre ambos diagnósticos, en relación con la población sana. A pesar de lo cual, los resultados no son del todo concluyentes. Basándonos en este hecho, hemos elaborado las siguientes hipótesis de estudio:

\section{Hipótesis 1:}

La personalidad, según la tipología de Cloninger, influye en la gravedad del Trastorno por Consumo de Alcohol, independientemente del sexo de la persona.

\section{Hipótesis 2:}

Una puntuación elevada en los rasgos temperamentales (búsqueda de novedad, evitación del daño, dependencia de la recompensa y persistencia) está relacionada con mayor gravedad del Trastorno por Consumo de Alcohol, y viceversa. 


\section{Hipótesis 3:}

La puntuación elevada en los rasgos caracteriales (autodirección, cooperación y trascendencia) está relacionada con menor gravedad del Trastorno por Consumo de Alcohol, y viceversa.

\section{Hipótesis 4:}

La relación de la personalidad según el TCI-R de Cloninger, con la gravedad del TCA, está mediada por el sexo.

Por todo lo expuesto anteriormente, y remitiéndonos al trabajo que nos ocupa, los objetivos de nuestro estudio son los siguientes:

1.- Conocer las características de los pacientes de la muestra y el patrón de consumo de alcohol (edad de inicio, edad de inicio del consumo patológico, tiempo de evolución, duración del consumo patológico, intensidad del mismo y gravedad de deseo -“craving"-, etc.), que presentan.

2.- Clasificar los pacientes seleccionados para el estudio en función de las características de su personalidad, según el cuestionario de Cloninger y analizar las diferencias por sexo.

3.- Analizar la gravedad de la dependencia al alcohol, en los pacientes de nuestro estudio, según el Índice Europeo de la Gravedad de la Adicción (EuropAsi).

4.- Analizar la intensidad de la dependencia de alcohol, según la Escala de Intensidad de la Dependencia de Alcohol (EIDA) y el componente obsesivo y compulsivo del deseo de consumo (OCDS) en los pacientes del estudio. 
5.- Analizar la relación entre la personalidad, según el cuestionario de personalidad de Cloninger, y la gravedad del trastorno del consumo de alcohol según el EUROPASI.

6.- Analizar la relación entre la personalidad, según el cuestionario de personalidad de Cloninger, y la intensidad de la dependencia de alcohol y el componente obsesivo y compulsivo del deseo de consumo.

7.- Analizar la relación de las categorías de personalidad en la gravedad, intensidad y componente obsesivo y compulsivo del consumo de alcohol.

8.- Analizar la influencia del sexo en la relación de las características de personalidad del cuestionario de Cloninger y la gravedad, intensidad y componente obsesivo y compulsivo del consumo de alcohol. 
Influencia de la Personalidad en la Gravedad de los Trastornos por Consumo de Alcohol 
Material y método 
Influencia de la Personalidad en la Gravedad de los Trastornos por Consumo de Alcohol 


\section{4.- MATERIAL Y MÉTODO}

\section{1.- Muestra y procedimiento}

El estudio se ha realizado en la Unidad de Trastornos por Consumo de Alcohol (UTA) de Salamanca, ubicada en el Paseo de San Vicente. Los datos clínicos relevantes proceden de la entrevista clínica realizada por el médico responsable de la unidad, a través de la cual aquellos pacientes con dificultades para la realización de la entrevista o que no desearan formar parte del estudio, no se incluyeron en el mismo. El periodo de inclusión de pacientes comprendió desde Noviembre de 2012 hasta Diciembre de 2015.

Se trata de un estudio transversal, observacional y descriptivo, con los siguientes criterios de inclusión:

- Nuevos pacientes procedentes de la Unidad de Trastornos por Consumo de Alcohol de Salamanca.

- Pacientes con diagnóstico de Trastorno por Uso de Alcohol.

- Pacientes cuya edad se encuentra comprendida entre los 18 años de edad y los 70 años de edad

- De ambos sexos.

- Pacientes que hayan decidido colaborar de manera voluntaria.

Constituyeron criterios de exclusión:

- Pacientes con consumo añadido de otras sustancias.

- Pacientes con dificultades cognitivas que impiden la correcta recogida activa de datos.

- Analfabetismo

- Pacientes menores de 18 años.

- Pacientes con comorbilidad con Trastornos Psicóticos.

En relación al procedimiento, los pacientes que acudían a consulta por primera vez a la U.T.A. fueron entrevistados por el médico responsable de la unidad, siguiendo el mismo procedimiento que cualquier paciente. En esta primera consulta se realiza una evaluación inicial, recogida de datos y solicitud de pruebas complementarias (hemograma, bioquímica y perfil hepático con 
GGT, GOT y GPT), estos marcadores biológicos se corresponden con los denominados indicadores indirectos, que reflejan el daño orgánico producido por el consumo de alcohol de forma crónica.

Posteriormente se valora la posibilidad de incluir al paciente en el estudio, a través de los criterios de inclusión y exclusión. Si el paciente es considerado apto para el estudio, se le deriva al "médico evaluador" para incluirlo en el mismo.

Una vez en contacto con el médico evaluador, los pacientes realizaban dos entrevistas con éste, de alrededor de 45 minutos de duración cada una, como requisito previo a la inclusión en el estudio. De este modo, se comprueba que el paciente cumple los criterios de inclusión, así como se descarta la existencia de criterios de exclusión.

Durante la primera visita con el médico evaluador, los pacientes fueron informados de las pruebas que se iban a realizar, el propósito del estudio y los tests a cumplimentar. En esa misma consulta, se recabó su colaboración voluntaria y se les aseguró que los datos serían utilizados exclusivamente con fines científicos, garantizándoles la confidencialidad.

Además, se les pedía que trataran de responder lo más sinceramente posible, teniendo en cuenta las limitaciones que su enfermedad les originaba en ese momento.

Una vez que los pacientes habían dado su consentimiento, recibieron las pruebas acordadas. En la primera entrevista, cumplimentaban la escala EuroPASI, de manera heteroaplicada, y el cuestionario de personalidad TCI-R, de manera autoaplicada, en el cual los pacientes empleaban unos 60-120 minutos en contestar. Todos aquellos que no entendían las preguntas, se fatigaban en su respuesta y/o daban respuesta erróneas en las preguntas de control, eran excluidos.

En la segunda visita, durante alrededor de 45 minutos, se evaluaban los aspectos de consumo de alcohol y otras sustancias, aspectos médicos y psiquiátricos y se les administraba el cuestionario EIDA de manera autoaplicada, y OCDS de "craving". Los pacientes que consumían otras sustancias, principalmente cocaína y/o cannabis eran excluidos. 
Las escalas fueron cumplimentaron, en uno de los despachos de la U.T.A.

Durante todo momento, la asistencia clínica de los pacientes, no sufrió ningún tipo de altercado, manteniendo su seguimiento y tratamiento de manera habitual.

\section{2.- Batería de instrumentos}

La batería de instrumentos quedó formada por las siguientes pruebas:

\subsection{1.- Entrevista semiestructurada}

En la entrevista semiestructurada se recogían por el médico responsable ciertos datos relevantes como: datos sociodemográficos (residencia, estado civil, estudios y situación laboral), patrón de consumo, características de consumo y psiquiátricas, tipo de bebida alcohólica, gramos de alcohol, síntomas de abstinencia (crisis convulsivas, alucinaciones, "delirium tremens"), polineuropatía y palimpsestos. Además se valoraba el estado psicopatológico del paciente, el tiempo de evolución de su patología, diagnóstico de TCA y de patologías comórbidas y finalmente el grado de motivación para el tratamiento y el tipo del mismo.

Finalmente los pacientes eran citados con el médico evaluador para llevara cabo el resto de baterías instrumentales.

\subsection{2.- Escala EuropAsi adaptada (Índice Europeo de la Gravedad de la Adicción)}

El EuropASI es la versión europea de la $5^{a}$ versión del ASI (Addiction Severity Index, Índice de Gravedad de la Adicción) desarrollada en Estados Unidos por McLlellan (1990) (McLellan AT et al 1992). El ASI fue creado en 1980 en la Universidad de Pensilvania (McLellan AT et al, 1980), con el 
objetivo de obtener un instrumento que permitiese conseguir información relevante para la evaluación clínica inicial de los pacientes con problemas de abuso de drogas.

El EuropASI es un instrumento básico para la práctica clínica, ya que permite realizar un diagnóstico multidimensional de los problemas de adicción, evaluar su gravedad y ponerlos en un contexto bio-psico-social. Este instrumento evalúa distintos aspectos de la vida de los pacientes que se han podido afectar por la patología adictiva. En concreto, explora las siguientes seis áreas de la vida potencialmente problemáticas:

- Salud física (16 ítems)

- Empleo / Recursos (26 ítems)

- Drogas / Alcohol (28 ítems)

- Situación legal (23 ítems)

- Historia familiar (51 ítems)

- Relaciones familiares / Sociales (26 ítems)

- Salud mental (22 ítems)

El EuropASI tiene la misma estructura para todas las áreas (GarcíaPortilla MP, et al 2006): ítems objetivos, autoevaluación del paciente, evaluación de la gravedad por parte del entrevistador y puntuación de validez de la información obtenida, realizada también por el entrevistador.

La parte inicial de ítems objetivos trata de percibir los problemas reales que tiene el paciente en ese área. La escala de autoevaluación del paciente está compuesta por dos ítems que evalúan las molestias o preocupaciones y el grado de importancia del tratamiento por parte de éste. Para realizar estas evaluaciones subjetivas los pacientes utilizan una escala tipo Likert de 5 puntos, donde: $0=$ Nada $\circ$ Ninguna $/ 1=$ Leve $/ 2=$ Moderada $/ 3=$ Considerable / 4 = Extrema. La tercera sección corresponde a la evaluación de la gravedad de esa área, que realiza el investigador. 
El rango de las puntuaciones posibles de gravedad para cada una de las diferentes áreas problema, oscila entre 0 (ausencia del problema) y 9 (problema extremo):

0-1: No hay problema real, y no está indicado el tratamiento, ayuda o diagnóstico.

2-3: Problema leve, no es necesario el tratamiento, ayuda o diagnóstico.

4-5: Problema moderado, está indicado algún tipo de tratamiento, ayuda o diagnóstico.

6-7: Problema considerable, el tratamiento, ayuda o diagnóstico es necesario .

8-9: Problema extremo, el tratamiento, ayuda o diagnóstico es absolutamente necesario.

De esta manera se obtiene un perfil de la gravedad del paciente en cada una de las áreas problema y podemos establecer un proceso de intervención uniforme que garantice el equilibrio entre las diferentes áreas de la vida del paciente que tradicionalmente están ligadas a los problemas de adicción (Bobes J, 2007).

La combinación selectiva de ítems de cada una de las áreas problemáticas del ASI ha dado lugar a medidas generales del estado del paciente en cada área, denominadas puntuaciones compuestas 0 “composites scores". Estas medidas han demostrado fiabilidad y validez en varios escenarios. Cada "composites scores" es la suma de las respuestas a varias preguntas dentro de un área de la escala ASI, ajustándose cada área en función del número total de elementos que la componenen, mediante la utilización de una fórmula matemática (McGahan, P.L.; Griffith, J. A.; Parente, R.; McLellan, A.T. 1986). 


\subsection{3.- Escala EIDA (Escala de Intensidad de la Dependencia de} Alcohol)

Se trata de un instrumento de medida autoaplicado. Derivado del SADQ (Cuestionario sobre la Gravedad de la Dependencia al Alcohol). En esta escala el periodo evaluado corresponde los últimos 6 meses ( Rubio G, et al 1998) ( Bobes J et al. 2002).

La escala EIDA está compuesta por subescalas: síntomas físicos de abstinencia, síntomas psicológicos de abstinencia, conductas para aliviar los síntomas de abstinencia, consumo habitual de alcohol, dificultad para controlar la ingestión y reinstauración de la sintomatología tras la recaída. Permite distinguir entre dependencia leve, moderada y grave. Su corrección se realiza siguiendo estas indicaciones:

- En los ítems 1-25 se emplea una escala de frecuencia de cuatro puntos: 0 (nunca o casi nunca), 1 (a veces), 2 (frecuentemente) y 3 (casi siempre).

- Las preguntas 23, 24 y 25 puntúan inverso: 3, 2, 1, 0.

- En los ítems 26 a 30 se emplea una escala de intensidad: 0 (nada), 1 (un poco), 2 (moderadamente) y 3 (bastante).

- Una puntuación menor de 21 indicaría dependencia leve.

- Entre 21 y 37 puntos indicaría dependencia moderada.

- Una puntuación superior a 37 sería indicio de dependencia grave (Iraurgi I, et al. 2002).

Esta escala ha sido validada en nuestro medio por Rubio G., Urosa B., Rubio M.C., Ulibarri S., y Mata F., (1996). 


\subsection{4.- Cuestionario sobre los componentes obsesivo-compulsivos de la bebida (OCDS)}

El cuestionario OCDS ("Obsesive Compulsive Drinking Scale") ha sido validado en nuestro medio por Rubio y López Ruiz (1999). Evalúa a la intensidad de los componentes obsesivo (preocupación por la bebida) y compulsivo (consumo de alcohol) de la bebida. Según este modelo, ambos componentes tienen su base común en el deseo ("craving"). Este cuestionario aborda el alcoholismo bajo el modelo del trastorno obsesivo compulsivo. Es un instrumento autoaplicado de 14 preguntas relacionadas con la idea de beber, la interferencia que dichas ideas ocasionan en el sujeto, la resistencia al consumo, la frecuencia de consumo y la interferencia que dicho consumo ocasiona en el sujeto. Cada pregunta tiene cinco posibles respuestas tipo Likert, que se puntúan de 0-4. La adaptación española aporta buenas propiedades psicométricas, con un coeficiente de consistencia interna de 0,89, una fiabilidad test-retest de 0,95 y validez convergente de $\rho=0,53$ con el IADS (Bobes Bascarán M.T., García-Portilla González M.P., 2013).

\subsection{5.- Cuestionario TCI-R (Cuestionario de temperamento y carácter de Cloninger, versión revisada).}

El Inventario de Temperamento y Carácter de Cloninger (TCl-R), es uno de los instrumentos más utilizados en el campo de los trastornos adictivos. Este autor propone un modelo psicobiológico de personalidad, que está formada por temperamento y carácter (Cloninger, Svrakic y Przybeck, 1993). El temperamento se refiere a las diferencias individuales en la intensidad de las respuestas automáticas y emociones básicas que son estables a lo largo de la vida, están determinadas genéticamente y presentan una correlación, más o menos específica, con determinadas áreas cerebrales. El autor distingue cuatro rasgos o dimensiones temperamentales que son búsqueda de novedad (BN), 
evitación del daño (ED), dependencia de la recompensa (DR) y persistencia (P). El carácter se refiere al conjunto de valores y metas individuales que influyen en la conducta de los sujetos y se desarrollan con la maduración y el aprendizaje. Existen tres dimensiones caracteriales: autodirección (AD), cooperación (CO) y autotrascendencia (AT) (Cloninger et al., 1993; Wong y Cloninger, 2010) (Ávila JJ et al 2015).

La escala está compuesta por 240 ítems que se responden en una escala Likert de 5 opciones: 1 = Falso $/ 2$ = Casi todo probablemente falso $/ 3=$ Igual cierto que falso $/ 4=$ Casi seguro 0 probablemente seguro $/ 5=$ Verdadero. Puntuándose cada una de las dimensiones de temperamento y carácter, en función de un número variable de subescalas, entre 3 y 5.

Para el inventario TCI se utilizó la versión revisada española (TCl-R) de Bayón (2004) y validada en nuestro país por Gutiérrez-Zotes et al., (2004). En dicha versión la puntuación de cada rasgo es transformada en puntuación "T" (percentiles). Wong et al., (2010) definen como rasgos prominentes aquellos que están en el tercio superior (percentil 67) o en el tercio inferior (percentil 33).

\section{3.- Búsqueda bibliográfica}

La búsqueda de la literatura científica se ha realizado de forma retrospectiva a través de bases de datos referenciales como PubMed (MEDLINE), Cochrane Library, Google Scholar y Scielo. Otras fuentes documentales han sido textos, manuales y monografías, algunos de ellos electrónicos, citados en el apartado de referencias bibliográficas, al final de este trabajo.

\section{4.- Análisis de datos}

A continuación describimos el análisis estadístico realizado. 


\section{Estadística descriptiva}

En todos los casos se ha comprobado la normalidad de las variables con el Test de Kolmogorov-Smirnov. Las variables cuantitativas fueron expresadas como media \pm desviación estándar y variables cualitativas fueron expresadas como número y porcentaje.

\section{Análisis bivariantes}

Se utilizó el Test Chi Cuadrado para analizar la asociación entre variables cualitativas. Mediante los Test T de Student o U Mann Whitney, según la normalidad de las variables, se comparó la media entre dos grupos y en el caso de que el número de grupos fuera mayor se realizó un análisis de la varianza mediante (ANOVA) y el Least significant difference (LSD) en los contrastes a posteriori.

Para analizar la relación entre dos variables cuantitativas se utilizó la Correlación de Pearson o Spearman en función de la normalidad de cada variable.

\section{Análisis multivariante}

En el análisis multivariante se ha utilizado el análisis de regresión lineal múltiple, mediante el modelo general lineal multivariante (GLM), para analizar la relación de la personalidad con la gravedad, intensidad y componente obsesivo compulsivo del consumo ajustado por edad y sexo. Este modelo también se utilizó para analizar la interacción del sexo con los diferentes aspectos de la personalidad para evaluar su influencia en la gravedad, intensidad y componente obsesivo compulsivo del consumo.

En todos los casos, para los contrastes de hipótesis se fijó un riesgo alfa de 0,05 como límite de significación estadística. El programa estadístico utilizado fue el IBM Statistical Package for the Social Sciences (SPSS) versión 23.0 (IBM Corp, Armonk, NY, USA). 
Influencia de la Personalidad en la Gravedad de los Trastornos por Consumo de Alcohol 
Influencia de la Personalidad en la Gravedad de los Trastornos por Consumo de Alcohol

Resultados 
Influencia de la Personalidad en la Gravedad de los Trastornos por Consumo de Alcohol 


\section{5.- RESULTADOS}

En este capítulo, procederemos a realizar una exposición de los resultados obtenidos, tras el análisis de cada uno de los objetivos que inicialmente nos propusimos estudiar. De esta manera obtendremos las características sociodemográficas de la muestra estudiada, las variables clínicas y de consumo relacionadas con la gravedad del TCA (cantidad de alcohol consumida, duración del consumo, existencia de tratamientos previos, tipo de consumo, etc), y las variables instrumentales relacionadas con el mismo (puntuación de la severidad médica y psiquiátrica de la escala EuropAsi, intensidad de la dependencia mediante la escala EIDA, deseo por el alcohol cuantificado mediante la escala OCDS, etc.).

\section{1- Objetivo 1}

Conocer las características de los pacientes de la muestra y el patrón de consumo de alcohol que presentan.

La muestra está compuesta por 304 pacientes afectos de Trastorno por Consumo de Alcohol (TCA), que acuden a la Unidad de Trastornos por consumo de alcohol de Salamanca, de los cuales 250 eran varones (82,2\%), y 54 mujeres (17,8\%). (Fig.27).

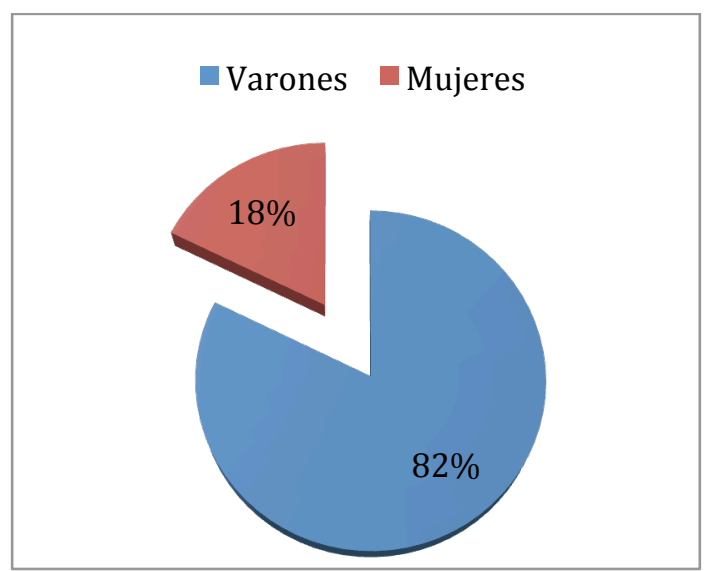

Fig. 27.- Distribución en sexo 
Edad: En nuestro estudio, la edad media de los varones era de 43,6 años (DE 9,7); y en el caso de las mujeres de 43,8, (DE 9,8). El intervalo de edad más frecuente estaba comprendido entre los 41 y los 50 años $(39,80 \%)$, siendo la edad máxima de 71 años y la mínima de 19. (Tabla 19 y Figura 28).

Tabla 19.- Edad de la muestra

\begin{tabular}{clcccccc}
\hline & \multicolumn{2}{c}{ Hombres } & \multicolumn{3}{c}{ Mujeres } & \multicolumn{3}{c}{ Total } \\
\hline & Media & DE & Media & DE & Media & DE & P \\
Edad & 43,6 & 9,7 & 43,8 & 9,8 & 43,6 & 9,7 & 0,903 \\
\hline
\end{tabular}

18-20 años $\quad$ 21-30 años $\square$ 31-40 años $\quad$ 41-50 años $\quad$ 51-60 años $\square$ 61-71 años2

Fig. 28.- Distribución de edad

Procedencia: La mayoría de los pacientes provenía del entorno urbano, un total de 193 (63,5\%), de los cuales 155 (62,0\%), eran varones y 38 (70,4\%), eran mujeres. Mientras que del entorno rural provenían 111 pacientes $(36,5 \%)$, de los que 95 (38,0\%), eran varones y 16 (29,6\%), eran mujeres (Tabla 20; Fig. 29).

Tabla 20.- Procedencia de la muestra

\begin{tabular}{cccccccc}
\hline & \multicolumn{2}{c}{ Hombres } & \multicolumn{2}{c}{ Mujeres } & \multicolumn{2}{c}{ Total } \\
\hline Procedencia & $\mathrm{N}$ & $\%$ & $\mathrm{~N}$ & $\%$ & $\mathrm{~N}$ & $\%$ & $\mathrm{P}$ \\
Urbano & 155 & $62,0 \%$ & 38 & $70,4 \%$ & 193 & $63,5 \%$ & 0,278 \\
Rural & 95 & $38,0 \%$ & 16 & $29,6 \%$ & 111 & $36,5 \%$ & \\
\hline
\end{tabular}




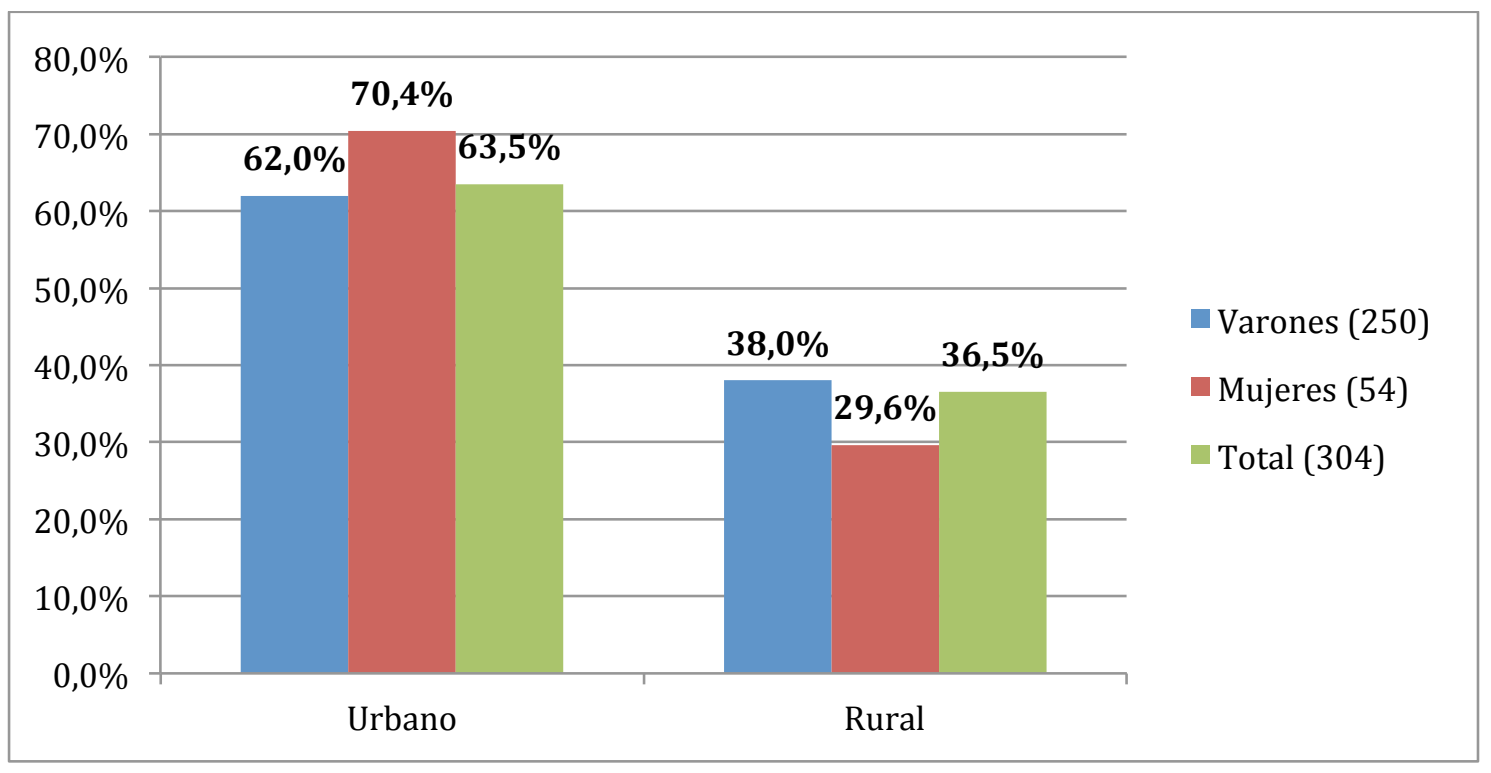

Fig. 29.- Procedencia

Estado civil: Del total de pacientes, 86 de ellos (28,4\%), estaban solteros, $163(53,6 \%)$ tenían pareja, y $54(17,8 \%)$ estaban separados. 71 hombres estaban solteros (28,4\%); 137 tenían pareja (54,8\%); 42 (16,8\%), estaban separados y no había ningún viudo. 15 mujeres estaban solteras (27,8\%), 26 tenían pareja (48,1\%); una estaba viuda (1,9\%); y $12(22,2 \%)$, estaban separadas (Tabla 21 y Figura 30).

Tabla 21.- Estado civil

\begin{tabular}{ccccccccc}
\hline & & \multicolumn{2}{c}{ Hombres } & \multicolumn{2}{l}{ Mujeres } & \multicolumn{2}{l}{ Total } \\
\hline \multirow{3}{*}{ Estado } & Soltero & $\mathrm{N}$ & $\%$ & $\mathrm{~N}$ & $\%$ & $\mathrm{~N}$ & $\%$ & $\mathrm{P}$ \\
Civil & Pareja & 137 & $54,8 \%$ & 26 & $48,1 \%$ & 163 & $53,6 \%$ & \\
& Viudo & 0 & $0,0 \%$ & 1 & $1,9 \%$ & 1 &, $3 \%$ & \\
& Separado & 42 & $16,8 \%$ & 12 & $22,2 \%$ & 54 & $17,8 \%$ & \\
\hline
\end{tabular}




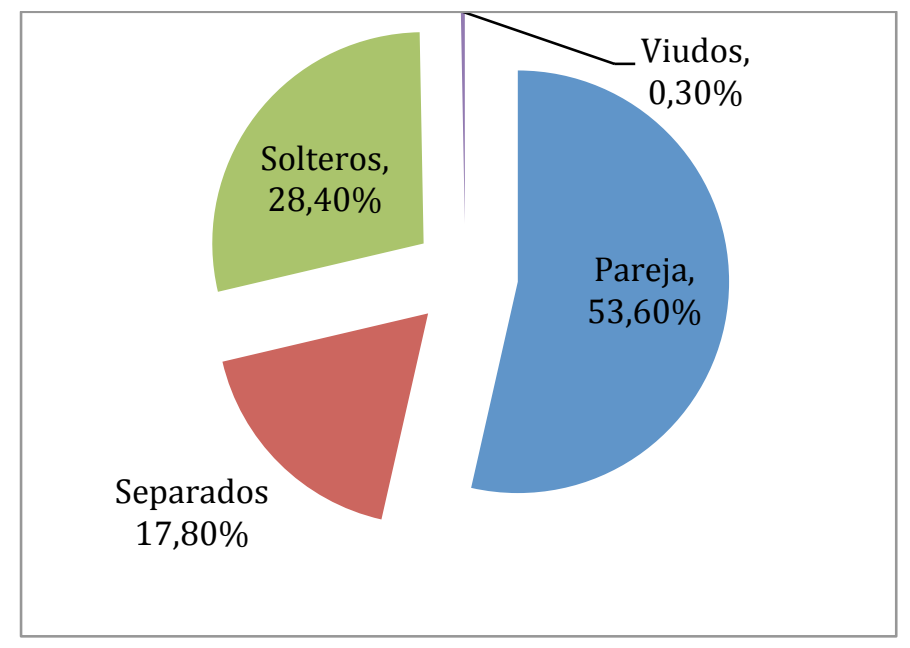

Fig. 30.- Distribución según estado civil

Nivel de estudios: Todos los pacientes de nuestra muestra tenían estudios, $66(21,8 \%)$ tenían el graduado escolar; 142 pacientes (46,6\%), habrían completado estudios de secundaria (ESO); 63 (20,7\%), tenían bachillerato o estudios similares (FP o $\mathrm{COU}$ ), y 33 estudios universitarios $(10,9 \%)$.

En relación con los varones 59 tenían el graduado escolar (23,6\%); 52 $(21,0 \%)$, la secundaria, 119 estudios de bachiller (47,6\%); y $20(8,0 \%)$, estudios universitarios. En el caso de las mujeres 7 de ellas (13,2\%), tenían el graduado escolar; 11 estudios de secundaria (20,8\%); 23 han acabado el bachiller (42,59\%); y 13 poseían estudios universitarios (24,1\%). (Tabla 22).

Tabla 22.- Nivel de estudios

\begin{tabular}{|c|c|c|c|c|c|c|c|c|}
\hline & \multicolumn{2}{|c|}{ Hombres } & \multicolumn{2}{|c|}{ Mujeres } & \multicolumn{2}{|c|}{ Total } & \multirow[b]{2}{*}{$\mathbf{P}$} \\
\hline & & $\mathbf{N}$ & $\%$ & $\mathbf{N}$ & $\%$ & $\mathbf{N}$ & $\%$ & \\
\hline \multirow{4}{*}{$\begin{array}{c}\text { Nivel } \\
\text { estudios }\end{array}$} & Universitarios & 20 & $8,0 \%$ & 13 & $24,1 \%$ & 33 & $10,9 \%$ & \\
\hline & $\begin{array}{c}\text { Graduado } \\
\text { escolar }\end{array}$ & 59 & $23,6 \%$ & 7 & $13,2 \%$ & 66 & $21,8 \%$ & \\
\hline & $\begin{array}{l}\text { Bachiller } \\
\text { elemental }\end{array}$ & 119 & $47,6 \%$ & 23 & $42,59 \%$ & 63 & $20,7 \%$ & \\
\hline & Secundaria & 52 & $21,0 \%$ & 11 & $20,8 \%$ & 142 & $46,6 \%$ & \\
\hline
\end{tabular}


Tipo de empleo: Los resultados se muestran a continuación. Se observa que más del $50 \%$ de la muestra trabaja a tiempo completo, y que tan sólo el $1,3 \%$ de nuestro estudio se encuentra cursando estudios (Tabla 23).

Tabla 23.- Tipo de empleo

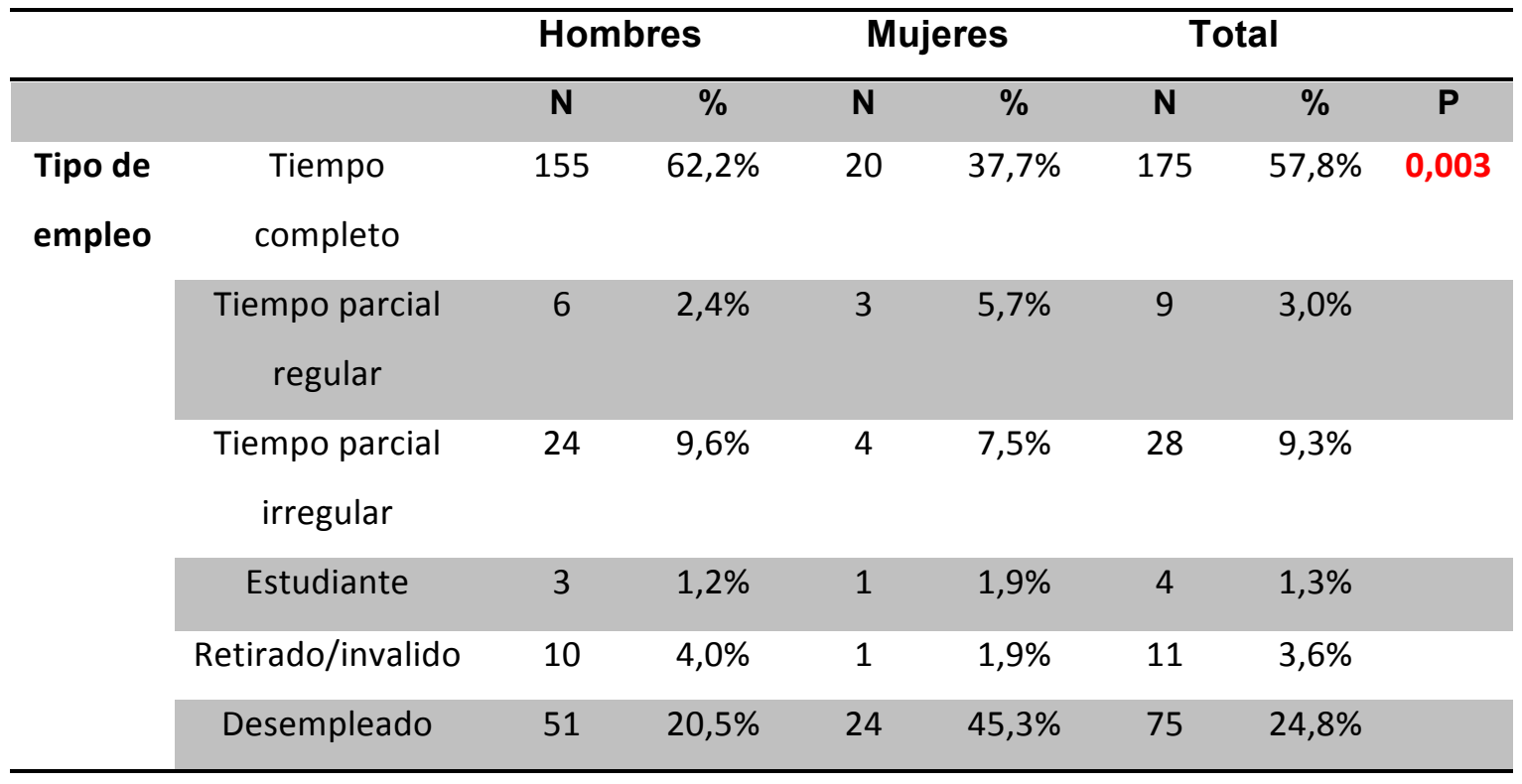

Actividad Laboral: La mayor parte se agrupan en la construcción y otros servicios, mientras que el $22,7 \%$ de la muestra no trabaja en la actualidad (Tabla 24).

Tabla 24.- Actividad laboral

\begin{tabular}{|c|c|c|c|c|c|c|c|c|}
\hline & & \multicolumn{2}{|c|}{ Hombres } & \multicolumn{2}{|c|}{ Mujeres } & \multicolumn{2}{|c|}{ Total } & \multirow[b]{2}{*}{$\mathbf{P}$} \\
\hline & & $\mathbf{N}$ & $\%$ & $\mathbf{N}$ & $\%$ & $\bar{N}$ & $\%$ & \\
\hline $\begin{array}{c}\text { Sector } \\
\text { de }\end{array}$ & $\begin{array}{l}\text { Sector } \\
\text { cuidados }\end{array}$ & 2 & ,8\% & 15 & $27,8 \%$ & 17 & $5,6 \%$ & 0,001 \\
\hline \multirow[t]{6}{*}{ actividad } & $\begin{array}{c}\text { Serv. } \\
\text { Administrativo }\end{array}$ & 12 & $4,8 \%$ & 5 & $9,3 \%$ & 17 & $5,6 \%$ & \\
\hline & Construcción & 67 & $26,8 \%$ & 3 & $5,6 \%$ & 70 & $23,0 \%$ & \\
\hline & Hostelería & 22 & $8,8 \%$ & 6 & $11,1 \%$ & 28 & $9,2 \%$ & \\
\hline & Otros servicios & 84 & $33,6 \%$ & 7 & $13,0 \%$ & 91 & $29,9 \%$ & \\
\hline & Profesionales & 8 & $3,2 \%$ & 4 & $7,4 \%$ & 12 & $3,9 \%$ & \\
\hline & No trabajan & 55 & $22,0 \%$ & 14 & $25,9 \%$ & 69 & $22,7 \%$ & \\
\hline
\end{tabular}


Diagnóstico: En cuanto al diagnóstico, 244 pacientes $(80,3 \%)$, presentaban una dependencia de alcohol, mientras que 60 de ellos $(19,7 \%)$, sufrían un abuso de esta sustancia. Esta diferencia, también se mantiene si analizamos la muestra en función del sexo. El 78,9\% de los hombres (197), presentaba una dependencia de alcohol, mientras que el 21,2\% (53 varones), un trastorno por abuso. En el caso de las mujeres, las diferencias son si cabe más acusadas, el $87,0 \%$ (47 de ellas), presentaban un diagnóstico de dependencia de alcohol, frente al 13,0\% (7), que presentaba un patrón de abuso, aunque estas diferencias no son significativas. Los resultados se muestran en función del sexo en la Tabla 25.

Tabla 25.- Diagnóstico principal

\begin{tabular}{|c|c|c|c|c|c|c|c|c|}
\hline & & \multicolumn{2}{|c|}{ Hombres } & \multicolumn{2}{|c|}{ Mujeres } & \multicolumn{2}{|c|}{ Total } & \multirow[b]{2}{*}{$\mathbf{P}$} \\
\hline & & $\mathbf{N}$ & $\%$ & $\mathbf{N}$ & $\%$ & $\mathbf{N}$ & $\%$ & \\
\hline \multirow[t]{2}{*}{ Diagnóstico } & Dependencia & 197 & $78,9 \%$ & 47 & $87,0 \%$ & 244 & $80,3 \%$ & 0,191 \\
\hline & Abuso & 53 & $21,2 \%$ & 7 & $13,0 \%$ & 60 & $19,7 \%$ & \\
\hline
\end{tabular}

Cantidad de alcohol consumo: En referencia a la cantidad consumida de alcohol, los pacientes presentaron una media de 210,7cc de vino, (DE 432,2); 1587,9 cc de cerveza (DE 1383,8); y 132,2cc de licor (DE 179,4) (Tabla 26).

Tabla 26.- Consumo de alcohol

\begin{tabular}{|c|c|c|c|c|c|c|c|c|}
\hline & & \multicolumn{2}{|c|}{ Hombres } & \multicolumn{2}{|c|}{ Mujeres } & \multicolumn{2}{|c|}{ Total } & \multirow[b]{2}{*}{$P$} \\
\hline & & Media & DE & Media & $\overline{D E}$ & Media & DE & \\
\hline \multirow{7}{*}{$\begin{array}{l}\text { Consumo } \\
\text { de alcohol }\end{array}$} & Consumo & 200,3 & 428,7 & 244,0 & 440,8 & 210,7 & 432,2 & 0,500 \\
\hline & de vino cc & & & & & & & \\
\hline & Consumo & 1632,0 & 1425,0 & 1411,1 & 1159,5 & 1587,9 & 1383,8 & 0,287 \\
\hline & de cerveza & & & & & & & \\
\hline & CC & & & & & & & \\
\hline & Consumo & 146,5 & 188,3 & 68,1 & 111,7 & 132,2 & 179,4 & 0,003 \\
\hline & de licor $\mathrm{Cc}$ & & & & & & & \\
\hline
\end{tabular}


Parámetros analíticos: Los parámetros analíticos, reflejan importantes alteraciones como consecuencia del TCA, principalmente en las transaminasas (GOT, GPT, GGT), y en el volumen corpuscular medio (VCM) (Tabla 27 y Figura 30).

Tabla 27.- Parámetros analíticos

\begin{tabular}{lcccccccc}
\hline & & \multicolumn{2}{l}{ Hombres } & \multicolumn{2}{c}{ Mujeres } & \multicolumn{2}{c}{ Total } \\
\hline \multirow{3}{*}{$\begin{array}{l}\text { Variables } \\
\text { biológicas }\end{array}$} & GOT & 51,1 & 123,2 & 33,6 & 25,7 & 47,9 & 113,3 & 0,368 \\
& GPT & 47,3 & 66,1 & 27,3 & 16,6 & 43,6 & 60,8 & 0,054 \\
& GGT & 157,7 & 334,9 & 138,8 & 270,3 & 154,0 & 323,7 & 0,731 \\
& VCM & 94,1 & 6,7 & 94,3 & 8,7 & 94,1 & 7,1 & 0,887 \\
\hline
\end{tabular}

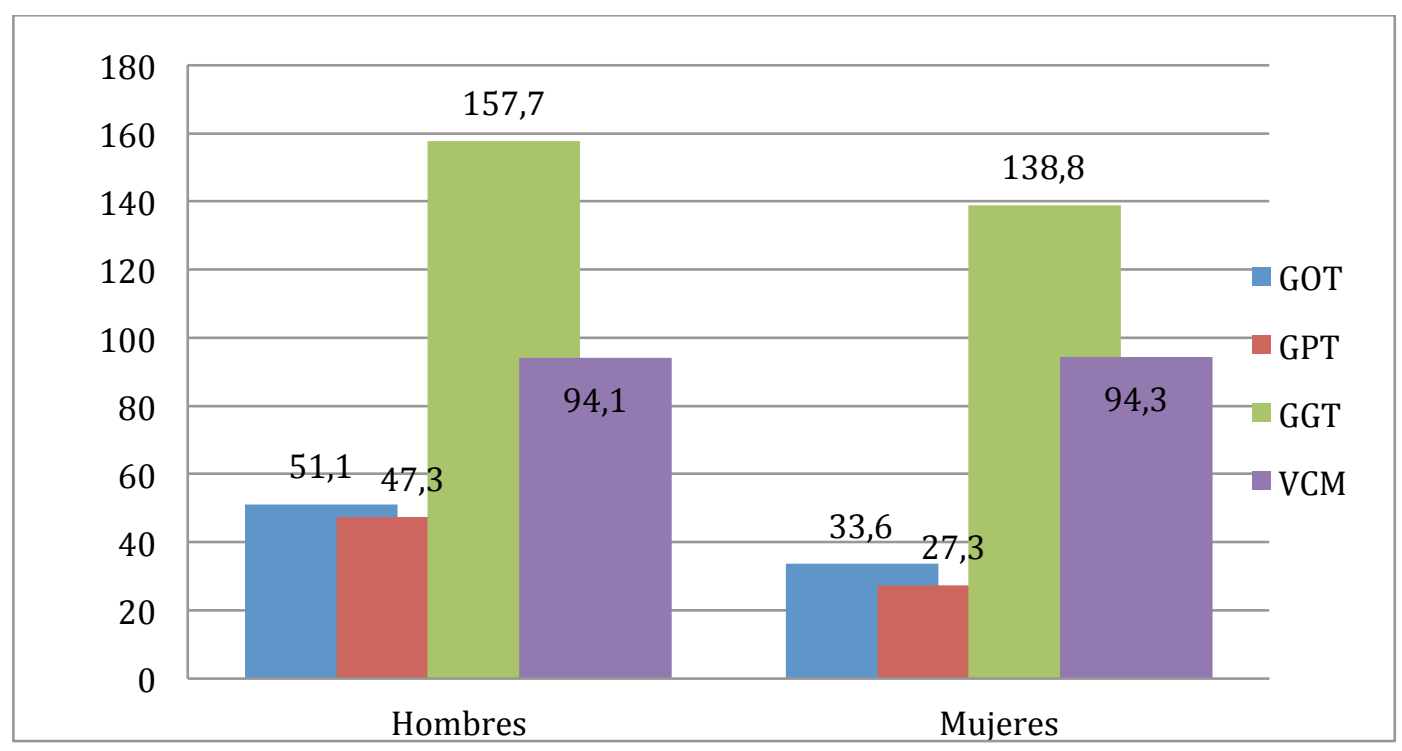

Fig. 30.- Valores analíticos en función del sexo

El perfil de nuestra muestra de estudio es el de un varón, de 43 años, con residencia, principalmente, en la ciudad, que convive en pareja, posee estudios básicos, trabaja en la construcción y otros servicios, consume preferentemente cerveza, con un perfil bioquímico hepático alterado por elevación significativa del enzima GGT y diagnosticado de presentar un trastorno por dependencia del alcohol. 


\section{2.- Objetivo 2}

Clasificar los pacientes seleccionados para el estudio en función de las características de su personalidad, según el cuestionario de Cloninger y analizar las diferencias por sexo.

Los resultados se agrupan en 7 características de personalidad: Búsqueda de Novedad, Evitación del Daño, Dependencia de Recompensa, Persistencia, Autodirección, Cooperación y Autotrascendencia. Las medias y la desviación estándar obtenidas en cada uno de los rasgos de personalidad quedan reflejadas en la Tabla 28 y Figura 31, en función del sexo.

Tabla 28.- Puntuación Inventario TCI-R

\begin{tabular}{cccccccc}
\hline & \multicolumn{2}{c}{ Hombres } & \multicolumn{2}{c}{ Mujeres } & \multicolumn{2}{c}{ Total } \\
\hline & Media & DE & Media & DE & Media & DE & P \\
Novedad & 62,4 & 28,9 & 62,8 & 32,3 & 62,5 & 29,4 & 0,935 \\
Evitación Daño & 71,8 & 26,7 & 77,2 & 26,2 & 72,7 & 26,6 & 0,176 \\
Recompensa & 52,3 & 31,4 & 50,4 & 28,6 & 52,0 & 30,9 & 0,691 \\
Persistencia & 51,5 & 33,6 & 40,8 & 31,5 & 49,6 & 33,4 & 0,034 \\
Autodirección & 24,5 & 25,3 & 17,6 & 23,4 & 23,2 & 25,1 & 0,064 \\
Cooperación & 44,8 & 30,5 & 50,2 & 30,3 & 45,8 & 30,4 & 0,240 \\
Autotrascendencia & 62,2 & 29,5 & 52,0 & 31,1 & 60,4 & 30,0 & 0,022 \\
\hline
\end{tabular}

La muestra se caracteriza por presentar puntuaciones elevadas en Búsqueda de Novedad y Evitación del Daño y puntuación muy baja en Autodirección. La puntuación baja en esta rasgo está asociada a la presencia de un trastorno de personalidad, según Cloninger.

Dado que las mujeres representan sólo el 17,8\% de nuestra muestra de estudio, hemos considerado pertinente el análisis de las características de personalidad como muestras independientes en función del sexo. Se observa que las mujeres obtienen en el Test de Cloninger, significativamente menor puntuación en Persistencia $(p=0,03)$, y Autotranscendencia $(P=0,02)$ (Figura 31). 


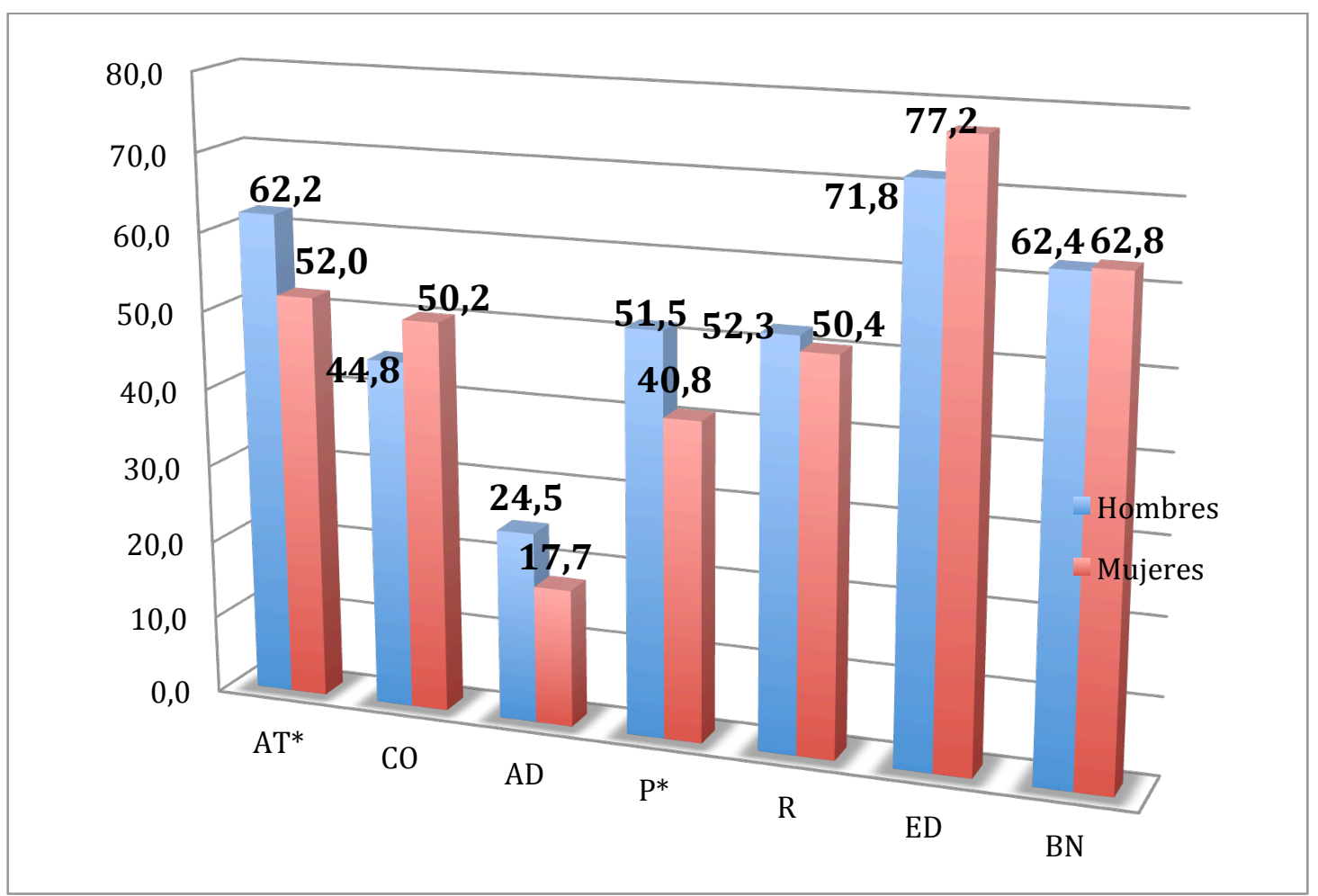

Fig. 31.- Puntuación TCI-R de Cloninger en función del sexo

\section{3.- Objetivo 3}

Analizar la gravedad de la dependencia al alcohol, en los pacientes del estudio, según el Índice Europeo de la Gravedad de la Adicción (EuropAsi).

\section{a) Salud Física}

A continuación, se muestran los resultados de las veces que los pacientes han estado hospitalizados, por causa médica, en función del sexo (Tabla 29). Además de los resultados de la severidad médica objetivada por el médico evaluador (Tabla 30). 
Tabla 29.- $\mathrm{N}^{\circ}$ de Hospitalizaciones médicas

\begin{tabular}{ccccccccc}
\hline & \multicolumn{2}{c}{ Hombres } & \multicolumn{2}{l}{ Mujeres } & \multicolumn{2}{l}{ Total } \\
\hline & & $\mathrm{N}$ & $\%$ & $\mathrm{~N}$ & $\%$ & $\mathrm{~N}$ & $\%$ & $\mathrm{P}$ \\
\hline $\mathbf{N}^{\circ}$ de veces & 0 & 156 & $62,4 \%$ & 32 & $60,4 \%$ & 188 & $62,0 \%$ & 0,960 \\
hospitalizado & 1 & 67 & $26,8 \%$ & 16 & $30,2 \%$ & 83 & $27,4 \%$ & \\
& 2 & 15 & $6,0 \%$ & 4 & $7,5 \%$ & 19 & $6,3 \%$ & \\
& 3 & 8 & $3,2 \%$ & 1 & $1,9 \%$ & 9 & $3,0 \%$ & \\
& 4 & 2 &, $8 \%$ & 0 & $0,0 \%$ & 2 &, $7 \%$ & \\
& 5 & 1 &, $4 \%$ & 0 & $0,0 \%$ & 1 &, $3 \%$ & \\
& 6 & 1 &, $4 \%$ & 0 & $0,0 \%$ & 1 &, $3 \%$ & \\
\hline
\end{tabular}

Tabla 30.- Severidad Médica

\begin{tabular}{cccccccc}
\hline & \multicolumn{3}{c}{ Hombres } & \multicolumn{2}{c}{ Mujeres } & \multicolumn{2}{c}{ Total } \\
\hline & Media & DE & Media & DE & Media & DE & P \\
Severidad Médica & 1,11 & 0,43 & 1,06 & 0,23 & 1,10 & 0,40 & 0,386 \\
& & & & & & & \\
\hline
\end{tabular}

\section{b) Salud Psiquiátrica}

Se muestran los resultados en relación con el número de veces que los pacientes han requerido ingreso hospitalario por causa psiquiátrica, el número de ocasiones en que han recibido tratamiento psiquiátrico ambulatorio, y la severidad psiquiátrica objetivada por el entrevistador (Tabla 31). 
Tabla 31.- Salud Psiquiátrica

\begin{tabular}{|c|c|c|c|c|c|c|c|c|}
\hline & & \multicolumn{2}{|c|}{ Hombres } & \multicolumn{2}{|c|}{ Mujeres } & \multicolumn{2}{|c|}{ Total } & \multirow[b]{2}{*}{$P$} \\
\hline & & $N$ & $\%$ & $N$ & $\%$ & $\mathrm{~N}$ & $\%$ & \\
\hline \multirow{4}{*}{$\begin{array}{l}\text { Tratamiento } \\
\text { Hospitalario } \\
\text { Psiquiátrico }\end{array}$} & 0 & 243 & $97,2 \%$ & 50 & 92,6 & 293 & $96,4 \%$ & 0,040 \\
\hline & & & & & $\%$ & & & \\
\hline & 1 & 4 & $1,6 \%$ & 4 & $7,4 \%$ & 8 & $2,6 \%$ & \\
\hline & 2 & 3 & $1,2 \%$ & 0 & $0,0 \%$ & 3 & $1,0 \%$ & \\
\hline \multirow{7}{*}{$\begin{array}{l}\text { Tratamiento } \\
\text { Ambulatorio } \\
\text { Psiquiátrico }\end{array}$} & 0 & 202 & $80,5 \%$ & 22 & 40,7 & 224 & $73,4 \%$ & 0,000 \\
\hline & & & & & $\%$ & & & \\
\hline & 1 & 44 & $17,9 \%$ & 31 & 57,4 & 75 & $24,7 \%$ & \\
\hline & & & & & $\%$ & & & \\
\hline & 2 & 2 &, $8 \%$ & 0 & $0,0 \%$ & 2 &, $7 \%$ & \\
\hline & 3 & 2 & ,8\% & 0 & $0,0 \%$ & 2 & ,7\% & \\
\hline & 4 & 0 & $0,0 \%$ & 1 & $1,9 \%$ & 1 & ,3\% & \\
\hline
\end{tabular}

Tabla 32.- Severidad Psiquiátrica

\begin{tabular}{cccccccc}
\hline & \multicolumn{2}{c}{ Hombres } & \multicolumn{2}{c}{ Mujeres } & \multicolumn{2}{c}{ Total } \\
\hline & Media & DE & Media & DE & Media & DE & P \\
$\begin{array}{c}\text { Severidad } \\
\text { Psiquiátrica }\end{array}$ & 1,11 & 0,43 & 1,26 & 0,48 & 1,14 & 0,45 & 0,027 \\
\hline
\end{tabular}

La repercusión del consumo de alcohol, en la esfera psiquiátrica, es más grave en las mujeres que los hombres: el $60 \%$ de las mujeres ha estado en tratamiento psiquiátrico ambulatorio y presentan significativamente más puntuación en el índice de severidad.

\section{c) Evaluación del consumo de Alcohol.}

Se muestran los resultados de los ítems de la escala EuropAsi, en relación con el consumo de alcohol, además de la severidad de este consumo evaluada por el entrevistador (Tabla 33). 
Tabla 33.- Evaluación del consumo de alcohol

\begin{tabular}{|c|c|c|c|c|c|c|c|}
\hline & \multicolumn{2}{|c|}{ Hombres } & \multicolumn{2}{|c|}{ Mujeres } & \multicolumn{2}{|c|}{ Total } & \multirow[b]{2}{*}{$\mathrm{P}$} \\
\hline & Media & $\mathrm{DE}$ & Media & DE & Media & $\mathrm{DE}$ & \\
\hline Edad de inicio & 15,6 & 3,8 & 18,0 & 5,0 & 16,0 & 4,1 & 0,001 \\
\hline $\begin{array}{c}\text { Duración del } \\
\text { consumo }\end{array}$ & 20,3 & 11,0 & 13,4 & 10,8 & 19,1 & 11,3 & 0,001 \\
\hline $\begin{array}{c}\text { Edad inicio } \\
\text { consumo patológico }\end{array}$ & 22,9 & 8,6 & 30,3 & 10,6 & 24,2 & 9,4 & 0,001 \\
\hline $\begin{array}{l}\text { Días que ha bebido } \\
\text { en el último mes }\end{array}$ & 25,4 & 9,1 & 26,8 & 7,3 & 25,6 & 8,8 & 0,270 \\
\hline $\begin{array}{c}\text { Dinero que ha } \\
\text { gastado en alcohol }\end{array}$ & 297,9 & 281,3 & 145,9 & 156,4 & 269,7 & 269,0 & 0,001 \\
\hline Gramos Alcohol & 144 & 57 & 113 & 42 & 139 & 56 & 0,001 \\
\hline $\begin{array}{l}\text { Severidad por el } \\
\text { entrevistador }\end{array}$ & 5,87 & 0,92 & 6,00 & 0,93 & 5,89 & 0,93 & 0,367 \\
\hline
\end{tabular}

Las mujeres presentan diferencias significativas en relación a los hombres. Inician el consumo de alcohol más tarde (18 años), este se vuelve problemático a mayor edad (30 años) y la duración de este consumo problemático es menor (13 años).

d) Evaluación del ámbito laboral

Tabla 34.- Evaluación del ámbito laboral

\begin{tabular}{cccccccc}
\hline & \multicolumn{3}{c}{ Hombres } & \multicolumn{2}{c}{ Mujeres } & \multicolumn{3}{c}{ Total } \\
\hline & Media & DE & Media & DE & Media & DE & P \\
& 2,71 & 2,152 & 2,60 & 1,974 & 2,69 & 2,119 & 0,742 \\
Severidad Laboral & & & & & & & \\
\hline
\end{tabular}


Tabla 35.- Fuente principal de ingresos

\begin{tabular}{llclcllll}
\hline & \multicolumn{2}{c}{ Hombres } & \multicolumn{2}{c}{ Mujeres } & \multicolumn{2}{c}{ Total } & P \\
\hline Empleo & $\mathrm{N}$ & $\%$ & $\mathrm{~N}$ & $\%$ & $\mathrm{~N}$ & $\%$ & \\
Paro & 133 & 53,6 & 19 & 35,8 & 152 & 50,5 & 0.001 \\
Ayuda Social & 51 & 20,6 & 6 & 11,3 & 57 & 18,9 & \\
Pensión S.S. & 12 & 4,8 & 6 & 11,3 & 18 & 6,0 & \\
Familia & 17 & 6,9 & 4 & 7,5 & 21 & 7,0 & \\
\hline
\end{tabular}

La fuente principal de ingresos, en la mitad de la muestra, provenía del trabajo y de diferentes prestaciones sociales en la otra mitad. Había diferencias significativas entre hombres y mujeres; en los primeros la fuente de ingresos era el trabajo y en las segundas la familia, porque las labores de casa eran su principal ocupación.

e) Evaluación del ámbito familiar

Tabla 36.- Evaluación del ámbito familiar

\begin{tabular}{cccccccc}
\hline & \multicolumn{2}{c}{ Hombres } & \multicolumn{2}{c}{ Mujeres } & \multicolumn{3}{c}{ Total } \\
& Media & DE & Media & DE & Media & DE & P \\
Severidad & & & & & & & \\
$\begin{array}{c}\text { repercusión } \\
\text { familiar por } \\
\text { entrevistador }\end{array}$ & 1,78 & 1,12 & 1,77 & 1,10 & 1,78 & 1,11 & 0,951 \\
\hline
\end{tabular}

Tabla 37.- Problemas en la familia en el último mes

\begin{tabular}{llllllll}
\hline & \multicolumn{2}{l}{ Hombres } & \multicolumn{2}{c}{ Mujeres } & & Total & P \\
\hline & $\mathrm{N}$ & $\%$ & $\mathrm{~N}$ & $\%$ & $\mathrm{~N}$ & $\%$ & \\
NO & 62 & 42,2 & 10 & 38,5 & 72 & 41,6 & 0.87 \\
$>15$ & 36 & 24,5 & 6 & 23,1 & 42 & 24,3 & \\
DíAS & & & & & & & \\
<15 & 49 & 33,3 & 10 & 38,5 & 59 & 34,1 & \\
DÍAS & & & & & & & \\
\hline
\end{tabular}


Más de la mitad de la muestra había tenido problemas familiares en el último mes, sin encontrar diferencias significativas entre hombres y mujeres.

\section{f) Evaluación del ámbito social-legal.}

Tabla 38.- Evaluación del ámbito social-legal.

\begin{tabular}{cccccccc}
\hline & \multicolumn{2}{c}{ Hombres } & \multicolumn{3}{c}{ Mujeres } & \multicolumn{3}{c}{ Total } \\
\hline & Media & DE & Media & DE & Media & DE & P \\
$\begin{array}{c}\text { Severidad } \\
\text { responsabilidad } \\
\text { legal }\end{array}$ & 1,10 & 0,50 & 1,00 & 0,00 & 1,08 & 0,45 & 0,160 \\
\hline
\end{tabular}

Tabla 39.- Acusaciones

\begin{tabular}{llcccccc}
\hline & \multicolumn{3}{c}{ Hombres } & \multicolumn{3}{c}{ Mujeres } & \multicolumn{2}{c}{ Total } & P \\
\hline & N & $\%$ & N & $\%$ & N & $\%$ & \\
NO & 138 & 55,6 & 46 & 86,8 & 184 & 61,1 & 0.001 \\
SI & 110 & 44,4 & 7 & 13,2 & 117 & 38,9 & \\
\hline
\end{tabular}

El 39\% de la muestra de estudio había sido acusado de diferentes tipos de delitos, principalmente de tráfico, bien por conducir bajo los efectos del alcohol, bien por otro tipo de infracciones del código de circulación. Algunos pacientes habían cometido varios delitos. En cuanto al sexo, los hombres habían cometido, significativamente más delitos que las mujeres.

Tabla 40.- Condenas

\begin{tabular}{|c|c|c|c|c|c|c|c|}
\hline & \multicolumn{2}{|c|}{ Hombres } & \multicolumn{2}{|c|}{ Mujeres } & \multicolumn{2}{|c|}{ Total } & \multirow[t]{2}{*}{$\mathbf{F}$} \\
\hline & $\mathrm{N}$ & $\%$ & $\mathrm{~N}$ & $\%$ & $\mathrm{~N}$ & $\%$ & \\
\hline NO & 216 & 87,1 & 50 & 94,3 & 266 & 88,4 & 0.24 \\
\hline SI & 32 & 12,9 & 3 & 5,7 & 35 & 11,6 & \\
\hline
\end{tabular}

En cuanto a su situación legal, el 11,6\% estaba cumpliendo condena y el $7,6 \%$ estaba pendiente de sentencia; no había diferencias entre ambos sexos. 
La puntuación de la severidad, dada por el entrevistador, era similar en hombres y mujeres.

\section{g) Composites Scores:}

Tabla 41.- Composites Scores por sexos

\begin{tabular}{|c|c|c|c|c|c|c|c|}
\hline & \multicolumn{2}{|c|}{ Hombres } & \multicolumn{2}{|c|}{ Mujeres } & \multicolumn{2}{|c|}{ Total } & \multirow[b]{2}{*}{$P$} \\
\hline & Media & $\mathrm{DE}$ & Media & $\mathrm{DE}$ & Media & DE & \\
\hline Alcohol & 0,387 & 0,145 & 0,403 & 0,166 & 0,390 & 0,148 & 0,467 \\
\hline Legal & 0,021 & 0,077 & 0,019 & 0,059 & 0,021 & 0,074 & 0,810 \\
\hline Familia & 0,277 & 0,236 & 0,260 & 0,225 & 0,274 & 0,233 & 0,638 \\
\hline Área médica & 0,150 & 0,157 & 0,126 & 0,108 & 0,146 & 0,150 & 0,287 \\
\hline Área psiquiátrica & 0,117 & 0,125 & 0,225 & 0,145 & 0,136 & 0,135 & 0,001 \\
\hline
\end{tabular}

\section{4.- Objetivo 4}

Analizar la intensidad de la dependencia de alcohol, según la Escala de Intensidad de la Dependencia de Alcohol (EIDA) y el componente obsesivo y compulsivo del deseo de consumo (OCDS) en los pacientes del estudio.

La puntuación total del EIDA en nuestra muestra es de 27,79 (DE 15,0), siendo de 27,0 (DE 14,4), en el caso de los hombres; y de 32,5 (DE 16,7), en el caso de las mujeres. Por lo tanto la dependencia del alcohol es significativamente más grave en las mujeres que en los hombres $(p=0.01)$ (Tablas 42 y 43 . Figura 32). 
Tabla 42.- Escala EIDA por sexos

\begin{tabular}{lllllllll}
\hline & \multicolumn{3}{c}{ Hombres } & \multicolumn{3}{c}{ Mujeres } & \multicolumn{3}{c}{ Total } \\
& Media & DE & Media & DE & Media & DE & P \\
\cline { 2 - 8 } Total & 27,0 & 14,4 & 32,5 & 16,7 & 27,9 & 15,0 & 0,015 \\
& & & & & & & & \\
\hline
\end{tabular}

Tabla 43.- Categorías Gravedad EIDA

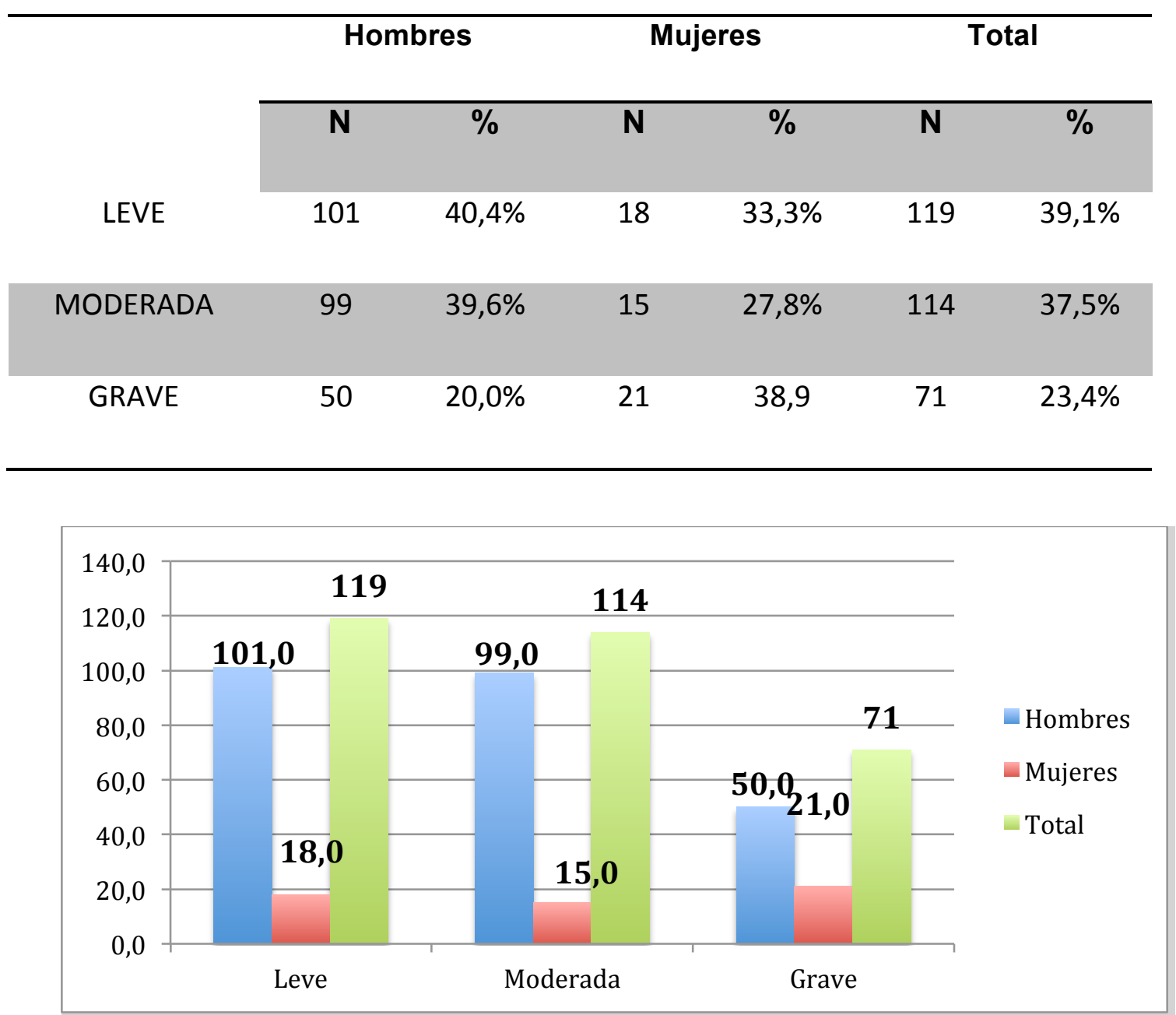

Fig. 32.- Puntuaciones escala EIDA por sexos

Más de la mitad de la muestra (60\%) padece un Trastorno por consumo de alcohol moderado y grave, medido por la escala EIDA (Tabla 43). 
En relación con la escala OCDS, la puntuación total de la muestra es de 15,1 (DE 7,8). Los hombres obtuvieron una puntuación de 14,6 (DE 7,2) y las mujeres 17,4 (DE 10,0), es decir, las mujeres refieren, significativamente, más deseo por el alcohol que los hombres.

La puntuación media en la subescala obsesión es 6,3 (DE 4,1); en los varones la media es 6,0 (DE 3,9) y en las mujeres 7,6 (DE 5,0), diferencia muy significativa $(p=0.008)$.

Por otro lado, las puntuaciones obtenidas en la subescala de compulsión serían de 8,87 para el total de la muestra (DE 4,4); siendo en el caso de los varones de 8,7 (DE 4,1) y en el caso de la mujeres de 9,8 (DE 5,4) (Tabla 44 y Figura 33).

\section{Tabla 44.- Escala OCDS en función del sexo}

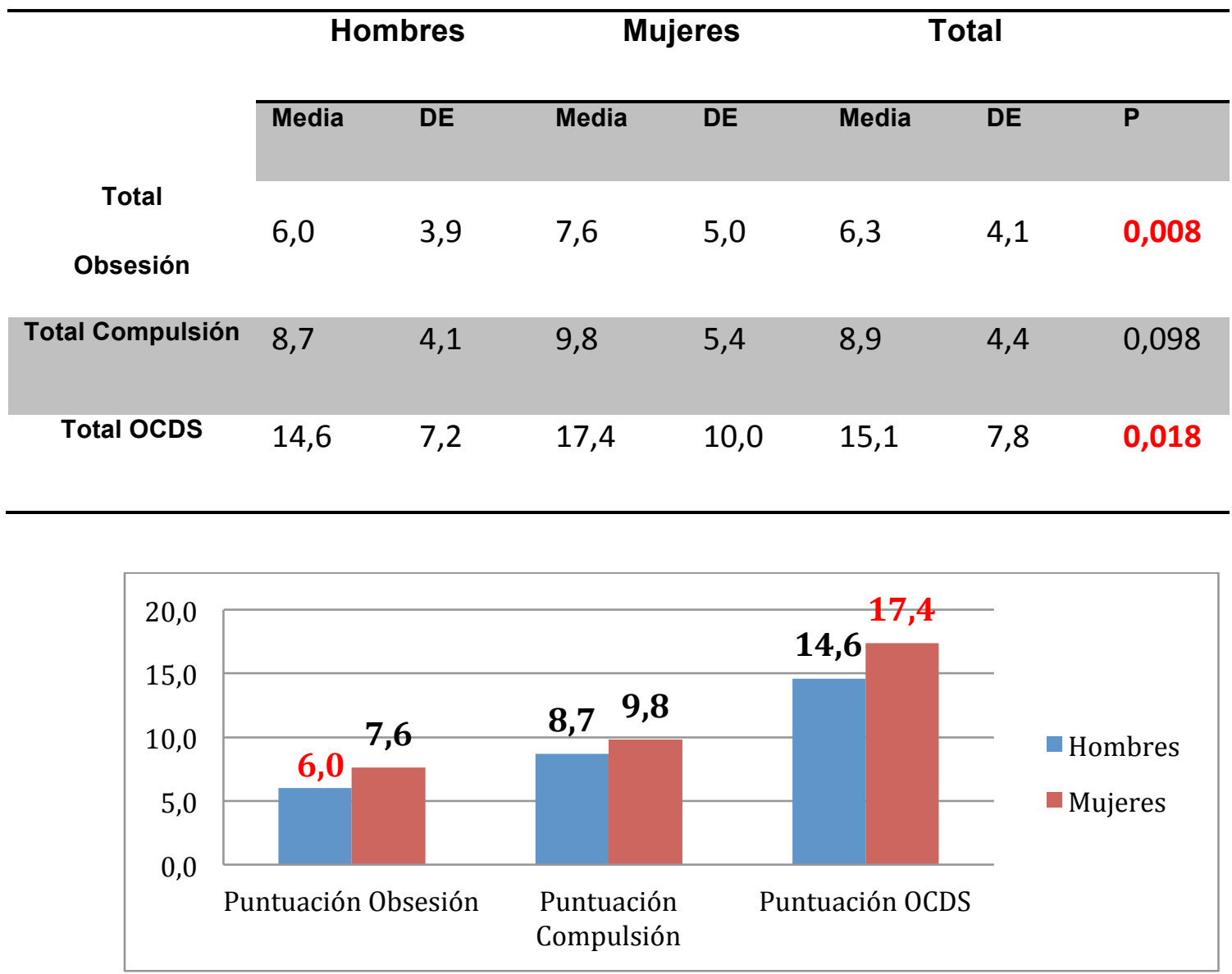

Fig. 33.- Puntuación escala OCDS, en función del sexo 


\section{5.- Objetivo 5}

Analizar la relación entre la personalidad, según el cuestionario de personalidad de Cloninger, y la gravedad del trastorno del consumo de alcohol según el EUROPASI.

Tabla 45.- Correlación EuropAsi y TCI-R

\begin{tabular}{lc}
\hline EUROPASI & TCI-R
\end{tabular}

\begin{tabular}{|c|c|c|c|c|c|c|c|c|}
\hline & & BN & ED & $\mathbf{R}$ & $\mathbf{P}$ & AD & CO & AT \\
\hline Salud Física & $\begin{array}{l}\text { Severidad } \\
\underline{\text { médica }}\end{array}$ &,- 062 & 104 &, 008 &,- 032 & ,063 & ,058 & , 024 \\
\hline $\begin{array}{c}\text { Salud } \\
\text { Psiquiátrica }\end{array}$ & $\begin{array}{l}\text { Severidad } \\
\text { psiquiátrica }\end{array}$ & ,016 &, $225^{* *}$ & $-170^{* *}$ & -,139* &,$- 152^{* *}$ &,- 048 &,$- 120^{*}$ \\
\hline \multirow{5}{*}{$\begin{array}{l}\text { Consumo } \\
\text { de alcohol }\end{array}$} & Edad de inicio &,$- 263^{* *}$ & $118^{*}$ & ,011 &,- 057 & ,027 & ,099 & ,007 \\
\hline & $\begin{array}{l}\text { Edad inicio } \\
\text { consumo } \\
\text { patológico }\end{array}$ &,$- 207^{* *}$ & ,077 & $136^{*}$ & ,022 & ,036 &, $163^{* *}$ & ,011 \\
\hline & $\begin{array}{l}\text { Duración } \\
\text { consumo }\end{array}$ & -,091 & ,032 &, $114^{*}$ & ,046 &,- 024 &, $122^{*}$ &,- 018 \\
\hline & $\begin{array}{c}\text { Gramos de } \\
\text { alcohol }\end{array}$ & $131^{*}$ &,- 061 & ,021 & ,080 &,- 065 &,- 087 & 052 \\
\hline & $\frac{\text { Severidad del }}{\text { alcohol }}$ & ,039 &, $126^{*}$ &,- 040 &,- 089 & -097 &,- 016 &,- 010 \\
\hline Laboral & $\frac{\text { Severidad }}{\text { Laboral }}$ & , 108 & ,038 &,- 072 & ,006 &,- 073 &,$- 129^{*}$ &,- 062 \\
\hline Legal & $\frac{\text { Severidad }}{\underline{\text { legal }}}$ & ,033 & ,006 & ,067 & ,064 & ,005 & ,043 &,- 057 \\
\hline Familiar & $\begin{array}{l}\frac{\text { Severidad }}{\text { repercusión }} \\
\underline{\text { familiar }}\end{array}$ & ,077 & ,049 &,- 121 & ,077 &,- 119 &,- 134 &,- 014 \\
\hline
\end{tabular}

BN: Búsqueda de Novedad. ED: Evitación del Daño. R: Dependencia de Recompensa. P:Persistencia.

AD: Autodirección. CO: Cooperación. AT: Transcendencia. 
No se encontró correlación entre la salud física y la personalidad de la muestra, según TCl-R. Sin embargo, sí se encontró correlación entre la salud psiquiátrica, positiva en relación con Evitación del daño $(r=0,225 ; p<0,01)$; y negativa con Dependencia de recompensa $(R)(r=-0,170 ; p<0,01), P(r=-$ $0,139$, ; $p<0,01)$, Autodirección $(r=-0,152 ; p<0,01)$, y Autotranscendencia ( $r=-$ $0,120 ; p<0,01)$.

Se encontró una correlación negativa con la edad de inicio y la Búsqueda de novedad $(r=0-, 263 ; p<0,01)$, y positiva entre los años que ha estado bebiendo hasta acudir a consulta y la Dependencia de recompensa ( $r=$ $0,114 ; p<0,01)$, y Cooperación $(r=0,122 ; p<0,01)$.

Existe una correlación negativa entre la edad de inicio del consumo patológico y la Búsqueda de novedad $(r=-0,207 ; p<0,01)$; y positiva en relación con ese mismo ítem y Dependencia de recompensa $(r=0,136 ; p<0,01) ; y$ Cooperación $(r=0,163 ; p<0,01)$.

Por otro lado, se encontró una correlación positiva entre Búsqueda de novedad y los gramos de alcohol consumidos $(r=0,131 ; p<0,01)$.

Existe una correlación positiva entre la severidad del alcohol por el entrevistador y la Evitación del daño $(r=126 ; p<0,01)$, y negativa entre la Cooperación y la severidad laboral para el entrevistador $(r=-0,129 ; p<0,01)$.

No existe correlación entre la personalidad y la gravedad legal para el entrevistador o la gravedad de la repercusión familiar valorada por el entrevistador (Tabla 45). 
Tabla 46.- Correlación Composites Scores y TCI-R

\begin{tabular}{cccccccc}
\hline $\begin{array}{c}\text { COMPOSITES } \\
\text { SCORES }\end{array}$ & BN & ED & $\mathbf{R}$ & $\mathbf{P}$ & AD & CO & AT \\
\hline ALCOHOL &, 086 &, 035 &,- 040 &, 005 &,$- 127^{*}$ &,- 099 &,- 045 \\
LEGAL &,- 020 &, 017 &, 022 &, 072 &,- 016 &,- 034 &, 042 \\
FAMILIA &, 038 &,$- 127^{*}$ &, 039 &, $121^{*}$ &, 022 &,- 014 &, 006 \\
AREA &,- 093 &, 104 &, 003 &,$- 153^{* *}$ &, 075 &, 049 &,- 034 \\
MEDICA & & & & & & & \\
ÁREA &,- 040 &, $279^{* *}$ &,- 065 &,$- 201^{* *}$ &,$- 204^{* *}$ &, 010 &,- 067 \\
PSIQUIÁTRICA & & & & & & & \\
\hline
\end{tabular}

En relación con Evitación del daño, existe una correlación positiva con el área psiquiátrica $(r=0,279 ; p<0,01)$, y negativa con el área familiar $(r=-0,127$; $P<0,01)$. Persistencia presenta una correlación positiva con el área de familia $(r=0,121 ; p<0,01)$; y negativa con el área médica $(r=-0,153 ; p<0,01)$; y con el área psiquiátrica $(r=-0,201 ; p<0,01)$. En cuanto a Autodirección, presenta una correlación negativa con el área alcohol $(r=-0,127 ; p<0,01)$; y con el área psiquiátrica $(r=-0,204 ; p<0,01)$. No existen correlaciones entre las restantes variables de personalidad (Búsqueda de novedad, Dependencia de recompensa, Cooperación y Autotrascendencia) y los composites scores (Tabla 46). 
Tabla A.- Diagnóstico Principal y TCI-R

\begin{tabular}{|c|c|c|c|c|c|}
\hline & & Media & $\%$ & DE & $\mathbf{P}$ \\
\hline \multirow[t]{2}{*}{ TCl-R: BN } & Dependencia & 243 & 62 & 30 & 0,710 \\
\hline & Abuso & 61 & 64 & 28 & \\
\hline \multirow[t]{2}{*}{ TCl-R: ED } & Dependencia & 243 & 75 & 26 & 0,003 \\
\hline & Abuso & 61 & 64 & 29 & \\
\hline \multirow{2}{*}{ TCl-R: R } & Dependencia & 243 & 51 & 31 & 0,189 \\
\hline & Abuso & 61 & 57 & 28 & \\
\hline \multirow[t]{2}{*}{ TCl-R: P } & Dependencia & 243 & 49 & 34 & 0,513 \\
\hline & Abuso & 61 & 52 & 33 & \\
\hline \multirow{2}{*}{ TCl-R: AD } & Dependencia & 243 & 21 & 24 & 0,011 \\
\hline & Abuso & 61 & 31 & 27 & \\
\hline \multirow[t]{2}{*}{ TCl-R: CO } & Dependencia & 243 & 44 & 30 & 0,028 \\
\hline & Abuso & 61 & 54 & 30 & \\
\hline \multirow{2}{*}{ TCl-R: AT } & Dependencia & 243 & 60 & 30 & 0,960 \\
\hline & Abuso & 61 & 60 & 29 & \\
\hline
\end{tabular}

Los pacientes con diagnóstico de dependencia, y, por consiguiente, con mayor gravedad del trastorno por consumo de alcohol, presentan significativamente puntuación más elevada en Evitación del Daño (ED) y menor puntuación en Autodirección (AD) y Cooperación (CO).

\section{6.- Objetivo 6}

Analizar la relación entre la personalidad, según el cuestionario de personalidad de Cloninger, y la intensidad de la dependencia del alcohol y el componente obsesivo $y$ compulsivo del deseo de consumo. 
Tabla 48.- Correlación EIDA y TCI-R

\begin{tabular}{|c|c|c|c|c|c|c|c|}
\hline EIDA & & & & & TCl-R & & \\
\hline & BN & ED & $\mathbf{R}$ & $\mathbf{P}$ & AD & $\mathrm{CO}$ & AT \\
\hline $\begin{array}{c}\text { DEPENDENCIA } \\
\text { LEVE }\end{array}$ & 167 & ,035 & ,052 &,- 044 & -155 &,- 109 &,- 010 \\
\hline $\begin{array}{l}\text { DEPENDENCIA } \\
\text { MODERADA }\end{array}$ & ,086 & ,068 &,- 113 & ,012 &,- 041 & ,038 & ,054 \\
\hline $\begin{array}{c}\text { DEPENDENCIA } \\
\text { GRAVE }\end{array}$ & ,015 &, $306^{* *}$ &,- 152 & -,195 &,$- 243^{*}$ &,- 140 &,- 186 \\
\hline EIDA TOTAL & ,190** & ,176** &,$- 126 *$ &,- 024 &,$- 321 * *$ &,$- 171 * *$ & ,080 \\
\hline
\end{tabular}

No existe correlación entre la Dependencia Leve y/o Dependencia Moderada y el TCl-R.

Por el contrario existe una correlación positiva entre Dependencia Grave y Evitación del daño $(r=0,306 ; p<0,01)$, y negativa con Autodirección $(r=-0,243$; $p<0,01)$.

EI EIDA total se correlaciona de manera positiva con Búsqueda de novedad $(r=0,190 ; p<0,01)$, y con Evitación del daño $(r=0,176 ; p<0,01)$; y de manera negativa con Dependencia de recompensa $(r=-0,126 ; p<0,01)$, Autodirección ( $r=-0,321 ; p<0,01)$; y con Cooperación $(r=-0,171 ; p<0,01)$ (Tabla 48 y Figura 34).

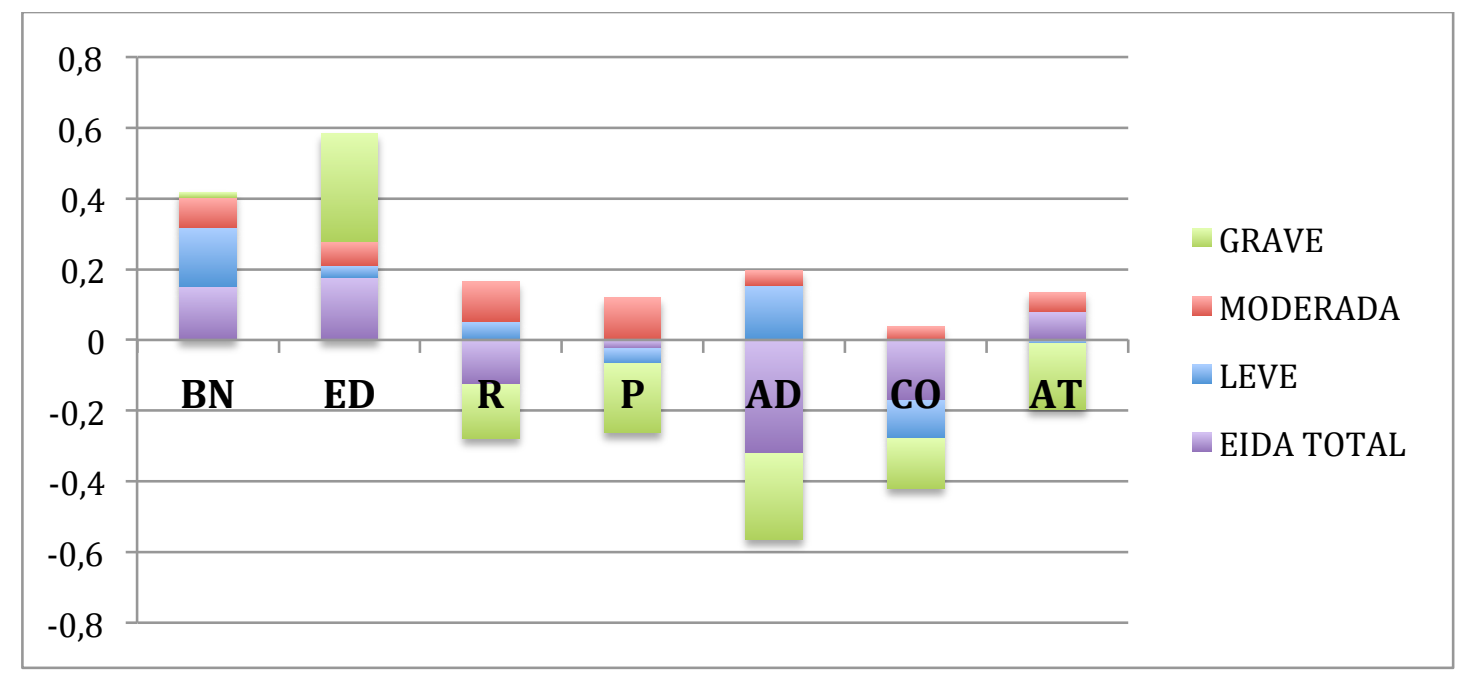

Figura 34.- Correlación EIDA y TCI-R 
Tabla 49.- Correlación OCDS y TCI-R

\begin{tabular}{|c|c|c|c|c|c|c|c|}
\hline \multirow[t]{2}{*}{ OCDS } & \multicolumn{7}{|c|}{ TCl-R } \\
\hline & BN & ED & $\mathbf{R}$ & $\mathbf{P}$ & AD & $\mathrm{CO}$ & AT \\
\hline $\begin{array}{l}\text { PUNTUACIÓN } \\
\text { TOTAL OBSESIÓN }\end{array}$ & ,116* &, $189 * *$ &,- 009 &,- 080 &,$- 359 * *$ &,$- 119 *$ & ,094 \\
\hline $\begin{array}{c}\text { PUNTUACIÓN } \\
\text { TOTAL } \\
\text { COMPULSIÓN }\end{array}$ & ,119* &, $207 * *$ &,- 062 &,$- 145^{*}$ &,$- 295 * *$ &,$- 163 * *$ &,- 019 \\
\hline $\begin{array}{l}\text { PUNTUACIÓN } \\
\text { TOTAL OCDS }\end{array}$ & ,123* &, $220 * *$ &,- 044 &,$- 123 *$ &,$- 352 * *$ &,$- 158 * *$ & ,041 \\
\hline
\end{tabular}

La puntuación total de la subescala de obsesión del OCDS se correlaciona de manera positiva con Búsqueda de Novedad $(r=0,116 ; p<0,01)$, y con Evitación del Daño ( $r=0,189 ; p<0,01)$, y de manera negativa con Autodirección ( $r=-0,359 ; p<0,01)$, y con Cooperación $(r=-0,119 ; p<0,01)$ ).

La puntuación total de la subescala de compulsión se correlaciona positivamente con Búsqueda de Novedad ( $r=0,119 ; p<0,01$ ); y Evitación del daño ( $r=0,207 ; p<0,01)$, y de manera negativa con Persistencia ( $r=$ 0145; $p<0,01)$, con Autodirección $(r=-0,295 ; p<0,01)$, y con Cooperación ( $r=-$ $0,163 ; p<0,01)$.

La puntuación total del OCDS se correlaciona de manera positiva con Búsqueda de novedad $(r=0,123 ; p<0,01)$, y con Evitación del daño ( $r=$ $0,220 ; p<0,01)$, y de manera negativa con Persistencia $(r=-0,123 ; p<0,01)$, con Autodirección $(r=-0,352 ; p<0,01)$, y con Cooperación $(R=-0,158 ; p<0,01)$ (Tabla 49 y Fig. 35). 


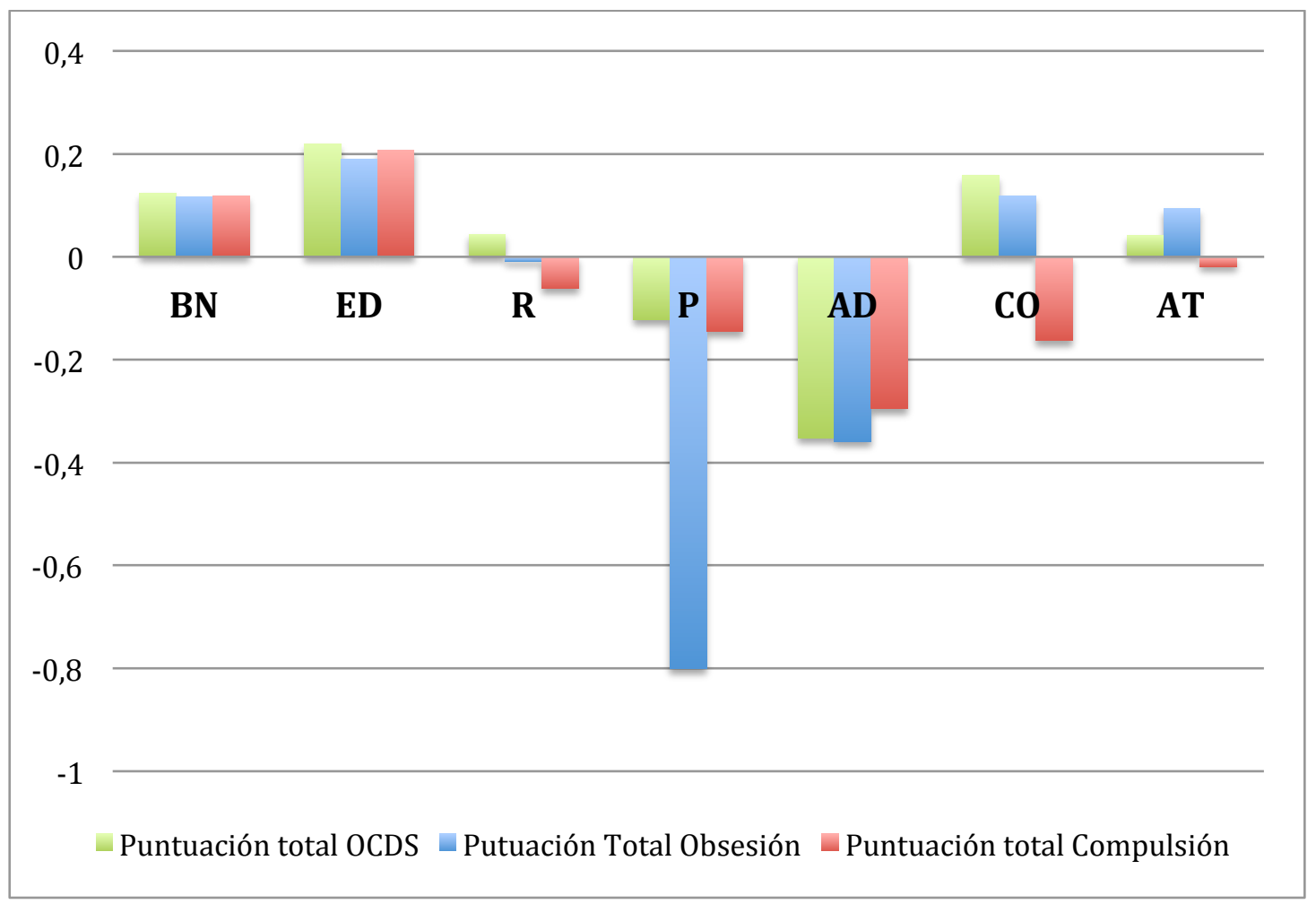

Figura 35.- Correlación OCDS y TCI-R

\section{7.- Objetivo 7}

Analizar la relación de las categorías de personalidad en la gravedad, intensidad y componente obsesivo y compulsivo de la dependencia del consumo de alcohol.

A continuación se realiza un modelo de regresión lineal múltiple de la personalidad (TCl-R), con la gravedad de la dependencia, evaluada mediante el Europasi, EIDA Y OCDS. En dicho modelo se toman como variables de ajuste la edad y el sexo, es decir que ambas variables no influyen en el resultado. 
Tablas 38.1: Regresión lineal múltiple de la personalidad, como variable independiente, Y EuropAsi como variable dependiente

\begin{tabular}{ccccc}
\hline $\begin{array}{l}\text { Severidad médica del } \\
\text { entrevistador }\end{array}$ & Lower & $\begin{array}{c}95 \% \text { Intervalo } \\
\text { Confianza }\end{array}$ & \\
\hline & B & Bound & Bound & \\
\hline NOVEDAD & $-0,001$ & $-0,003$ & 0,001 & 0,433 \\
DAÑO & 0,004 & 0,001 & 0,007 & 0,015 \\
RECOMPENSA & 0,001 & $-0,002$ & 0,003 & 0,465 \\
PERSISTENCIA & $-0,002$ & $-0,004$ & 0,001 & 0,193 \\
AUTODIRECCIÓN & 0,004 & 0,001 & 0,008 & 0,011 \\
COOPERACION & 0,000 & $-0,003$ & 0,002 & 0,778 \\
AUTOTRASCENDENCIA & 0,002 & 0,000 & 0,005 & 0,042 \\
\hline
\end{tabular}

Variable dependiente (severidad médica del entrevistador), variables independientes: Novedad, Riesgo, Recompensa, Persistencia, Autodirección, Cooperacion, Autotrascendencia y variables de ajuste: edad y sexo

\begin{tabular}{ccccc}
\hline $\begin{array}{c}\text { Severidad psiquiátrica } \\
\text { del entrevistador }\end{array}$ & Lower & Upper & Sig. \\
\hline & Bound & Bound & \\
\hline NOVEDAD & 0,000 & $-0,001$ & 0,002 & 0,594 \\
DAÑO & 0,001 & $-0,001$ & 0,003 & 0,417 \\
RECOMPENSA & 0,000 & $-0,002$ & 0,002 & 0,975 \\
PERSISTENCIA & 0,000 & $-0,001$ & 0,002 & 0,594 \\
AUTODIRECCIÓN & $-0,002$ & $-0,004$ & 0,001 & 0,145 \\
COOPERACION & 0,001 & $-0,001$ & 0,003 & 0,515 \\
AUTOTRASCENDENCIA & 0,000 & $-0,002$ & 0,001 & 0,634 \\
\hline
\end{tabular}

Variable dependiente (severidad psiquiátrica del entrevistador), variables independientes: Novedad, Riesgo, Recompensa, Persistencia, Autodirección, Cooperacion, Autotrascendencia y variables de ajuste: edad y sexo. 


\begin{tabular}{ccccc}
\hline $\begin{array}{c}\text { Severidad del } \\
\text { alcohol del } \\
\text { entrevistador }\end{array}$ & Lower & Upper & Sig. \\
\hline & Bound & Bound & \\
\hline NOVEDAD & 0,001 & $-0,004$ & 0,006 & 0,785 \\
DAÑO & 0,000 & $-0,007$ & 0,006 & 0,923 \\
RECOMPENSA & $-0,002$ & $-0,007$ & 0,004 & 0,585 \\
PERSISTENCIA & $-0,003$ & $-0,008$ & 0,002 & 0,278 \\
AUTODIRECCIÓN & 0,001 & $-0,007$ & 0,008 & 0,887 \\
COOPERACION & 0,000 & $-0,006$ & 0,006 & 0,978 \\
AUTOTRASCENDENCIA & 0,003 & $-0,002$ & 0,008 & 0,291 \\
\hline
\end{tabular}

Variable dependiente (severidad del alcohol por el entrevistador), variables independientes: Novedad, Riesgo, Recompensa, Persistencia, Autodirección, Cooperacion, Autotrascendencia y variables de ajuste: edad y sexo

\begin{tabular}{ccccc}
\hline $\begin{array}{c}\text { Severidad legal por el } \\
\text { entrevistador }\end{array}$ & B & Lower & Upper & Sig. \\
Confianza & Bound & Bound & \\
\hline NOVEDAD & 0,000 & $-0,001$ & 0,002 & 0,616 \\
DAÑO & 0,000 & $-0,001$ & 0,002 & 0,639 \\
RECOMPENSA & 0,000 & $-0,001$ & 0,002 & 0,538 \\
PERSISTENCIA & 0,001 & 0,000 & 0,003 & 0,130 \\
AUTODIRECCIÓN & $-0,002$ & $-0,004$ & 0,000 & 0,087 \\
COOPERACION & 0,002 & 0,000 & 0,003 & 0,040 \\
\hline AUTOTRASCENDENCIA & $-0,001$ & $-0,003$ & 0,000 & 0,123 \\
\hline
\end{tabular}

Variable dependiente (severidad legal del entrevistador), variables independientes: Novedad, Riesgo, Recompensa, Persistencia, Autodirección, Cooperacion, Autotrascendencia y variables de ajuste: edad y sexo. 


\begin{tabular}{ccccc}
\hline $\begin{array}{c}\text { Severidad familiar por } \\
\text { el entrevistador }\end{array}$ & B & Lower & $\begin{array}{c}95 \% \text { Intervalo } \\
\text { Confianza }\end{array}$ & \\
\hline & & Upper & Sig. \\
NOVEDAD & 0,001 & $-0,005$ & 0,007 & 0,773 \\
DAÑO & 0,004 & $-0,004$ & 0,012 & 0,352 \\
RECOMPENSA & $-0,003$ & $-0,010$ & 0,004 & 0,429 \\
PERSISTENCIA & 0,005 & $-0,001$ & 0,011 & 0,119 \\
AUTODIRECCIÓN & $-0,006$ & $-0,016$ & 0,003 & 0,172 \\
COOPERACION & $-0,001$ & $-0,008$ & 0,006 & 0,800 \\
AUTOTRASCENDENCIA & $-0,002$ & $-0,008$ & 0,005 & 0,591 \\
\hline
\end{tabular}

Variable dependiente (severidad por el familiar entrevistado), variables independientes: Novedad, Riesgo, Recompensa, Persistencia, Autodirección, Cooperacion, Autotrascendencia y variables de ajuste: edad y sexo.

En el Europasi encontramos asociación positiva entre severidad médica valorada por el entrevistador y los rasgos de personalidad Evitación del daño (beta=0,004, $\quad \mathrm{p}=0,015), \quad$ Autodirección (beta $=0,004, \quad \mathrm{p}=0,011) \quad \mathrm{y}$ Autotrascendencia (beta $=0,004, p=0,042$ ).

También existe asociación positiva entre la severidad legal percibida por el médico entrevistador y la variable de Cooperación del TCI-R (beta $=0,002$; $p=0,040$ ). Sin embargo, no se ha encontrado asociación entre las restantes variables de severidad del Europasi (severidad psiquiátrica, severidad del alcohol y severidad familiar) y los rasgos de personalidad.

Tablas 38.2: Personalidad como variable independiente y variable dependiente EuropAsi (Características del consumo) 


\begin{tabular}{ccccc}
\hline $\begin{array}{c}\text { Edad inicio del } \\
\text { consumo }\end{array}$ & B & $\begin{array}{c}\text { Lower } \% \text { Intervalo } \\
\text { Confianza }\end{array}$ & Upper & Sig. \\
\hline Bound & Bound & \\
\hline NOVEDAD & $-0,028$ & $-0,050$ & $-0,007$ & 0,011 \\
DAÑO & 0,006 & $-0,023$ & 0,034 & 0,705 \\
RECOMPENSA & 0,017 & $-0,008$ & 0,041 & 0,175 \\
PERSISTENCIA & 0,008 & $-0,014$ & 0,031 & 0,468 \\
AUTODIRECCIÓN & $-0,006$ & $-0,040$ & 0,028 & 0,711 \\
\hline COOPERACION & $-0,015$ & $-0,041$ & 0,012 & 0,283 \\
\hline AUTOTRASCENDENCIA & $-0,009$ & $-0,032$ & 0,014 & 0,438
\end{tabular}

Variable dependiente (edad inicio del consumo), variables independientes: Novedad, Riesgo, Recompensa, Persistencia, Autodirección, Cooperacion, Autotrascendencia y variables de ajuste: edad y sexo

\begin{tabular}{ccccc}
\hline Duración del consumo & & & $\begin{array}{c}95 \% \text { Intervalo } \\
\text { Confianza }\end{array}$ & \\
\hline & B & Lower & Upper & Sig. \\
& & Bound & Bound & \\
NOVEDAD & $-0,028$ & $-0,068$ & 0,012 & 0,169 \\
DAÑO & $-0,013$ & $-0,067$ & 0,040 & 0,619 \\
RECOMPENSA & $-0,004$ & $-0,049$ & 0,041 & 0,850 \\
PERSISTENCIA & 0,031 & $-0,011$ & 0,073 & 0,151 \\
AUTODIRECCIÓN & $-0,012$ & $-0,075$ & 0,050 & 0,701 \\
COOPERACION & 0,006 & $-0,043$ & 0,055 & 0,822 \\
AUTOTRASCENDENCIA & $-0,025$ & $-0,067$ & 0,017 & 0,240
\end{tabular}

Variable dependiente (años que ha estado bebiendo), variables independientes: Novedad, Riesgo, Recompensa, Persistencia, Autodirección, Cooperacion, Autotrascendencia y variables de ajuste: edad y sexo. 


\begin{tabular}{ccccc}
\hline $\begin{array}{c}\text { Edad inicio consumo } \\
\text { patológico }\end{array}$ & B & Lower & Up $\%$ Intervalo \\
Confianza & \\
\hline & & Bound & Bound & \\
NOVEDAD & $-0,054$ & $-0,100$ & $-0,009$ & 0,019 \\
DAÑO & $-0,004$ & $-0,064$ & 0,056 & 0,897 \\
RECOMPENSA & 0,011 & $-0,040$ & 0,062 & 0,678 \\
PERSISTENCIA & 0,044 & $-0,004$ & 0,092 & 0,071 \\
AUTODIRECCIÓN & $-0,012$ & $-0,083$ & 0,058 & 0,730 \\
COOPERACION & $-0,013$ & $-0,069$ & 0,042 & 0,633 \\
AUTOTRASCENDENCIA & $-0,037$ & $-0,085$ & 0,011 & 0,131 \\
\hline
\end{tabular}

Variable dependiente (edad inicio del consumo patológico), variables independientes: Novedad, Riesgo, Recompensa, Persistencia, Autodirección, Cooperacion, Autotrascendencia y variables de ajuste: edad y sexo.

\begin{tabular}{ccccc}
\hline Gramos de alcohol & & & $\begin{array}{c}95 \% \text { Intervalo } \\
\text { Confianza }\end{array}$ & \\
\hline & B & Lower & Upper & Sig. \\
& & Bound & Bound & \\
NOVEDAD & 0,048 & $-0,265$ & 0,361 & 0,761 \\
DAÑO & $-0,056$ & $-0,472$ & 0,360 & 0,791 \\
RECOMPENSA & 0,085 & $-0,265$ & 0,435 & 0,632 \\
PERSISTENCIA & $-0,085$ & $-0,414$ & 0,244 & 0,611 \\
AUTODIRECCIÓN & $-0,385$ & $-0,874$ & 0,103 & 0,121 \\
\hline COOPERACION & $-0,009$ & $-0,392$ & 0,374 & 0,963 \\
AUTOTRASCENDENCIA & $-0,113$ & $-0,442$ & 0,217 & 0,501 \\
\hline
\end{tabular}

Variable dependiente (gramos de alcohol), variables independientes: Novedad, Riesgo, Recompensa, Persistencia, Autodirección, Cooperacion, Autotrascendencia y variables de ajuste: edad y sexo.

En cuanto a las características de consumo de alcohol del Europasi encontramos asociación positiva significativa entre edad de inicio del consumo 
y edad de inicio del consumo patológico y el rasgo Búsqueda de novedad (beta $=-0,028, p=0,011$ y beta $=-0,054 ; p=0,019$ ).

Tablas 38.3: Composites Scores

\begin{tabular}{ccccc}
\hline ALCOHOL & Lower & $\begin{array}{c}95 \% \text { Intervalo } \\
\text { Confianza }\end{array}$ & Sig. \\
& B & Bound & Bound & \\
NOVEDAD & 0,002 & $-0,063$ & 0,067 & 0,954 \\
DAÑO & 0,011 & $-0,067$ & 0,089 & 0,780 \\
RECOMPENSA & 0,016 & $-0,050$ & 0,082 & 0,635 \\
PERSISTENCIA & 0,021 & $-0,042$ & 0,083 & 0,515 \\
AUTODIRECCIÓN & $-0,042$ & $-0,131$ & 0,047 & 0,353 \\
COOPERACION & $-0,028$ & $-0,103$ & 0,047 & 0,462 \\
\hline AUTOTRASCENDENCIA & $-0,037$ & $-0,102$ & 0,027 & 0,257
\end{tabular}

Variable dependiente (alcohol), variables independientes: Novedad, Riesgo, Recompensa, Persistencia, Autodirección, Cooperacion, Autotrascendencia y variables de ajuste: edad y sexo

\begin{tabular}{ccccc}
\hline LEGAL & & & $\begin{array}{c}95 \% \text { Intervalo } \\
\text { Confianza }\end{array}$ & \\
& B & Lower & Upper & Sig. \\
& & Bound & Bound & \\
NOVEDAD & 0,003 & $-0,030$ & 0,036 & 0,862 \\
DAÑO & 0,018 & $-0,021$ & 0,057 & 0,372 \\
RECOMPENSA & 0,006 & $-0,027$ & 0,040 & 0,707 \\
PERSISTENCIA & 0,018 & $-0,014$ & 0,049 & 0,269 \\
AUTODIRECCIÓN & 0,012 & $-0,033$ & 0,056 & 0,609 \\
COOPERACION & $-0,007$ & $-0,044$ & 0,031 & 0,720 \\
AUTOTRASCENDENCIA & 0,005 & $-0,027$ & 0,038 & 0,754 \\
\hline
\end{tabular}

Variable dependiente (legal), variables independientes: Novedad, Riesgo, Recompensa, Persistencia, Autodirección, Cooperacion, Autotrascendencia y variables de ajuste: edad y sexo. 


\begin{tabular}{ccccc}
\hline FAMILIA & & \multicolumn{3}{c}{$\begin{array}{c}\text { Intervalo } \\
\text { Confianza }\end{array}$} \\
& & & Upper & Sig. \\
& B & Lower & Bound & \\
NOVEDAD & 0,029 & $-0,073$ & 0,131 & 0,574 \\
DAÑO & $-0,085$ & $-0,207$ & 0,037 & 0,171 \\
RECOMPENSA & 0,017 & $-0,087$ & 0,120 & 0,755 \\
PERSISTENCIA & 0,065 & $-0,034$ & 0,163 & 0,197 \\
AUTODIRECCIÓN & $-0,083$ & $-0,222$ & 0,056 & 0,243 \\
COOPERACION & 0,007 & $-0,110$ & 0,124 & 0,910 \\
\hline AUTOTRASCENDENCIA & $-0,046$ & $-0,147$ & 0,055 & 0,370 \\
\hline
\end{tabular}

Variable dependiente (familia), variables independientes: Novedad, Riesgo, Recompensa, Persistencia, Autodirección, Cooperacion, Autotrascendencia y variables de ajuste: edad y sexo.

\begin{tabular}{ccccc}
\hline ÁREA MÉDICA & Lower & $\begin{array}{c}95 \% \text { Intervalo } \\
\text { Confianza }\end{array}$ & \\
\hline & B & Bound & Bound & \\
NOVEDAD & $-0,003$ & $-0,067$ & 0,061 & 0,927 \\
DAÑO & 0,069 & $-0,007$ & 0,146 & 0,076 \\
RECOMPENSA & $-0,007$ & $-0,072$ & 0,059 & 0,838 \\
PERSISTENCIA & $-0,025$ & $-0,087$ & 0,037 & 0,428 \\
AUTODIRECCIÓN & 0,074 & $-0,014$ & 0,161 & 0,099 \\
COOPERACION & 0,021 & $-0,053$ & 0,094 & 0,579 \\
AUTOTRASCENDENCIA & 0,005 & $-0,059$ & 0,068 & 0,883 \\
\hline
\end{tabular}

Variable dependiente (área médica), variables independientes: Novedad, Riesgo, Recompensa, Persistencia, Autodirección, Cooperacion, Autotrascendencia y variables de ajuste: edad y sexo. 


\begin{tabular}{ccccc}
\hline ÁREA PSIQUIÁTRICA & & & $\begin{array}{c}95 \% \text { Intervalo } \\
\text { Confianza }\end{array}$ & \\
\hline & B & Lower & Upper & Sig. \\
& & Bound & Bound & \\
NOVEDAD & 0,001 & $-0,053$ & 0,056 & 0,957 \\
DAÑO & 0,082 & 0,016 & 0,147 & 0,015 \\
RECOMPENSA & $-0,029$ & $-0,085$ & 0,027 & 0,310 \\
PERSISTENCIA & $-0,017$ & $-0,069$ & 0,036 & 0,535 \\
AUTODIRECCIÓN & $-0,060$ & $-0,135$ & 0,015 & 0,117 \\
COOPERACION & 0,040 & $-0,022$ & 0,103 & 0,206 \\
AUTOTRASCENDENCIA & $-0,005$ & $-0,060$ & 0,049 & 0,849 \\
\hline
\end{tabular}

Variable dependiente (área psiquiátrica), variables independientes: Novedad, Riesgo, Recompensa, Persistencia, Autodirección, Cooperacion, Autotrascendencia y variables de ajuste: edad y sexo.

En los Composites Scores, hay una asociación positiva entre el área psiquiátrica y Evitación del daño (ED). No encontramos asociación entre las demás áreas de Europasi (alcohol, legal, familia y médica) y los rasgos de personalidad del TCI-R.

TABLAS 39: Modelo de regresión lineal múltiple de la intensidad del alcohol, como variable dependiente y la personalidad (TCI-R), como variables independientes. 


\begin{tabular}{ccccc}
\hline $\begin{array}{c}\text { EIDA DEPENDENCIA } \\
\text { LEVE }\end{array}$ & \multicolumn{3}{c}{$\begin{array}{c}95 \% \text { Intervalo } \\
\text { Confianza }\end{array}$} \\
\hline B & $\begin{array}{c}\text { Lower } \\
\text { Bound }\end{array}$ & Upper Bound & Sig. \\
NOVEDAD & 0,015 & $-0,014$ & 0,043 & 0,314 \\
DAÑO & 0,001 & $-0,032$ & 0,033 & 0,966 \\
RECOMPENSA & 0,023 & $-0,008$ & 0,054 & 0,148 \\
PERSISTENCIA & $-0,004$ & $-0,032$ & 0,025 & 0,799 \\
AUTODIRECCIÓN & $-0,017$ & $-0,054$ & 0,020 & 0,366 \\
COOPERACION & $-0,013$ & $-0,045$ & 0,020 & 0,431 \\
AUTOTRASCENDENCIA & $-0,002$ & $-0,030$ & 0,027 & 0,905 \\
\hline
\end{tabular}

Variable dependiente (gravedad leve), variables independientes: Novedad, Riesgo, Recompensa, Persistencia, Autodirección, Cooperacion, Autotrascendencia y variables de ajuste: edad y sexo.

\begin{tabular}{ccccc}
\hline $\begin{array}{c}\text { EIDA DEPENDENCIA } \\
\text { MODERADA }\end{array}$ & & \multicolumn{3}{c}{$\begin{array}{c}\text { \% Intervalo } \\
\text { Confianza }\end{array}$} \\
\hline B & Lower & Upper Bound & Sig. \\
Bound & & 0,063 & 0,136 \\
DOVEDAD & 0,027 & $-0,009$ & 0,074 & 0,331 \\
RECOMPENSA & $-0,024$ & $-0,025$ & 0,007 & 0,112 \\
PERSISTENCIA & 0,003 & $-0,034$ & 0,041 & 0,856 \\
AUTODIRECCIÓN & 0,024 & $-0,030$ & 0,078 & 0,375 \\
COOPERACION & 0,022 & $-0,019$ & 0,064 & 0,282 \\
AUTOTRASCENDENCIA & 0,020 & $-0,018$ & 0,058 & 0,303 \\
\hline
\end{tabular}

Variable dependiente (gravedad moderada), variables independientes: Novedad, Riesgo, Recompensa, Persistencia, Autodirección, Cooperacion, Autotrascendencia y variables de ajuste: edad y sexo 


\begin{tabular}{ccccc}
\hline $\begin{array}{c}\text { EIDA DEPENDENCIA } \\
\text { GRAVE }\end{array}$ & & & $\begin{array}{c}\text { 95 } \% \text { Intervalo } \\
\text { Confianza }\end{array}$ & \\
\hline & B & Lower & Upper Bound & Sig. \\
NOVEDAD & 0,037 & $-0,062$ & 0,137 & 0,453 \\
DAÑO & 0,143 & 0,032 & 0,254 & 0,012 \\
RECOMPENSA & $-0,049$ & $-0,157$ & 0,060 & 0,374 \\
PERSISTENCIA & 0,002 & $-0,080$ & 0,084 & 0,959 \\
AUTODIRECCIÓN & $-0,024$ & $-0,157$ & 0,108 & 0,715 \\
COOPERACION & 0,042 & $-0,086$ & 0,169 & 0,516 \\
AUTOTRASCENDENCIA & $-0,049$ & $-0,141$ & 0,044 & 0,295
\end{tabular}

Variable dependiente (gravedad grave), variables independientes: Novedad, Riesgo, Recompensa, Persistencia, Autodirección, Cooperacion, Autotrascendencia y variables de ajuste: edad y sexo.

\begin{tabular}{|c|c|c|c|c|}
\hline \multirow[t]{2}{*}{ EIDA: TOTAL } & \multicolumn{4}{|c|}{$\begin{array}{c}95 \% \text { Intervalo } \\
\text { Confianza }\end{array}$} \\
\hline & B & $\begin{array}{l}\text { Lower } \\
\text { Bound }\end{array}$ & Upper Bound & Sig. \\
\hline NOVEDAD & 0,070 & 0,008 & 0,131 & 0,026 \\
\hline DAÑO & 0,111 & 0,037 & 0,184 & 0,003 \\
\hline RECOMPENSA & $-0,048$ & $-0,111$ & 0,014 & 0,129 \\
\hline PERSISTENCIA & 0,020 & $-0,039$ & 0,079 & 0,512 \\
\hline AUTODIRECCIÓN & $-0,048$ & $-0,131$ & 0,036 & 0,263 \\
\hline COOPERACION & $-0,006$ & $-0,077$ & 0,064 & 0,861 \\
\hline AUTOTRASCENDENCIA & 0,053 & $-0,007$ & 0,114 & 0,084 \\
\hline
\end{tabular}

Variable dependiente (EIDA total), variables independientes: Novedad, Riesgo, Recompensa, Persistencia, Autodirección, Cooperacion, Autotrascendencia y variables de ajuste: edad y sexo.

No existe relación entre la dependencia leve y moderada del EIDA y la escala TCl-R de personalidad. Sin embargo, sí existe una relación entre la dependencia grave y la Evitación de daño (beta $=0,143 ; p=0,12$ ). También entre 
la puntuación total de EIDA y la Búsqueda de novedad (beta=0,070; $p=0,026$ ), y Evitación del daño (beta=0,111; $p=0,003$ ).

Tabla 40: Regresión lineal múltiple de la personalidad, como variable independiente, y el componente obsesivo compulsivo del consumo, como variable dependiente.

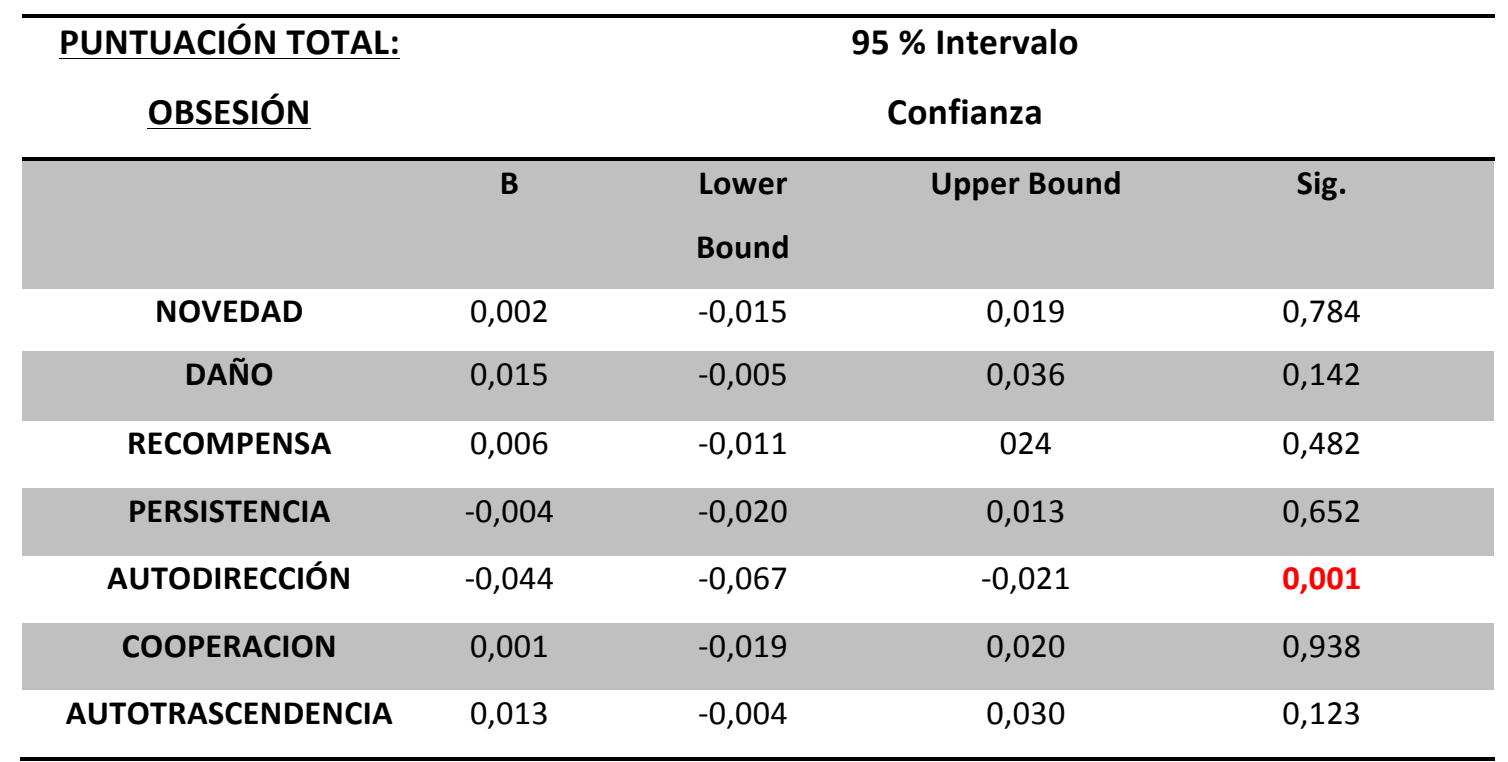

Variable dependiente (Puntuación Total Obsesión), variables independientes: Novedad, Riesgo, Recompensa, Persistencia, Autodirección, Cooperacion, Autotrascendencia.Variables ajuste: edad, sexo.

\begin{tabular}{ccccc}
\hline $\begin{array}{c}\text { PUNTUACIÓN TOTAL: } \\
\text { COMPULSIÓN }\end{array}$ & B & 95 \% Intervalo \\
Confianza & \\
\hline & & Bound & Upper Bound & Sig. \\
NOVEDAD & 0,009 & $-0,010$ & 0,027 & \\
DAÑO & 0,025 & 0,003 & 0,047 & 0,357 \\
RECOMPENSA & 0,006 & $-0,013$ & 0,025 & 0,027 \\
PERSISTENCIA & $-0,011$ & $-0,029$ & 0,006 & 0,548 \\
AUTODIRECCIÓN & $-0,020$ & $-0,045$ & 0,006 & 0,208 \\
COOPERACION & $-0,008$ & $-0,029$ & 0,013 & 0,126 \\
AUTOTRASCENDENCIA & 0,004 & $-0,015$ & 0,022 & 0,445 \\
\hline
\end{tabular}

Variable dependiente (Puntuación total compulsión), variables independientes: Novedad, Riesgo, Recompensa, Persistencia, Autodirección, Cooperacion, Autotrascendencia y variables de ajuste: edad y sexo. 


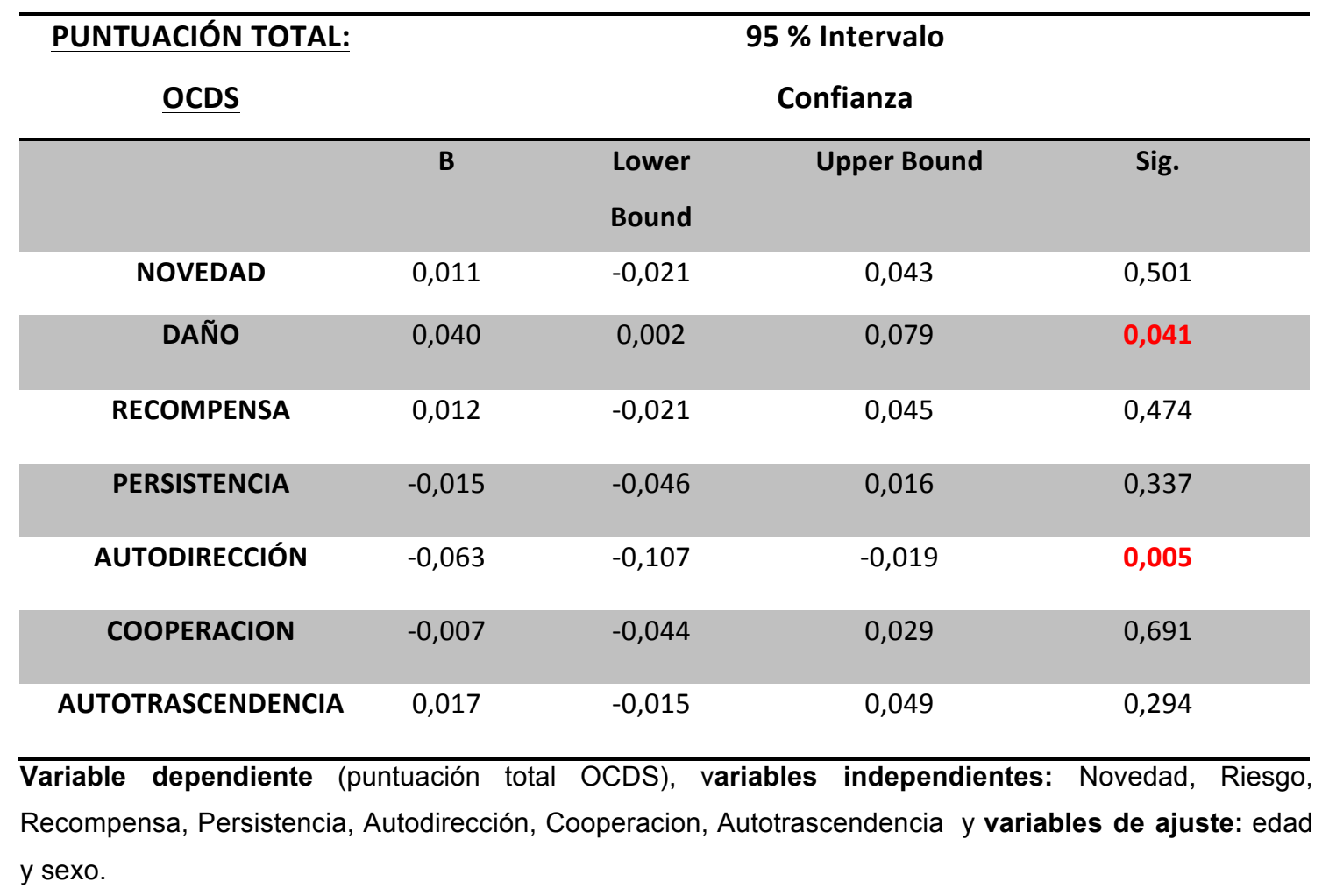

En cuanto a la relación entre la escala OCDS y la personalidad según TCl-R, observamos que existe una relación negativa entre la puntuación del componente obsesivo y Autodirección (beta $=-0,044 ; p=0,001$ ) y una relación positiva entre el componente compulsivo y el rasgo Evitación del daño (beta $=0,025 ; p=0,027$ ).

Finalmente, observamos una relación entre la puntuación total de la escala OCDS y Evitación del daño y Autodireccción, positiva la primera (beta $=0,040 ; p=0,041$ ) y negativa la segunda (beta $=-0,063 ; p=0,005$ ). 
Tablas 41: Regresión lineal múltiple de la personalidad, como variable independiente y variables biológicas de gravedad como variables dependientes.

\begin{tabular}{ccccc}
\hline GOT & \multicolumn{3}{c}{$\begin{array}{c}\text { 95 Intervalo } \\
\text { Confianza }\end{array}$} \\
& B & Lower & Upper Bound & Sig. \\
& & Bound & \\
NOVEDAD & $-0,210$ & $-0,993$ & 0,572 & 0,596 \\
DAÑO & 0,431 & $-0,610$ & 1,473 & 0,415 \\
RECOMPENSA & $-0,605$ & $-1,482$ & 0,272 & 0,175 \\
PERSISTENCIA & $-0,316$ & $-1,141$ & 0,508 & 0,450 \\
AUTODIRECCIÓN & 0,010 & $-1,212$ & 1,232 & 0,987 \\
\hline COOPERACION & 0,632 & $-0,328$ & 1,592 & 0,195 \\
\hline AUTOTRASCENDENCIA & 0,362 & $-0,463$ & 1,188 & 0,387 \\
\hline
\end{tabular}

Variable dependiente (GOT), variables independientes: Novedad, Riesgo, Recompensa, Persistencia, Autodirección, Cooperacion, Autotrascendencia y variables de ajuste: edad y sexo.

\begin{tabular}{|c|c|c|c|c|}
\hline \multirow[t]{2}{*}{ GPT } & \multicolumn{4}{|c|}{$\begin{array}{c}95 \% \text { Intervalo } \\
\text { Confianza }\end{array}$} \\
\hline & B & $\begin{array}{l}\text { Lower } \\
\text { Bound }\end{array}$ & Upper Bound & Sig. \\
\hline NOVEDAD & $-0,061$ & $-0,473$ & 0,350 & 0,768 \\
\hline DAÑO & 0,142 & $-0,406$ & 0,689 & 0,610 \\
\hline RECOMPENSA & $-0,276$ & $-0,737$ & 0,185 & 0,239 \\
\hline PERSISTENCIA & $-0,174$ & $-0,608$ & 0,259 & 0,428 \\
\hline AUTODIRECCIÓN & $-0,199$ & $-0,841$ & 0,443 & 0,541 \\
\hline COOPERACION & 0,439 & $-0,066$ & 0,943 & 0,088 \\
\hline AUTOTRASCENDENCIA & 0,143 & $-0,291$ & 0,577 & 0,517 \\
\hline
\end{tabular}

Variable dependiente (GPT), variables independientes: Novedad, Riesgo, Recompensa, Persistencia, Autodirección, Cooperacion, Autotrascendencia y variables de ajuste: edad y sexo 


\begin{tabular}{|c|c|c|c|c|}
\hline \multirow[t]{2}{*}{ GGT } & \multicolumn{4}{|c|}{$\begin{array}{c}95 \% \text { Intervalo } \\
\text { Confianza }\end{array}$} \\
\hline & B & $\begin{array}{l}\text { Lower } \\
\text { Bound }\end{array}$ & Upper Bound & Sig. \\
\hline NOVEDAD & $-0,300$ & $-1,689$ & 1,089 & 0,670 \\
\hline DAÑO & 0,028 & $-1,821$ & 1,876 & 0,976 \\
\hline RECOMPENSA & 0,729 & $-0,827$ & 2,285 & 0,356 \\
\hline PERSISTENCIA & $-1,166$ & $-2,629$ & 0,298 & 0,118 \\
\hline AUTODIRECCIÓN & $-0,702$ & $-2,871$ & 1,467 & 0,523 \\
\hline COOPERACION & $-0,317$ & $-2,020$ & 1,387 & 0,714 \\
\hline AUTOTRASCENDENCIA & 0,105 & $-1,361$ & 1,570 & 0,888 \\
\hline
\end{tabular}

Variable dependiente (GGT), variables independientes: Novedad, Riesgo, Recompensa, Persistencia, Autodirección, Cooperacion, Autotrascendencia y variables de ajuste: edad y sexo.

\begin{tabular}{|c|c|c|c|c|}
\hline \multirow[t]{2}{*}{ VCM } & \multicolumn{4}{|c|}{$\begin{array}{c}95 \% \text { Intervalo } \\
\text { Confianza }\end{array}$} \\
\hline & B & $\begin{array}{l}\text { Lower } \\
\text { Bound }\end{array}$ & Upper Bound & Sig. \\
\hline NOVEDAD & $-0,017$ & $-0,055$ & 0,022 & 0,393 \\
\hline DAÑO & 0,012 & $-0,040$ & 0,063 & 0,650 \\
\hline RECOMPENSA & 0,013 & $-0,030$ & 0,056 & 0,551 \\
\hline PERSISTENCIA & $-0,017$ & $-0,058$ & 0,024 & 0,405 \\
\hline AUTODIRECCIÓN & 0,022 & $-0,038$ & 0,083 & 0,463 \\
\hline COOPERACION & $-0,023$ & $-0,071$ & 0,024 & 0,332 \\
\hline AUTOTRASCENDENCIA & 0,004 & $-0,015$ & 0,022 & 0,684 \\
\hline
\end{tabular}

Variable dependiente (VCM), variables independientes: Novedad, Riesgo, Recompensa, Persistencia, Autodirección, Cooperacion, Autotrascendencia y variables de ajuste: edad y sexo.

No existe asociación entre las variables biológicas de gravedad y las variables del TCI-R. 


\section{8.- Objetivo 8}

Analizar la influencia del sexo en la relación de las características de personalidad del cuestionario de Cloninger y la gravedad, intensidad y componente obsesivo y compulsivo de la dependencia del alcohol.

Tablas 42: Interacción del sexo con la personalidad para predecir la gravedad de consumo

Tablas 42.1: Europasi

\begin{tabular}{|c|c|c|c|c|c|}
\hline & $\begin{array}{l}\text { SEVERIDAD } \\
\text { MÉDICA }\end{array}$ & $\begin{array}{c}\text { SEVERIDAD } \\
\text { PSIQUIÁTRICA }\end{array}$ & $\begin{array}{l}\text { SEVERIDAD } \\
\text { ALCOHOL }\end{array}$ & $\begin{array}{l}\text { SEVERIDAD } \\
\text { LEGAL }\end{array}$ & $\begin{array}{l}\text { SEVERIDAD } \\
\text { FAMILIAR }\end{array}$ \\
\hline & \multicolumn{5}{|c|}{ Sig. } \\
\hline SEXO - NOVEDAD & 0,687 & 0,383 & 0,667 & 0,808 & 0,904 \\
\hline SEXO - DAÑO & 0,015 & 0,251 & 0,823 & 0,757 & 0,289 \\
\hline SEXO - RECOMPENSA & 0,778 & 0,657 & 0,317 & 0,793 & 0,047 \\
\hline SEXO - PERSISTENCIA & 0,430 & 0,943 & 0,520 & 0,302 & 0,060 \\
\hline $\begin{array}{c}\text { SEXO- } \\
\text { AUTODIRECCIÓN }\end{array}$ & 0,108 & 0,438 & 0,931 & 0,171 & 0,505 \\
\hline SEXO-COOPERACIÓN & 0,965 & 0,611 & 0,796 & 0,082 & 0,201 \\
\hline $\begin{array}{c}\text { SEXO - } \\
\text { AUTOTRASCENDEN. }\end{array}$ & 0,065 & 0,005 & 0,475 & 0,311 & 0,917 \\
\hline
\end{tabular}

El sexo está influyendo en la relación entre la severidad médica y la variable de Evitación del daño del TCI-R. Éste también influye entre la severidad psiquiátrica y la Autotranscendencia del TCI-R. 
Por otro lado, el sexo no influye entre la severidad del alcohol, ni la severidad legal, y el TCl-R.

Por el contrario, el sexo sí influye entre la severidad valorada por el familiar y la Dependencia de recompensa.

Tablas 42 .2: Europasi Consumo

\begin{tabular}{|c|c|c|c|}
\hline & Edad inicio & $\begin{array}{c}\text { Edad inicio consumo } \\
\text { patológico }\end{array}$ & $\begin{array}{l}\text { Duración } \\
\text { consumo } \\
\text { patológico }\end{array}$ \\
\hline & \multicolumn{3}{|c|}{ Sig. } \\
\hline$\underline{\text { SEXO - NOVEDAD }}$ & 0,052 & 0,083 & 0,029 \\
\hline SEXO - DAÑO & 0,803 & 0,760 & 0,882 \\
\hline SEXO - RECOMPENSA & 0,369 & 0,294 & 0,186 \\
\hline SEXO - PERSISTENCIA & 0,395 & 0,191 & 0,186 \\
\hline SEXO - AUTODIRECCIÓN & 0,964 & 0,951 & 0,415 \\
\hline SEXO - COOPERACIÓN & 0,727 & 0,681 & 0,643 \\
\hline SEXO - AUTOTRASCENDENCIA & 0,772 & 0,345 & 0,199 \\
\hline
\end{tabular}

\begin{tabular}{clllll}
\hline & $\begin{array}{c}\text { Gramos } \\
\text { alcohol }\end{array}$ & GOT & GPT & GGT & VCM \\
\hline SEXO-NOVEDAD & 0,696 & 0,773 & 0,840 & 0,840 & 0,657 \\
$\underline{\text { SEXO- DAÑO }}$ & 0,646 & 0,751 & 0,852 & 0,864 & 0,517 \\
$\underline{\text { SEXO - RECOMPENSA }}$ & 0,779 & 0,263 & 0,451 & 0,716 & 0,522 \\
$\underline{\text { SEXO - PERSISTENCIA }}$ & 0,786 & 0,808 & 0,799 & 0,172 & 0,519 \\
$\begin{array}{c}\text { SEXO- } \\
\text { AUTODIRECCIÓN }\end{array}$ & 0,189 & 0,986 & 0,755 & 0,465 & 0,455 \\
$\begin{array}{c}\text { SEXO- } \\
\text { COOPERACIÓN }\end{array}$ & 0,131 & 0,329 & 0,178 & 0,219 & 0,509 \\
$\begin{array}{c}\text { SEXO- } \\
\text { AUTOTRASCENDEN. }\end{array}$ & 0,866 & 0,589 & 0,695 & 0,619 & 0,90 \\
\hline & & & & & \\
\hline
\end{tabular}


El sexo está influyendo en la relación de la duración del consumo patológico y la Búsqueda de novedad.

En cuanto a las variables biológicas de consumo, el sexo no influye entre éstas y las variables de personalidad.

Tablas 42 .3: Composites Scores

\begin{tabular}{|c|c|c|c|c|c|}
\hline & ALCOHOL & LEGAL & FAMILIA & MÉDICA & PSIQUIÁTRICA \\
\hline & \multicolumn{5}{|c|}{ Sig. } \\
\hline SEXO - NOVEDAD & 0,809 & 0,673 & 0,821 & 0,952 & 0,073 \\
\hline SEXO - DAÑO & 0,446 & 0,801 & 0,179 & 0,096 & 0,072 \\
\hline SEXO - RECOMPENSA & 0,821 & 0,771 & 0,756 & 0,776 & 0,537 \\
\hline SEXO - PERSISTENCIA & 0,495 & 0,528 & 0,364 & 0,658 & 0,672 \\
\hline $\begin{array}{c}\text { SEXO - } \\
\text { AUTODIRECCIÓN }\end{array}$ & 0,693 & 0,774 & 0,466 & 0,412 & 0,278 \\
\hline SEXO - COOPERACIÓN & 0,464 & 0,962 & 0,936 & 0,457 & 0,295 \\
\hline $\begin{array}{c}\text { SEXO - } \\
\text { AUTOTRASCENDENCIA }\end{array}$ & 0,140 & 0,627 & 0,698 & 0,698 & 0,982 \\
\hline
\end{tabular}

Observamos, según los datos expuestos, que el sexo no influye entre las variables de personalidad, según el TCl-R, y los composites scores. 
Tablas 44: Interacción del sexo con la personalidad para predecir la intensidad de consumo

\begin{tabular}{|c|c|c|c|c|}
\hline \multicolumn{5}{|c|}{ EIDA DEPENDENCIA Y TOTAL } \\
\hline & LEVE & MODERADA & GRAVE & Total \\
\hline \multicolumn{5}{|c|}{ SIG. } \\
\hline SEXO - NOVEDAD & 0,553 & 0,186 & 0,307 & 0,041 \\
\hline SEXO - DAÑO & 0,092 & 0,228 & 0,018 & 0,006 \\
\hline SEXO - RECOMPENSA & 0,553 & 0,444 & 0,884 & 0,286 \\
\hline SEXO - PERSISTENCIA & 0,712 & 0,852 & 0,194 & 0,448 \\
\hline $\begin{array}{c}\text { SEXO - } \\
\text { AUTODIRECCIÓN }\end{array}$ & 0,277 & 0,796 & 0,230 & 0,496 \\
\hline SEXO - COOPERACIÓN & 0,866 & 0,387 & 0,706 & 0,910 \\
\hline$\frac{\text { SEXO - }}{\text { AUTOTRASCENDENCIA }}$ & 0,960 & 0,651 & 0,395 & 0,233 \\
\hline
\end{tabular}

Existe una influencia del sexo entre la dependencia grave, puntuación total del EIDA y Evitación del daño.También influye entre Búsqueda de novedad y puntuación total del EIDA. 
Tablas 45: Interacción del sexo con la personalidad para predecir el componente obsesivo compulsivo del consumo

\begin{tabular}{|c|c|c|c|}
\hline & OCDS & & \\
\hline & $\begin{array}{c}\text { Puntuación } \\
\text { total Obsesión }\end{array}$ & $\begin{array}{c}\text { Puntuación total } \\
\text { Compulsión }\end{array}$ & $\begin{array}{c}\text { Puntuación } \\
\text { total }\end{array}$ \\
\hline & \multicolumn{3}{|c|}{ Sig. } \\
\hline SEXO - NOVEDAD & 0,958 & 0,638 & 0,785 \\
\hline SEXO - DAÑO & 0,398 & 0,105 & 0,158 \\
\hline SEXO - RECOMPENSA & 0,790 & 0,828 & 0,792 \\
\hline SEXO - PERSISTENCIA & 0,906 & 0,495 & 0,661 \\
\hline SEXO - AUTODIRECCIÓN & 0,002 & 0,351 & 0,024 \\
\hline SEXO - COOPERACIÓN & 0,924 & 0,696 & 0,905 \\
\hline SEXO - AUTOTRASCENDENCIA & 0,264 & 0,916 & 0,556 \\
\hline
\end{tabular}

Existe una influencia del sexo entre la puntuación total de la subescala obsesión del OCDS y la variable de Autodirección del TCI-R, además de entre la puntuación total de la OCDS y la variable de Autodirección del TCI-R.

No se observa influencia en el resto de variables. 
Influencia de la Personalidad en la Gravedad de los Trastornos por Consumo de Alcohol 
Influencia de la Personalidad en la Gravedad de los Trastornos por Consumo de Alcohol

Discusión 
Influencia de la Personalidad en la Gravedad de los Trastornos por Consumo de Alcohol 


\section{6.- DISCUSIÓN}

En el presente capítulo emplearemos los resultados obtenidos en nuestro trabajo, para poder comprobar la veracidad de nuestras hipótesis, para ello analizaremos el perfil de nuestra muestra, la características de ésta en función del modelo psicobiológico de Cloninger (TCl-R), los factores descriptivos de la gravedad del TCA, las correlaciones entre la gravedad del TCA y la personalidad, y la influencia del sexo en nuestro estudio

\section{- Perfil de nuestra muestra:}

La edad media obtenida en nuestro estudio fue de 43,6 años (DE 9,7), siendo igual en los hombres (43,6 años), que en las mujeres (43,8 años). La mayor parte de la muestra se encontraba comprendida entre los 41 y los 50 años $(39,80 \%)$, y a continuación entre los 31 y los 40 años $(29,28 \%)$. Sin embargo, si comparamos nuestros resultados, con los recogidos desde 1995 hasta 2013 en el último estudio EDADES 2015, éste sitúa la edad prevalente de ciudadanos que presentan una posible dependencia de alcohol (AUDIT > 0 $=20$ ), entre los 45 y 54 años (prevalencia del 0,7); a continuación el grupo más susceptible sería el comprendido entre los 15 y 24 años de edad (prevalencia del 0,6). En función del sexo, en los hombres la edad más frecuente para sufrir una posible dependencia de alcohol sería entre los 45 y 54 años (prevalencia del 1,1$)$, mientras que en el caso de las mujeres sería entre los 15 y los 24 años (prevalencia del 0,3).

En cuanto al género, la muestra fue mayoritariamente masculina, donde un $82,2 \%$ eran varones ( $\mathrm{N}: 250)$, mientras que un $17,8 \%$ pertenecía al género femenino (N:54). Esta proporción (5/1), coincide con la obtenida en otros trabajos, como el realizado por Mesa et al. en 2016, donde también obtienen una prevalencia del $80,1 \%$ de varones, en un estudio naturalístico, multicéntrico y prospectivo. Hecho que además puede extrapolarse a la población general con TCA, según se recoge del mismo estudio de prevalencias nacional (EDADES 2015), donde los ciudadanos con posible dependencia de alcohol (AUDIT> $0=20$ ), son mayoritariamente hombres, en relación con las mujeres $(0,8$ vs 0,1$)$. 
En relación al nivel de estudios, todos los pacientes de nuestra muestra con TCA, habían sido escolarizados, y los resultados son similares a los obtenidos en otros estudios (Díaz Mesa, E.M. et al en 2016). De los cuales 66 $(21,8 \%)$ tenían el graduado escolar; 142 pacientes $(46,6 \%)$, habrían completado estudios de secundaria (ESO); 63 (20,7\%), tenían bachillerato o estudios similares (FP o COU), y 33 estudios universitarios (10,9\%). La realidad, es que según se desprende de los datos del INE, la prevalencia de consumo de alcohol es mayor en las personas con estudios, a pesar de que el consumo habitual se suele observar más frecuentemente entre aquellos que poseen los niveles de formación más altos $(77,8 \%$ entre los universitarios vs al $40,6 \%$ sin estudios primarios) (ENSE 2011/12 MSSSI/INE)

En nuestra muestra el $62,2 \%$ de los pacientes, se encuentra activo laboralmente a tiempo completo, la mayor parte de ellos se agrupan en la construcción y otros servicios, mientras que el $22,7 \%$ de la muestra no trabaja en la actualidad. Estos datos concuerdan con los de la población general nacional, donde la mayor prevalencia de consumo en el último año se concentra en la población que está trabajando $(75,7 \%)$, seguidos de los desempleados (68,8\%) (ENSE 2011/12 MSSSI/INE).

En referencia a la cantidad de alcohol consumida, los pacientes presentaron consumo mayoritario de cerveza 1587,9 cc (DE 1383,8); seguido del vino con una media de $210,7 \mathrm{cc}$ de vino, $(432,2)$; y finalmente del licor con un consumo medio 179,4cc (DE 179,4), observando que la muestra representativa de las mujeres consume menos cantidad de alcohol (113 gr./día; p: 0.000), que los hombres. Resultados similares se muestran en la población general, en la que tanto hombres como mujeres consumen principalmente cerveza, seguido de vino, combinados y/o cubatas (principalmente los fines de semana), y licores, sobre todo si nos centramos en el rango de edad que con mayor prevalencia sufren un TCA, el de 55-64 años y el de 45-54 años (ENSE 2011/12 MSSSI/INE).

Con relación al subtipo de TCA presentado, encontramos que 244 pacientes $(80,3 \%)$, presentan una dependencia de alcohol, mientras que 60 de ellos (19,7\%), sufren un abuso de esta sustancia. Esta diferencia, también se mantiene si analizamos la muestra en función del sexo. El 78,9\% de los hombres (197), presentaba una dependencia de alcohol. En el caso de las 
mujeres, las diferencias son si cabe más acusadas, el 87,0\% (47 de ellas), presenta un diagnóstico de dependencia de alcohol, frente al 13,0\% (7), que presenta un patrón de abuso.

Los resultados que se obtienen a nivel nacional se desprenden de la encuesta EDADES 2015, en la cual se recogen los datos relativos al consumo de riesgo (AUDIT>8), y al consumo intensivo de alcohol.

En la población general el consumo de riesgo es mayor en hombres que en mujeres en todas las edades excepto en las más jóvenes -15 a 24 años-.

En las mujeres el consumo de riesgo se concentra en los fines de semana y en los hombres el consumo es tradicionalmente diario. El $85,3 \%$ de los hombres, cuyo consumo medio diario de alcohol supone un riesgo para su salud, bebe a diario, mientras que este porcentaje sólo llega al 56,6\% en mujeres. En cambio, de las mujeres bebedoras de riesgo, el 26,8\% concentra la bebida en los fines de semana, frente al 9,2\% de los hombres

Por otro lado, el consumo intensivo de alcohol es más frecuente en los más jóvenes, alcanzando el $8 \%$ entre los 15 y los 34 años, para luego descender a la mitad entre los 35 y los 64 años. Solo a partir de los 65 años está por debajo del $2 \%$. La frecuencia de consumo intensivo en el último mes es mayor en hombres $(7,1 \%)$ que en mujeres $(2,1 \%)$, y lo es en todos los grupos de edad. La razón de prevalencias entre hombres y mujeres es 3,4.

En conclusión el perfil de nuestra muestra es el de un varón, de 43 años, que reside en la ciudad, que convive en pareja, con estudios básicos, que trabaja en la construcción y otros servicios y consume preferentemente cerveza, con un perfil bioquímico hepático alterado por elevación significativa del enzima GGT y diagnosticado de un trastorno por dependencia del alcohol.

- Descripción de la muestra, en función de su personalidad, según el cuestionario TCI-R de Cloninger.

Al clasificar los pacientes seleccionados de nuestro estudio, en función del sexo y de las características de su personalidad, según el cuestionario de Cloninger, encontramos que los pacientes presentan puntuaciones elevadas en Búsqueda de Novedad (BN) y Evitación del Daño (ED), y una puntuación muy 
baja en Autodirección (AD), aunque estos resultados no sean significativos ni en la muestra general, ni en la evaluación por sexos.

Las puntuaciones elevadas en Búsqueda de Novedad (BN) se relacionan con sujetos que exhiben marcada búsqueda de nuevas sensaciones, se aburren fácilmente en situaciones rutinarias, y presentan impulsividad, desorganización y conductas extravagantes (Villarejo Ramos, A. 2012). Algunos autores señalan su relación con la toma de decisiones errónea (Tomassini et al., 2012).

Las puntuaciones altas en Evitación del Daño (ED), se suele relacionar con personas más cautelosas, inhibidas, temerosas, tímidas y propensas a la depresión y ansiedad lo cual en conjunto pronostica una mejor evolución de la patología y de la adherencia al tratamiento, sin embargo, estas diferencias no son significativas en la muestra general de nuestro estudio, ni en la evaluación en función del sexo (Wong et al, 2010).

Por otro lado, una puntuación baja en Autodirección (AD), se relaciona con sujetos con baja autoestima, dificultad para controlar sus emociones y autorregularse, con carencia de metas en su vida y tendencia a achacar sus problemas a los demás. Siendo probablemente la más dependiente de la experiencia directa del individuo en la interacción con el medio (Wong et al, 2010).

En esta misma línea, el estudio de Basieux et al (2001), también corrobora que los pacientes alcohólicos muestran significativamente puntuación elevada en $B N$ y baja en $A D$, y este hallazgo es más acusado en los sujetos con inicio precoz de la enfermedad.

La puntuación baja en $A D$ puede ser causa o consecuencia de la enfermedad. Por un lado, un ambiente poco propicio a la autonomía, en el sentido de determinar los modos propios de vivir y los objetivos vitales, puede favorecer que las sustancias con las que se comienza experimentando puedan llegar a cumplir muchas funciones que pudieron aprenderse por otros medios: pueden reducir el malestar, favorecer la interacción social, el rendimiento laboral, la autoestima y la aceptación social, etc. (Wedekind et al. 2013. Villarejo Ramos, A. 2012). Según estos autores la baja puntuación en autodirección (AD) sería origen de la dependencia del alcohol, antes que consecuencia de la misma. Por otro lado, una puntuación baja en AD podría 
ser secundaria a la enfermedad alcohólica, tal y como defienden Pedrero et al (2011), quienes señalan que esta baja puntuación se correlaciona con déficits prefrontales que inciden en la errónea toma de decisiones e incapacidad para controlar los efectos reforzantes del alcohol, que, por una parte, mantienen la dependencia y, por otra, son factores de riesgo para la recaída.

Si analizamos la personalidad de nuestra muestra, en función del sexo, encontramos que las mujeres, presentan puntuaciones significativamente más bajas en Persistencia (P), y Autotrascendencia (AT), que los hombres.

Las puntuaciones bajas en Persistencia $(\mathbf{P})$, que presentan las mujeres, están relacionadas con la capacidad para invertir esfuerzos en tareas con dificultad, superando la frustración y la fatiga. Dichas puntuaciones se relacionan con una peor evolución y un mayor número de recaídas, mostrando mayor dificultad a la hora de mantener la abstinencia (Pedrero et al 2006).

Una puntuación baja en Autotrascendencia (AT), rasgo asociado a la espiritualidad, a la percepción y codificación del sí mismo como parte de un todo no necesariamente tangible. A pesar de que ésta es la dimensión más influida por factores sociales, culturales y nacionales, se ha sugerido que existe una contribución genética similar para las 7 dimensiones del modelo de personalidad de Cloninger. Dichas puntuaciones se relacionan con una peor evolución, y un menor grado de abstinencia (Ávila, J.J et al. 2016).

En conclusión, las diferencias de personalidad atribuidas a las mujeres de nuestro estudio, se relacionan con un mayor número de recaídas y por tanto con una peor evolución de su TCA. Wedekind, D., Bandelow, B., Heitman, S., Havemann-Reinecke, U. y Engel, K. R. (2013), estudiaron las características de personalidad en una muestra de sujetos con TCA y obtuvieron puntuaciones elevadas en Evitación del Daño (ED), y puntuaciones significativamente bajas en Autodirección (AD), proponiendo que estas características originan mayor vulnerabilidad para padecer un TCA.

- Análisis de la gravedad del TCA, según el Índice Europeo de la Gravedad de la Adicción (EuropAsi), la Escala de Intensidad de la Dependencia de Alcohol (EIDA) y el componente obsesivo y compulsivo del deseo de consumo (OCDS) 
La puntuación del Î́ndice Europeo de la Gravedad de la AdicciónEuropAsi, y sus Composites Scores, se analizan a continuación.

a) Salud Física: La severidad médica observada por el médico es mayor en el caso de los hombres con una media de 1,11 puntos (DE 0,43), frente a los 1,06 de las mujeres (DE 0,23), aunque estos resultados no son estadísticamente significativos, en nuestro estudio. Estos datos concuerdan con los extraídos de otros estudios, donde los hombres tienen mayor probabilidad de presentar otras enfermedades crónicas, y por consiguiente ser hospitalizados por estos motivos, que las mujeres (Mesa et al. 2016)

b) Salud Psiquiátrica: ésta es más grave en el caso de las mujeres, con una puntuación de 1,26 (DE 0,48), frente al 1,11 (DE 0,43), de los varones. Estos resultados concuerdan con la mayor existencia de problemas afectivos en la población femenina con TCA, lo cual provoca una mayor prevalencia de intentos de suicidio, depresión e insomnio que requirieron tratamiento psiquiátrico, en comparación con los hombres (Mesa et al. 2016).

c) Evaluación del consumo de Alcohol: la edad media de inicio de consumo en nuestra muestra es de 16 años (DE 4,1), siendo de 15,6 años (DE 3,8 ), en el caso de los hombres, y de 18 años ( $D E 5,0$ ), en el caso de las mujeres. Datos que coinciden con otros estudios donde los hombres se iniciaron a una edad media significativamente menor que las mujeres (Díaz Mesa, E.M. et al en 2016), y con una tendencia a mantenerse estable entorno a los 16 años a nivel nacional (EDADES 2015)

Observamos que los hombres han consumido más tiempo que las mujeres, con una duración del consumo de 20,3 años (DE 11,0), en el caso de ellos, frente a los 13,4 años (DE 10,8) de ellas. Además, ellos presentan un consumo mayor: $144 \mathrm{gr}$ de alcohol frente a $114 \mathrm{gr}$ de alcohol. Estos resultados concuerdan con la mayoría de los estudios encontrados en la literatura, donde ellos presenta un patrón más abusivo, temprano y regular (Alvanzo et al., 2011; Buu et al., 2014; Green et al., 2009). 
La severidad objetivada por el entrevistador, es mayor en el caso de las mujeres, siendo de 6 puntos (DE 0,93), frente a los 5,87 de media en el caso de los hombres (DE 0,92).

d) Evaluación del ámbito laboral: El uso de sustancias influye en el ámbito socioeconómico. Los hombres presentan una mayor severidad laboral objetivada por el entrevistador $(2,71, \mathrm{DE} 2,152)$, frente a las mujeres $(2,60$, DE 1,974), aunque estas diferencias no son estadísticamente significativas. Se detecta un patrón de mercado laboral caracterizado por el predominio de trabajos manuales en los hombres, y por profesiones técnicas, administrativas, comerciales y los trabajos domésticos en las mujeres. Por otra parte, las mujeres han trabajado menos tiempo a jornada completa, como han mostrado otros estudios (Green et al., 2009; Huang et al., 2011).

e) Evaluación del ámbito familiar: Una extensa gama de investigación apunta a que el entorno familiar es más disfuncional en mujeres con TCA que en hombres (Kopak et al., 2012; Shand et al., 2011). Según nuestro estudio, no hay grandes diferencias en los problemas en el ámbito familiar ni en las puntuaciones de gravedad en esta área.

La severidad del los problemas familiares, según el entrevistados es prácticamente similar en ambos sexos, siendo de 1,78 (DE:1,12), en el caso de los hombres, y de 1,77 (DE1,10), en el caso de las mujeres, sin que estas diferencias sean significativas. Según Cranford, Tennen y Zucker (2015), siguiendo la teoría de la incompatibilidad de rol, el consumo sería más incongruente con los roles sociales del adulto, como el matrimonio en el caso de la mujer, lo que podría generar más problemas de pareja.

f) Evaluación del ámbito legal: La severidad legal es ligeramente superior en el caso de los hombres, siendo de 1,10 (DE 0,50), frente a 1,00 en el caso de las mujeres (DE 0,00), Lo cual concuerda con otros estudios (Green et al., 2009; Haas y Peters, 2000), donde hubo más hombres que mujeres que hubiesen estado en el calabozo o detenidos, aunque estas diferencias no sean significativas. 
g) Composites Scores: En relación con el perfil de gravedad de la adicción, cuando se observan los composites scores, se ve que hay pocas diferencias, y éstas muestran que las mujeres tienen mayor gravedad en los dominios de la vida relacionas con la salud mental (Mesa et al. en 2016). Sin embargo, los hombres de este estudio presentan más problemas relacionados con el uso de sustancias en todas las áreas de la vida (drogas, alcohol, familia, legal y área médica), en consonancia con lo que muestran otros estudios (Cotto et al., 2010; Kopak et al., 2012; Najt et al., 2011; Palmer et al., 2010).

La puntuación total de la escala EIDA en nuestra muestra es de 27,79 (DE 14,83), lo que corresponde con una dependencia moderada (entre 21 y 37 puntos). Por sexos, encontramos una puntuación de 26,78 (DE 14,24), en el caso de los hombres; y de 32,46 (DE 16,69), en el caso de las mujeres. Siendo la dependencia del alcohol significativamente más grave en las mujeres que en los hombres ( $p: 0.01$ ). Resultados similares se publican en otros estudios (Ávila, J.J et al. 2016 y Guardia Serecigni, J. et al. 2011), donde la gravedad de la muestra era moderada 27,61 (DE 14,72), 36,84 (DE: 16,51), respectivamente, aunque en las mujeres era mayor la severidad de la dependencia del alcohol 33,86 (DE 17,08).

Como excepción a la norma, observamos una tendencia a la dependencia grave, en un estudio preliminar con diferente objetivo, en una muestra tomada en la Unidad de Tratamiento del Alcoholismo de Salamanca en 2015 , donde la mayoría de los pacientes (45\%) presenta una dependencia grave, seguidos de una dependencia leve (28\%), y una dependencia moderada (27\%) (Fernández Ovejero, R. 2015.Tesis Doctoral).

Concluimos, por tanto, que la dependencia de nuestros pacientes es moderada (entre 21 y 37 puntos), a pesar de que ellas puntúan con mayor gravedad que los varones $(32,5 ; \mathrm{p}: 0.01)$

En relación con la escala OCDS la puntuación total de la muestra es de 15,13 (DE 7,8). Los hombres obtuvieron una puntuación de 14,64 (DE 7,1) y las mujeres 17,43 (DE 10,0). En otros artículos encontramos una puntuación media de 14,80 (DE 7,85), siendo de 14,24 (DE 7,14) en los hombres y de 17,48 (DE 10,28) en las mujeres (Ávila, JJ, 2016). 
La puntuación media en la subescala obsesión es 6,26 (DE 4,1); y la puntuación obtenidas en la subescala de compulsión serían de 8,87 (DE 4,4).

En conclusión, las mujeres refieren, significativamente, más deseo por el alcohol que los hombres (17,4; p: 0.01).

- Analizar la relación entre la personalidad, según el cuestionario de personalidad de Cloninger, y la gravedad del TCA.

Una puntuación elevada en Búsqueda de Novedad (BN) implica una menor edad de inicio del consumo de alcohol, menor edad de inicio del consumo patológico, más cantidad de gramos de alcohol consumidos, mayor gravedad de la dependencia valorada mediante EIDA y mayor puntuación en el componente obsesivo, compulsivo y total de la escala OCDS. Ninguna de las áreas del EUROPASI aparece alterada de forma significativa, tampoco influye el diagnóstico.

Las personas con puntuaciones elevadas en Evitación del Daño (ED) inician el consumo de alcohol más tarde, presentan mayor severidad psiquiátrica y de alcohol evaluadas por el entrevistador, presentan un diagnóstico de dependencia del alcohol, de manera que su dependencia puede ser definida como grave y obtienen puntuación elevada en la escala EIDA. Además se relaciona con mayor componente obsesivo, compulsivo y puntuación total de la escala OCDS.

Aunque presentan mayor severidad psiquiátrica, en la puntuación objetiva de este área ("composite scores"), coincidiendo con lo descrito anteriormente, sin embargo, presentan menor gravedad en el ámbito familiar según su puntuación objetiva.

Las puntuaciones elevadas en Dependencia de Recompensa (DR), se relacionan con mayor edad de inicio del consumo patológico, y mayor tiempo de consumo, a pesar de lo cual muestran una menor severidad psiquiátrica en la escala EuropAsi. Estas personas obtienen bajas puntuaciones totales en la escala EIDA. En relación con su puntuación objetiva no observamos correlaciones significativas.

Una puntuación elevada en Persistencia (P), se relaciona con una menor severidad psiquiátrica, tanto en la puntuación subjetiva como objetiva 
("composites scores"), y con una menor severidad médica también en esta última. Además estas puntuaciones se relacionan con menor compulsión por la bebida y menor puntuación total de la escala OCDS.

Con respecto a la Autodirección (AD), puntuaciones elevadas en este ítem, se relacionan con una menor severidad psiquiátrica, tanto en las puntuaciones subjetivas como objetivas ("composites scores"); y con la ausencia de un diagnóstico por dependencia de alcohol. Éstas personas suelen presentar menores puntuaciones en relación con una dependencia grave y una menor puntuación de la escala total del EIDA. Además, y para concluir se relacionan con puntuaciones bajas ante la obsesión y la compulsión por la bebida, además de puntuaciones totales bajas en la escala OCDS.

Cuanto mayor es la puntuación en Cooperación (CO), más tarde es la edad de inicio del consumo patológico de alcohol y más años ha estado bebiendo, lo cual no tiende a relacionarse con un diagnóstico de dependencia de alcohol. Estos pacientes obtienen bajas puntuaciones en EIDA total, y en la obsesión, compulsión y la puntuación total del OCDS.

Y para finalizar, en relación con la variable de Autotrascendencia (AT), las puntuaciones elevadas en este ítem, se relacionan únicamente con una menor severidad psiquiátrica

- Influencia del sexo en la relación de las características de personalidad del cuestionario de Cloninger y la gravedad, intensidad y componente obsesivo y compulsivo del consumo de alcohol.

El sexo está influyendo en la relación entre la Búsqueda de Novedad (BN), y la duración del consumo patológico. También existe una influencia del sexo entre la Evitación del Daño (ED), y la severidad médica, la dependencia grave y la intensidad por la bebida total (EIDA)

Existe una influencia del sexo entre la Dependencia de Recompensa (DR) y la severidad objetivada por un familiar. El sexo está influyendo en la relación entre la Autodirección (AD) y la obsesión por la bebida, además de la puntuación global de la obsesión-compulsión por la misma (OCDS). En último lugar, la Autotrascendencia (AT), se ve influida por el sexo ante la severidad 
psiquiátrica. severidad médica y la variable de Evitación del daño del TCI-R. Éste también influye entre la severidad psiquiátrica y la Autotranscendencia del TCl-R.

No existe influencia del sexo sobre la Persistencia (P), y la Cooperación (CO), y el resto de variables.

Según lo expuesto anteriormente, podemos comprobar la veracidad de las hipótesis de estudio que nos planteamos.

\section{Hipótesis 1:}

La personalidad, según la tipología de Cloninger, influye en la gravedad del Trastorno por Consumo de Alcohol, independientemente del sexo de la persona.

La gravedad del TCA, en nuestro estudio viene dada principalmente, por la puntación obtenida en el EUROPASI, en la escala EIDA, en la escala OCDS y diagnóstico (abuso y/o dependencia del alcohol). En relación a la existencia de correlaciones entre la personalidad y las distintas variables que definen la gravedad, encontramos:

Puntuaciones elevadas en Búsqueda de Novedad (BN), se relacionan con una mayor gravedad del TCA, la cual viene definida por una edad de inicio del consumo más temprana, así como la edad de inicio del consumo patológico, un mayor gasto económico en alcohol, un consumo de mayor cantidad de alcohol, mayor dependencia de la sustancia (mayor puntuación del EIDA), una mayor probabilidad de sufrir una dependencia grave, y mayor obsesión y compulsión por la bebida, además de mayor puntuación total de la escala OCDS.

Las puntuaciones elevadas en Evitación del Daño (ED), también se relacionan con un consumo más perjudicial de alcohol, definido por una mayor severidad psiquiátrica, mayor severidad en el consumo de alcohol y mayor tendencia a la dependencia grave, definida por la escala EIDA. 
La Dependencia de Recompensa (DR) se asocia con una menor severidad psiquiátrica, con un consumo de alcohol mantenido durante más años, a pesar de presentar una edad de inicio del consumo patológico más tardía y con una menor intensidad de la dependencia (EIDA).

La Persistencia (P), se relaciona con un mejor pronóstico, observándose que puntuaciones elevadas en este ítem, se relacionan con menor severidad psiquiátrica y menor obsesión por la bebida además de una menor puntuación conjunta del OCDS.

El ítem de Autodirección (AD), recoge también a aquellos pacientes que presentarían menor gravedad de su TCA, a través de una menor severidad psiquiátrica, y menor probabilidad de dependencia grave y de intensidad de la dependencia (EIDA total).

La Cooperación (CO), se relaciona con más tiempo de consumo (años que ha estado bebiendo) y con mayor edad del inicio del consumo patológico. Además puntuaciones elevadas en cooperación, se relacionan con una menor severidad laboral.

Ya para concluir, observamos que la Autotrascendencia (AT), también se relaciona con una menor gravedad, relacionándose con una menor severidad psiquiátrica.

\section{Hipótesis 2:}

Una puntuación elevada en los rasgos temperamentales (búsqueda de novedad, evitación del daño, dependencia de la recompensa y persistencia) está relacionada con mayor gravedad del Trastorno por Consumo de Alcohol, y viceversa.

Efectivamente los rasgos temperamentales, de Búsqueda de Novedad (BN), y de Evitación del Daño (ED), se corresponden con un mayor grado de severidad del TCA, ya que estos pacientes comienzan el consumo de alcohol más jóvenes, al igual que el consumo de alcohol patológico. Este consumo se da con mayor intensidad, y con una dependencia grave del alcohol. Además este conjunto de sujetos presentan una mayor compulsión y deseo ("craving") por la bebida, lo cual produce un mayor grado de severidad médica. 
A conclusiones similares llegan otros investigadores, quienes relacionan puntuaciones elevadas en Búsqueda de Novedad (BN), con un mayor abandono del tratamiento, lo cual prevé una mayor gravedad y peor evolución del TCA (Kravitz, H. M.; Fawcett, J.; McGuire, M.; Kravitz, G. S.; Whitney, M. 1999; Evren, C.; Durkaya, M.; Evren, B.; Dalbudak, E.; Cetin, R. 2012).

La correlación positiva de las dimensiones Búsqueda de Novedad (BN) y Evitación del Daño (ED), con la severidad de la dependencia del alcohol (EIDA), que encontramos en nuestro estudio, puede indicar que ambos rasgos son importantes en el mantenimiento de la enfermedad, como otros estudios han señalado (Tomassini et al., 2012).

Sin embargo no existe relación entre puntuaciones elevadas en Dependencia de Recompensa (DR), y Persistencia (P), con una mayor gravedad del TCA.

\section{Hipótesis 3:}

La puntuación elevada en los rasgos caracteriales (autodirección, cooperación y autotrascendencia) está relacionada con menor gravedad del Trastorno por Consumo de Alcohol, y viceversa.

Ante los mismos resultados concluimos que las puntuaciones elevadas en Autodirección (AD), se relacionan con una menor obsesión por la bebida, y con una mayor severidad médica. Las puntuaciones elevadas en Cooperación (CO), únicamente se relacionan con una mayor severidad legal; y las puntuaciones elevadas de Autotrascendencia (AT), sólo se relacionan con mayor severidad médica.

Diversos investigadores han encontrado que los pacientes con abstinencia prolongada presentan puntuaciones elevadas en Autodirección (AD) y Cooperación (CO), lo cual sería constituyente de un factor de buen pronóstico y de menor gravedad en relación con su TCA. (Andó et al., 2012; Monras et al. 2008)

Por otro lado, los resultados que obtenemos en nuestro estudio, reflejan una puntuación baja en Autodirección (AD). La puntuación baja en AD puede ser secundaria a la enfermedad alcohólica, como consecuencia de los 
problemas y adversidades sobrevenidos durante el desarrollo de la dependencia del alcohol, o el origen de la dependencia del alcohol (Wedekind et al. 2013), sea como fuere, estas puntuaciones se relacionan con un mayor riesgo para la recaída, además de constituír un factor en el mantenimiento de la dependencia (Pedrero et al 2011); por lo que, en conclusión las puntuaciones obtenidas en nuestra muestra se asocian con una peor evolución, una mayor gravedad y un peor pronóstico del TCA.

\section{Hipótesis 4:}

La relación de la personalidad según el TCl-R de Cloninger, con la gravedad del TCA, está mediada por el sexo.

Efectivamente, tres de las cuatro variables temperamentales, Búsqueda de Novedad (BN), Evitación del Daño (ED) y Dependencia de Recompensa (DR), se encuentra influidas por el sexo, en su relación con la gravedad del TCA, a través de la duración del consumo patológico, de la severidad médica, del tipo de dependencia, de la intensidad del consumo, y de la severidad familiar objetivada. Sin embargo no existe relación entre la Persistencia y la gravedad del TCA, a través del sexo.

Por otro lado, dos de las tres variables caracteriales, Autodirección (AD) y Autotrascendencia (AT), se encuentran influidas por el sexo en su relación con la gravedad del TCA, a través de la obsesión por la bebida y el deseo ("craving") por la misma, y a través de la severidad psiquiátrica, sin que haya esta relación con la variable de Cooperación (CO), y ninguno de los otros ítems asociados con gravedad, y el sexo.

En cuanto a las limitaciones en nuestro estudio, se trata de un estudio observacional, naturalístico, epidemiológico y de práctica clínica habitual, donde la muestra nos viene dada de forma no experimental, pero al obtener una muestra grande, obtenemos una imagen más aproximada a la realidad. 
Otra de las limitaciones que nos hemos encontrado viene dada por el mismo cuestionario del inventario TCl-R que consta de 240 ítems. En algunas ocasiones los pacientes no pudieron completarlo bien por falta de tiempo, bien por dificultades en la compresión de algunos ítems. Esta limitación se ha intentado solventar mediante la elaboración de versiones más abreviadas de 140 (Pedrero, 2006) y 60 ítems (Pedrero, 2009), aunque está en fase experimentación y validación.

La información obtenida sobre el perfil de personalidad de los pacientes con mayor gravedad del TCA, es tan solo descriptiva. Estos datos deberán ser tenidos en cuenta en fases posteriores a este estudio para la valoración de la efectividad de una intervención más dirigida en aquellos pacientes con un perfil de mayor gravedad, siendo idónea la realización con diseños controlados diferentes a este estudio, en un futuro. 
Influencia de la Personalidad en la Gravedad de los Trastornos por Consumo de Alcohol 
Influencia de la Personalidad en la Gravedad de los Trastornos por Consumo de Alcohol

Conclusiones 
Influencia de la Personalidad en la Gravedad de los Trastornos por Consumo de Alcohol 


\section{7.- CONCLUSIONES}

Los resultados obtenidos en este trabajo nos permiten expresar las siguientes conclusiones, todas referidas a los pacientes con Trastorno por Consumo de Alcohol de la Unidad de Salamanca.

Conclusión 1a: Los pacientes con TCA de este estudio, son mayoritariamente varones, con una edad media de 43,6 años, provenientes de un entorno urbano, con pareja, con estudios hasta la educación secundaria obligatoria (ESO), y con un empleo a tiempo completo, normalmente en la construcción u otros servicios.

Conclusión $2^{\mathrm{a}}$ : Los pacientes de la muestra presentan mayoritariamente un diagnóstico de dependencia de alcohol, con un consumo principalmente de cerveza y un aumento patológico de la GGT media de 154 u/L.

Conclusión $3^{\mathrm{a}}$ : En cuanto a su personalidad, evaluada mediante TCI-R, se caracteriza por puntuaciones elevadas en Búsqueda de Novedad y Evitación del Daño, con una puntuación muy baja en Autodirección. Las mujeres presentan menor puntuación en Persistencia y Autotrascendencia que los hombres, de manera significativa.

Conclusión 4a: Las mujeres consumen menos alcohol, que los hombres. Inician el consumo de alcohol dos años más tarde que ellos e inician el consumo patológico de alcohol más tarde, siendo la duración del consumo menor. Más de la mitad de las mujeres (57\%; p: 0.000) habían recibido tratamiento ambulatorio por patología psiquiátrica. Además éstas presentan mayor puntuación en gravedad psiquiátrica (1,26; p: 0.02), que los varones.

Conclusión 5a: El 39\% de la muestra de estudio había sido acusado de diferentes tipos de delitos, principalmente de tráfico, Los hombres de la muestra, han cometido significativamente más delitos que las mujeres. 
Conclusión $6^{\text {a: }}$ El Trastorno por consumo de alcohol es significativamente más grave en las mujeres que en los hombres, evaluado mediante la escala EIDA. Además ellas presentan más deseo por el alcohol que sus homólogos masculinos (OCDS).

Conclusión $7^{\text {a: }}$ Las puntuaciones elevadas en BN obtenidas en nuestra muestra, están en relación con un inicio del consumo del alcohol, y del consumo patológico más precoz. Además la cantidad consumida de alcohol es mayor, así como la intensidad de la dependencia (EIDA)

Conclusión $8^{\mathrm{a}}$ : Las puntuaciones elevadas obtenidas en ED en nuestro estudio se relacionan con mayor gravedad del alcohol, mayor severidad en el área psiquiátrica, y el diagnóstico de dependencia del alcohol es más frecuente. Estos pacientes presentan una mayor intensidad de la dependencia de alcohol (EIDA) y mayor deseo por el mismo (OCDS).

Conclusión 9a: Las puntuaciones bajas obtenidas en $A D$ en nuestra muestra, se relacionan con una mayor severidad psiquiátrica, mayor severidad en el área del alcohol y psiquiátrica del EuropAsi. Además los pacientes con puntuaciones significativamente más bajas, presentan un diagnóstico de dependencia de alcohol. Para concluir, estos pacientes presentan una mayor obsesión y deseo ("craving"), por la bebida (OCDS).

Conclusión 10a: Puntuaciones elevadas en BN y ED, como las obtenidas en nuestro estudio, se correlacionan con una mayor intensidad en la dependencia de alcohol (EIDA total). Además de con una dependencia grave en el caso de la ED.

Conclusión 11a: Las puntuaciones bajas en $A D$ obtenidas en nuestra muestra, implican una dependencia más grave.

Conclusión $12^{\mathrm{a}}$ : No existe relación entre la personalidad según el cuestionario TCI-R de Cloninger y la dependencia leve o moderada de alcohol. 
Conclusión 13a: Puntuaciones elevadas en BN, ED y bajas en AD, como las obtenidas en nuestro estudio, se relacionan con un mayor deseo por el consumo ("craving"), tanto en su componente obsesivo, como compulsivo.

Conclusión 14a: El sexo influye en la relación entre la BN y la duración del consumo patológico. También influye en la relación entre ED y la severidad médica, la dependencia grave y la intensidad de la dependencia de alcohol (EIDA total). Para finalizar se observa un influencia del sexo entre la AD y la obsesión por la bebida, además del deseo ("craving") por la misma.

Conclusión 15a: Los pacientes varones presentan puntuaciones elevadas en BN y ED, tiene un diagnóstico de dependencia del alcohol, inician el consumo precozmente, éste es más prolongado, el grado de dependencia es grave según cuestionario EIDA y presentan un deseo ("craving") importante por el alcohol.

Conclusión 16ª : Las mujeres presentan puntuaciones más elevadas en ED y más bajas en $A D$ que sus homólogos, pero inician el consumo de alcohol más tarde, la duración de este consumo es menor, y consumen menos cantidad, aunque la dependencia es más grave evaluada mediante EIDA, con mayor severidad médica según Europasi y mayor deseo por el alcohol ("craving"). 
Influencia de la Personalidad en la Gravedad de los Trastornos por Consumo de Alcohol 
Referencias Bibliográficas 
Influencia de la Personalidad en la Gravedad de los Trastornos por Consumo de Alcohol 


\section{8.- REFÉRENCIAS BIBLIOGRÁFICAS}

Abou-Saleh, M.T.; Janca, A. (2004). The epidemiology of substance misuse and comorbid psychiatric disorders. Acta Neuropsychiatrica. 16:3 -8.

Addolorato, G.; Leggio, L.; Abenavolli, L.; Agabio, R.; Caputo, F.; Capristo, E.; Colombo, G.; Gessa, G.L.; Gasbarrini, G. (2006) Baclofen in the treatment of alcohol withdrawal syndrome: a comparative study vs diazepam. American Journal Medicine. 119: 13-8.

Addy, P.H.; Radhakrishnan, R.; Cortes, J. A.; and D'Souza, D. C, (2012). Comorbid Alcohol, Cannabis, and Cocaine Use Disorders in Schizophrenia: Epidemiology, Consequences, Mechanisms, and Treatment. Focus. 10:140-153 Agrawal, A.; Health, A.C.; Lynskey, M.T (2011). DSM-IV to DSM-5. Addiction, 106: 1935- 1943.

Agrawal, A.; Narayanan, G.; Oltmanns, T.F. (2013) Personality pathology and alcohol dependence at midlife in a community sample. Personality Disorders. 4(1):55-61.

Ahima, R.S.; and Osei, S.Y. (2001). Molecular reguand prospects for therapeutic strategies behavior lation of eatin new insights. Trends in Molecular Medicine. 7, 205- 213.

Akerman, S.C.; Brunette, M.F.; Noordsy, D.L.; and Green, A.I. (2014). Pharmacotherapy of Co-Occurring Schizophrenia and Substance Use Disorders. Current Addiction Reports. 1:251-260

Akiskal, H.S. (2000). Mood disorders: introduction and overview. In Comprehensive Textbook of Psychiatry, B.J. Sadock and V.A. Sadock, eds. (New York: Lippincott, Williams \& Wilkins), pp. 1284- 1298.

Álamo, C., López-Muñoz, F. y Cuenca, E. (2002). Bases neurobiológicas del trastorno dual: hipótesis etiopatogénicas. En G. Rubio, F. López-Muñoz, C. Álamo, J. Santo- Domingo (Eds.). Trastornos psiquiátricos y abuso de sustancias. Madrid. Editorial Médica Panamericana.

Albatal, C. (2015). Perfil clínico y de personalidad en patología dual. Tesis 
doctoral. Universidad de Murcia.

Alonso Fernández, F.; Matilla, V. Bases psicosociales del alcoholismo (1979). Editorial Garsi. Madrid : Real Academia Nacional de Medicina.

Altar, C.A. (1999). Neurotrophins and depression. Trends in Pharmacol Science. 20, 59-61.

Altisent, R.; Pico, M.V.; Delgado, M.T.; Mosquera, J.; Auba, J.; Córdoba, R. (1997). Protocolo de alcohol en atención primaria. FMC Doyma ed. 3 (supl 4): 5-8.

Alvanzo, A. A.; Storr, C. L.; La Flair, L.; Green, K. M.; Wag- ner, F. A.; Crum, R. M. (2011). Race/ethnicity and sex differences in progression from drinking initiation to the development of alcohol dependence. Drug and alcohol dependence, 118, 375-382.

Álvarez Pedrero, A. y Ávila Escribano, J.J. (2015). Clinical and evolutionary characteristics of alcoholic hallucinosis. Study of six cases. Actas Españolas de Psiquiatría. 43(4):159-60.

American Psychiatric Association. (2000). Diagnostic and statistical manual for mental disorders, 4th edition, Revised Text. Washington, D.F: Autor (trad. cast.: Barcelona, Masson, 2001).

American Psychiatric Association. (2013). Diagnostic and statistical manual for mental disorders, 5th edition, DSM. Washington, D.F: American Psychiatric Publishing.

Anderson, P.; Chisholm, D.; Fuhr, D.C. (2009). Effectiveness and costeffectiveness of policies and programmes to reduce the harm caused by alcohol. Lancet. 373: 2234-46

Andó, B.; Must, A.; Kurgyis, E.; Szkaliczki, A.; Drótos, G.; Rózsa, S... Y Álmos, P.Z. (2012). Personality traits and coping compensate for disadvantageous decisión-making in long-term alcohol abstinence. Alcohol and Alcoholism, 47, 18-24. 
Anthenelli, R.M. (1997). A basic clinical approach to diagnosis in patients with comorbid psychiatric and substance use disorders. In: Miller, N.S., Ed. Principles and Practice of Addictions in Psychiatry. Philadelphia, PA: W.B. Saunders Company, 119-126.

Arackal, BS.; Benegal, V. (2007). Prevalence of sexual dysfunction in male subjects with alcohol dependence. Indian Journal Psychiatry. 49:109-112.

Arborelius, L., Owens, M.J., Plotsky, P.M., and Nemeroff, C.B. (1999). The role of corticotropin-releasing factor in depression and anxiety disorders. Journal of Endocrinology. 160, 1-12.

Ávila Escribano, J.J. (1989) Estudio de la personalidad en las esposas de pacientes alcohólicos. Tesis Doctoral. Universidad de Salamanca.

Ávila Escribano, J.J.; Marcos Martín, M.; Pastor Encinas I.; Laso Guzmán F.J. (2012). Tratamiento de la dependencia del alcohol. Medicine. 11(23):141220.

Ávila J.J.; Pérez, A.; Rodríguez, M.; Recio, J.; Fraile, E. (2012). Valor predictivo de la personalidad en la evolución del alcoholismo. Póster presentado en las XXXIX Jornadas Nacionales de Socidrogalcohol, Tarragona.

Ávila, J.J.; Sánchez, M.; Álvarez, A.; López, A.; Recio, J.; Rodríguez, M.; Fraile E. (2016). Capacidad de predicción del inventario de temperamento y carácter de Cloninger (TCl-R) en la evolución de los trastornos por uso de alcohol. Adicciones, 28,3:136-143.

Ayesta, F.J. (2002). Bases bioquímicas y neurobiológicas de la adicción al alcohol. Adicciones. 14(1): S63-78.

Babor, T.F. (2010). Alcohol: No ordinary commordity. Reseach and Public Policy. Oxford University Press. 2nd edition

Babor, T.F. (2010). La ciencia de la salud pública y la estrategia mundial sobre el alcohol. Boletín de la Organización Mundial de la Salud 2010;88:643-643.

Baigent, M.F. (2005). Understanding alcohol misuse and comorbid psychiatric 
disorders. Current Opinion in Psychiatry. 18:223-8.

Baillie, A.J.; Stapinski, L.; Crome, E.; Morley, K.; Sannibale, C.; Haber, P.; Teesson, M. (2010). Some new directions for research on psychological interventions for comorbid anxiety and substance use disorders. Drug and Alcohol Review 29:518-524.

Baker, A. L.; Thornton, L. K.; Hiles, S.; Hiles, y L.; Lubman, D. I. (2012). Psychological interventions for alcohol misuse among people with co-occurring depression or anxiety disorders: a systematic review. Journal of Affective Disorders, 137, 217-229.

Balanzá-Martínez, V.; Crespo-Facorro, B.; González-Pinto, A. and Vieta, E. (2015). Bipolar disorder comorbid with alcohol use disorder: focus on neurocognitive correlates. Frontiers in Physiology. 6:108.

Baldessarini, R.J.; Pompili, M.; Tondo, L. (2006). Suicide in bipolar disorder: risk and management. CNS Spectrums. 11, 465-471.

Baler, R.D.; Volkow, N.D. (2006). Drug Addiction: The neurobiology of disrupted self- control. Trends Molecular Medicine. 12 (1): 559-66.

Ball, S.A.; Tennen, H.; Poling, J.C.; Kranzler, H.R.; Rounsaville, B.J. (1997). Personality, temperament, and character dimensions and the DSM-IV personality disorders in substance abusers. Journal of Abnormal Psychology, $106,545-553$.

Barnea, Z.; Teichman, M.; Rahav, G. (1992). Personality, cognitive, and interpersonal factors in adolescent substance use: a longitudinal test of an integrative model. Journal of Early Adolescence, 11, 56-95.

Barratt, E.S.; Stanford, M.S.; Kent, T.A.; Felthous, A. (1997). Neuropsychological and cognitive psychophysiological substrates of impulsive aggression. Biological Psychiatry, 41(10):1045-61.

Basiaux, P., Le Bon, O., Dramaix, M., Massat, I., Souery, D., Mendlewicz, J....Verbanck, P. (2001). Temperament and character inventory (TCI) 
personality profile and sub-typing in alcoholic patients: a controlled study. Alcohol and Alcoholism, 36, 584-587.

Batki, S.L. (2015). What Is the Right Pharmacotherapy for Alcohol Use Disorder in Patients With Schizophrenia?. Journal of Clinical Psychiatry 76(10):1336-1337.

Bayon, C. (2006). Modelo psicobiológico de personalidad de Cloninger: Aproximación integradora en la evaluación de los trastornos de personalidad y proceso psicoterapéutico. Psiquiatría.com Revista internacional online. 10(1).

Becoña, E. (2014). Trastornos relacionados con sustancias y trastornos adictivos. Medicina Psicosomática y Psiquiatria de Enlace Revista Iberoamericana de Psicosomática, 110.

Benito, A.; Haro, G.; Orengo, T.; González, M.; Fornés, T.; C Mateu, C. (2012). Dependencia de Opiáceos tipo II o antisocial: utilidad del Modelo Psicobiológico de Cloninger en adicciones. Adicciones, 24, 2, 131-138

Berke, J.D. and Hyman, S.E. (2000). Addiction, dopamine, and the molecular mechanisms of memory. Neuron. 25, 515-532.

Bischof, G.; Rumpf, H.J.; Meyer, C.; Hapke, U.; John, U. (2005). Influence of psychiatric comorbidity in alcohol-dependent subjects in a representative population survey on treatment utilization and natural recovery. Addiction. 100:787-96.

Bizzarri, J. V.; Rucci, P.; Sbrana, A.; Miniati, M.; Raimondi, F.; Ravani, L.; Massei, G.J.; Milani, F.; Milianti, M.; Massei G.; Gonnelli, C.; Cassano, G.B. (2009). Substance use in severe mental illness: self-medication and vulnerability factors. Psychiatry Res. 165, 88-95.

Bjork, J. M.; Hommer, D. W.; Grant, S. J.; Danube, C. (2004). Impulsivity in abstinent alcohol-dependent patients: Relation to control subjects and type 1/type 2-like traits. Alcohol, 34, 133-150.

Blanchard, J.J.; Brown, S.A.; Horan, W.P.; Sherwood, A.R. (2000). Substance use disorders in schizophrenia: review, integration, and a proposed 
model. Clinical Psycholical Review. 20(2):207-34.

Bloomfield, K; Stockwell, T; Gmel, G; Rehn, N. (2003). International comparisons of alcohol consumption. Alcohol Research Health. 27:95-109.

Bobes Bascarán, M.T.; García-Portilla González, M.P. (2013). Evaluación y diagnóstico del trastorno por consumo de alcohol. Sociodrogalcohol. sociodroalcohol2013.org.

Bobes, J.; Bascarán, M.A.; Bobes Bascarán, M.A., Carballo, J.L.; Díaz Mesa, E.M.; Flórez, G.; García-Portilla, M.P.; Sáiz, P.A. (2007). Valoración de la gravedad de la adicción: Aplicación a la gestión clínica y monitorización de los tratamientos. PNSD. Ministerios de Sanidad y Consumo.

Bobes, J.; G-Portilla, M.P.; Bascarán, M.T.; Bousoño, M. (2002). Capítulo 3. Instrumentos de evaluación para los trastornos debidos al consumo de sustancias psicotropas: alcohol y otras drogas. Banco de Instrumentos Básicos para la Práctica de la Psiquiatría Clínica. Ars Médica. 2a ed,15-26.

Bordalejo, D.; Boullosa, O.; Hadid, E.; Puricell, M.; Romero, E.; Tannenhaus, L.; Vieitez, A.; Vázquez, G. (2014). Factores de carácter y temperamento según el modelo psicobiológico de personalidad de Cloninger en una muestra de pacientes bipolares eutímicos de la ciudad de Buenos Aires. Revista Argentina de Clínica Neuropsiquiátrica, 18, 4, 263-295.

Boschloo, L.; Vogelzangs, N.; van den Brink, W.; Smit, J. H.; Beekman, A. T. F.; Penninx, B. W .J. H. (2013). The role of negative emotionality and impulsivity in depressive/anxiety disorders and alcohol dependence. Psychological Medicine, 43, 1241-1253.

Brady, K.T.; Sonne, S.C. (1995). The relationship between substance abuse and bipolar disorder. Journal of Clinical Psychiatry. 56 Suppl. 3:19-24.

Brady, K. T., Verduin, M. L. (2005). Pharmacotherapy of comorbid mood, anxiety, and substance use disorders. Substance Use \& Misuse, 40, 20212041.

Brand, D.A.; Saisana, M.; Rynn, L.A.; Pennoni, F.; Lowenfels, A.B. (2007). 
Comparative analysis of alcohol control policies in 30 countries. Plos Medicine. 4: e151.

Braverman, M. (2001). Research on resilience and its implications for tobacco pre- vention. Nicotine \& Tobacco Research, 1(1), 67-72.

Bravo de Medina, R.; Echeburúa, E.; Aizpiri, J. (2007). Características psicopatológicas y dimensiones de personalidad en los pacientes dependientes del alcohol: un estudio comparativo. Adicciones. 19,4:371-381.

Bravo de Medina, R.; Echeburúa, E.; Aizpiri, J. (2008). Diferencias de sexo en la dependencia del alcohol: dimensiones de personalidad, características psicopatológicas y trastornos de la personalidad. Psicothema, 20 (2), 218-223.

Brière, F.N.; Rohde, P.; Seeley, J.R.; Klein, D.; Lewinsohn, P.M. (2014). Comorbidity between mayor depression and alcohol use disorder from adolescence to adulthood. Comprehensive Psychiatry. 55, 526-533.

Brinkman, S.; Stockwell, T.; Chikritzhs, T. (2000). An indicator approach to the measurement of alcohol related violence. In P. Williams (Ed.), Alcohol, Young People and Violence. Canberra: Australian Institute of Criminology, Research and Public Policy.

Britton, P.C.; Stephens, B.; Wu, J.; Kane, C.; Gallegos, A.; Asharafioun, L.; Tu, X. Conner, K.R. (2015). Comorbid depression and alcohol use disorders and prospective risk for suicide attempt in the year following inpatient hospitalation. Journal of Affective Disorders. 187, 151-155.

Brown, S. A.; Irwin, M.; and Schuckit, M. (1991). Changes in anxiety among abstinent male alcoholics. Journal of Studies on Alcohol 52:55-61.

Brown, S.E.; Suples, T.; Adinoff, B.; Thomas, N.R. (2001). Drug abuse and bipolar disorder: comorbidity or misdiagnosis?. Journal of Affective Disorders. 65:105-15.

Burns, L.; Teesson, M.; O'Neill, K. (2005). The impact of comorbid anxiety and depression on alcohol treatment outcomes. Addiction. 100:787-96 
Burroughs, A.K.; Morgan, M.Y.; Sherlock, S. (1985) Double-blind controlled trial of bromocriptine, chlordiacepoxide and chlormethiazole for alcohol withdrawal symptoms. Alcohol Alcohol. 20: 263-271.

Buu, A., Dabrowska, A., Mygrants, M., Puttler, L. I., Jester, J. M., y Zucker, R. A. (2014). Gender differences in the developmental risk of onset of alcohol, nicotine, and marijuana use and the effects of nicotine and marijuana use on alcohol outcomes. Journal of studies on alcohol and drugs, 75, 850-858.

Cangas, A.J; Olivencia, J.J. (2001). Relación de los trastornos de personalidad con el seguimiento de instrucciones terapéuticas y las recaídas en sujetos drogodependientes. Psicología conducutal, 9, 541-549.

Cappell, H.; Greeley, J. (1987). Alcohol and tension reduction. En: H.T. Blane, K.E. Leonard, (Eds.). Psychological theories of drinking and alcoholism. New York. Guildford Press.

Capps, B.; Hall, W.; Carter, A. (2012). Addiction. In: Chadwick R. Encyclopedia of applied ethics. 2nd. Ed. San Diego: Academic Press; 22-30.

Carbonari, J.C.; DiClemente, C.C. (2000). Using transtheoretical model profiles to differentiate levels of alcohol abstinence success. Journal of Consulting Clinical Psychology. 68: 810-817.

Carrà, G.; Bartoli, F.; Crocamo, C.; Brady, K.T.; Clerici, M. (2014). Attempted suicide in people with co-occurring bipolar and substance use disorders: systematic review and meta-analysis. Journal of Affective Disorders. 167:125-35.

Carlezon, W.A. Jr.; Thome, J.; Olson, V.G.; Lane-Ladd, S.B.; Brodkin, E.S.; Hiroi, N.; Duman, R.S.; Neve, R.L.; and Nestler, E.J. (1998). Regulation of cocaine reward by CREB. Science 282, 2272-2275.

Carmiol, N.; Peralta, J. M.; Almasy, L.; Contreras, J.; Pacheco, A.; Escamilla, M. A.; Knowles, E.E.; Raventós, H.; Glahn, D.C. (2014). Shared genetic factors influence risk for bipolar disorder and alcohol use disorders. European Psychiatry. 29, 282-287. 
Casas, M.; Franco, M.D.; Goikolea, J.M.; Jiménez-Arriero, M.A.; MartínezRaga, J.; Roncero, C.; Szerman, N. (2008). Trastorno bipolar asociado al uso de sustancias adictivas (patologla dual). Revisión sistemática de la evidencia científica y consenso entre profesionales expertos. Actas Españolas de Psiquiatrĺa; 36(6):350-361.

Casas M., Guardia J., (2002), Patología psiquiátrica asociada al alcoholismo. Adicciones. 14.supl. 1.

Castle, D.J. (2008). Anxiety and substance use: Layers of complexity. Expert Review of Neurotherapeutics 8:493-501.

Chinchilla Moreno, A. (2008). La depresión y sus máscaras. Editorial Médica Panamericana S.A. 1a ed., 1a imp. ISBN: 8479038713.

Chutuape, M.A.; De Wit, H. (1995). Preferences for ethanol and diazepam in anxious individuals: an evaluation of the self-medication hypothesis. Psychopharmacology, 121, 91-103.

Cloninger, C. R.; Svrakic, D. M.; Przybeck, T. R. (1993). A psychobiological model of temperament and character. Archives General Psychiatry, 50, 975990.

Cloninger, C.R.; Svrakic, D.M.; Przybeck, T.R. (1993) A psychological model of temperament and character. Archives General Psychiatry, 50:975-990.

Cloninger, R. C.; Bayon, C.; Svrakic, D.M. (1998) Measurement of temperament and character in mood disorders: a model of fundamental states as personality types. Journal of Affective Disorders, 51,1:21-32.

Cloninger, C.R. (1998) The genetics and psychobiology of the seven-factor model of personality. En: Silk KR (ed). Biology of personality dimensions. Washington: American Psychiatric Press, 63-92.

Cloninger,C.R.(1994)The genetic structure of personality and learning: A phylogenetic model. Clinical Genetics, 46, 124-137.

Cloninger, C.R.; Przybeck, T.R.; Svrakic, D.M.; Wetzel, R.D. (1994) The 
Temperament and Character Inventory (TCl): a guide to its development and use. Washington: Washington University Center for Psychobiology os Personality.

Cloninger, C.R. (1987). A systematic method for clinical description and classification of personality variants. Archives General Psychiatry; 44:573-588.

Cloninger, C. R. (2000). A practical way to diagnosis personality disorder: A proposal. Journal of Personality Disorders, 14, 99-108.

Comparative quantification of health risk: global and regional burden of disease attributable to selected major risk factors. Geneva: World Health Organization. (2004). 1, 959-1109.

Colom, F.; Vieta, E. (2004). A perspective on the use of psychoeducation, cognitive- behavioral therapy and interpersonal therapy for bipolar patients. Bipolar Disorder. 6:480-6.

Compton, W.M.; Dawson, D.A.; Goldstein, R. B.; Grant, B. F. (2013). Crosswalk between DSM-IV dependence and DSM-5 substance use disorders for opioids, cannabis, cocaine and alcohol. Drug and Alcohol Dependence, $122: 38.46$

Compton, W.M.; Thomas, Y.F.; Stinson, F.S.; Grant, B.F. (2007). Prevalence, correlates, disability and comorbidity of DSM-IV drug abuse and dependence in the United States: results from the national epidemiologic survey on alcohol and related conditions. Archives of General Psychiatry. 64:566-76.

Connors ,G.J.; DiClemente, C.C.; Dermen, K.H.; Kadden, R.; Carroll, K.M.; Frome, M.R. (2000). Predicting the therapeutic alliance in alcoholism treatment. Journal of Studies on Alcohol and Drugs. 61: 139-149.

Conway, K.P.; Kane, R.J.; Ball, S.A.; Poling, J.C.; Rounsaville, B.J. (2003). Personality, substance of choice, and polysubstance involvement among substance dependent patients. Drug and Alcohol Dependence. 71:65-75. 
Conway, K.P.; Swendsen, J.D.; Rounsaville, B.J.; Merikangas, K.R. (2002). Personality, drug of choice, and comorbid psychopathology among substance abusers. Drug Alcohol Dependence. 65:225-34.

Cosci, F.; Schruers, K. R.; Abrams, K.; Griez, E. J. (2007). Alcohol use disorders and panic disorder: a review of the evidence of a direct relationship. Journal of Clinical Psychiatry, 68, 874-880.

Cotto, J. H.; Davis, E., Dowling, G. J., Elcano, J. C., Staton, A. B., y Weiss, S. R. (2010). Gender effects on drug use, abuse, and dependence: a special analysis of results from the National Survey on Drug Use and Health. Gender medicine, 7, 402-413.

Craighead, W.E.; Miklowitz, D.J.; Craighead, L.W. (2013). Psychopathology; History, diagnosis, and empirical foundations. 2a ed. United States of America.

Cranford, J. A., Tennen, H., y Zucker, R. A. (2015). Using multiple methods to examine gender differences in al- cohol involvement and marital interactions in alcoholic probands. Addictive Behaviors, 41, 192-198

Crowe, LC.; George, WH. (1989). Alcohol and human sexuality: review and integration. Psychological Bulletin. 105:374-386.

Crump, C.; Sundquist, K.; Winkleby, M.A.; Sundquist, J. (2013). Comorbidities and Mortality in Bipolar Disorder. A Swedish National Cohort Study. JAMA Psychiatry. 70(9): 931-939.

Damez-Werno, D.; LePlant, Q.; Sun, H.; Scobie, K.N.; Dietz, D.M.; Walker, I.M.; Koo, J.W.; Vialou, V.F.; Mouzon, E.; Russo, S.J.; Nestler, E.J. (2012). Drug experience epigenetically primes Fosb gene inducibility in rat nucleus accumbens. Jouranl Neuroscience. 32 (30): 10267-72.

De Jong, C.A.; van den Brink, W.; Harteveld, F.M.; van der Wielen, E.G. (1993). Personality disorders in alcoholics and drug addicts. Comprehensive Psychiatry. 34(2): 87-94.

Díaz Mesa, E.M.; García Portilla, Fernández Artamendi, S.; A. Sáiz, P.; Bobes Bascarán, T.; Casares, M.J.; Fonseca, E. Al-Halabí, S.; Bobes, J. 
(2016). Diferencias de género en la gravedad de la adicción. Adicciones, 28, 4, 221-230

Dick, D. M., Smith, G., Olausson, P., Mitchell, S. H., Lee- man, R. F., O'Malley, S. S. y Sher, K. (2010). Understanding the construct of impulsivity and its relationship to alcohol use disorders. Addiction Biology, 15, 217-226.

DiClemente, C.C.; Hughes, S.O. (1990). Stages of change profiles in outpatient alcoholism treatment. Journal of Substance Abuse. 2: 217-235.

Di Florio, A.; Craddock, N.; and Van Den Bree, M. (2014). Alcohol misuse in bipolar disorder. A systematic review and meta-analysis of comorbidity rates. European Psychiatry 29, 117-124.

Dom, G.; D' haene, P.; Hulstijn, W.; Sabbe, B. (2006). Impulsivity in abstinent early- and late-onset alcoholics: Differences in self report measures and a discounting task. Addiction, 101, 50-9.

Dougherty, D. M.; Mathias, C. W.; Tester, L.; Marsh, D. M. (2004). Age at first drink relates to behavioral measures of impulsivity: The immediate and delayed memory tasks. Alcoholism: Clinical Experimental Research, 28, 408 - 14.

Drake, R.E.; Mueser, K.T.; Brunette, M.F.; McHugo, G.J. (2004). A review of treatments for people with severe mental illnesses and co-occurring substance use disorders. Psychiatry Rehabilitation Journal. 27(4):360-74.

Drevets, W.C. (2001). Neuroimaging and neuropathological studies of depression: Implications for the cognitive-emotional features of mood disorders. Current Opinion in Neurobiology. 11, 240-249.

Driessen, M.; Veltrup, C.; Wetterling, T.; John, U.; Dilling, H. (1998). Axis I and axis II comorbidity in alcohol dependence and the two types of alcoholism. Alcoholism: Clinical and Experimental Research, 22, 77-86.

Do, E.K. and Mezuk, B. (2013). Comorbidity between hypomania and substance use disorders. Journal of Affective Disorders. 150, 974-980.

Dougherty D.M., Bjork, J.M., Moeller, F.G., Harper, R.A., Marsh, D.M., 
Mathias, C.W. \& Swann, A.C. (2003). Familial transmission of continuous performance test behavior: attentional and impulsive response characteristics. Journal of General Psychology, 130, 5-21

D'Souza, D.C.; Abi-Saab, W.M.; Madonick, S.; Forselius-Bielen, K.; Doersch, A.; Braley, G.; Gueorguieva, R.; Cooper, T.B.; Krystal, J.H. (2005). Delta-9- tetrahydrocannabinol effects in schizophrenia: implications for cognition, psychosis, and addiction. Biological Psychiatry. 57(6): 594-608.

Ducci, F.; Enoch, M. A.; Funt, S.; Virkkunen, M.; Albaugh, B.; Goldman, D. (2007). Increased anxiety and other similarities in temperament of alcoholics with and without antisocial personality disorder across three diverse populations. Alcohol, 41, 3-12.

Duman, R.S., Heninger, G.R., and Nestler, E.J. (1997). A molecular and cellular hypothesis of depression. Archives of General Psychiatry. 54, 597-606.

Dunner, D.L.; Hensel, B.M.; Fieve, R.R. (1979). Bipolar illness: factors in drinking behavior. American Journal of Psychiatry;136:53-5.

Echeburúa, E.; De Medina, R. B.; Aizpiri, J. (2007). Comorbidity of alcohol dependence and personality disorders: a comparative study. Alcohol, 42, 618622.

Echeburúa, E.; De Medina, R. B.; Aizpiri, J. (2008). Variables de personalidad, alteraciones psicopatológicas y trastornos de la personalidad en pacientes con dependencia de alcohol en función de la tipología de Cloninger. Psicothema, 20 (4), 525-530.

Eckardt, M.J.; File, S.E.; Gessa, G.L.; Grant, K.A.; Guerra, C.; Hoffman, P.L.; Kalant, H.; Koob, G.F.; Li, T.K.; Tabakoff, B. (1998) Effects of moderate Talcohol consumption on the central nervous system. Alcohol Clinical and Experimental Research, 22, 998-1040.

Encuesta Nacional de Salud de España 2011/12 (ENSE 2011/12). Ministerio de Sanidad, Servicios Sociales e Igualdad. 
Encuesta sobre alcohol y drogas en España (EDADES) (2015). Ministerio de Sanidad, Servicios Sociales e Igualdad Secretaría de Estado de Servicios Sociales e Igualdad. Delegación del Gobierno para el Plan Nacional sobre Drogas. Madrid.

Evren, C.; Kural, S.; Erkiran, M. (2006). Antisocial personality disorder in Turkish substance dependent patients and its relationship with anxiety, depression and history of childhood abuse. Israel Journal of Psychiatry Related Sciences, $43,40-46$.

Evren, C.; Durkaya, M.; Evren, B.; Dalbudak, E.; Cetin, R. (2012). Relationship of relapse with impulsivity, novelty seeking and craving in male alcohol-depen- dent inpatients. Drug and Alcohol Review, 31, 81-90

Eysenck, H. J. (1997). Addiction, Personality and Motivation. Human Psychopharmacology: Clinical and Experimental, 12 (2), S79-S87.

Fassino, S.; Daga, G.A.; Delsedime, N.; Rogna, L.; Boggio, S. (2004). Quality of life and personality disorders in heroin abusers. Drug and Alcohol Dependence, 76, 73-80.

Fatseas, M.; Denis, C.; Lavie, E.; Auriacombe, M. (2010). Relationship between anxiety disorders and opiate dependence a systematic review of the literature: Implications for diagnosis and treatment. Journal of Substance Abuse Treatment, 38, 220-230.

Fava, M. and Kendler, K.S. (2000). Major depressive disorder. Neuron 28, 335-341.

Fernández Montalvo, J.; Echeburúa, E. (2006). Uso y abuso de los autoinformes en la evaluación de los Trastornos de Personalidad. Revista de Psicopatología y Psicología Clínica. Vol. 11; Nº1, pp. 1-12.

Fernández Montalvo, J.; Landa, N.; López-Goñi, J. J.; Lorea, I. (2006). Personality disorders in alcoholics: a comparative study with the IPDE and the MCMI-II. Addictive Behaviours, 31, 1442-1448. 
Fernández Montalvo, J.; Landa, N.; López-Goñi, J. J .; Lorea, I.; Zarzuela, A. (2002). Trastornos de la personalidad en alcohólicos: un estudio descriptivo. Revista de Psicopatología y Psicología Clínica, 7 (3), 217-225.

Fernández Montalvo, J., López-Goñi, J.J., Landa, N., Illescas, C., Lorea, I. Zarzuela, A. (2004). Trastornos de personalidad y abandonos terapéuticos en pacientes adictos: resultados en una comunidad terapéutica. International Journal of Clinical and Health Psychology, 4, 271-283.

Fernandez Alonso, F. (1988) Alcohol dependencia. Personalidad del Alcohólico. Editorial Salvat Barcelona.

Fernández Ovejero, R. (2015). Alteraciones de la esfera sexual en pacientes con trastorno por consumo de alcohol y su repercusión en la calidad de vida. Tesis Doctoral. Universidad de Salamanca

Fein, G.; Di Sclafani, V.; Finn, P. (2010). Sensation seeking in longterm abstinent alcoholics, treatment-naive active alcoholics, and nonalcoholic controls. Alcoholism: Clinical Experimental Research, 34, 1045-51.

Finn, P.R. (2002). Motivation, Working Memory, and Decision Making: A Cognitive- Motivational Theory of Personality Vulnerability to Alcoholism. Behavioral Cognitive Neuroscience Reviews. 1:183.

Foster, T.; Gillespie, K.; McClelland, R.; Patterson, C. (1999). Risk factors for suicide independent of DSM-III-R Axis I disorder. Case-control psychological autopsy study in Northern Ireland. British Journal of Psychiatry. 175:175-79.

Frisher, M.; Collins. J.; Millson, D.; Crome, I.; Croft, P. (2004). Prevalence of comorbid psychiatric illness and substance misuse in primary care in England and Wales. Journal of Epidemiology Community Health.; 58:1036-1041.

Fuchs, E.; Gould, E. (2000). Mini-review: in vivo neurogenesis in the adult brain: regulation and functional implications. European Journal of Neuroscience. 12, 2211-2214.

Galán, I.; González, M.J. (2014). Patrones de consumo de alcohol en España: 
un país en transición. Revista Española de Salud Pública, 88:529-540.

Galen, L.W., Henderson, M.J., Whitman, R.D. (1996). The utility of novelty seeking, harm avoidance and expectancy in the prediction of drinking. Addictive Behaviors, 22, 93-106.

García, A.; Portella, E. (2002). Los estudios del coste del alcoholismo: marco conceptual, limitaciones y resultados en España. Adicciones. 14 (1): 1-13

García-Portilla, M.P.; Bascarán, M.T.; Sáiz, P.A.; Bousoño, M.; Bobes, J. (2006) Banco de instrumentos Básicos para la Práctica de la Psiquiatría Clínica. Barcelona. Ars Medica.

Gemma, S.; Vichi, S.; Testai, E. (2006). Individual susceptibility and alcohol effects:biochemical and genetic aspects. Annali dell'Instituto Superiori Sanità; 42:8-16.

Gerdner, A.; Nordlander, T.; Pedersen, T. (2002). Personality factors and drug of choice in female addicts with psychiatric comorbidity. Substance Use and Misuse, 37, 1-18.

Gibson, S.; Becker, J. (1973). Changes in alcoholics' self-reported depression. Quaterly Journal of Studies on Alcohol, 34, 829-836.

Gil, J.A.; Pastor, J.F.; De Paz, F.; Barbosa, M.; Macías, J.A.; Maniega, M.A.; Rami, L.; Cañizares, S. (2002) Neurobiología de la adicción a las drogas de abuso. Revista Neurología, 35 (1): 361.

Girón García S. (2014). Interdictores en el tratamiento del alcoholismo. Una revisión crítica. Revista Española de Drogodependencias. 39 (3) 21011-347.

Glatt, M.M.; George, H.R.; Frisch, E.P. (1966). Evaluation of chlormethiazole in the treatment for alcohol withdrawal syndrome. Results of a controlled trial. Acta Pschyatrica Scandinava. 192: 121-137.

Global status report on alcohol and health. World Health Organization (2014). 
Gómez-Perretta, C.; Pérez, M.I.; Portolés, M.; Salom, R. (2001). Teoría tridimensional de la personalidad: aplicación a los trastornos por abuso de sustancias. Actas Españolas de Psiquiatría, 29,143-147.

Grant, B.F.; Hasin, D. S.; Stinson, F. S.; Dawson, D. A; Goldstein, R. B.; Smith, S.; Huang, B.; Saha, T. D. (2006). The epidemiology of DSM-IV panic disorder and agoraphobia in the United States: results from the National Epidemiologic Survey on Alcohol and Related Conditions. Journal Clinical Psychiatry; 67, 363-374.

Grant, B.F.; Hasin, D.S.; Stinson, F.S.; Dawson, D.A.; June Ruan, W.; Goldstein, R.B.; Smith, S.M.; Saha, T.D.; Huang, B. (2005). Prevalence, correlates, co-morbidity, and comparative disability of DSM-IV generalized anxiety disorder in the USA: results from the National Epidemiologic Survey on Alcohol and Related Conditions. Psychological Medicine; 35:1747-1759.

Grant, B.F.; Stinson, F.S.; Dawson, D.A.; Chou, S.P.; Dufour, M.C.; Compton, W.; Pickering, R.P.; Kaplan, K. (2004). Prevalence and cooccurrence of substance use disorders and independent mood and anxiety disorders: Results from the National Epidemiologic Survey on Alcohol and Related Conditions. Archives of General Psychiatry 61:807-816

Grant, B.F.; Stinson, F.S.; Hasin, D.S.; Dawson, D.A.; Chou, S.P.; June Ruan, W.; Huang, B. (2005). Prevalence, Correlates, and Comorbidity of Bipolar Disorder and Axis I and II Disorders: Results From the National Epidemiologic Survey of Alcohol and Related Conditions Journal of Clinical Psychiatry 66(10):1205-15.

Grant, V.V.; Stewar,t S.H.; Mohr, C.D. (2009). Coping-anxiety and copingdepression motives predict different daily mood-drinking relationships. Psychology of Addictive Behavior 23:226-37.

Green, T. C., Grimes Serrano, J. M., Licari, A., Budman, S. H., y Butler, S. F. (2009). Women who abuse pres- cription opioids: findings from the Addiction Severity Index-Multimedia Version Connect prescription opioid database. Drug and alcohol dependence, 103, 65-73. 
Grucza, R. A.; Goldberg, L. R. (2007). The comparative validity of 11 modern personality inventories: predictions of behavioral acts, informant reports, and clinical indicators. Journal of Personality Assessment, 89, 167-187.

Goodman, A. (2008). Neurobiology of addicticon. An integrative review. Biochemical Pharmacology. 75 (1): 226-322.

Goodwin, F.K.; Jamison, K.R.; (1990). Manic-depressive illness, New York: Oxford University Press.

Goodwin, R. D.; Lipsitz, J. D.; Chapman, T. F.; Mannuzza, S.; Klein, D. F.; Fyer, A. J. (2006). Alcohol use disorders in relatives of patients with panic disorder. Compehensive Psychiatry, 47, 88-90.

Gual, A. (2006). Alcoholismo. En J. Vallejo Ruiloba (Ed.): Introducción a la psicopatología y la psiquiatría (6a edic.). Barcelona: Elsevier/Masson.

Gual, A., He, Y., Torup, L., Van den Brink, W.; Mann, K. (2013). A randomised, double-blind, placebo controlled, efficacy study of nalmefene, as needed use, in patients with alcohol dependence. European Neuropsychopharmacology 23, 1432-1442.

Guardia, J. (2012). Trastornos mentales y del comportamiento asociados al consumo excesivo de alcohol. En: F. Pascual y J. Guardía (Eds). Monografías sobre alcoholismo (pp 219- 294). Barcelona: Socidrogalcohol.

Guardia, J.L.; Segura, L.; Gonzalo, B. (2000). Aplicaciones de las técnicas de neuroimagen en las conductas adictivas. Trastornos Adictivos, 12, 395-411.

Guardia, J.L.; Surkov, S.I.; Cardús, M. (2011). Bases neurobiológicas de la adicción. En: Bobes J, Casas M y Gutiérrez M. Manual de Trastornos Adictivos. 2a Edición. ADAMED Laboratorios.p. 25-33.

Guardia Serecigni, J. (2011) Cambio de paradigma en el tratamiento del alcoholismo de baja gravedad. Adicciones; 23:299-316.

Guardia Serecigni, J.; Estorch, M.; Surkov, S.; Del Valle Camacho, M.; García Ribas, G. (2011). La Escala Multidimensional de Craving de Alcohol y 
el SPECT con yodobenzamida como predictores de recaída precoz en pacientes que presentan dependencia del alcohol. Adicciones, 23,2. 157-164

Guardia Serecigni, J. (2015). Los Antagonistas de los Receptores Opioides en el Tratamiento del Alcoholismo. Adicciones, 27,3:214-230.

Guerri, C. (2012). Bioquímica de las adicciones. SEBBM, 172 (1):1-7.

Guo, R.; Ren ,J. (2010). Alcohol and acetaldehyde in public health: from marvel to menace. Int J Environ Res Public Health. 7:1285-1301.

Gutiérrez, F.; Sangorrín, J.; Martín-Santos, R.; Torres, X.; Torrens, M. (2002). Measuring the core features of personality disorders in substance abusers using the Temperamentand Character Inventory (TCI). Journal of Personality Disorders, 16, 344-359.

Gutierrez Fisac, J.L. (1995). Indicadores de consumo de alcohol en España. Medicina Clínica. (Barcelona).104:544-50.

Guyton, A.C.; Hall, J.E. (2006). Textbook of Medical Physiology. 11na. Ed. Philadelphia: Elservier Saunders.

Harris, E.C.; Barraclough, B. (1997). Suicide as an outcome for mental disorders. A meta-analysis. British Journal of Psychiatry 170, 205-228.

Hartz, S.M.; Pato, C.N.; Medeiros, H.; Cavazos-Rehg, P.; Sobell, J.L.; Knowles, J.A.; Bierut, L.J.; Pato, M.T. (2014). Comorbidity of Severe Psychotic Disorders With Measures of Substance Use. JAMA Psychiatry.71(3):248-254.

Harver B. (2003). Comorbid psychiatric disorders predict and influence treatment outcome in female alcoholics. European Addictions Research. 9:3944.

Hashimoto, E.; Tayama, M.; Ishikawa, H.; Yamamoto, M.; Saito, T. (2015). Influence of comorbid alcohol use disorder on treatment response of depressive patients. Journal of Neural Transmission, 122 (2), 301-306. 
Hasin, D.; O’Brien, C.P.; Auriacombe, M.; Borges, G.; Bucholz, K.; Budney, A.; Grant, B. F. (2013). DSM-5 criteria for substance use disorders: Recommendations and rationale. American Journal of Psychiatry, 170: 834851.

Hasin, D.; Fenton, M.C.; Skodol, A.; Krueger ,R.; Keyes, K.; Geier, T.; Greenstein, E.; Blanco, C.; Grant B. (2011). Personality Disorders and the 3Year Course of Alcohol, Drug, and Nicotine Use Disorders. Archives of General Psychiatry. November ; 68(11): 1158-1167.

Hasin, D., Liu, X., Nunes, E., Mccloud, S., Samet, S., Endicott, J. (2002). Effects of major depression on remission and relapse of substance dependence. Archives of General Psychiatry 59, 375-380.

Haas, A. L., y Peters, R. H. (2000). Development of subs- tance abuse problems among drug-involved offenders. Evidence for the telescoping effect. Journal of substance abuse, 12, 241-253.

Havassy, B.E.; Alvidrez, J.; Owen, K.K. (2004). Comparisons of patients with comorbid psychiatric and substance use disorders: implications for treatment and service delivery. American Journal of Psychiatry.; 161:139- 145.

Heinz, A.; Highley, J.D.; Gorey, J.G.; Saunders, R.C.; Jones, D.W.; Hommer, D.; Zajiecek, K.; suomi, S.J.; Lesch, K.P.; Weinberger, D.R.; Linnoila, M. (1998). In vivo association between alcohol intoxication, agresión and serotonin transporter availability in nonhuman primates. American Journal of Psychiatry, 155, 1023-1028.

Helzer, J.E.; Pryzbeck, T.R. (1988). The co-occurrence of alcoholism with other psychiatric disorders in the general population and its impact on treatment, Journal of Studies on Alcohol.;49:219-24.

Henriksson, M.M., Aro, H.M., Marttunen, M.J., Heikkinen, M.E., Isometsa, E.T., Kuoppasalmi, K.I., Lonnqvist, J.K. (1993). Mental disorders and comorbidity in suicide. American Journal of Psychiatry 150, 935-940.

Hesse, M. (2009). Integrated psychological treatment for substance use and 
co-morbid anxiety or depression vs. treatment for substance use alone. A systematic review of the published literature. BMC Psychiatry, 9:6.

Hicks, B. M.; Durbin, C. E.; Bloningen, D. M.; lacono, W. G.; McGue, M. (2011). Relationship between personality change and the honest and course of alcohol dependence in young adulthood. Addiction, 107, 540-548.

Hill, S. Y.; Shen, S.; Lowers, L.; Loske-Wellman, J.; Matthews, A.G.; McDermott, M. (2008). Psychopathology in offspring from multiplex alcohol dependence families with and without parental alcohol dependence: a prospective study during childhood and adolescence. Psychiatry Research, $160,155-166$.

Hittner J. B.; Swickert R. (2006). Sensation seeking and alcohol use: a metaanalytic review. Addictive Behavioral, 31, 1383-401.

Hoey, L.; Nehum, A.; Vance Bryan, K. (1994). A prospective evaluation of benzodiazepine guidelines in the management of patients hospitalized for alcohol withdrawal. Pharmacotherapy. 14: 579-585.

Hollbrook, A,; Crowther, R; Lotter, A.; Gheng, C.; King, D. (1999). Metaanalysis of benzodiazepine use in the treatment of acute alcohol withdrawal.. Canadian Medical Association Journal. 160:649-655.

Holsboer, F. (2001). Stress, hypercortisolism and corticosteroid receptors in depression: implications for therapy. Journal of Affective Disorders. 62, 77-91.

Horger, B.A.; lyasere, C.A.; Berhow, M.T.; Messer, C.J.; Nestler, E.J., and Taylor, J.R. (1999). Enhancement of locomotor activity and conditioned reward to cocaine by brain-derived neurotrophic factor. Journal of Neuroscience. 19, 4110-4122.

Hosak, L.; Preiss, M.; Halir, M.; Cermakova, E.; Csemy, L. (2004). Temperament and character inventory $(\mathrm{TCl})$ personality profile in metamphetamine abusers: a controlled study. European Psychiatry, 19, 193195. 
Huang, D. Y., Evans, E., Hara, M., Weiss, R. E., y Hser, Y. I. (2011). Employment Trajectories: Exploring Gender Differences and Impacts of Drug Use. Journal of vocational behavior, 79, 277-289

Hunt, G.E.; Siegfried, N.; Morley, K.; Sitharthan, T. and Cleary, M. (2013). Psychosocial interventions for people with both severe mental illness and substance misuse. Cochrane Database System Reviews. 10:CD001088.

Iraurgi, I.; González, F.; et al. (2002) Capítulo 2. En: Iraurgi I, González F, editores. Instrumentos de Evaluación en Drogodependencias. Aula Médica, p. 80-120.

Isbell, H.; Fraser, H.F.; Wikler, A.; Belleville, R.E. y Eiseman, A.J. (1995). An experimental study of the etiology of "rum fits" and delirium tremens. Journal of Studies on Alcohol, 16,1- 33.

Jelinek, E. M. (1960) The Disease Concept of Alcoholism. New Haven, Hillhouse Press.

Jiménez, G.; Ponce, G.; Rubio, G.; Palomo, T. (2003). Bases neurobiológicas del consumo de sustancias. En J. Bobes García, M. Casas Brugué y M. Gutiérrez Fraile (Eds.). Manual de evaluación y tratamiento de drogodependencias. Barcelona. Ars Medica.

Johnson, C.; Drgon, T.; McMahon, F. J. and Uhl, G. R. (2009). Convergent genome wide association results for bipolar disorder and substance dependence. American Journal of Medical Genetics. Part B, Neuropsychiatric. Genetics. 150B, 182-190.

Jones, K.D.; Gill, C.; Ray, S. (2012). Review of the proposed DSM-5 substance use Disorder. Journal of Addictions \& Offender Counseling, 33: 115 133.

Jordaan, G.P.; Emsley, R. (2014). Alcohol-induced psychotic disorder: a review. Metabolic Brain Disease;29(2):231-43.

Jordaan, G.P.; Warwick, J.M.; Nel D.G.; Hewlett, R.; Emsley, R. (2012). 
Alcohol-induced psychotic disorder: brain perfusion and psychopathology before and after anti-psychotic treatment. Metabolic Brain Disease. 27(1):67-77.

Kadden, R.M.; Carroll, K.; Donovan, D.; Cooney, N.; Monti Abrams, D.; Litt, M.; Hester, R. (1992). Cognitive-Behavioral Coping Skills Therapy Manual: A Clinical Research Guideline for Therapists Treating Individuals with Alcohol Abuse and Dependence. National Institute on Alcohol Abuse and Alcoholism. Rockville. MD.

Kaufmann, C.N.; Chen, L.Y.; Crum, R.M.; Mojtabai, R. (2014). Treatment seeking and barriers to treatment for alcohol use in persons with alcohol use disorders and comorbid mood or anxiety disorders. Social Psychiatry and Psychiatric Epidemiology, 49 (9),1489-1499.

Keller M. (1966) Discurso en homenaje a la memoria del profesor E.M. Jellinek. Simposio Internacional sobre Alcoholismo. Santiago de Chile

Kendler,K.S.; Heath,A.C.; Neale,M.C.; Kessler,R.C.; Eaves,L.J. (1993). Alcoholism and major depression in women. A twin study of the causes of comorbidity. Archives General Psychiatry. 50(9):690-8.

Kerridge, B.T.; Saha, T.D.; Gmel, G.; Rehm, J. (2013). Taxometric analysis of DSM-IV and DSM-5 alcohol use disorders. Drug and Alcohol Dependence, 129: 60-69.

Kessler, R.C. (1995). Epidemiology of psychiatric comorbidity, In: Tsuang MT, Tohen M, Zahner GEP, eds Textbook in Psychiatric Epidemiology, New York:Wiley:179-97.

Kessler, R.C.; Chiu, W.T.; Demler, O.; Merikangas, K.R.; Walters, E.E. (2005). Prevalence, severity, and comorbidity of 12-month DSM-IV disorders in the National Comorbidity Survey Replication. Archives General Psychiatry.; 62:617-627.

Kessler, R.C.; McGonagle, K.A.; Zhao, S.; Nelson, C.B.; Hughes, M.; Eshleman, S.; Wittchen, H.U.; Kendler, K.S. (1994). Lifetime and 12-month prevalence of DSM-III-R psychiatric disorders in the United States. Results from 
the National Comorbidity Survey. Archives General Psychiatry.; 51:8-19.

Kessler, R. C.; Rubinow, D. R.; Holmes, C.; Abelson, J. M.; and Zhao, S. (1997). The epidemiology of DSM-III-R bipolar I disorder in a general population survey. Psychological Medicine. 27, 1079-1089.

Killam, K.F.; Olds, J.; Sinclair, J. (1957). Further studies on the effects of centrally acting drugs on self- stimulation. Journal of Pharmacological Experimental Therapy, 19, 157.

Knyazev, G.G.; Slobodskaya, H.R.; Kharchenko, I.I.; Wilson, G.D. (2004). Personality and substance use in Russian youths: the predictive and moderating role of behavioural activation and gender. Personality and individual differences, 37, 827-843.

Köhnke, M. D. (2008). Approach to the genetics of alcoholism: a review based on pathophysiology. Biochem Pharmacol, 75, 160-177.

Koola, M.M.; McMahon, R.P.; Wehring, H.J.; Liu, F.; Mackowick, K.M.; Warren, K.R.; Feldman, S.; Shim, J-C.; Love, R.C.; Kelly D.L. (2012). Alcohol and Cannabis Use and Mortality in People with Schizophrenia and Related Psychotic Disorders. Journal of Psychiatry Research. 46(8): 987-993.

Kopak, A. M., Chen, A. C., Haas, S. A., y Gillmore, M. R. (2012). The importance of family factors to protect against substance use related problems among Mexican heritage and White youth. Drug and alcohol dependence, 124, 34-41.

Kraus, M.L (1985) Randomized clinical trial of atenolol in patients with alcohol withdrawal. New England Journal of Medicine. 313(15):905-9

Kravitz, H. M.; Fawcett, J.; McGuire, M.; Kravitz, G. S.; Whitney, M. (1999). Treatment attrition among alcohol dependent men: is it related to novelty seeking personality traits?. Journal of Clinical Psychopharmacology, 19, 51-56.

Kruenger, R. F. (2007) Linking Antisocial Behavior, Substance Use, and Personality: An Integrative Quantitative Model of the Adult Externalizing 
Spectrum. Journal of Abnormal Psychology.116 (4): 645-666.

Kuo, P.H.; Neale, M.C.; Walsh, D.; Patterson, D.G.; Riley, B.; Prescott, C.A.; Kendler, K.S. (2010). Genome-wide linkage scans for major depression in individuals with alcohol dependence. Journal of Psychiatry Research 44:61619.

Kuo, P-H.; YAng, H-J.; Soong, W-T.; CHen, W.J. (2002). Substance use among adolescents in Taiwan: associated personality traits, incompetence, and behavioral/emotional problems. Drug and alcohol dependence, 67, 27-39.

Kupfer, D.J.; Kuhl, E.A.; Regier, D.A. (2013). DSM-5-the future arrived. JAMA, 309: 1691- 1692.

Kushner, M.G.; Abrams, K.; Borchardt, C. (2000). The relationship between anxiety disorders and alcohol use disorders: a review of major perspectives and findings. Clinical Psychology Review, 20, 149-171.

Kushner M.G.; Sher K.J.; Erickson D.J. (1999). Prospective analysis of the relation between DSM- III anxiety disorders and alcohol use disorders. American Journal of Psychiatry; 156:723-732.

Landa, N.; Fernández-Montalvo, J.; López-Goñi, J.J.; Lorea, I. (2005). Trastornos de personalidad en alcohólicos: un estudio con el IPDE. Psicología Conductual, 13, 2, 275-287.

Lang, A. (1983). Addictive personality: A viable construct? En P. Levison, D. Gerstein y D. Maloff (Eds.), Commonalities in substance abuse and habitual behavior (pp. 157-235). Lexington, MS: Lexington Books of D. C. Heath.

Langas, A. M.; Malt, U.F.; Opjordsmoen, S. (2012). In-depth study of personality disorders in first-admission patients with substance use disorders. BMC Psychiatry 12, 180.

Lejuez, C.W. (2010). Behavioral and biological indicators of impulsivity in the development of alcohol use, problems, and disorders. Alcoholism: Clinical Experimental Research. 34 (8): 1334-1345.

Liotti, M.; Mayberg, H.S. (2001). The role of functional neuro-imaging in the 
neuropsychology of depression. Journal of Clinical and Experimental Neuropsychology. 23, 121-136.

Li ,Y.; Mao, Y.; Zhang, Y.; Cai, S.; Chen, G.; Ding, Y.; Guo, J.; Chen, K.; Jin, M. (2014). Alcohol drinking and upper aerodigestive tract cancer mortality: A systematic review and meta-analysis. Oral Oncology,50:269-275

Litt, M.; Hester, R. (1992) Cognitive-Behavioral Coping Skills Therapy Manual: A Clinical Research Guideline for Therapists Treating Individuals with Alcohol Abuse and Dependence. National Institute on Alcohol Abuse and Alcoholism. Rockville. MD.

Le Bon, O.; Basiaux, P.; Streel, E.; Tecco, J.; Hanak, C.; Hansenne, M.; et al. (2004). Personality profile and drug of choice; a multivariate analysis using Cloninger's TCl on heroin addicts, alcoholics, and a random population group. Drug Alcohol Dependence. 73:175-182.

Lemos, J.C.; Roth, C.A.; Messinger, D.I.; Gill, H.K.; Phillips, P.E.; Chavki, C. (2012). Repeated stress dysregulates k-opioid receptor signaling in the dorsal raphe through a p38 $\alpha$ MAPK-dependent mechanism. Journal Neuroscience. 32 (36): 12325-36.

León, M. L.; González, L.; León A.; de Armas, J.; Urquiza; A.; Rodriguez, G. (2015) Bases neurológicas de la adicción al alcohol. Revista Finlay, 4(1): 13 Lopez Izuel, C. (2005). Cuidados enfermeros. Barcelona: Masson.

López-Goñi, J. J.; Fernández-Montalvo, J.; Arteaga, A. (2011). Addiction Treatmen Dropout: Exploring Patients Characteristics. The Americam Journal on Addictions, 21, 78-85.

Loranger, A.W.; Sartorius, N.; Andreoli, A.; Berger, P.; Bucleim, P.; Channabasavanna, S.M. (1994). The International Personality Disorder Examination: The World Health organization/ alcohol/ Drug abuse and Mental Health Administration International Pilot Study of Personality Disorders. Archives of General Psychiatry, 51, 215-224.

Lukasiewicz, M.; Blecha, L.; Falissard, B.; Neveu, X.; Benyamina, A.; 
Reynaud, M.; Gasquet, I. (2009). Dual diagnosis: Prevalence, risk factors and relationship with suicide risk in a nationwide simple of French prisoners. Alcoholism: Clinical and Experimental Research, 33, 160-168.

MacKinnon, D.F.; Zandi, P.P.; Cooper, J.; Potash, J.B.; Simpson, S.G.; Gershon E.; Nurnberger, J.; Reich T.; DePaulo, J.R. (2002). Comorbid bipolar disorder and panic disorder in families with a high prevalence of bipolar disorder. American Journal of Psychiatry.159:30-5.

Mandelli, L.; Mazza, M.; Di Nicola, M.; Zarinotto, L.; Harnic, D.; Catalano, V.; Tedeschi, D.; Martinotti, G.; Bria, P.; Janiri, L.; Serreti, A. (2012). Role of substance abuse comorbidity and personality disorders: Harm Avoidance influences medium term treatment outcome. Psychopathology, 45, 174-178.

Malcolm, R.; Myrick, H.; Roberts, J.; Wang, W.; Anton, R.F.; Ballenger, J.C. (2002). The effects of carbamazepine and lorazepam on single versus multiple previous alcohol withdrawals in an outpatient randomized trial. Journal General Internal Medicine. 17: 349-355.

Mann, K. (2004). Pharmacotherapy of alcohol dependence. A review of the clinical data. CNS Drugs. 18:485-504.

Mann, K., Bladstrom, A., Torup, L., Gual, A. y Van den Brink, W. (2013). Extending the treatment options in alcohol dependence: a randomized controlled study of as- needed nalmefene. Biological Psychiatry, 73, 706- 713.

Manji, H.K.; Drevets, W.C.; and Charney, D.S. (2001). The cellular neurobiology of depression. Nature Medicine. 7, 541-547.

Manzanares, J.; García, M. S.; Celorrio, M. L.; Sánchez, M. M.; Rubio, G. (2010). Trastornos por ansiedad y adicciones. En: G. Haro, J. Bobes, M. Casas, J. Didia, G. Rubio (Eds.), Tratado sobre patología dual. Reintegrando la salud mental (pp. 531-571). Castellón: MRA Médica.

Marmorstein, N. R. (2012). Anxiety disorders and substance use disorders: different associations by anxiety disorder. Journal of Anxiety Disorders, 26, 8894. 
Marquenie, L. A.; Schadé, A.; van Balkom, A. J.; Comijs, H. C.; de Graaf, R.; Vollebergh, W. Van Den Brink, W. (2007). Origin of the comorbidity of anxiety disorders and alcohol dependence: findings of a general population study. European Addiction Research, 13, 39-49.

Martínez-González, J.M.; Graña, J. L.; Trujillo, H. M. (2009). Influencia de los trastornos de personalidad y patrones de consumo en la eficacia de un programa de prevención de recaídas para el tratamiento del alcoholismo. Adicciones, 21, 105-12.

Martins, S.S.; Gorelick, D.A. (2011). Conditional substance abuse and dependence by diagnosis of mood or anxiety disorder or schizophrenia in the U.S. population. Drug and Alcohol Dependence. 119(1-2):28-36.

Mateos Agut, J.; Mateos Agut M. (2005). Rasgos diferenciales del temperamento y el carácter en un grupo de alcohólicos vs población general. Adicciones, 17,4 : 325-335.

Mayo Smith, M.F.; Beecher, L.H.; Fischer, T.L.; Gorelick, D.A.; Guillaume, J.L.; Hill, A.; Jara, G.; Kasser, C.; Melbourne, J. (2004). Working Group on the Management of Alcohol Withdrawal Management of alcohol withdrawal delirium. An evidence-based practice guideline. Archives of Internal Medicine. $12 ; 164(13): 1405-12$.

Mayo Smith, M. (1997). Pharmacological management of alcohol withdrawal. A meta- analysis and evidence-based practice guideline. JAMA. 278: 144-151.

McEachin, R.C.; Keller, B.J.; Saunders, E.F. and Mcinnis M.G. (2008). Modeling gene-by-environment interaction in comorbid depression with alcohol use disorders via an integrated bioinformatics approach. BioData Mining. 1:213.

McEwen, B.S. (2000). Allostasis and allostatic load: implications for neuropsychopharmacology. Neuropsychopharmacology 22, 108-124.

McGahan, P.L.; Griffith, J. A.; Parente, R.; McLellan, A.T. (1986). Additction Severity Index. Composite Scores Manual. The University of 
Pennsylvania/Veterans Administration Center for Supported by Grants from the National Institute of Drug Abuseand the Veterans Administration.

McGlashan, T.H. (1989). Comparison of adolescent and adult-onset unipolar depression, American Journal of Psychiatry; 146.9:1208-11.

McLellan, A.T.; Kushner, H.; Metzger, D.; Peters, R.; Smith, I.; Grissom, G. Pettinati, H.; Argeriou, M. (1992). The Fifth Edition of the addiction severity index. Journal of Substance Abuse Treatment;9(3):199-213.

McLellan, A.T.; Luborsky, L.; Woody, G.E.; O'Brien, C.P. (1980). An improved diagnostic evaluation instrument for substance abuse patients. the addiction severity index. Journal of Nervous and Mental Disease. 168(1):26-33.

Merikangas, K. R.; Akiskal, H. S.; Angst, J.; Greenberg, P. E.; Hirschfeld, R. M.; Petukhova, M.; Kessler, R.C. (2007). Lifetime and 12-month prevalence of bipolar spectrum disorder in the National Comorbidity Survey replication. Arch. Gen. Psychiatry 64, 543-552.

Meszaros Z.S., Dimmock J.A, Snyder R.P., Abdul-Malak, Leontieva L., Canfield K., Batki S.L., (2011). Predictors of Smoking Severity in Patients with Schizophrenia and Alcohol Use Disorders. American Journal of Addiction; 20(5): 462-46.

Miller, W.R.; Rollnick, S. (1999). La entrevista motivacional. Preparar para el cambio de conductas adictivas. Paidós Ibérica. Barcelona.

Miller, W.R.; Zweben, A.; Di Clemente, C.C.; Rychtarick, R.G. (1992). Motivational enhancement therapy manual. A clinical research guide for therapist treating individuals with alcohol abuse and dependence. Proyect Match Monograph Series. Volume 2. Bethesda; NIAAA.

Milivojevic, D.; Milovanovic, S.D.; Jovanovic, M.; Svrakic, D.M.; Svrakic, N.M.; Svrakic, S.M.; Cloninger R. (2012). Temperament and Character Modify Risk of Drug Addiction and Influence Choice of Drugs. The American Journal on Addictions, 21: 462- 467. 
Mitchell, J. D.; Brown, E. S.; and Rush, A. J. (2007). Comorbid disorders in patients with bipolar disorder and concomitant substance dependence. Journal of Affective Disorders. 102, 281-287.

Moeller, F. G.; Dougherty, D. M.; Barratt, E. S.; Oderinde, V.; Mathias, C.W.; Harper, R. A., Swann, A.C. (2002). Increased impulsivity in cocaine dependent subjects independent of antisocial personality disorder and aggression. Drug Alcohol Dependence, 68,105-111.

Monras, M. (2010). Características diferenciales del alcoholismo femenino. Adicciones. 22,4,339-352

Monras, M.; Mondon, S.; Jou, J. (2008). Características de personalidad en pacientes alcohólicos mediante el cuestionario "Temperament and Character Inventory" (TCl). Diferencias según la existencia de abuso de benzodiazepinas (BZD) y trastornos de la personalidad. Adicciones, 20, 143-148.

Monras, M.; Mondon, S.; Jou J. (2008). Using the temperament and character inventory $(\mathrm{TCl})$ to predict out- come after inpatient detoxification during 100 days of outpatient treatment. Alcohol and Alcoholism, 43, 583-588.

Monte Secades, R.; Rabuñal Rey, R. (2011). Guía de práctica clínica: Tratamiento de abstinencia alcohólica, 2a edición. Galicia Clinica. 72 (2): 51-64.

Montes Gan, V.; Urosa Sanz, B.; Rubio Valladolid, G.; Poyo Calvo, F. (2006). Validación de la Escala sobre el Deseo de Beber - EDB. Clínica y Salud, 17(2), 203-223.

Mosquera Nogueira J; Guimerans Freijeiro C; Gómez Ben B; Davila Ddomínguez N. (2005). Desintoxicación ambulatoria de alcohol: una opción segura. Adicciones. 17 (1), 29-32.

Moss, H.B.; Chen, C.M.; Yi, H-J. (2007). Subtypes of alcohol dependence in a nationally representative sample. Drug and Alcohol Dependence, 91: 149-158.

Moustgaard, H.; Joutsenniemi, K.; Sihvo, S.; Martikainen, P. (2013). Alcohol-related deaths and social factors in depression mortality: a register- 
based follow-up of depressed in-patients and antidepressant users in Finland. Journal of Affective Disorders. 148(2-3), 278-285.

Nace, E.P.; Davis, C.W.; Gaspari, J.P. (1991). A systematic assessment of the comorbidity of DSM III R personality disorder in alcoholic outpatients. Comprehensive Psychiatry, 34, 447,454.

Naimi, T.S.; Xuan, Z.; Brown, D.W.; Saitz, R. (2013). Confounding and studies of 'moderate' alcohol consumption: the case of drinking frequency and implications for low- risk drinking guidelines. Addiction.108: 1534-1543.

Naranjo, C.A.; Kadlec, K.E.; Sanhueza, Woodley-Remus, D.; Sellers E.M. (1990). Fluoxetine differentially alters alcohol intake and other consummatory behaviors in problem drinkers. Clinical Pharmacology and Therapeutics 47:490498.

National Institute on Alcohol Abuse and Alcoholism (NESARC) (2010). Alcohol use and alcohol use disorders in the United States, a 3-year follow-up: main findings from the 2004-2005 wave 2 national epidemiologic survey on alcohol and related conditions. 8,2.

Najt, P., Fusar-Poli, P., y Brambilla, P. (2011). Co-occurring mental and substance abuse disorders: a review on the potential predictors and clinical outcomes. Psychiatry research, 186, 159-164.

Nery, F. G.; Hatch, J. P.; Monkul, E. S.; Matsuo, K.; Zunta-Soares, G. B.; Bow- den, C. L.; Jair, C.S. (2013). Trait impulsivity is increased in bipolar disorder patients with comorbid alcohol use disorders. Psychopathology 46, 145-152.

Nery, F. G.; Matsuo, K.; Nicoletti, M. A.; Monkul, E. S.; Zunta-Soares, G. B.; Hatch, J. P.; Lafer, B.; Soares, J.C. (2011). Association between prior alcohol use disorders and decreased prefrontal gray matter volumes in bipolar I disorder patients. Neuroscience Letter. 503, 136-140.

Nestler, E.J. (2001). Molecular basis of neural plasticity underlying addiction. Nature Reviews Neuroscience. 2, 119-128. 
Nestler, E.J.; Barrot, M.; DiLeone, R.J.; Eisch, A.J.; Gold, S.J.; Monteggia,.LM. (2002). Neurobiology of Depression. Neuron, 34 (1), 13-25.

New, A. S.; Stanley, B. (2010). Opioid deficit in borderline personality disorder: self- cutting, substance abuse and social dysfunction. American Journal Psychiatry, 167, 882-884.

Nielsen, D. A.; Ho, A.; Bahl, A.; Varma, P.; Kellogg, S.; Borg, I.; Kreek, M. J. (2012). Former heroin addicts with or without a history of cocaine dependence are more impulsive tan controls. Drug and Alcohol Dependence, 124, 113-20.

Niemi-Pynttäri, J.A.; Sund, R.; Putkonen, H.; Vorma, H.; Wahlbeck, K.; Pirkola, S.P. (2013). Substance-induced psychoses converting into schizophrenia: a register-based study of 18,478 Finnish inpatient cases. Journal of Clinical Psychiatry.74(1):e94-9.

Nimmerrichter, A.A.; Walter, H.; Gutierrez-Lobos, K.E.; Lesch, O.M. (2002). Double- blind trial of gamma-hydroxybutyrate and chlormethiazole in the treatment of alcohol withdrawal. Alcohol Alcohol. 37: 67-73.

Nöel, X.; Bervers, D.; Bechara, A.; Hanak, C.; Kornreich, Ch.; Verbanck, P.; Le Bon, O. (2011). Neurocognitive determinants of novelty and sensationseeking in indi- viduals with alcoholism. Alcohol and Alcoholism, 46, 407- 415.

Ntais, C.; Pakos, E.; Kyzas, P.; loannidis, J.P. (2005). Benzodiazepines for alcohol withdrawal. Cochrane Database of Systematic Reviews. (3): CD005063.

Nunes, E.V.; Levin, F.R. (2004). Treatment of depression in patients with alcohol or other drug dependence: a meta-analysis. JAMA. 291:1887-96.

Nunes, E.V.; Levin, F.R. (2008). Treatment of co-occurring depression and substance dependence: using meta-analysis to clinical recomendations. Psychiatric Annals. 38:730-8.

Nurnberger, J. I. Jr.; Foroud, T.; Flury, L.; Meter, E.T.; Wiegand, R. (2002). Is there a genetic relationship between alcoholism and depression?. Alcohol Research \& Health. 26(3):233-40. 
Nurnberg, H.G.; Rifkin, A.; Doddi, S. (1993) A systematic assessment of the comorbidity of DSM-III-R personality disorders in alcoholic outpatients. Comprehensive Psychiatry, 34,447-454.

OECD Health Statistics (database) (2012) OECD: Health Data: Pharmaceutical market.

O'Hara, R.E.; Armeli, S.; Tennen, H. (2014). Drinking-to-Cope Motivation and Negative Mood-Drinking Contingencies in a Daily Diary Study of College Students. Journal of Studies on Alcohol Drugs. 75(4): 606-614.

Olds, J.; Milner, P.M. (1954). Positive reinforcement produced by electrical stimulation of septal area and other regions of rat brain. Journal of Comprehensive Physiology and Psychology, 47, 419- 427

Oleson, E.B.; Gentry, R.N.; Chioma, V.C.; Cheer, J.F. (2012). Subsecond dopamine reléase in the nucleus acumbens predicts conditioned punishment and its successful avoidance. Journal Neuroscience; 32 (42): 14804-8

Oliva, C.; Clavijo, A. (2008). Alcholismo y adicciones: su manejo en la atención primaria de salud. In: Álvarez Sintes R. Medicina General Integral. Tomo 3. La Habana: ECIMED; 295-311.

Olmos Espinosa, R.; Díaz Moreno, H.; Bandres Moya, F. (2005). Marcadores biológicos de alcoholismo comparados mediante la utilización de curvas ROC. Psiquiatría Biológica.12(4):144-9.

Oquendo, M. A.; Currier, D.; Liu, S. M.; Hasin, D. S.; Grant, B. F.; and Blanco, C. (2010). Increased risk for suicidal behavior in comorbid bipolar disorder and alcohol use disorders: results from the National Epidemiologic Survey on Alcohol and Related Conditions (NESARC). Journal Clinical Psychiatry 71, 902-909.

Orengo, T.; M. González, M.; Benito A.; Ballester, F.; Cervera, G.; Haro G. (2007). El modelo psicobiológico de Cloninger en dependientes de opiáceos. Trastornos Adictivos. 9(2):108-15 
Organización Mundial de la Salud (2010). Estrategia mundial para reducir el uso nocivo del alcohol, Ginebra. (EB126/2010/REC/2).

Organización Mundial de la Salud. Serie de Informes Técnicos, 944. (2007). Ginebra, Organización Mundial de la Salud.

Ozdemir, V.; Bremner, K.E.; Naranjo, C.A. (1994). Treatment of alcohol withdrawal syndrome. Annals of Medicine. 26(2):101-5.

Palmer, E. J., Jinks, M., y Hatcher, R. M. (2010). Substance use, mental health, and relationships: A comparison of male and female offenders serving community senten- ces. International journal of law and psychiatry, 33, 89-93.

Palomar, J. (1999). Relación entre el funcionamiento familiar y la calidad de vida en familias con un miembro alcohólico. Salud Mental;22(6):13-21.

Pälsson, A. (1986). The efficacy of early chlormethiazole medication in the prevention of delirium tremens. A retrospective study of the outcome of different drug treatment strategies at the Helsingborg psychiatric clinics, 1975-1980. Acta Psychiatrica Scandinavica, 73: 140-145.

Parada, M.; Corral, M. (2011). Definición del concepto de consumo intensivo de alcohol - adolescente (binge drinking). Adicciones, 23:53-63

Parial, S. (2015). Bipolar disorder in women. Indian Journal of Psychiatry.57 (Suppl 2): S252-S263.

Paris, J. (2005). Neurobiological dimensional models of personality: A review of the models of Cloninger, Depue, and Siever. Journal of Personality Disorders, $19,156-170$.

Parker, G.; Hadzi-Pavlovic, D.; Parker, K.; Malhi, G.; Mitchell, P.; Wilhelm, K. et al. (2003). An Australian validation study of the temperament and carácter inventory. ActaPsychiatrica Scandinavica, 108, 359-366.

Parthasarathy, S., Weisner, C.M. (2005). Five-year trajectories of health care utilization and cost in a drug and alcohol treatment sample. Drug and Alcohol Dependence. 80, 231-240. 
Pattison, E.M.; Kaufman, E. (1982). The alcoholism síndrome: Definitions and models. In E.M. Pattison \& E. Kaufman (Eds.) Encyclopedic Handbook Of alcoholism. (3-30), New York: Gardner Press

Pedrero et al. (2011). Diferencia de personalidad entre adictos al alcohol y controles emparejados: relación con sintomatología frontal y subtipos de adictos. Psicothema, 23, 100-106.

Pedrero Pérez, E.J (2006). TCl-140: propiedades psicométricas, relación con el TCl-R y con variables de personalidad. Estudio de una muestra de adictos en tratamiento. Trastornos Adictivos 8:155-67.

Pedrero Pérez E.J. (2009). TCl-67: versión abreviada del TCI-R de Cloninger. Proceso de creación y administración a una muestra de adictos a sustancias en tratamiento. Trastornos Adictivos 11(1): 12-23.

Pedrero, E.; Rojo, G. (2008). Diferencias de personalidad entre adictos a sustancias y población general. Estudio con el TCl-R de casos clínicos con controles emparejados. Adicciones, 20 (3), 251-262.

Pedrero, E. J.,; Ruiz, J. M.; Olivar, A.; Rojo, G.; Llanero, M.; Puerta, C. (2011). Diferencia de personalidad entre adictos al alcohol y controles emparejados: relación con sintomatología frontal y subtipos de adictos. Psicothema, 23, 100-106.

Pedrero, E. J; Ruíz, J.M. (2012). Subtipos de adictos a la cocaína con y sin consumo problemático de alcohol asociado: hacia una neuropsicología de la personalidad aplicada a la clínica. Adicciones, 24(4), 291-300.

Pedrero, E. J.; Olivar, A.; Puerta, C. (2007). El carácter como predictor de trastornos de la personalidad en adictos: la tipología caracterial de Cloninger y su abordaje psicosocial. Revista Española de Drogodependencias, 32,342-369.

Pedrero Pérez, E. J.; Puerta-García, C.; Langares-Roibas, A.; Sáez, A.; Maldonado A. (2003). Prevalencia e intensidad de trastornos de personalidad en adictos a sustancias en tratamiento en un centro de atención a las drogodependencias. Trastornos adictivos, 25 (3), 241-255. 
Pedrero Pérez, E.J.; Ruiz Sánchez de León, J.M.; Olivar Arroyo, A.; Rojo Mota, G.; Marcos Llanero, L.; Puerta García, C. (2011). Diferencias de personalidad entre adictos al alcohol y controles emparejados: relación con sintomatología frontal y subtipos de adictos . Psicothema. 23, 1, 100-106

Pelissolo, A.; Corruble, E. (2002). Facteurs de personnalité dans les troubles dépressifs: appor ts du modèle psychobiologique de Cloninger. L'Encéphale, 28, 363-73.

Pérez, B.; de Vicente, M.P.; García, L.; Romero, C.; Oliveras, M.A. (2008). Prevalencia de psicopatología en dependientes de alcohol en tratamiento ambulatorio. Trastornos Adictivos. 10:42-8.

Pérez Rial, S.; Ortíz, S., Manzanares, J. (2003). Neurobiología de la dependencia alcohólica. Trastornos adictivos. 5 (1): 4-12.

Pettinati, H.M.; Oslin, D.W.; Kampman, K.M.; Dundon, W.D.; Gallis, T.L.; Dackis, C.A.; O'Brien, C.P. (2010). A double-blind, placebo-controlled trial combining sertralina and naltrexone for treating co-occurring depression and alcohol dependence. American Journal Psychiatry. 167: 668-75

Pettinati, H.M. (2013). Current status of co-occurring mood and substance use disorders: a new therapeutic target. American Journal of Psychiatry 170, 23.

Peugh, J.; Bel enko, S. (2001). Alcohol drugs and sexual function: a review. Journal PsychoactiveDrugs. 33:223-232.

Plan Nacional sobre Drogas (PNDS) (2009). Estrategia Nacional Sobre Drogas. Delegación del Gobierno para el Plan Nacional sobre Drogas Ministerio de Sanidad y Política Social 2009-2016

Plan Nacional sobre Drogas (2013) Encuesta Estatal sobre Uso de Drogas en Enseñanzas Secundarias. Madrid: Ministerio de Sanidad, Servicios Sociales e Igualdad.

Pliakas, A.M.; Carlson, R.R.; Neve, R.L.; Konradi, C.; Nestler, E.J.; and Carlezon, W.A. Jr. (2001). Altered responsiveness to cocaine and increased immobility in the forced swim test associated with elevated CREB expression in 
the nucleus accumbens. Journal of Neuroscience. 21, (18):7397-7403.

Poldrugo, F.; Forti, B. (1988). Personality disorders and alcoholism treatment outcomes. Drug and Alcohol Dependence, 21, 171-176.

Ponce, G.; Jiménez-Arriero, M.Á.; Rubio, G. (2003). Tratamiento farmacológico de la dependencia alcohólica. Trastornos Adictivos. 5(1):27-32.

Preuss, U. W.; Johann, M.; Fehr, C.; Koller, G.; Wodarz, N.; Hesselbrock, V.; Wong, W. M.; Soyka, M. (2009). Personality disorders in alcohol-dependent individuals: relationship with alcohol dependence severity. European Addiction Research, 15, 188- 195.

Pud, D., Eisenberg, E., Sprecher, E., Rogowski, Z., Yarnitsky, D. (2004). The tridimensional personality theory and pain: Harm avoidance and reward dependence traits correlate with pain perception in healthy volunteers. European Journal of Pain, 8, 31-38.

Pulido, J. (2014). Estudios poblacionales en España sobre daños relacionados con el consumo de alcohol. Revista Española Salud Pública; 88:493-513.

Rae, A.; Joyce, P.R.; Luty, S.E.; Mulder, R.T. (2002). The effect of a history of alcohol dependence in adult mayor depression. Journal of Affective Disorders, 70, 281-290.

Raimo, E.; Schuckit, M. (1998). Alcohol dependence and mood disorders. Addictive Behaviors, 23, 933-946.

Rajkowska, G. (2000). Histopathology of the prefrontal cortex in major depression: What does it tell us about dysfunctional monoaminergic circuits? Progress in Brain Research. 126, 397-412.

Rane, A.; Nadkarni, A.; Kanekar, J.; Fernandes, W.; Borker, H.A.; Pereira, Y. (2012). Alcohol use in schizophrenia: prevalence, patterns, correlates and clinical outcomes in Goa, India. The Psychiatrys. 36,257-262.

Regier, D.A.; Farmer, M.E.; Rae, D.S.; Locke, B.Z.; Keith, S.J.; Judd, L.L.; Goodwin, F.K. (1990). Comorbidity of mental disorders with alcohol and other 
drug abuse. Results from the Epidemiologic Catchment Area (ECA) Study. JAMA.; 264:2511-2518.

Regier, D.A.; Farmer, M.E.; Rae, D.S.; Myers, J.K.; Kramer, M.; Robins, L.N.; George, L.K.; Karno, M.; Locke, B.Z. (1993). One-month prevalence of mental disorders in the United States and sociodemographic characteristics: the Epidemiologic Catchment Area study. Acta Psychiatry Scandinavica. 88(1):3547.

Rehm, J.; Patra, J. (2012) Different guidelines for different countries? On the scientific basis of low-risk drinking guidelines and their implications. Drug and Alcohol Review. 31: 156-161.

Rehm, J.; Rehm, M.X.; Shield, K.D.; Gmel, G.; Gual, A. (2013) Alcohol consumption, alcohol dependence and related harms in Spain, and the effect of treatment-based interventions on alcohol dependence. Adicciones, 25:11-8.

Rehm, J.; Room, R.; Graham, K.; Monteiro, M.; Gmel, G.; Sempos, C.T. (2003) The relationship of average volume of alcohol consumption and patterns of drinking to burden of disease: an overview. Addiction. 98(9):1209-28.

Rehm, J.; Shield, K.D.; Joharchi, N.; Shuper, P.A. (2012) Alcohol consumption and the intention to engage in unprotected sex: systematic review and meta-analysis of experimental studies. Addiction. 107:51-59.

Rehm, J.; Taylor, B.; Mohapatra, S.; Irving, HM.; Baliu- nas, D.; Patra, J. (2010) et al. Alcohol as a risk factor for liver cir- rhosis: a systematic review and meta-analysis. Drug Al- cohol Rev. 29:437-445.

Rehm, J.; Zatonksi, W.; Taylor, a B.; Anderson, P. (2011). Epidemiology and Icohol policy in Europe. Addiction. 106 (suppl 1): 11-19.

Reid, A.G.; Lingford, A.R.; Cancela, L.M.; Kalivas, P.W. (2012). Substance abuse disorders. Handbook Clinical Neurology,106 (1): 419-31

Reoux, J.P.; Saxon, A.J.; Malte, C.A.; Baer, J.S.; Sloan, K.L. (2001). Divalproex sodium in alcohol withdrawal: a randomized double-blind placebo 
controlled clinical trial. Alcoholism: Clinical and Experimental Research. 25: 1324-1329.

Shand, F. L., Degenhardt, L., Slade, T., y Nelson, E. C. (2011). Sex differences amongst dependent heroin users: histories, clinical characteristics and predictors of other substance dependence. Addictive behaviors, 36, 27- 36.

Riper, H.; Andersson, G.; Hunter, S.B.; Wit, J.; Berking, M.; and Cuijpers, P. (2013). Treatment of comorbid alcohol use disorders and depression with cognitive-behavioural therapy and motivational interviewing: a meta-analysis. Addiction, 109, 394-406.

Ritson, B.; Chick, J. (1986). Comparison of two benzodiazepines in the treatment of alcohol withdrawal: effects on symptoms and cognitive recovery. Drug and Alcohol Dependence.18: 329-334.

Rivera, J.M.; Prados, J.M. (2001). Relación entre perfiles de ansiedad y drogadicción: implicaciones para el tratamiento. Trastornos Adictivos, 3(4), 287. Rivera Reyes, O.A. (1984). El Enfermo alcohólico: Consideraciones Etiológicas y Terapéuticas. Revista Médica Hondureña. Vol. 52 Pág 110-118 Robinson, T.E.; Berridge, K.C. (1993). The neural basis of drug craving: An incentive- sensitization theory of addiction. Brain Reserch Review, 18, 247-291

Rodríguez García, F.D. (2014). Consumo de alcohol en la adolescencia. Consideraciones médicas y orientaciones educativas. Salud Mental; 37:255260.

Rojas, J.C. (2003). Neurobiología del abuso y dependencia del alcohol. Conceptos clínicos, funcionales y moleculares. Archivos Neurociencias México, 8 (3): 128-38.

Roozen, H. G.; Wetering, B.J. Franken, H.A. (2013). Does alcohol craving mediate the impulsivity-aggression relatinship in recently detoxified alcoholdependent patients? American Journal Drug Alcohol Abuse, 3 9(1), 57-60.

Room, R.; Makela, K. (2000). Typologies of the cultural position of drinking. Stud Alcohol. 61:475-83. 
Roth, R.M.; Brunette, M.F.; Green, A.I. (2005). Treatment of substance use disorders in schizophrenia: a unifying neurobiological mechanism? Current Psychiatry Reports. 7(4): 283-9.

Rubio, G.; Ponce, G.; Jiménez-Arriero, M.A.; Palomo, T.; Ferre, F. (2002). Effectiveness of topiramate in control of alcohol craving. European Psypharmacology. 12 (suppl 2):S63.

Rubio, G.; Ponce, G.; Ortíz, S.; Oliva, J.M.; Manzanares, J.; JiménezArriero, M.A. et al. (2002). Tratamiento farmacológico de la dependencia alcohólica. European Psypharmacology .12 (suppl 3):S398.

Rubio, G.; Urosa, B.; Santo Domingo, J. (1998). Validación de la escala de la intensidad de la dependencia al alcohol (EIDA). Psiquiatría Biológica, 5 (1): 4447.

Rubio, G.; Urosa, B.; Rubio, M.C.; Ulibarri, S.; Mata F. (1996). Validación del cuestionario sobre la gravedad de la dependencia al alcohol (Severity Alcohol Dependence Questionnaire) en población española. Anales de Psiquiatría, 12 (7), 33-38.

Rubio Valladolid, G.; López Ruiz, M. (1999). Validación del cuestionario sobre los componentes obsesivo-compulsivo de bebida en alcohólicos españoles. Adicciones, 11(1):7-15.

Sáiz Martínez, P.A., Jimenez Treviño, L.; Díaz Mesa, E.M.; García-Portilla González, M.P.; Marina González, P.; Al-Halabí, S.; Szerman N.; Bobes García, J.; Ruiz, P. (2014). Patología dual en trastornos de ansiedad: recomendaciones en el tratamiento farmacológico. Adicciones, 26, 254-274.

Sánchez-Peña, J.F.; Álvarez-Cotoli, P.; Rodríguez-Solano, J.J. (2012). Trastornos psiquiátricos asociados a alcoholismo: seguimiento a 2 años de tratamiento. Actas Españolas de Psiquiatría. 40(3):129-35

Sandín, B. (2013). DSM-5: ¿Cambio de paradigma en la clasificación de los trastornos mentales? Revista de Psicopatología y Psicología Clínica, 18: 255286. 
Saníger Herrera, J.M.; Alonso Santos, B.; Soler Serra, E.; López Higuera, M.J. (2004) Tratamiento de la dependencia alcohólica Jano 18-24.Vol. LXVII Nº 1. 526 .

Sapolsky, R.M. (2000). Glucocorticoids and hippocampal atrophy in neuropsychiatric disorders. Archives General of Psychiatry. 57, 925-935.

Sarasa Renedo A.; Sordo, L.; Molist, G.; Hoyos, J.; Guitart, A.M.; Barrio, G. (2014). Principales daños sanitarios y sociales relacionados con el consumo de alcohol. Revista Española Salud Pública; 88:469-491.

Sclafani, V.; Finn, P.; Fein, G. (2007). Psychiatric comorbidity in long-term abstinent alcoholic individuals. Alcoholism: Clinical and Experimental Research, 31, 795-803.

Se-Won, L.; Kang-Seob, O.; Young-Chul, S.; Seung-Gul, K.; Leen, K.; Young-Min, P.; Won, K.; Heon-Jeong L. (2008). Clinical and temperamental differences between early and late-onset alcoholism in Korean men. Comprehensive Psychiatry, 49, 94-97.

Schade, A.; Marquenie, L.A.; Van Balkom, A.J.; De Beurs, E.; Van Dyck, R.; Van Den Brink, W. (2003). Do comorbid anxiety disorders in alcohol-dependent patients need specific treatment to prevent relapse? Alcohol and Alcoholism. 38:255-262.

Schadé, A.; Marquenie, L. A.; Van Balkom, A. J.; Koeter, M. W.; de Beurs, E.; Van den Brink, W.; Van Dyck, R. (2005). The effectiveness of anxiety treatment on alcohol- dependent patients with a comorbid phobic disorder: a randomized controlled trial. Alcoholism: Clinical and Experimental Research, 29, 794-800.

Schied, H.W.; Kimmerle, K.; Braunschweiger, M. (1986). A retrospective comparison of delirium tremens cases before and after the availability of chlormethiazole. Acta Pschyatrica Scandinava. 73:1667-170.

Schifano F. (2002). European dimensions of dual diagnosis. In Dual Diagnosis: Substance Misuse and Psychiatric Disorders (ed. GH Rassool): 58 - 65. 
Blackwell Science.

Schoepf, D., Uppal, H.; Potluri, R.; Heun, R.(2014). Physical comorbidity and its relevance on mortality in schizophrenia: a naturalistic 12-year follow-up in general hospital admissions. European Archives of Psychiatry and Clinical Neuroscience. 264:3-28.

Shaw-Lutchman, T.Z.; Barret, M.; Wallace, T.; Gilden, L.; Zachariou, V.; Impey, S.; Duman, R.S.; Storm, D.; Nestler, E.J. (2002). Regional and cellular mapping of CRE- mediated transcription during naltrexone-precipitated morphine withdrawal. Journal of Neuroscience. 1;22(9):3663-72.

Shoval, G.; Shmulewitz, D.; Wall, M.M.; Aharonovich, E.; Spivak, B.; Weizman A, Hasin, D. (2014). Alcohol dependence and suicide-related ideation/behaviors in an Israeli household simple, with and without major depression. Alcoholism: Clinical and Experimental Research. 38 (3), 820-825.

Schuckit, M. A. (2009). An overview of genetic influences in alcoholism. Journal Substance Abuse Treatment, 36, 5-14.

Schuckit, M.A.; Smith, T.L.; Chacko, Y. (2006). Evaluation of a depressionrelated model of alcohol problems in 430 probands from the San Diego prospective study. Drug and Alcohol Dependence. 82(3):194-203.

Schuckit, M.A., Smith, T.L., Danko, G.P., Pierson, J., Trim, R., Nurnberger Jr., J.I., Kramer, J., Kuperman, S., Bierut, L.J., Hesselbrock, V. (2007). A comparison of factors associated with substance-induced versus independent depressions. Journal of Studies on Alcohol and Drugs. 68, 805-808.

Schuckit, M. A.; Smith, T. L.; Heron, J.; Hickmam, M.; Macleod, J.; Lewis, G.; Davis, J. M.; Hibbeln, J. R.; Brown, S.; Zuccolo, L.; Miller, L. L.; DaveySmith, G. (2011). Testing a level of response to alcohol-based model of heavy drinking and alcohol problems in 1,905 17-years-olds. Alcoholism: Clinical Experimental Research, 35, 1897-279.

Schuckit, M.A.; Tipp, J.E.; Bergman, M.; Reich, W.; Hesselbrock, V.M.; Smith, T.L. (1997). Comparison of induced and independent major depressive 
disorders in 2945 alcoholics. American Journal of Psychiatry, 154, 948-957.

Schultz, W. (2000). Multiple reward signals in the brain. Nature Reviews Neuroscience. 1, 199-207.

Shield, K.D.; Rylett, M.; Gmel, G.; Gmel, G.; Kehoe-Chan, T.A.; Rehm, J. (2013). Global alcohol exposure estimates by country, territory and region for 2005 a contribution to the Comparative Risk Assessment for the 2010 Global Burden of Disease Study. Addiction, 108:912-22.

Shin, S. H., Hong, H. G. y Jeon, S. M. (2012). Personality and alcohol: The role of impulsivity. Addictive Behaviors, 37, 102-107.

Simons, J. S.; Carey, K. B.; Wills, T. A. (2009): Alcohol abuse and dependence symptoms: a multidimensional model of common and specific etiology. Psychology of Addictive Behaviors, 23, 415-427.

Slutske, W. S.; Heath, A. C.; Madden, P. A.; Bucholz, K. K.; Statham, D. J.; Martin, N. G. (2002). Personality and the genetic risk for alcohol dependence. Journal. Abnormal Psychology, 111, 124-133.

Smith, J.P., and Book, S.W. (2010). Comorbidity of generalized anxiety disorder and alcohol use disorders among individuals seeking outpatient substance abuse treatment. Addictive Behaviors 35:42-45.

Smith, M.A.; Makino, S.; Kvetnansky, R. and Post, R.M. (1995). Stress and glucocorticoids affect the expressing of brain-derived neurotrophic factor and neurotrophin-3 mRNAs in the hippocampus. The Journal of Neuroscience. 15, 1768-1777.

Smith, M.J., Wang L., Cronenwett, Morris B. Goldman M.B., Mamah D., Barch D.M., and Csernansky J.G. (2011). Alcohol Use Disorders Contribute to Hippocampal and Subcortical Shape Differences in Schizophrenia. Schizophrenia Reseach. ; 131(1-3): 174-183.

Smith J.P.; Randall C.L., (2012). Anxiety and Alcohol Use Disorders: Comorbidity and Treatment Considerations. Alcohol Research: Current 
Reviews, Volume 34, Issue Number 4.

Socidrogalcohol (2008). Alcoholismo Guías Clínicas basadas en la evidencia científica. Socidrogalcohol. 2a Ed. Valencia

Sociodrogalcohol (2012). Monografías Alcoholismo. $1^{\text {a }}$ Ed. Barcelona

Soler Vila, H.; Galan, I.; Valencia Martin, J.L.; Leon Muñoz, L.M.; Guallar Castillon, P.; Rodriguez Artalejo, F. (2014). Binge Drinking in Spain, 20082010. Alcoholism: Clinical Experimental Research. 38(3):810-9.

Spanagel, R.; Vengeliene, V. (2012). New pharmacological treatment strategies for relapse prevention. Current Topics in Behavioral Neurosciences, $13,583-609$.

Staiger, P.K.; Kambouropoulos, N.; Dawe, S. (2007). Should personality traits be considered when refining substance misuse treatment programs? Drug and Alcohol Review, 26, 17-23.

Strakowski, S.M.; Leck, P.E. Jr; McElroy, S.L.; Lonczak, H.S.; West, S.A.; (1995). Chronology of comorbid and principal syndromes in firs-episode psychosis, Comprehensive Psychiatry;36:106-12.

Swann, A. C. (2010). The strong relationship between bipolar and substance use disorder. Annals of the New York Academy of Science. 1187, 276-293. -

Tamerin, J.; Weiner, S. y Mendelson J. (1970). Alcoholics expectancies and recall of experiences during intoxication. American Journal of Psychiatry,126, 1687-1704.

Tomassini, A., Struglia, F., Spaziani, D., Pacifico, R., Stratta, P. y Rossi, A. (2012). Decision making, impulsivity and personality traits in alcohol-dependent subjects. American Journal on Addictions, 21, 263-267.

Saitz, R.; O'Malley, S.S. (1997). Pharmacotherapies for alcohol abuse. Withdrawal and treatment. Medical Clinical North America. 81(4):881-907

Svrakic, D.M.; Draganic, S.; Hill, K.; Bayon, C.; Przybeck, T.R.; Cloninger, 
C.R. (2002). Temperament, character, and personality disorders: etiologic, diagnostic, treatment issues. Acta Psychiatrica Scandinavica, 106, 189-195.

Svrakic, D.M.; Whitehead, C.; Przybeck, T.R.; Cloninger, C.R. (1993). Differential diagnosis of personality disorders by the seven-factor model of temperament and character. Archives of General Psychiatry; 50:991-999.

Szerman, N.; Peris, L.; Balaguer, A. (2010). Patología dual: Protocolos de intervención. Trastornos de Personalidad. Barcelona: Edikamed.

Taylor, B.; Irving, HM.; Kanteres, F.; Room, R; Borges, GL.; Cherpitel, CJ. et al. (2010). The more you drink, the harder you fall: a systematic review and meta- analysis of how acute alcohol consumption and injury or collision risk increase together. Drug Alcohol Dependence,110:108-116.

Thomas, S.E.; Randall, P.K.; Book, S.W.; and Randall, C.L. (2008). A complex relationship between co-occurring social anxiety and alcohol use disorders: What effect does treating social anxiety have on drinking? Alcoholism: Clinical \& Experimental Research. 32:77-84.

Tohen, M.; Greenfield, S.F.; Weiss, R.D.; Zarate, C.A. J; y Vagge, L.M. (1998). El efecto de la comorbilidad de los trastornos por consumo de sustancias sobre el curso del trastorno bipolar: una revisión. Harvard Review of Psychiatry. 6:133-141.

Tolliver, B. K., and Hartwell, K. J. (2012). Implications and strategies for clinical management of co-occurring substance use in bipolar disorder. Psychiatric Annals. 42, 190-197.

Torrens M, Fonseca F, Mateu G, Farré M. (2005). Efficacy of antidepressants in substance use disorders with and without comorbid depression. A systematic review and meta-analysis. Drug and Alcohol Dependence. 78:1-22.

Tramacere, I.; Negri, E.; Bagnardi, V.; Garavello, W.; Ro- ta M, Scotti, L. et al. (2010) A meta-analysis of alcohol drinking and oral and pharyngeal cancers. Part 1: overall results and dose-risk relation. Oral Oncol. 46:497-503. 
Trull, T.J.; Jahng, S.; Tomko, R.L.; Wood, P.K.; Sher, K.J. (2010). Revised nesarc personality disorder diagnoses: gender, prevalence, and comorbidity with substance dependence disorders. Journal of Personality Disorders. 24(4): $412-426$.

Tsai, J.; Rosenheck, R.A. (2013). Psychiatric comorbidity among adults with schizophrenia: A latent class analysis. Psychiatry Research.; 210(1): 16-20.

Uhart, M.; Wand, G. S. (2009). Stress, alcohol and drug interaction: an update of human research. Addiction Biology, 14, 43-64.

Uramura, K.; Funahashi, H.; Muroya, S.; Shioda, S.; Takigawa, M.; and Yada, T. (2001). Orexin activates phospholipase C- and protein kinase Cmediated $\mathrm{Ca} 2+$ signaling in dopamine neurons of the ventral tegmental area. Neuroreport 12, 1885-1889.

Vagenas, P.; Lama, J.R.; Ludford, K.T.; Gonzales, P.; Sanchez, J.; Altice, F.L. (2013). A systematic review of alcohol use and sexual risk-taking in Latin America. Revista Panameña Salud Publica. 34:267-274.

Vaillant, G.E. (1983). The Natural History of Alcoholism: Causes, Patterns, and Paths to Recovery. Cambridge. 1a Ed.

Valencia Martín, J.L. (2014). Aspectos metodológicos en la medición del consumo de alcohol: la importancia de los patrones de consumo. Revista Española Salud Pública; 88:433-446.

Valencia Martín, J.L.; Galán, I.; Rodríguez Artalejo, F. (2007). Binge drinking in Madrid, Spain. Alcoholism: Clinical Experimental Research, 31:1723-30.

Valencia Martín, J.L.; González, M.J.; Galán I. (2014). Aspectos metodológicos en la medición del consumo de alcohol: la importancia de los patrones de consumo. Revista Española de Salud Pública; 4, 88:433-446.

Vallejo Nágera, A. (1997). La edad del pavo. Consejos para lidiar con la rebeldía de los adolescentes. Barcelona:Temas de Hoy.

Vallejo J.; Leal C. (2012). Tratado de Psiquiatría. Marbán Libros S.L. (C). 
Madrid, España.

Velicer, W.F.; Norman, G.J.; Fava, J.L.; Prochaska, J.O. (1999). Testing 40 predictions from the transtheoterical model. Addictive Behaviors. 24: 455-469.

Verheul, R., Van den Brink, W., Hartgers, C. (1995). Prevalence of personality disorders among alcoholics and drug Addicts: an overview. Eur Addict Res,1:166-177.

Vicente Herrero, M.T. (2015). Consumo de alcohol en España. Aspectos evolutivos. Una problemática con repercusión en salud pública. Revista Electrónica Medicina, Salud y Sociedad. 5, 2.

Villafuerte, S.; Heitzeg M. M.; Foley, S.; Wendy, Yau, W. Y.; Majczenko, K.; Zubieta, J. K.; Zucker, R. A.; Burmeister, M. (2012). Impulsiveness and insula activation during reward anticipation are associated with genetic variants in GABRA2 in a family sample enriched for alcoholism. Molecular Psychiatry 17, 511-519.

Villarejo Ramos, A. (2012). Las bases biopsicológicas de la imputabilidad en la conducta impulsiva. Cuadernos médico forense vol.18 no.2 Málaga

Vinet, E.V.; Faúndez, X. (2012). Consumo de alcohol y drogas en adolescentes evaluado a través del MMPI-A. Salud Mental; 35:205-213.

Volkow,N.;Koob,G.F.;McLellan,A.T.(2016). Neurobiologic Advances from the Brain Disease Model of Addiction. The New England Journal of Medicine. $374: 36371$

Voris, J.; Smith, N.L.; Rao, S.M.; Thorne, D.L.; Flowers, Q.J. (2003). Gabapentin for the treatment of ethanol withdrawal. Substance Abuse. 24: 1129-132.

Wagner, T.; Krampe, H.; Stawicki, S.; Reinhold, J.; Jahn, H.; Mahlke, K., Barth, U.; Sieg, S.; Maul, O.; Galwas, C.; Aust, C.; Kröner-Herwig, B.; Brunner, E.; Poser, W.; Henn, F.; Rüther, E.; Ehrenreich, H. (2004). Substantial decrease of psychiatric comorbidity in chronic alcoholics upon integrated outpatient treatment - results of a prospective study. Journal of 
Psychiatric Research, 38, 619-635.

Walker, B. W.; Zorrilla, E. P.; Koob, G. F. (2011). Systemic k-opioid receptor antagonism by norbinaltorphimine reduces dependence-induced excessive alcohol self- administration in rats. Addiction Biology, 16, 116-119.

Walter, M.; Gunderson, J.G.; Zanarini, M. C.; Sanislow, C. A.; Grilo, C. M., McGlashan, T. H.; Slodol, A. E. (2009). New onsets of substance use disorders in borderline personality disorder over 7 years of follow-ups: findings from the Collaborative Longitudinal Personality Disorders Study. Addiction, 104, 97-103.

Wang, J.C.; Hinrichs, A.L.; Stock, H.; Budde, J.; Alien, R.; Bertelsen, S.; Kwon, J.M.; Wu, W.; Dick, D.M.; Rice, J.; Jones, K.; Nurnberger, JI Jr.; Tischfield, J.; Porjesz, B.; Eenberg, H.J.; Hesselbrock, V.; Crowe, R.; Schuckit, M.; Begleiter, H.; Reich, T.; Goate, A.M.; Bierut, L.J. (2004). Evidence of common and specific genetic effects: association of the muscarinic acetylcholine receptor M2 (CHRM2) gene with alcohol dependence and major depressive syndrome. Human Molecular Genetics. 13:1903-11.

Watkins, K.E.; Hunter, S.B.; Burnam, M.A.; Pincus H.A.; Nicholson G. (2005). Review of treatment recommendations for persons with a co-occurring affective or anxiety and substance use disorder. Psychiatric Services 56:913926.

Watson, S.J.; Trujillo, K.A.; Herman, I.P.; Akil, H. (1989). Neuroanatomical and neurochemical substrates of drug-seeking behavior: Overview and future directions. En: A. Goldstein (Ed.). Molecular and cellular aspects of the drug addictions. New York. Springer- Verlag. 29-91.

Wedekind, D.; Bandelow, B.; Heitman, S.; Havemann-Reinecke, U.; Engel, K. R. (2013). Attachement style, anxiety coping and personality-styles in withdrawn alcohol addicted inpatients. Substance Abuse Treatment, Prevention, and Policy, 8, 1-7.

Weiss, R.D.; Mirin, S.M. (1987). Substance abuse as an attempt at selfmedication, Psychiatry Medicine. 3:357-67. 
Williams, D.; Mc Bride, A.J. (1998). The drug treatment of alcohol withdrawal symptoms: a systematic review. Alcohol Alcohol. 33: 103-115.

Williams, L.; Jacka, F.; Pasco, J.; Henry, M.; Dodd, S.; Nicholson, G.; Kotowicz, M.; Berk, M. (2010). The prevalence of mood and anxiety disorders in Australian women. Australasian Psychiatry 18:250-255.

Willie, J.T.; Chemelli, R.M.; Sinton, C.M.; and Yanagisawa, M. (2001). To eat or to sleep? Orexin in the regulation of feeding and wake- fulness. Annual Review of Neuroscience 24, 429-458.

Wills, T.A.; Windle, M.; CleArY, S.D. (1998). Temperament and novelty seeking in adolescent substance use: Convergence of dimensions of temperament with constructs from Cloninger's theory. Journal of Personality and Social Psychology, 74, 387-406.

Winokur, G.; Coryell, W.; Akiskal, H.S.; Maser, J.D.; Keller, M.B.; Endicott, J. Mueller, T. (1995). Alcoholism in manic-depressive (bipolar) illness: familial illness, course of illness and the primary-secondary distinction. American Journal of Psychiatry; 152:365-72.

Wirkner, K.; Poelchen, W.; Koles, L.; Muhlberg, K.; Scheiber, P.; Allgaier, C.; Illes, P. (1999). Etanol induced inhibition of NMDA receptor channels. Neurochemistry International, 35, 153-162.

Wise, A.R. (1996). Neurobiology of addiction. Current Opinion on Neurobiology, $6,243-251$.

Wise, R.A. (2000). Addiction becomes a brain disease. Neuron, 26 (1): 27-33.

Wong, K. M.; Cloninger, C. R. (2010). A person-centered approach to clinical practice. Focus Personality and Temperament, 8, 199-215.

Wyman, K.; and Castle, D.J. (2006). Anxiety and substance use disorder comorbidity: Prevalence, explanatory models and treatment implications. Journal of Dual Diagnosis 2:93-119.

Yip, S.W.; Doherty, J.; Wakeley, J.; Saunders, K.; Tzagarakis, C.; de Wit, 
H.; Goodwin, G. M.; Rogers, R. D. (2012). Reduced subjective response to acute alcohol administration among young men with a broad bipolar phenotype. Neuropsychopharmaology, 37, 1815

Zaazaa, A.; Bella, A.J.; Shamloul, R.; (2013) Drug addiction and sexual dysfunction. Endocrinology Metabolism Clinics North America. 42:585-592.

Zhornitsky, S.; Stip, E.; and Potvin, S. (2011). Evolution of Substance use, Neurological and Psychiatric Symptoms in Schizophrenia and Substance use Disorder Patients: A 12-Week, Pilot, Case-Control Trial with Quetiapine. Frontiers in Psychiatry. 13;2:22.

Zhu, M.Y.; Klimek, V.; Dilley, G.E.; Haycock, J.W.; Stockmeier, C.; Overholser, J.C.; Meltzer, H.Y.; and Ordway, G.A. (1999). Elevated levels of tyrosine hydroxylase in the locus coeruleus in major depression. Biol. Psychiatry 46, 1275-1286.

Zikos, E.; Gill, K.J.; Charney, D.A. (2010). Personality disorders among alcoholic outpatients: prevalence and course in treatment. Canadian Journal of Psychiatry. 55(2): 65-73.

Zilberman, M.L.; Tavares, H.; El-Guebaly, N. (2003). Relationship between craving and personality in treatment-seeking women with substance-related disorders. BMC Psychiatry, 3,1,1-5.

Zuckerman, M. (1994). Behavioral Expression and Biosocial Bases of Sensation Seeking.New York: Cambridge University Press. 
Influencia de la Personalidad en la Gravedad de los Trastornos por Consumo de Alcohol

Anexos 
Influencia de la Personalidad en la Gravedad de los Trastornos por Consumo de Alcohol 


\section{9.- ANEXOS}

\section{1.- Entrevista semiestructurada.}

FECHA DE LA ENTREVISTA:

1.- Datos sociodemográficos:

- Edad

- Sexo: Varón / Mujer

- Residencia: Ciudad/ Rural

- Estado civil: 1.Soltero / 2.Casado o en pareja / 3. Separado o divorciado/ 4 Viudo.

- Estudios

- Situación Laboral

2.- Características de consumo:

- Tipo de consumo: Pérdida de control / Alcohol en ayunas

- Patrón de consumo: Diario / Fin de semana

- Tipo de bebida: Vino / Cerveza / Alcohol.

- Gr de Alcohol

3.- Clínica de abstinencia

4.- Palimpsestos: si / no

5.- Polineuropatía: si / no

6.- Malos tratos: si / no

7.- Estado psicopatológico del paciente

8.- Grado de motivación para el tratamiento

9.- Antecedentes familiares médico psiquiátricos

10.- Diagnóstico de TCA (DSM IV-R)

11.- Tipo de tratamiento

12.- Parámetros analíticos

9.2.- Escala EuropAsi. Índice Europeo de Gravedad de la Adicción (EuropASI)

(Modificada y reducida para adaptación a un estudio con pacientes con Trastorno por consumo de Alcohol) 


\section{EVALUACIÓN FÍSICA}

Invalidez por problemas físicos: SI NO

Ingresos por problemas físicos: SI NO

Puntuación área física:

EVALUACIÓN PSIQUIATRICA

Invalidez por problemas psiquiátricos SI NO

Tratamiento ambulatorio SI NO

Tratamiento hospitalario SI NO

Puntuación área psiquiátrica

EVALUACION ADICTIVA USO DE ALCOHOL
A: Cualquier dosis

Edad de inicio:

A lo largo de la vida:

B: Grandes cantidades

Edad de inicio:

A lo largo de la vida:

Días último mes:

¿Cuántas veces ha tenido delirium tremens?:

¿Crisis convulsivas? SI NO

$\mathrm{n}^{\circ}$ de veces que ha recibido tratamiento:

¿Cuánto dinero diría usted que ha gastado en el último mes en alcohol? $(€)$

Cantidad de alcohol (grs.)

Alcohol en ayunas SI NO

Pérdida del control del consumo SI NO

Puntuación área adictiva

\section{EVALUACION LABORAL}

Nivel de estudios

Trabajo:

Activo

Paro 
Jubilado

Incapacidad

Ama de casa

Puntuación área laboral

\section{EVALUACION SOCIAL}

\begin{tabular}{|c|c|}
\hline Problemas legales & $\mathrm{SI}$ \\
\hline Cárcel & SI \\
\hline
\end{tabular}

EVALUACION FAMILIAR

Evaluación del ámbito familiar

Problemas en la familia en el último mes

Puntuación área familiar

Puntuación total EIDA

Puntuación total deseo ("craving")

GOT

GPT

GGT

VCM

Puntuación inventario de personalidad

Diagnóstico primario

Diagnóstico secundario

\section{3.- Escala EIDA}

Intente recordar un período de tiempo en los últimos 6 meses en los que usted haya bebido mucho. Ahora marque $(\mathrm{X})$ en la casilla correspondiente a la frecuencia con que las siguientes manifestaciones le ocurrieron durante ese período. 
Durante ese período de tiempo que bebía mucho:

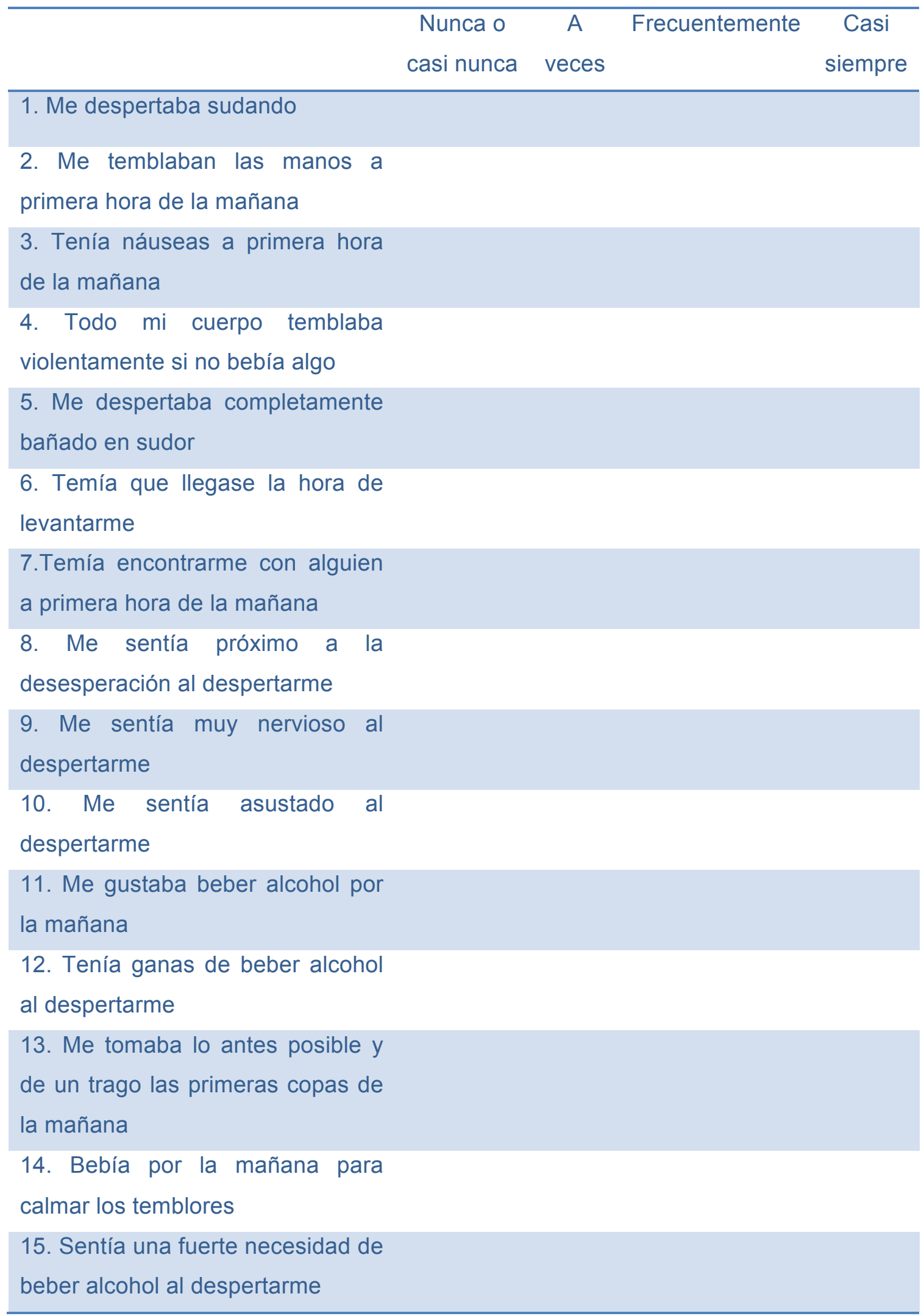


16. Bebía más de 4 copas de licor al día (el equivalente es una botella de vino u 8 cañas de cerveza)

17. Bebía más de 8 copas de licor al día (el equivalente son 2 botellas de vino o 16 cañas de cerveza)

18. Bebía más de 16 copas de licor al día (el equivalente son 3,5 de vino o 32 cañas de cerveza)

19. Bebía más de 32 copas de licor al día (el equivalente son 7 botellas de vino o 64 cañas de cerveza)

20. Llegaba a beber en menos de 1 hora 8 copas de licor (el equivalente son 2 botellas de vino o 18 cañas de cerveza)

\section{Después de haber tomado algunas copas me apetecía seguir bebiendo \\ 22. Cuando comenzaba a beber me resultaba muy difícil parar hasta que no estaba bastante bebido}

23. No bebía alcohol hasta después de haber finalizado mis tareas (trabajo, estudio, reuniones, etc.)

24. Si bebía alcohol, no sobrepasaba el límite que me había propuesto

25. Había días en los que conseguía no beber nada 
¿Cómo se sentiría por la mañana, después de haber pasado esos 2 días bebiendo bastante?

\section{Nada Un poco Moderadamente Bastante}

26. Por la mañana comenzaría a

sudar

27. Tendría temblor en las manos

28. Tendría náuseas

29. Mi cuerpo temblaría

30. Mis deseos por beber serían

Puntuación total: __ (preguntas 23 a 25 puntúan en sentido inverso)

\section{4.- Cuestionario sobre los componentes obsesivo-compulsivos de la bebida (OCDS)}

Instrucciones: Conteste a las siguientes preguntas indicando la cantidad de alcohol que usted bebe y sus intentos para controlar su bebida. Marque con un círculo el número que corresponda a la contestación más apropiada a su caso.

1.¿Cuándo usted no está bebiendo, cuánto tiempo tiene su mente ocupada con pensamientos, deseos o imágenes relacionadas con el alcohol?

\begin{aligned} & \hline 0. Nada \\ & \hline 1. Menos de 1 hora diaria \\ & 2. De 1 a 3 horas diarias \\ & 3. De 4 a 8 horas diarias \\ & 4. Más de 8 horas diarias \\ & \hline\end{aligned}

2.- ¿Con qué frecuencia tiene usted esos pensamientos?

0. Nunca

1. No más de 8 veces al día

2. Más de 8 veces al día, pero estoy libre de ellos la mayor parte del tiempo 
3. Más de 8 veces al día y durante la mayor parte del tiempo

4. Los pensamientos son tan frecuentes que no se pueden contar y/o raramente pasa una hora sin que ocurran

Anote aquí la máxima puntuación de las preguntas $1 \quad 0 \quad 2$

3. ¿Cuánto tiempo interfieren estos pensamientos, deseos o imágenes en sus actividades (o responsabilidades) sociales o laborales? Esta pregunta se refiere a si existe algo que usted no pueda llevar a cabo o deje de hacer por ellos. (Si en el momento actual no trabaja, indique cómo cree que se vería afectado su rendimiento si estuviese trabajando)

\begin{tabular}{|c|c|}
\hline 0. & $\begin{array}{l}\text { Pensar en la bebida no interfiere nunca. Puedo desenvolverme } \\
\text { perfectamente }\end{array}$ \\
\hline 1. & $\begin{array}{l}\text { Los pensamientos sobre la bebida interfieren ligeramente en mis } \\
\text { actividades sociales o laborales, pero } \mathrm{mi} \text { rendimiento no se ve } \\
\text { perjudicado }\end{array}$ \\
\hline 2. & $\begin{array}{l}\text { Los pensamientos sobre la bebida interfieren claramente en mi } \\
\text { desenvolvimiento social o laboral, aunque me puedo defender }\end{array}$ \\
\hline 3. & $\begin{array}{l}\text { Los pensamientos sobre la bebida causan importantes perjuicios en mi } \\
\text { rendimiento ocupacional o social }\end{array}$ \\
\hline 4. & $\begin{array}{l}\text { Los pensamientos sobre la bebida interfieren totalmente en mi } \\
\text { rendimiento social o laboral }\end{array}$ \\
\hline
\end{tabular}

4. ¿Cuánta ansiedad o preocupación le causan a usted estos pensamientos, deseos o imágenes relacionada con la bebida durante el tiempo en que usted no está bebiendo alcohol?

\begin{aligned} & \hline 0. Ninguna \\ & 1. Leve, infrecuente y no demasiado molesta \\ & 2. Moderada, frecuente y perturbadora, aunque el malestar es manejable \\ & 3. Intensa, muy frecuente y muy molesta \\ & 4. Malestar extremo, casi constante e incapacitante \\ & \hline\end{aligned}


5. Durante el tiempo en que usted no bebe, ¿cuánto esfuerzo le cuesta resistirse o ignorar estos pensamientos, deseos o imágenes? (Señale los esfuerzos que hace para resistirse a estos pensamientos, no si tiene éxito o fracaso en controlarlos)

0 . Mis pensamientos son tan escasos que no necesito enfrentarme a ellos. Si tengo pensamientos siempre me enfrento a ellos

1. Trato de resistirme a ellos la mayor parte del tiempo

2. Hago algún esfuerzo para resistirme

3. Cedo a todos los pensamientos sin intentar controlarlos, pero lo hago con cierto rechazo

4. Cedo voluntaria y completamente a tales pensamientos

6. Cuando usted no está bebiendo, ¿en qué medida tiene éxito al intentar parar o alejar tales pensamientos?

0. Siempre consigo parar o alejar tales pensamientos

1. Normalmente soy capaz de parar o desviar tales pensamientos con algún esfuerzo y concentración

2. A veces soy capaz de parar o desviar tales pensamientos

3. Raramente consigo parar tales pensamientos y solamente puedo desviarlos con dificultad

4. Rara vez soy capaz de desviar tales pensamientos, incluso momentáneamente

7. Cuando usted bebe alcohol, ¿cuántas copas se toma al día?
$0 . \quad$ Ninguna
1. Menos de una copa diaria
2. 1-2 copas al día
3. 3-7 copas al día
4. 8 o más copas al día 
8. Cuando usted bebe alcohol ¿cuántos días a la semana bebe?

\begin{aligned} & \hline 0. Ninguno \\ & \hline 1. No más de 1 día a la semana \\ & 2. $2-3$ días a la semana \\ & 3. $4-5$ días a la semana \\ & 4. $6-7$ días a la semana \\ & \hline\end{aligned}

Anote aquí la máxima puntuación de las preguntas $7 \quad$ u 8

9. ¿En qué medida su consumo de alcohol interfiere en su trabajo? Esta pregunta se refiere a si existe algo que usted no hace o no puede hacer debido a su consumo de alcohol. (Si en el momento actual no trabaja, ¿en qué medida cree que se vería afectado su rendimiento si estuviese trabajando?)

\begin{tabular}{|c|c|}
\hline 0. & $\begin{array}{l}\text { Mi consumo de alcohol nunca interfiere. Puedo desenvolverme } \\
\text { perfectamente }\end{array}$ \\
\hline 1. & $\begin{array}{l}\text { Mi consumo de alcohol interfiere ligeramente en mi trabajo, pero en } \\
\text { conjunto mi rendimiento no se ve perjudicado }\end{array}$ \\
\hline 2. & $\begin{array}{l}\text { Mi consumo de alcohol interfiere claramente en mi trabajo, pero aún } \\
\text { me puedo defender }\end{array}$ \\
\hline 3. & La bebida produce graves perjuicios en mi trabajo \\
\hline 4. & $\begin{array}{l}\text { Los problemas de la bebida interfieren totalmente en la realización de } \\
\text { mi trabajo }\end{array}$ \\
\hline
\end{tabular}

10.¿En qué medida interfiere su consumo de alcohol en sus actividades sociales? Esta pregunta se refiere a si existe algo que usted no hace o no puede hacer debido a su consumo de alcohol?

0. La bebida nunca interfiere. Puedo desenvolverme perfectamente

1. La bebida interfiere ligeramente en mis actividades sociales, pero en conjunto mi comportamiento no se ve perjudicado

2. La bebida interfiere claramente en mis actividades sociales

3. La bebida causa graves perjuicios en mis actividades sociales 
4. Los problemas de la bebida interfieren totalmente en mis actividades sociales

Anote aquí la máxima puntuación de las preguntas 9 o 10

11.Si a usted se le impidiese beber cuando desea una copa, ¿en qué medida se encontraría nervioso o molesto?
$0 . \quad$ No estaría nada nervioso o irritado
1. Estaría ligeramente nervioso o irritado
2. La inquietud o irritación aumentarían, pero podría controlarlas
3. Estaría muy nervioso o irritado
4. Mi ansiedad o irritación serían incontrolables

12.¿Cuánto esfuerzo realiza para resistirse a beber alcohol? (Solamente puntúe sus esfuerzos para resistirse, no su éxito o fracaso en controlar realmente la bebida)

\begin{tabular}{|c|c|}
\hline 0. & $\begin{array}{l}\text { Mi consumo de alcohol es tan escaso que no necesito resistirme. Si } \\
\text { bebo, estoy todo el tiempo resistiéndome a beber }\end{array}$ \\
\hline 1. & Trato de resistirme la mayor parte del tiempo \\
\hline 2. & Hago algún esfuerzo para resistirme \\
\hline 3. & $\begin{array}{l}\text { Cedo a casi todas las copas sin intentar controlarme, pero lo hago con } \\
\text { cierto rechazo }\end{array}$ \\
\hline 4. & No hago ningún esfuerzo para resistirme a ninguna copa \\
\hline
\end{tabular}

13. ¿Cómo es de fuerte su deseo de consumir bebidas alcohólicas?

\begin{tabular}{ll}
\hline 0. & No tengo ninguno \\
1. & Algún deseo de beber \\
2. & Fuerte deseo de beber \\
3. & Muy fuerte deseo de beber \\
4. & El deseo hacia la bebida es incontrolable e irresistible \\
\hline
\end{tabular}

\section{4.¿Cómo es su control sobre el consumo de alcohol?}
$0 . \quad$ Tengo un control completo
1. Normalmente soy capaz de controlar mi consumo
2. Sólo puedo controlar el consumo con dificultad 
Influencia de la Personalidad en la Gravedad de los Trastornos por Consumo de Alcohol

3. Tengo que beber y sólo puedo retrasar el consumo con dificultad

4. Rara vez soy capaz de retrasar el consumo, incluso por poco tiempo

Anote aquí la máxima puntuación de las preguntas $\begin{array}{llll}13 & 0 & 14\end{array}$ 


\section{5.- Cuestionario TCI-R (Cuestionario de temperamento y carácter de Cloninger, versión revisada).}

\section{TCIMR}

\begin{tabular}{|c|c|c|c|c|c|}
\hline \multirow{2}{*}{$\begin{array}{l}\text { Para cada una de las siguientes } \\
\text { preguntas, por favor marque con una } \\
\text { " } X \text { " el numero que mejor describa } \\
\text { como se siente o actua habitualmente } \\
\text { (solo un numero para cada pregunta). }\end{array}$} & 1 & 2 & 3 & 4 & 5 \\
\hline & Falso & $\begin{array}{l}\text { Casi todo } \\
\text { probablemente } \\
\text { falso }\end{array}$ & $\begin{array}{l}\text { Igual cierto que } \\
\text { falso }\end{array}$ & $\begin{array}{l}\text { Casi seguro o } \\
\text { probablemente } \\
\text { seguro }\end{array}$ & Verdadero \\
\hline
\end{tabular}

\begin{tabular}{|c|c|c|c|c|c|c|}
\hline 1. & $\begin{array}{l}\text { A menudo hago cosas nuevas simplemente por diversión o emoción, aunque } \\
\text { la mayoria de la gente piense que es una perdida de tiempo. }\end{array}$ & 1 & 2 & 3 & 4 & 5 \\
\hline 电. & $\begin{array}{l}\text { Suelo confiar en que todo irá bien, aunque sea en situaciones que preocuparian } \\
\text { a la mayoría de la gente. }\end{array}$ & 1 & 2 & 3 & 4 & 5 \\
\hline 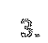 & Siento con frecuencia que soy una victima de las circunstancias. & 1 & 2 & 3 & 4 & 5 \\
\hline 4 & Suelo aceptar a los demás tal y como son, aunque sean muy diferentes a mi. & 1 & 2 & 3 & 4 & 5 \\
\hline 㗪 & Me gustan más los retos que los trabajos fáciles. & 1 & 2 & 3 & 4 & 5 \\
\hline s. & Con frecuencia pienso que mi vida tiene poco sentido o proposito. & 1 & 2 & 3 & 4 & 5 \\
\hline 7 & $\begin{array}{l}\text { Me gusta ayudar a encontrar soluciones a los problemas para que todo el } \\
\text { mundo salga beneficiado. }\end{array}$ & 1 & 2 & 3 & 4 & 5 \\
\hline 鼠. & $\begin{array}{l}\text { Soy muy impaciente a la hora de empezar cualquier trabajo que tenga que } \\
\text { hacer. }\end{array}$ & 1 & 2 & 3 & 4 & 5 \\
\hline 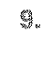 & $\begin{array}{l}\text { A menudo me siento tenso y preocupado en situaciones poco familiares, aún } \\
\text { cuando otros piensan que no hay motivos para preocuparse. }\end{array}$ & 1 & 2 & 3 & 4 & 5 \\
\hline 16. & $\begin{array}{l}\text { Con frecuencia hago cosas en función de cómo me siento en ese momento } \\
\text { sin pensar en cómo se han hecho en el pasado. }\end{array}$ & 1 & 2 & 3 & 4 & 5 \\
\hline 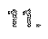 & Suelo hacer las cosas a mi manera sin ceder a los deseos de los demás. & 1 & 2 & 3 & 4 & 5 \\
\hline 算唯 & $\begin{array}{l}\text { A menudo siento una poderosa sensación de unión con todas las cosas que } \\
\text { me rodean. }\end{array}$ & 1 & 2 & 3 & 4 & 5 \\
\hline 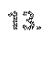 & $\begin{array}{l}\text { Haría cualquier cosa dentro de la legalidad para llegar a ser rico y famoso, } \\
\text { aunque con ello perdiese la confianza de algunos buenos amigos. }\end{array}$ & 1 & 2 & 3 & 4 & 5 \\
\hline 74 & Soy más reservado y me controlo más que la mayoria de la gente. & 1 & 2 & 3 & 4 & 5 \\
\hline$\eta$ & $\begin{array}{l}\text { Me gusta hablar abiertamente con mis amigos de mis experiencias y } \\
\text { sentimientos, en vez de guardármelos para mi. }\end{array}$ & 1 & 2 & 3 & 4 & 5 \\
\hline 管. & Tengo menos energía y me canso antes que la mayoria de la gente. & 1 & 2 & 3 & 4 & 5 \\
\hline
\end{tabular}




\begin{tabular}{|c|c|c|c|c|}
\hline 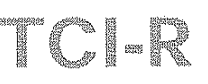 & $1]$ falso & $\begin{array}{l}2 \text { Casitodo } \\
\text { probablemente } \\
\text { falso }\end{array}$ & $\begin{array}{l}\text { 3. Igual cierto } \\
\text { que falso }\end{array}$ & $\begin{array}{l}44 \text { Casi seguro o } \\
\text { probabiemente } \\
\text { seguro }\end{array}$ \\
\hline
\end{tabular}

\begin{tabular}{|c|c|c|c|c|c|c|}
\hline & & & & & & \\
\hline Tit. & Casi nunca me siento libre para elegir lo que quiero hacer. & 1 & 2 & 3 & 4 & 5 \\
\hline 触. & Me parece que no comprendo muy bien a la mayoría de la gente. & 1 & 2 & 3 & 4 & 5 \\
\hline 10. & $\begin{array}{l}\text { Con frecuencia evito conocer a extraños porque no me siento seguro con } \\
\text { gente que no conozco. }\end{array}$ & 1 & $2]$ & 3 & 4 & 5 \\
\hline 20. & Me gustar agradar a la gente todo lo que puedo. & 1 & 2 & 3 & 4 & 5 \\
\hline 2 & A menudo deseo ser más inteligente que el resto de la gente. & 1 & 2 & 3 & 4 & 5 \\
\hline 22 & $\begin{array}{l}\text { Ningún trabajo es lo suficientemente duro como para impedir que dé lo mejor } \\
\text { de mí. }\end{array}$ & 1 & 2 & 3 & 4 & 5 \\
\hline 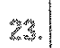 & A menudo espero que otro me solucione mis problemas. & 1 & 2 & 3] & 4 & 5 \\
\hline 24 & $\begin{array}{l}\text { Con frecuencia me gasto el dinero hasta quedarme sin nada o me endeudo } \\
\text { por pedir demasiados créditos. }\end{array}$ & 1 & 2 & 3 & 4 & 5 \\
\hline 2.5. & $\begin{array}{l}\text { Con frecuencia, cuando estoy relajado, tengo inesperados destellos de intuición } \\
\text { o comprensión. }\end{array}$ & 1 & 2 & 3 & 4 & [5] \\
\hline 2 & $\begin{array}{l}\text { No me preocupa mucho el que yo o mi manera de hacer las cosas le gusta } \\
\text { a la gente. }\end{array}$ & 11 & 2 & 3 & 4 & 5 \\
\hline $2 \%$. & $\begin{array}{l}\text { Suelo intentar conseguir lo que quiero para mi ya que, de cualquier forma, es } \\
\text { imposible satisfacer a todos. }\end{array}$ & 11 & $2]$ & 3] & 4 & 5 \\
\hline 28. & No tengo paciencia con la gente que no acepta mis puntos de vista. & 1 & 2 & 3 & 4 & 5 \\
\hline 23. & $\begin{array}{l}\text { Algunas veces me siento tan en contacto con la naturaleza que todo parece } \\
\text { ser parte de un solo ser viviente. }\end{array}$ & 1 & 2 & 3. & 4 & 5 \\
\hline 30. & $\begin{array}{l}\text { Cuando tengo que conocer a gente nueva soy más tímido que la mayoría de } \\
\text { las personas. }\end{array}$ & 1 & 2 & 3 & 4 & 5 \\
\hline 維。 & Soy más sentimental que la mayoría de la gente. & 11 & 2 & 3 & 4 & 5 \\
\hline 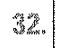 & Pienso que la mayoria de las cosas que se llaman milagros son pura casualidad. & 1 & 2 & 3 & 4 & 5 \\
\hline 管等. & Cuando alguien de alguna forma me hace daño suelo intentar vengarme. & 1 & 2 & 3 & 4 & 5 \\
\hline 急忽. & $\begin{array}{l}\text { Mis acciones están determinadas mayoritariamente por influencias que están } \\
\text { fuera de mi control. }\end{array}$ & 1 & 2 & 3 & 4 & 5 \\
\hline 路 & Cada día intento dar un paso más hacia mis metas. & 1 & 2 & 3 & 4 & 5 \\
\hline
\end{tabular}



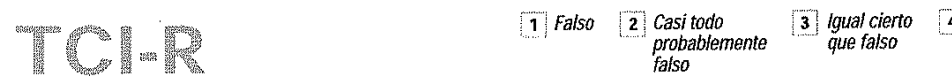

Casiseguro o 5 Verdadero
probablemente falso

\begin{tabular}{|c|c|c|c|c|c|}
\hline 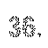 & Por favor haz un círculo en el número cuatro, este es un item de validez. & (1) 2 & 3 & 4 & 5 \\
\hline 32 & Soy una persona muy ambiciosa. & 12 & 3 & 4 & 5 \\
\hline 3as & $\begin{array}{l}\text { Suelo estar tranquilo y seguro en situaciones que la mayoria de la gente } \\
\text { encontraria fisicamente peligrosas. }\end{array}$ & \begin{tabular}{|l|l|}
1 & 2 \\
\end{tabular} & 3 & 4 & 5 \\
\hline 3 & Pienso que no es inteligente ayudar a gente débil que no puede ayudarse a si misma. & 12 & 3 & 4 & 5 \\
\hline 80. & $\begin{array}{l}\text { No me siento tranquilo si trato a otra gente de forma injusta, aunque ellos } \\
\text { hayan sido injustos conmigo. }\end{array}$ & 112 & 3 & 4 & 5 \\
\hline 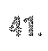 & Por lo general la gente me dice cómo se siente. & 12 & 3 & 4 & 5 \\
\hline 42. & $\begin{array}{l}\text { Algunas veces he sentido que formo parte de algo que no tiene limites ni } \\
\text { fronteras en el espacio o en el tiempo. }\end{array}$ & 112 & 3 & 4 & 5 \\
\hline A & $\begin{array}{l}\text { Algunas veces siento un contacto espiritual con otra gente que no puedo explicar } \\
\text { con palabras. }\end{array}$ & $17[2$ & 3 & 4 & 5 \\
\hline 44 & Me gusta que la gente pueda hacer lo que quiera, sin reglas estrictas ni normas. & 12 & 3 & 4 & 5 \\
\hline 萑管 & Cuando fracaso en algo, todavia me esfuerzo más en hacerlo mejor. & 12 & 3 & 4 & 5 \\
\hline 能. & $\begin{array}{l}\text { Generalmente me preocupa más que a la mayoría de la gente que algo pueda } \\
\text { ir mal en un futuro. }\end{array}$ & 12 & 3 & 4 & 5 \\
\hline $4:$ & Suelo pensar en todos los detalles antes de tomar una decisión. & 12 & 3 & 4 & 5 \\
\hline 4 & Tengo varios malos hábitos que me gustaria poder abandonar. & 112 & 3 & 4 & 5 \\
\hline 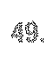 & Los demás me controlan demasiado. & 12 & 3 & 4 & 5 \\
\hline 30 & Me gusta ser útil a los demás. & 112 & 3 & 4 & 5 \\
\hline 501. & $\begin{array}{l}\text { Por lo general consigo que la gente me crea, incluso cuando sé que estoy } \\
\text { exagerando o diciendo cosas que no son ciertas. }\end{array}$ & 112 & 3 & 4 & 5 \\
\hline 32 & $\begin{array}{l}\text { Algunas veces he sentido que mi vida era dirigida por una fuerza espiritual } \\
\text { superior a cualquier ser vivo. }\end{array}$ & 112 & 3 & 4 & 5 \\
\hline 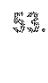 & $\begin{array}{l}\text { Tengo reputación de ser una persona muy práctica que no se deja llevar por } \\
\text { las emociones. }\end{array}$ & 12 & 3 & 4 & 5 \\
\hline 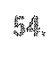 & $\begin{array}{l}\text { Me conmueven profundamente las peticiones de caridad (por ej. cuando alguien } \\
\text { me pide ayuda para los niños minusválidos). }\end{array}$ & 02 & 3 & 4 & 5 \\
\hline
\end{tabular}




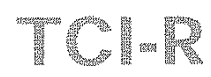

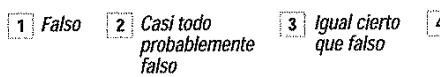

4) Casi seguro o 5 Verdadero
probablemente seguro

\begin{tabular}{|c|c|c|c|c|c|}
\hline 管篦. & $\begin{array}{l}\text { Suelo tener tanto empeño por las cosas que continuo trabajando incluso después } \\
\text { de que muchas personas se han dado por vencidas. }\end{array}$ & 12 & 3 & 4 & 5 \\
\hline 56. & $\begin{array}{l}\text { He tenido momentos de gran felicidad en los cuales, repentinamente, he tenido } \\
\text { una clara y profunda sensación de unidad con todo lo que existe. }\end{array}$ & 12 & 3 & 4 & 5 \\
\hline 策. & Sé lo que quiero hacer en mi vida. & 12 & 3 & 4 & 5 \\
\hline $5 \%$ & A menudo no me enfrento a los problemas porque no sé lo que hay que hacer. & 172 & 3 & 4 & 5 \\
\hline 3.8. & Prefiero gastar dinero a ahorrarlo. & (1) 2 & 3 & 4 & 5 \\
\hline 80. & $\begin{array}{l}\text { A menudo me han llamado "adicto al trabajo" debido a mi entusiasmo por } \\
\text { trabajar mucho. }\end{array}$ & 112 & 3 & 4 & 5 \\
\hline 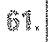 & Me recupero rápidamenie cuando me avergüenzan o me humillan. & 12 & 3 & 4 & 5 \\
\hline Q6. & Me gusta luchar por conseguir más y mejores cosas cada vez. & 12 & 3 & 4 & 5 \\
\hline 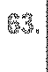 & $\begin{array}{l}\text { Por lo general necesito muy buenas razones para cambiar mi manera habitual } \\
\text { de hacer las cosas. }\end{array}$ & 112 & 3 & 4 & 5 \\
\hline 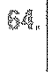 & $\begin{array}{l}\text { Suelo estar relajado y despreocupado, incluso en situaciones en que casi todo } \\
\text { el mundo tiene miedo. }\end{array}$ & 12 & 3 & 4 & 5 \\
\hline t6. & Las películas y las canciones tristes me parecen bastante aburridas. & 11,2 & 3 & 4 & 5 \\
\hline 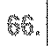 & A menudo, las circunstancias me obligan a hacer cosas en contra de mi voluntad. & (1] 2 & 3 & 4 & 5 \\
\hline 镐. & Generalmente disfruto siendo mezquino con gente que lo ha sido conmigo. & (1) 2 & 3 & 4 & 5 \\
\hline 锿. & $\begin{array}{l}\text { A menudo me fascina tanto lo que estoy haciendo, que pierdo la noción de } \\
\text { todo, como si me desconectara del tiempo y del lugar. }\end{array}$ & 112 & 3 & 4 & 5 \\
\hline 6. & Pienso que no tengo un propósito claro en mi vida. & 112 & 3 & 4 & 5 \\
\hline 70 & $\begin{array}{l}\text { A menudo me siento tenso y preocupado en situaciones poco familiares, aún } \\
\text { cuando otros piensan que no existe peligro. }\end{array}$ & 112 & 3 & 4 & 5 \\
\hline $7 \%$ & $\begin{array}{l}\text { Suelo guiarme por intuición, corazonadas o instintos sin considerar todos los } \\
\text { detalles. }\end{array}$ & 12 & 3 & 4 & 5 \\
\hline 12 & Me gusta destacar en todo aquello que hago. & $12]$ & 3 & 4 & 5 \\
\hline$T^{\prime}$ & $\begin{array}{l}\text { A menudo siento una fuerte conexión espiritual o emocional con la gente que } \\
\text { me rodea. }\end{array}$ & $12]$ & 3 & 4 & 5 \\
\hline
\end{tabular}




\begin{tabular}{|c|c|c|c|c|c|c|}
\hline 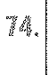 & $\begin{array}{l}\text { Generalmente intento ponerme en el lugar de los otros para poder realmente } \\
\text { comprenderles. }\end{array}$ & 1 & 2 & 3 & 4 & 5 \\
\hline 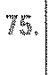 & $\begin{array}{l}\text { Principios como la honestidad y la justicia tienen poca importancia en algunos } \\
\text { aspectos de mi vida. }\end{array}$ & 1 & 2 & 3 & 4 & 5 \\
\hline 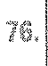 & Soy más trabajador que la mayoría de la gente. & 1 & 2 & 3 & 4 & 5 \\
\hline 7 & $\begin{array}{l}\text { Por lo general insisto en que las cosas se hagan de una forma ordenada y } \\
\text { meticulosa, aún cuando los demás piensan que no es importante. }\end{array}$ & 1 & 2 & 3 & 4 & 5 \\
\hline mis & Me siento seguro y confiado en la mayoría de las situaciones sociales. & 1 & 2 & 3 & 4 & 5 \\
\hline 79 & $\begin{array}{l}\text { A mis amigos les resulta dificil conocer mis sentimientos porque raramente les } \\
\text { comento lo que pienso. }\end{array}$ & 1 & 2 & 3 & 4 & 5 \\
\hline 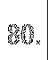 & Sé comunicar mis sentimientos a los demás. & 1 & 2 & 3 & 4 & 5 \\
\hline 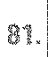 & Tengo más energía y me canso menos que la mayoria de la gente. & 1 & 2 & 3 & 4 & 5 \\
\hline 82 & $\begin{array}{l}\text { Con frecuencia interrumpo lo que estoy haciendo porque me preocupo sin } \\
\text { razón, aunque mis amigos me digan que todo saldrá bien. }\end{array}$ & 1 & 2 & 3 & 4 & 5 \\
\hline 節食. & A menudo deseo ser más poderoso que los demás. & 11 & 2 & 3 & 4 & 5 \\
\hline 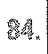 & Es raro que los miembros de un equipo tengan un reparto justo. & 1 & 2 & 3 & 4 & 5 \\
\hline 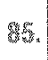 & No cambio mi manera de actuar por complacer a los otros. & 1 & 2 & 3 & 4 & 5 \\
\hline 毁店。 & No soy tímido con personas desconocidas. & 1 & 2 & 3 & 4 & 5 \\
\hline 毁箐。 & $\begin{array}{l}\text { Paso la mayor parte de mi tiempo haciendo cosas que parecen ser necesarias, } \\
\text { pero que no tienen realmente importancia para mí. }\end{array}$ & 1 & 2 & 3 & 4 & 5 \\
\hline 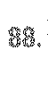 & $\begin{array}{l}\text { No creo que en las decisiones de negocios deban influir principios religiosos } \\
\text { éticos sobre lo que está bien o mal hecho. }\end{array}$ & 1 & 2 & 3 & 4 & 5 \\
\hline 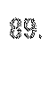 & $\begin{array}{l}\text { A menudo, intento dejar a un lado mis propios valores y opiniones, para que } \\
\text { pueda entender mejor las experiencias de los demás. }\end{array}$ & 1 & 2 & 3 & 4 & 5 \\
\hline 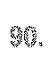 & Muchos de mis hábitos me dificultan lograr metas que merecen la pena. & 1 & 2 & 3 & 4 & 5 \\
\hline \$l. & $\begin{array}{l}\text { He hecho verdaderos sacrificios personales para hacer de este mundo un lugar } \\
\text { mejor donde vivir, tales como tratar de prevenir la guerra, pobreza e injusticia. }\end{array}$ & 1 & 2 & 3 & 4 & 5 \\
\hline 92 & Tardo tiempo en abrirme a los demás. & 1 & 2 & 3 & 4 & 5 \\
\hline
\end{tabular}




\begin{tabular}{|c|c|c|c|c|c|}
\hline 9 & Siento placer viendo a mis enemigos sufrir. & 11 & 3 & 4 & 5 \\
\hline 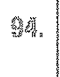 & $\begin{array}{l}\text { Me gusta empezar los trabajos enseguida, independientemente de que sean } \\
\text { muy duros. }\end{array}$ & 12 & 3 & 4 & 5 \\
\hline 䠣。 & $\begin{array}{l}\text { A menudo la gente piensa que estoy en la luna porque soy poco consciente } \\
\text { de lo que ocurre a mi alrededor. }\end{array}$ & $1] \longdiv { 2 }$ & 3 & 4 & 5 \\
\hline 5 & En general me gusta ser frio y estar distanciado de los demás. & 12 & 3 & 4 & 5 \\
\hline 3\%. & Lloro con más facilidad que la mayoria de la gente cuando veo una pelicula triste. & 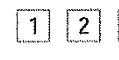 & 3 & 4 & 5 \\
\hline 98 & $\begin{array}{l}\text { Me recupero con más rapidez que la mayoría de la gente de enfermedades } \\
\text { leves y/o situaciones de estrés. }\end{array}$ & 12 & 3 & 4 & 5 \\
\hline gig. & $\begin{array}{l}\text { Con frecuencia pienso que soy parte de una fuerza espinitual de la que depende } \\
\text { toda la vida. }\end{array}$ & 12 & 3 & 4 & 5 \\
\hline 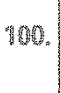 & $\begin{array}{l}\text { Antes de ser capaz de confiar en mí mismo en situaciones tentadoras o dificiles } \\
\text { de afrontar, necesito practicar más para desarrollar hábitos adecuados. }\end{array}$ & (1) 2 & 3 & 4 & 5 \\
\hline $91 \%$ & Por favor redondea el número uno, es un ítem de validez. & (1) 2 & 3 & 4 & 5 \\
\hline topes & $\begin{array}{l}\text { Me gusta tomar decisiones rápidas de forma que pueda ponerme cuanto antes } \\
\text { a hacer lo que tenga que hacer. }\end{array}$ & 12 & 3 & 4 & 5 \\
\hline 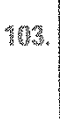 & $\begin{array}{l}\text { Normalmente, me siento confiado haciendo cosas que los demás considerarian } \\
\text { peligrosas (Como conducir un coche a mucha velocidad por una carretera } \\
\text { mojada o helada). }\end{array}$ & 12 & 3 & 4 & 5 \\
\hline $16 x^{2}$ & Me gusta explorar nuevas formas de hacer las cosas. & & 3 & 4 & 5 \\
\hline 镂管 & Disfruto más ahorrando que gastándome el dinero en ocio o diversión. & (1] 2 & 3 & 4 & 5 \\
\hline 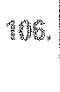 & $\begin{array}{l}\text { He tenido experiencias personales en las que me he sentido en contacto con } \\
\text { un poder divino y espiritual. }\end{array}$ & 12 & 3 & 4 & 5 \\
\hline mente & Tengo tantos defectos que no me gusto mucho. & (1) 2 & 3 & 4 & 5 \\
\hline Then & La mayoría de la gente parece ser más eficiente de lo que yo soy (tener más capacidades). & 12 & 3 & 4 & 5 \\
\hline 䨢og. & Suelo desobedecer reglas y leyes cuando creo que no me van a pillar. & 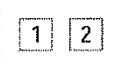 & 3 & 4 & 5 \\
\hline 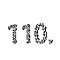 & Incluso con amigos prefiero no abrirme mucho. & 12 & 3 & 4 & 5 \\
\hline 辋售, & Cuanto más duro es un trabajo más me gusta. & 12 & 3 & 4 & 5 \\
\hline
\end{tabular}




\begin{tabular}{|c|c|c|c|c|}
\hline 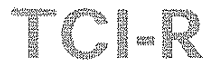 & 1 Falso & $\begin{array}{l}2 . \text { Casi todo } \\
\text { probablemente } \\
\text { falso }\end{array}$ & $\begin{array}{l}\text { (3) gual cierto } \\
\text { que falso }\end{array}$ & $\begin{array}{l}4 \text { Casiseguro o } \\
\text { probablemente } \\
\text { seguro }\end{array}$ \\
\hline
\end{tabular}

\begin{tabular}{|c|c|c|c|c|c|}
\hline 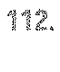 & $\begin{array}{l}\text { A menudo, al mirar cosas cotidianas, me sucede algo maravilloso, tengo la } \\
\text { sensación de que las estoy viendo por primera vez. }\end{array}$ & 72 & 3 & 4 & 5 \\
\hline 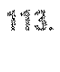 & $\begin{array}{l}\text { Me suelo sentir tenso y preocupado cuando tengo que hacer algo nuevo y poco } \\
\text { familiar. }\end{array}$ & 112 & 3 & 4 & 5 \\
\hline 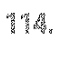 & Soy muy impaciente cuando tengo que empezar a trabajar en alguna tarea asignada. & $1] 2$ & 3 & 4 & 5 \\
\hline 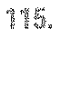 & $\begin{array}{l}\text { Tengo poca fuerza de voluntad para resistir tentaciones fuertes, aunque sepa } \\
\text { que voy a sufrir las consecuencias. }\end{array}$ & 12 & 3 & 4 & 5 \\
\hline 嘴. & Si me siento preocupado, suelo encontrarme mejor con amigos que estando solo. & $1]$ & 3 & 4 & 5 \\
\hline 1管。 & Suelo conseguir más cosas de las que la gente espera de mi. & 12 & 3 & 4 & 5 \\
\hline 筞㤦 & $\begin{array}{l}\text { Experiencias religiosas me han ayudado a entender el verdadero propósito de } \\
\text { mi vida. }\end{array}$ & $1]$ & 3 & 4 & 5 \\
\hline 『ras. & $\begin{array}{l}\text { Generalmente me esfuerzo más que el resto de la gente porque quiero hacer } \\
\text { las cosas lo mejor que puedo. }\end{array}$ & $17 \quad 2$ & 3 & 4 & 5 \\
\hline 124 & Por favor redondea el número cinco, es un item de validez. & 112 & 3 & 4 & 5 \\
\hline 12. & $\begin{array}{l}\text { Me suelo sentir con más energia y confianza que la mayoria de la gente, incluso } \\
\text { después de situaciones de estrés y/o enfermedades leves. }\end{array}$ & 12 & 3 & 4 & 5 \\
\hline 128. & $\begin{array}{l}\text { Cuando nada nuevo sucede suelo empezar a buscar algo que me resulte } \\
\text { excitante o novedoso. }\end{array}$ & 112 & 3 & 4 & 5 \\
\hline 12 & Me gusta pensar las cosas durante largo tiempo antes de tomar decisiones. & $1] 2$ & 3 & 4 & 5 \\
\hline 9] & $\begin{array}{l}\text { La gente que se relaciona conmigo tiene que aprender a hacer las cosas a mi } \\
\text { manera. }\end{array}$ & $1 1 \longdiv { 2 }$ & 3 & 4 & 5 \\
\hline 125 & Suelo establecer contactos muy afectuosos con la mayoría de la gente. & $1][2$ & 3 & 4 & 5 \\
\hline 12 & Con frecuencia soy descrito como excesivamente ambicioso. & 12 & 3 & 4 & 5 \\
\hline 127. & Prefiero leer un libro que hablar acerca de mis sentimientos con otras personas. & $1]$ & 3 & 4 & 5 \\
\hline 能然。 & Me gusta vengarme de la gente que me ha hecho daño. & (1) 2 & 3 & 4 & 5 \\
\hline 129. & $\begin{array}{l}\text { Si algo no sale como tengo previsto tengo más tendencia a abandonarlo que } \\
\text { a seguir intentándolo durante mucho tiempo. }\end{array}$ & $11]$ & 3 & 4 & 5 \\
\hline 130. & Es fácil para otras personas acercarse a mi emocionalmente. & (1) 2 & 3 & 4 & 5 \\
\hline
\end{tabular}




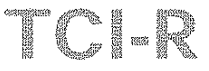

1. Falso

2. Casi todo probablo

3 lgual cierto que falso

4. Casi seguro o
probablement probable

\begin{tabular}{|c|c|c|c|c|c|c|}
\hline 131. & $\begin{array}{l}\text { Probablemente me encontraría relajado y a gusto quedando con gente } \\
\text { desconocida, aún cuando me hubieran dicho que eran poco amistosos. }\end{array}$ & 1 & 2 & 3 & 4 & 5 \\
\hline 管然。 & Por favor marque el número dos, es un item de validez. & 1 & 2 & 3 & 4 & 5 \\
\hline 133 & En general no me gusta la gente que tiene ideas distintas a las mias. & 1 & 2 & 3 & 4 & 5 \\
\hline 134. & Con frecuencia me cuesta iniciar un proyecto. & 11 & 2 & 3 & 4 & 5 \\
\hline 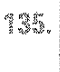 & $\begin{array}{l}\text { Por lo general soy hábil deformando o exagerando la realidad para contar una } \\
\text { historia divertida o gastar una broma a alguien. }\end{array}$ & 11 & 2 & 3 & 4 & 5 \\
\hline 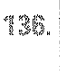 & $\begin{array}{l}\text { Me es muy dificil cambiar mi manera de hacer las cosas porque me pongo } \\
\text { nervioso, me canso o me preocupo. }\end{array}$ & 1] & 2 & 3 & 4 & 5 \\
\hline 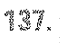 & Soy más perfeccionista que la mayoria de la gente. & 1 & 2 & 3 & 4 & 5 \\
\hline 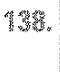 & $\begin{array}{l}\text { Con frecuencia la gente piensa que soy demasiado independiente porque no } \\
\text { hago lo que ellos quieren. }\end{array}$ & $1]$ & 2 & 3 & 4 & 5 \\
\hline 138. & Se me da mejor ahorrar que a la mayoria de la gente. & 7 & 2 & 3 & 4 & 5 \\
\hline 40. & A menudo dejo una actividad si requiere más tiempo de lo que yo pensaba. & $1]$ & 2 & 3 & 4 & 5 \\
\hline 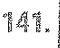 & El que algo esté bien o mal es tan sólo una cuestión de opiniones. & 1 & 2 & 3 & 4 & 5 \\
\hline $1 / 42$ & A menudo aprendo mucho de otra gente. & 1 & 2 & 3 & 4 & 5 \\
\hline 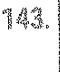 & $\begin{array}{l}\text { Creo que la vida depende de un orden o poder espiritual que no puede ser } \\
\text { explicado del todo. }\end{array}$ & 1 & 2 & 3 & 4 & 5 \\
\hline 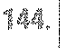 & A no ser que sea muy cuidadoso las cosas me suelen ir mal. & 1 & 2 & 3 & 4 & 5 \\
\hline WA & $\begin{array}{l}\text { Soy más lento que la mayoria de la gente para entusiasmarme con ideas y } \\
\text { actividades nuevas. }\end{array}$ & 1 & 2 & 3 & 4 & 5 \\
\hline 14. & $\begin{array}{l}\text { Probablemente podría conseguir más cosas de las que logro, pero no veo la } \\
\text { necesidad de exigirme más allá de lo estrictamente necesario. }\end{array}$ & 1 & 2 & 3 & 4 & 5 \\
\hline 87. & $\begin{array}{l}\text { Suelo permanecer alejado de situaciones sociales en las que tengo que conocer } \\
\text { a gente nueva, incluso si me aseguran que serán amistosos. }\end{array}$ & 1 & 2 & 3 & 4 & 5 \\
\hline 148 & $\begin{array}{l}\text { A menudo me siento tan en conexión con la gente que tengo a mi alrededor, } \\
\text { que es como si no hubiera separación entre nosotros. }\end{array}$ & 1 & 2 & 3 & 4 & 5 \\
\hline 148 & $\begin{array}{l}\text { En la mayoría de las situaciones mi forma natural de responder se basa en las } \\
\text { buenas costumbres que he desarrollado. }\end{array}$ & 1 & 2 & 3 & 4 & 5 \\
\hline
\end{tabular}




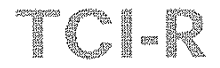

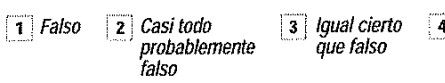

ר. Con frecuencia tengo que dejar lo que estoy haciendo, porque comienzo a preocuparme de que algo salga mal.

ing

Con frecuencia me dicen que soy distraído porque me meto tanto en lo que estoy haciendo que pierdo la noción de todo.

152 Generalmente, tengo en cuenta los sentimientos de otras personas tanto como los mios.

15. Con frecuencia soy descrito como muy poco ambicioso.

7. en una zona montañosa con curvas escarpadas) que estar quieto o inactivo durante horas.

1. Alguna gente piensa que soy demasiado tacaño o mirado con el dinero.

75: Prefiero las viejas formas de hacer las cosas, "ensayadas y correctas", que intentar formas "nuevas y mejores".

15. Con frecuencia hago cosas para ayudar a evitar la extinción de animales y plantas.

15 S A menudo me esfuerzo hasta el agotamiento o intento hacer más de lo que realmente puedo.

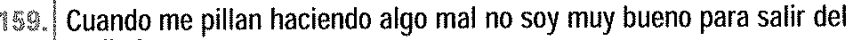
atolladero.

Tิ que son más fuertes que la mayoría de los impulsos que me aparecen temporalmente.

13. Pienso que tendré suerte en el futuro.

192. Me abro fácilmente con las demás personas, aún cuando no los conozco demasiado.

16:3. Cuando fracaso en conseguir alguna cosa al principio, el poder conseguirlo se convierte en mi reto personal.

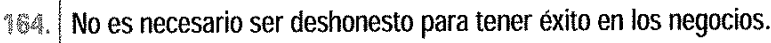

165. En las conversaciones suelo ser mejor escuchando que hablando.

164. No seria feliz en un trabajo donde no pudiese comunicarme con otras personas. $\begin{array}{llll}1 & 2 & 3 & 4 \\ 5\end{array}$

\begin{tabular}{llll}
\hline 1 & 2 & 3 &
\end{tabular}

11 2] 35

1] 2] $3 \square 5$

\begin{tabular}{llllll}
\hline 1$]$ & $2]$ & 3 & 4 & 5 \\
\hline
\end{tabular}

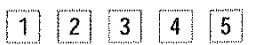

\begin{tabular}{llllll}
\hline 1 & 2 & 3 & 4 & 5 \\
\hline
\end{tabular}

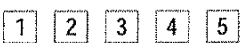

\begin{tabular}{lllll}
\hline 1 & 2 & 3 & 4 & 5 \\
\hline
\end{tabular}

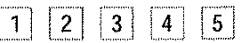

11 2 3 4 5

\begin{tabular}{lllll}
\hline 1 & 2 & 3 & 4 & 5
\end{tabular}

1] 2 3 . 5

(1) 2545

\begin{tabular}{llll}
\hline 1 & 2 & 3 & 5 \\
\hline
\end{tabular}

\begin{tabular}{lllll}
\hline 1 & 2 & 3 & 4 & 5 \\
\hline
\end{tabular}

\begin{tabular}{ll|l|l|l|}
\hline 1 & 2 & 3 & 4 & 5 \\
\hline
\end{tabular} 


\begin{tabular}{|c|c|c|c|c|}
\hline 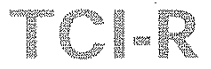 & 11 Fals & $\begin{array}{l}2 \text { Casi todo } \\
\text { probablemente } \\
\text { falso }\end{array}$ & $\begin{array}{l}3 \text { g gual cierto } \\
\text { que falso }\end{array}$ & $\begin{array}{l}4 . \text { Casi seguro o } \\
\text { probablemente } \\
\text { seguro }\end{array}$ \\
\hline
\end{tabular}

\begin{tabular}{|c|c|c|c|c|c|c|}
\hline 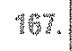 & Mis actitudes están determinadas por influencias que están fuera de mi control. & 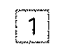 & 2 & 3 & 4 & 5 \\
\hline 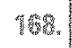 & A menudo desearía ser el más fuerte. & 1 & 2 & 3 & 4 & 5 \\
\hline 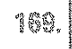 & Suelo necesitar siestas o periodos de descanso extras porque me canso con facilidad. & 1 & 2 & 3 & 4 & 5 \\
\hline 170 & $\begin{array}{l}\text { Me cuesta mucho mentir, aunque lo tenga que hacer para no herir los sentimientos } \\
\text { de otros. }\end{array}$ & 11 & 2 & 3 & 4 & 5 \\
\hline 171. & Siempre pienso que las cosas saldrán bien, sea cual sea el problema. & 7 & 2 & 3 & 4 & 5 \\
\hline 敕篦. & Me cuesta disfrutar gastándome el dinero en mi mismo, aunque tenga mucho ahorrado. & 7 & 2 & 3 & 4 & 5 \\
\hline The & A menudo hago mi mejor trabajo bajo circunstancias dificiles. & 1 & 2 & 3 & 4 & 5 \\
\hline m. & Me gusta guardarme los problemas para mi. & 1 & 2 & 3 & 4 & 5 \\
\hline 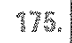 & Tengo una imaginación muy viva y desarrollada. & 1 & 2 & 3 & 4 & 5 \\
\hline Then & Me gusta más estar en casa que viajar o explorar nuevos lugares. & 1 & 2 & 3 & 4 & 5 \\
\hline 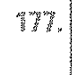 & $\begin{array}{l}\text { Las relaciones de amistad intensas con las demás personas son muy importantes } \\
\text { para mi. }\end{array}$ & 1 & 2 & 3 & 4 & 5 \\
\hline T7. & A menudo tengo el deseo de seguir siendo siempre joven. & 1 & 2 & 3 & 4 & 5 \\
\hline Tha & Me gusta leer todo lo que tengo que firmar. & 1 & 2 & 3 & 4 & 5 \\
\hline 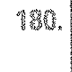 & $\begin{array}{l}\text { Pienso que me encontraria confiado y relajado con desconocidos, aunque me } \\
\text { dijeran que están enfadados conmigo. }\end{array}$ & 1 & 2 & 3 & 4 & 5 \\
\hline 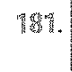 & $\begin{array}{l}\text { Siento que es más importante ser afectivo y comprensivo con la gente que ser } \\
\text { práctico e inflexible. }\end{array}$ & 11 & 2 & 3 & 4 & 5 \\
\hline 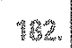 & Con frecuencia desearia tener poderes especiales como Supermán. & 1 & 2 & 3 & 4 & 5 \\
\hline 10 & Me gusta compartir lo que he aprendido con los demás. & 1 & 2 & 3 & 4 & 5 \\
\hline 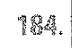 & Suelo considerar las situaciones dificiles como desafíos u oportunidades. & 11 & 2 & 3 & 4 & 5 \\
\hline 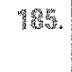 & $\begin{array}{l}\text { La mayoria de la gente que conozco sólo miran por ellos mismos sin importarles } \\
\text { quien salga perjudicado. }\end{array}$ & 1 & 2 & 3 & 4 & 5 \\
\hline 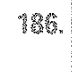 & $\begin{array}{l}\text { Para recuperarme de enfermedades leves o situaciones de estrés necesito } \\
\text { mucho apoyo, descanso y tranquilidad. }\end{array}$ & 1 & 2 & 3 & 4 & 5 \\
\hline
\end{tabular}



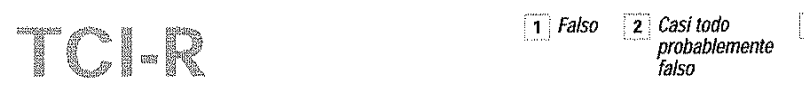

3.] gual ciento
que falso 4 Casi seguro o 5 Verdadero
probablemente seguro

\begin{tabular}{|c|c|c|c|c|c|c|}
\hline 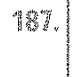 & $\begin{array}{l}\text { Sé que existen principios en la vida que uno no puede violar sin sufrir las } \\
\text { consecuencias a largo plazo. }\end{array}$ & 11 & 2 & 3 & 4 & 5 \\
\hline 180. & No quiero ser más rico que los demás. & 1 & 2 & 3 & 4 & 5 \\
\hline 189. & Cuando empiezo un trabajo me gusta ir lentamente aunque sea fácil de hacer. & 1 & 2 & 3 & 4 & 5 \\
\hline 190 & Arriesgaria mi vida para hacer del mundo un lugar mejor. & 1 & 2 & 3 & 4 & 5 \\
\hline 191. & Cuando la gente pasa mi trabajo por alto, me obstino más en tener éxito. & 11 & 2 & 3 & 4 & 5 \\
\hline 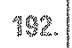 & Con frecuencia desearía detener el paso del tiempo. & 1 & 2 & 3 & 4 & 5 \\
\hline 193. & Odio tomar decisiones basadas únicamente en mi primera impresión. & 1 & 2 & 3 & 4 & 5 \\
\hline 18. & Prefiero estar solo que tener que cargar con los problemas de otras personas. & 1 & 2 & 3 & 4 & 5 \\
\hline 195. & No quiero ser más admirado que el resto de la gente. & 11 & 2 & 3 & 4 & 5 \\
\hline 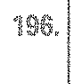 & $\begin{array}{l}\text { Necesito mucha ayuda de los demás para que me enseñen a tener buenas } \\
\text { costumbres. }\end{array}$ & 1 & 2 & 3 & 4 & 5 \\
\hline 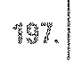 & Me gusta hacer los trabajos rápidamente y después ofrecerme para hacer más. & 1 & 2 & 3 & 4 & 5 \\
\hline 19te. & Me cuesta tolerar gente que es muy diferente a mi. & 1 & 2 & 3 & 4 & 5 \\
\hline 10 & Cuando alguien me hace daño, prefiero ser amable antes que intentar vengarme. & 1 & 2 & 3 & 4 & 5 \\
\hline 200 & Realmente, me gusta estar ocupado. & 1 & 2 & 3 & 4 & 5 \\
\hline the & Intento cooperar lo máximo posible con los demás. & 1 & 2 & 3 & 4 & 5 \\
\hline 202 & Suelo tener exito gracias a mi ambición y a mi trabajo duro. & 1 & 2 & 3 & 4 & 5 \\
\hline 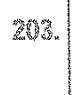 & $\begin{array}{l}\text { Por lo general, es fácil que me caiga bien gente que tiene valores distintos a } \\
\text { los mios. }\end{array}$ & 1 & 2 & 3 & 4 & 5 \\
\hline 204 & $\begin{array}{l}\text { Las buenas costumbres se han convertido en parte de mi, y me salen de forma } \\
\text { natural y espontánea casi todo el tiempo. }\end{array}$ & 11 & 2 & 3 & 4 & 5 \\
\hline $20 \%$ & $\begin{array}{l}\text { Odio cambiar mi manera de hacer las cosas aunque me digan que hay formas } \\
\text { nuevas y mejores de hacerlas. }\end{array}$ & 11 & 2 & 3 & 4 & 5 \\
\hline 200 & $\begin{array}{l}\text { Pienso que no es sabio creer en cosas que no pueden ser explicadas } \\
\text { cientificamente. }\end{array}$ & 1 & 2 & 3 & 4 & 5 \\
\hline
\end{tabular}




\begin{tabular}{|c|c|c|c|c|c|c|}
\hline $20 \%$ & Estoy dispuesto a sacrificarme mucho para tener éxito. & 1 & 2 & 3 & 4 & 5 \\
\hline 200. & Me gusta imaginarme a mis enemigos sufriendo. & 1 & 2 & 3 & 4 & 5 \\
\hline 208 & Por favor redondea el número tres, es un ítem de validez. & (1] & 2 & 3 & 4 & 5 \\
\hline 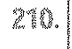 & Me gusta prestar atención a los detalles en todo aquello que hago. & 1 & 2 & 3 & 4 & 5 \\
\hline 2.1. & Por lo general me siento libre para elegir lo que quiero hacer. & 1 & 2 & 3 & 4 & 5 \\
\hline 21 & $\begin{array}{l}\text { A menudo me involucro tanto en lo que estoy haciendo que llego a olvidar } \\
\text { donde estoy durante un instante. }\end{array}$ & 1 & 2 & 3 & 4 & 5 \\
\hline 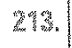 & Me gusta que los demás sepan que me preocupo por ellos. & 1 & 2 & 3 & 4 & 5 \\
\hline 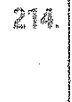 & $\begin{array}{l}\text { La mayor parte del tiempo preferiria hacer algo arriesgado (como lanzarme ei } \\
\text { paracaidas o ala delta) antes que tener que quedarme quieto e inactivo durante } \\
\text { unas horas. }\end{array}$ & 1 & 2 & 3 & 4 & 5 \\
\hline 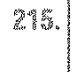 & $\begin{array}{l}\text { Debido a que suelo gastar mucho dinero de forma impulsiva me cuesta ahorrar, } \\
\text { incluso para cosas especiales como unas vacaciones. }\end{array}$ & 1 & 2 & 3 & 4 & 5 \\
\hline 2. & A menudo cedo a los deseos de mis amigos. & 1 & 2 & 3 & 4 & 5 \\
\hline 215. & Nunca me preocupo de las cosas terribles que puedan ocurrir en un futuro. & 1 & 2 & 3 & 4 & 5 \\
\hline 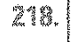 & A la gente le resulta fácil acudir a mi en busca de ayuda, simpatia y comprensión. & 1 & 2 & 3 & 4 & 5 \\
\hline 219. & La mayoría de las veces perdono con rapidez a quien me ha hecho daño. & 1 & 2 & 3 & 4 & 5 \\
\hline 20 & $\begin{array}{l}\text { Pienso que mi forma espontánea de actuar es consistente con mis metas y mis } \\
\text { principios a largo plazo. }\end{array}$ & 1 & 2 & 3 & 4 & 5 \\
\hline $22 \%$ & Al hacer cosas, prefiero esperar a que otro tome el mando. & 1 & 2 & 3 & 4 & 5 \\
\hline 222 & Me divierte comprarme cosas. & 1 & 2 & 3 & 4 & 5 \\
\hline 2225. & $\begin{array}{l}\text { He tenido experiencias que me han aclarado tanto mi papel en la vida, que me } \\
\text { han hecho sentir muy feliz y emocionado. }\end{array}$ & 1 & 2 & 3 & 4 & 5 \\
\hline 224 & Suelo respetar las opiniones de los demás. & 1 & 2 & 3 & 4 & 5 \\
\hline 252 & $\begin{array}{l}\text { Mi conducta se encuentra fuertemente guiada por determinadas metas que he } \\
\text { establecido en mi vida. }\end{array}$ & 1 & 2 & 3 & 4 & 5 \\
\hline 222 & Suele ser tonto favorecer el éxito de otra gente. & 1 & 2 & 3 & 4 & 5 \\
\hline
\end{tabular}




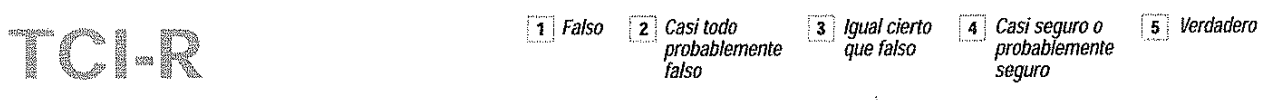

\begin{tabular}{|c|c|c|c|c|c|c|}
\hline 27 & A menudo desearía poder vivir siempre. & 1 & 2 & 3 & 4 & 5 \\
\hline 21285. & Cuando alguien me señala mis fallos suelo trabajar más duro para corregirlos. & 1 & 2 & 3 & 4 & 5 \\
\hline 220 & $\begin{array}{l}\text { No dejaria de hacer lo que estoy haciendo sólo por haber tenido varios fracasos } \\
\text { seguidos. }\end{array}$ & $1]$ & 2 & 3 & 4 & 5 \\
\hline 2$)$ & Generalmente tengo buena suerte en todo lo que intento. & 1 & 2 & 3 & 4 & 5 \\
\hline 2 & Desearía ser el/la más guapo/a de todos. & 1 & 2 & 3 & 4 & 5 \\
\hline 232 & $\begin{array}{l}\text { Probablemente las experiencias misticas son sólo deseos dificiles de ocurrir } \\
\text { en la realidad. }\end{array}$ & 1 & 2 & 3 & 4 & 5 \\
\hline 223 & $\begin{array}{l}\text { Los derechos individuales son más importantes que las necesidades de cualquier } \\
\text { grupo. }\end{array}$ & 1 & 2 & 3 & 4 & 5 \\
\hline 23 & La falta de honestidad sólo causa problemas si te descubren. & 1 & 2 & 3 & 4 & 5 \\
\hline 285 & Los buenos hábitos me facilitan hacer las cosas en la forma que quiero. & 1 & 2 & 3 & 4 & 5 \\
\hline 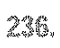 & Los demás y las circunstancias suelen ser los responsables de mis problemas. & 1 & 2 & 3 & 4 & 5 \\
\hline $23 \%$ & Suelo poder rendir "a tope" todo el día sin tener que esforzarme. & 1 & 2 & 3 & 4 & 5 \\
\hline 23. & Quiero ser el mejor en todo lo que hago. & 1 & 2 & 3 & 4 & 5 \\
\hline 23. & $\begin{array}{l}\text { Aunque los demás me pidan que tome una decisión rápida, casi siempre pienso } \\
\text { en todos los hechos detenidamente antes de tomarla. }\end{array}$ & 1 & 2 & 3 & 4 & 5 \\
\hline 240 & Cuando hay algo que hacer, suelo presentarme rápidamente como voluntario. & 1 & 2 & 3 & 4 & 5 \\
\hline
\end{tabular}




\section{6.- Consentimiento informado}

\section{HOJA INFORMATIVA PARA EL PACIENTE Y CONSENTIMIENTO INFORMADO}

\section{Evaluación de la personalidad según el Cuestionario TCl-R de Cloninger en pacientes con Trastorno por Consumo de Alcohol.}

Su médico le invita a participar en un programa de investigación médica en el que se quieren estudiar la relación entre su personalidad y la gravedad de su Trastorno por Consumo de Alcohol.

Se le propone que conteste cuatro cuestionarios que incluye preguntas sobre su personalidad, las características de su enfermedad, el deseo por el consumo de alcohol y la intensidad de su dependencia. El tratamiento que recibirá será el mismo que si no participara en el estudio y está orientado a obtener una mejoría clínica.

Su participación y colaboración en este estudio es absolutamente voluntaria entendiendo que su consentimiento está destinado a mejorar la evolución clínica de su enfermedad.

Tanto usted como otras personas pueden beneficiarse de su participación en este programa de investigación aportando nuevos datos que servirán para mejorar la calidad de vida y el manejo clínico de su enfermedad.

Los resultados obtenidos serán incluidos en una base de datos y serán objeto de análisis estadístico conservando siempre su anonimato y sin permitir que personas ajenas tengan acceso a su historial clínico, acorde con la legislación de protección de datos vigente. Estos datos podrán ser usados finalmente con fines médicos o de divulgación científica de los resultados.

Cualquier duda sobre esta información consúltela con su médico. 
Paciente:

Firma:

Fecha:
Médico:

Firma:

Fecha:

\section{Principales complicaciones del abuso del alcohol. (García-Gutierrez, E. 2004)}

- Afectaciones neurológicas Neuropatía periférica distal, cefalea, temblores, convulsiones (sobre todo en personas predispuestas a la epilepsia), miopatía alcohólica aguda, degeneración cerebelosa, daño cortical difuso con demencia alcohólica, lesiones degenerativas del cerebro, médula espinal y nervios periféricos (en casos avanzados), falta de fuerza muscular, calambres y dolores en las piernas y los brazos, accidentes vasculares encefálicos. Intoxicación alcohólica aguda, síndrome de abstinencia, ambliopía alcohol-tabaco, pelagra, manifestaciones tóxico- metabólicas, enfermedad de Marchiafava-bignami, mielinosis central de la protuberancia. - Efectos sobre el aparato digestivo y glándulas anexas Glositis, esofagitis, gastritis, diarreas, úlcera gastro-duodenal; várices esofágicas; cáncer gástrico, de la boca y del esófago; hepatitis, hígado graso, cirrosis hepática, pancreatitis aguda hemorrágica y pancreatitis crónica. Efectos sobre el aparato cardiovascular Aterosclerosis temprana, hipertensión arterial, infarto del miocardio, cardiomiopatías. - Efectos sobre el aparato genitourinario

Disfunción sexual, reducción de hormonas masculinas por la acción de alcohol sobre el testículo y la hipófisis, reducción de la entrada de sangre en los cuerpos cavernosos debido a la aterosclerosis temprana, deformidades del niño al nacer y graves trastornos de la inteligencia o la conducta en los casos menos severos (feto alcohólico). Trastornos vesicales. Cáncer de vejiga.

4- Afectación psiquiátrica 
Depresión con ideas y conducta suicidas, pesadillas, insomnio, celos enfermizos, alucinaciones auditivas y visuales, delirios de daño y persecución, alteraciones de conducta.

5- Otros efectos negativos sobre la salud.

Tendencia a neoplasias, inmunosupresión de los alcohólicos sensible a la vitamina $\mathrm{E}$, el síndrome alcohólico-fetal. 